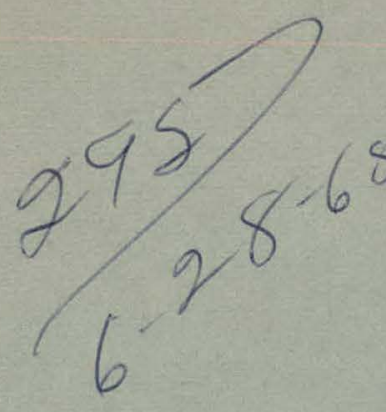

ORNL-3504

UC.80 - Reactor Technology

TID.4500 (4lst ed.)

\title{
IRRADIATION EFFECTS IN THE EGCR FUEL
}

C. D. Baumann
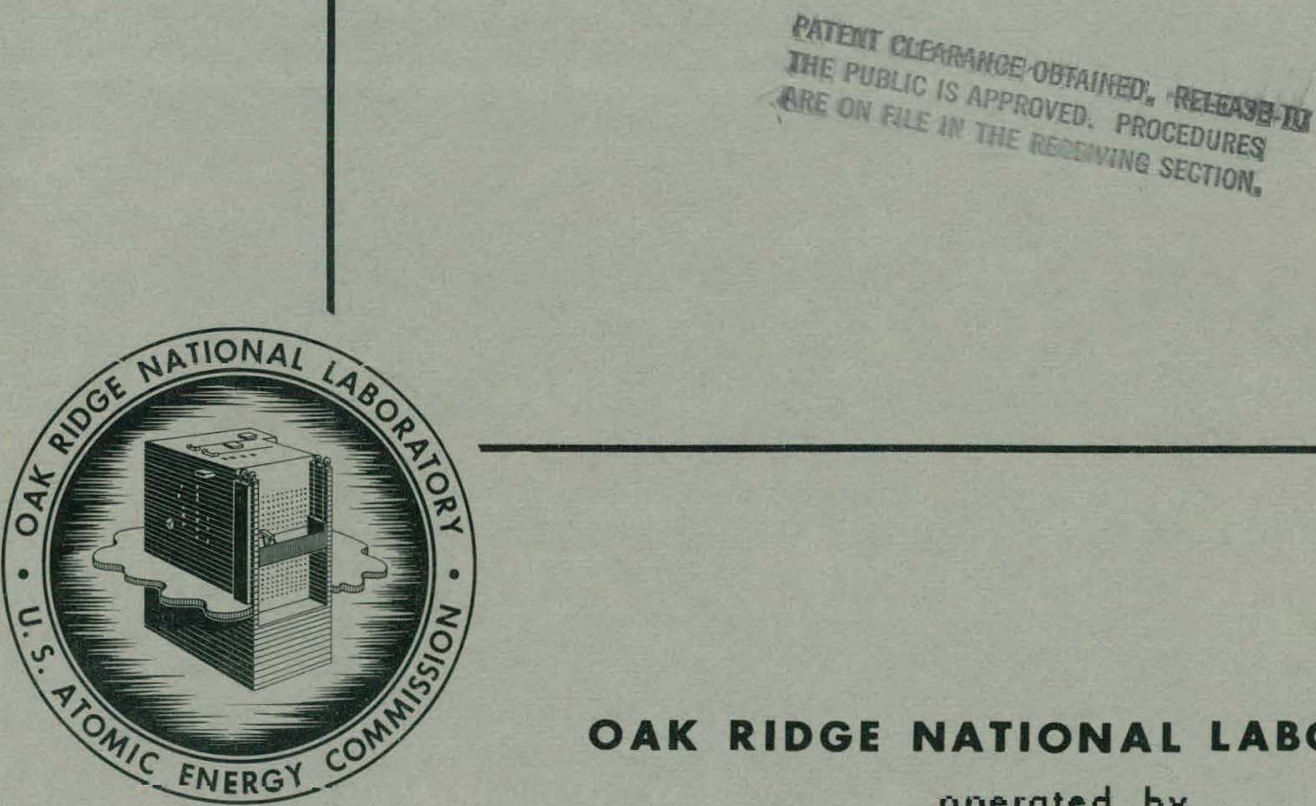

OAK RIDGE NATIONAL LABORATORY

$$
\text { operated by }
$$

UNION CARBIDE CORPORATION

for the

U.S. ATOMIC ENERGY COMMISSION 


\section{DISCLAIMER}

This report was prepared as an account of work sponsored by an agency of the United States Government. Neither the United States Government nor any agency Thereof, nor any of their employees, makes any warranty, express or implied, or assumes any legal liability or responsibility for the accuracy, completeness, or usefulness of any information, apparatus, product, or process disclosed, or represents that its use would not infringe privately owned rights. Reference herein to any specific commercial product, process, or service by trade name, trademark, manufacturer, or otherwise does not necessarily constitute or imply its endorsement, recommendation, or favoring by the United States Government or any agency thereof. The views and opinions of authors expressed herein do not necessarily state or reflect those of the United States Government or any agency thereof. 


\section{DISCLAIMER}

Portions of this document may be illegible in electronic image products. Images are produced from the best available original document. 
Printed in USA. Price $\$ 5.00$. Available from the Clearinghouse for Federal Scientific and Technical Information, National Bureau of Standards,

U.S. Department of Commerce, Springfield, Virginia

\section{LEGAL NOTICE}

This report was prepared as an account of Government sponsored work. Neither the United States, nor the Commission, nor any person acting on behalf of the Commission:

A. Makes any warranty or representation, expressed or implied, with respect to the accuracy, completeness, or usefulness of the information contained in this report, or that the use of any information, apparatus, method, or process disclosed in this report may not infringe privately owned rights; or

B. Assumes any liabilities with respect to the use of, or for damages resulting from the use of any information, apparatus, method, or process disclosed in this report.

As used in the above, "person acting on behalf of the Commission" includes any employee or contractor of the Commission, or employee of such contractor, to the extent that such employee or contractor of the Commission, or employee of such contractor prepares, disseminates, or provides access to, any information pursuant to his employment or contract with the Commission, or his employment with such contrartor. 
ORNL-3504

Contract No. W-7405-eng-26

REACTOR CHEMISTRY DIVISION

\section{IRRADIATION EFFECTS IN THE EGCR FUEL}

C. D. Baumann

JUNE 1965

\footnotetext{
OAK RIDGE NATIONAL LABORATORY

Oak Ridge, Tennessee

operated by

UNION CARBIDE CORPORATION

for the
}

U.S. ATOMIC ENERGY COMMISSION 


\section{THIS PAGE \\ WAS INTENTIONALLY \\ LEFT BLANK}




\section{CONTENTS}

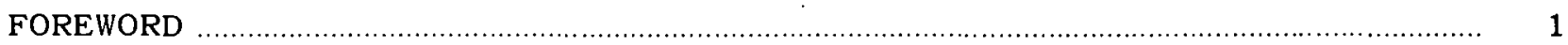

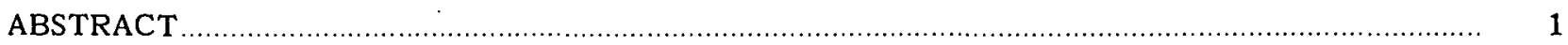

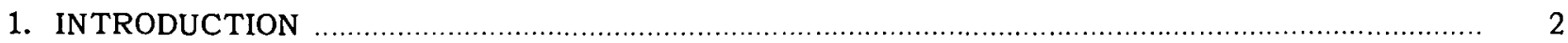

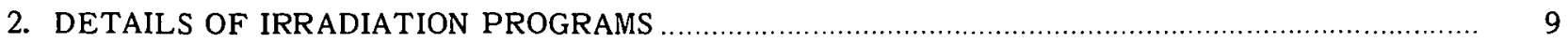

2.1 The Fuel Test Program (Miniature Capsules) ...................................................................... 10

2.2 The Prototype Capsule Test Program ................................................................................ 12

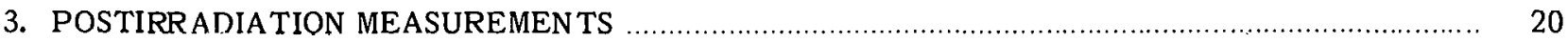

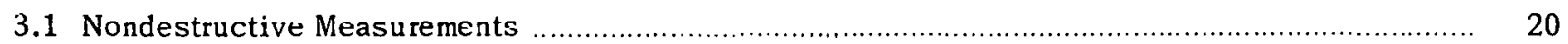

3.2 Fission Gas and Canning Atmosphere Sampling and Analysis ........................................... 20

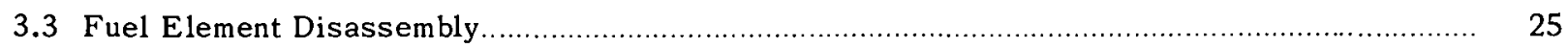

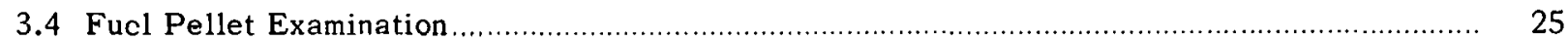

3.5 Effect of Low-Boiling-Point Alkali-Metal Fission Products on Pressure Buildup ................... 25

3.6 Component Examinations .......................................................................................................... 25

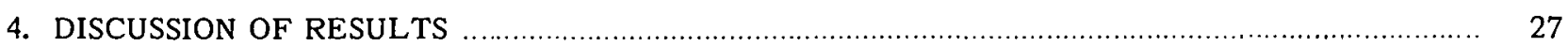

4.1 Effect of Pellet Geometry on Redistribution of Fuel, Ratchetting, and Wrinkling of Can ......... 27

4.2 Fission Gas and Volatile Fission Product Release ................................................................ 30

4.3 Results for EGCR Prototype Experiments ................................................................................ 58

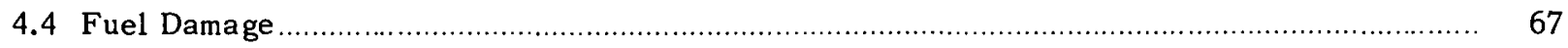

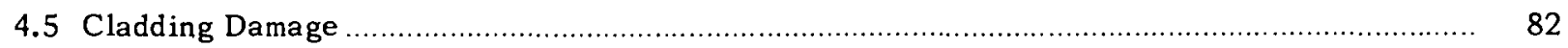

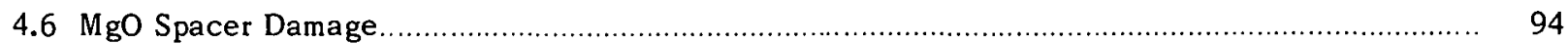

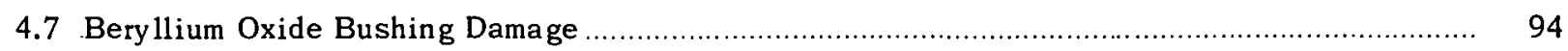

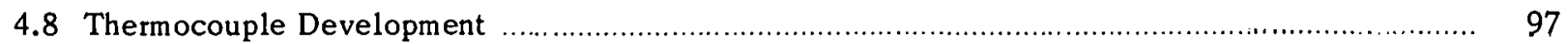

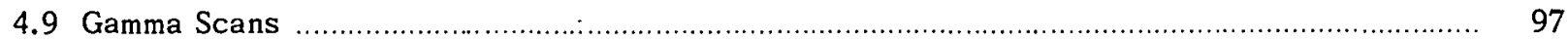

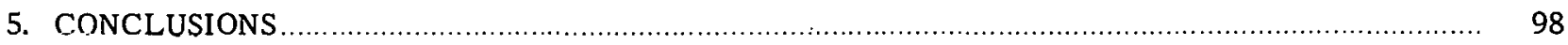

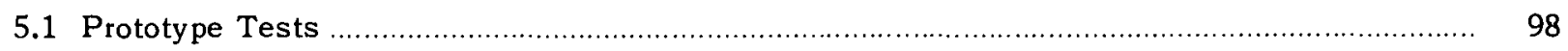

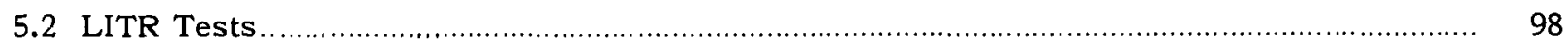

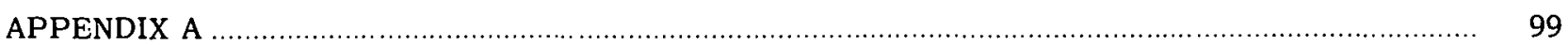

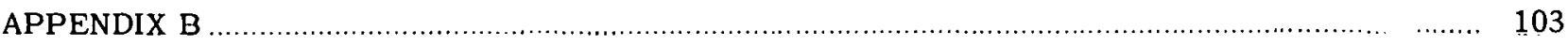

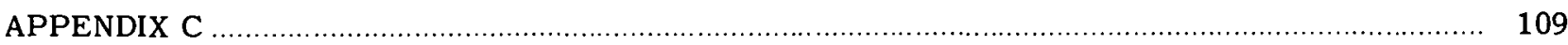




\title{
IRRADIATION EFFECTS IN THE EGCR FUEL
}

\author{
C. D. Baumann
}

\section{FOREWORD}

This is a documentation of the experiments performed and the data accumulated during the early period of the Experimental Gas-Cooled Reactor (EGCR) fuel element design. Design studies for the fuel element were done in the Reactor Division under G. Samuels, and are reported by him in the "Introduction." Preirradiation testing and fuel fabrication studies were done in the Metals and Ceramics Division under the direction of J. H. Coobs. Experiment construction and in-pile operation were done by the group under D. B. Trauger in the Reactor Division. These are described in Sect. 2, "Details of Irradiation Program," written by $\mathrm{D}$. B. Trauger. The postirradiation measurements and radiation damage evaluations were under the direction of J. G. Morgan and O. Sisman, Reactor Chemistry Division.

Interpretation of the metallugraphic data and the metallngraphic examinations in the hot cells were under the direction of E. L. Long, Metals and Ceramics Division. Part of the postirradiation examinations were made at the General Electric Vallecitos Atomic Laboratory. The chemical analyses for flux monitoring, fuel burnup, etc., were done by the ORNL Analytical Chemistry Division. To these and the many others who assisted in the accumulation of the data reported here, our appreciation is gratefully acknowledged.

\section{ABSTRACT}

Two general types of experiments were carried out concurrently to develop the fuel elements for the initial loading of the EGCR. A series of 16 prototype elements were tested in the ORR and 22 miniature fuel capsules were irradiated in the Low-Intensity Test Reactor (LITR).

The prototype elements were similar to the proposed EGCR elements except that (1) the ends of the pellets were not dished; (2) the length was two-ninths that of the proposed element; and (3) in some cases, pellet geometry differed.

The general purpose of these experiments was to proof-test the proposed EGCR elements and, particularly, to investigate pellet-geometry effects.

The miniature fuel capsule experiments were designed primarily to investigate the dependence of fission-gas release upon fuel characteristics and upon operating conditions.

In the prototype experiments it was found that (1) no significant amount of fuel migration or shifting occurred in hollow, uncored pellet test elements even though the pellets were quite friable after irradialiun; (2) ratchetting har nscurred to a slight degree; (3) ridges formed on the cladding opposite pellet interfaces when the cladding was at $1500^{\circ} \mathrm{F}$ or above, and sigma phase and small voids were found in the neighborhood of the ridges; (4) no significant $\mathrm{UO}_{2}$-cladding or fill-gas-cladding interactions occurred except for a small amount of cladding nitriding when the fuel contained a large amount of nitrides; and (5) the fission-gas release (in these experiments only) was not as temperature sensitive as expected. 
The miniature fuel experiments showed that fission-gas release (1) increased for burnups above about $15,000 \mathrm{Mwd}$ per metric ton of $\mathrm{UO}_{2}$; (2) increased as burnup rate increased; (3) was quite sensitive to fuel structure, that is, the smaller the ratio of closed voids to total voids, the better the fission-gas retention; (4) dependence on $\mathrm{O} / \mathrm{U}$ ratio was confused by density effects; and (5) diffusion constants for xenon and krypton were about the same.

\section{INTRODUCTION}

G. Samuels

The purpose of the EGCR fuel irradiation program was twofold: (1) to serve as a proof test for the individual elements of the fuel assembly, and (2) to yield design data for determining the mechanical lifetime of the fuel from the standpoint of fission product pressure buildup within the capsules.

Although a considerable amount of irradiation experience had bcen gained abuut $\mathrm{UO}_{2}$ prior to the start of the program, the bulk of this work had been directed toward the development of small-diameter solid $\mathrm{UO}_{2}$ pellets for a high-pressure water-cooled system. A number of basic differences in pellet design, operating temperatures, and overall system required a program directed toward the EGCR characteristics.

The EGCR is a combined experimental and power demonstration reactor under construction at Oak Ridge, Tennessee. It will be fueled with enriched $\mathrm{UO}_{2}$ clad in stainless steel; the fuel will be moderater with graphite and cooled with helium. The plant is designed to produce $85 \mathrm{Mw}$ thermal and $22 \mathrm{Mw}$ electrical power, with a reactor coolant outlet temperature of $1043^{\circ} \mathrm{F}$, a system pressure of 315 psia, and a coolant flow rate of $427,000 \mathrm{lb} / \mathrm{hr}$.

The reactor core is a vertical cylinder $15 \mathrm{ft} 10 \mathrm{in}$, in diameter and $19 \mathrm{ft}$. 4 in. high, with an active region that is $11 \mathrm{ft} 10 \mathrm{in}$. in diameter and $14 \mathrm{ft} 6 \mathrm{in.}$ high. The core is constructed of monolithic graphite columns 16 in. by 16 in. square and $19 \mathrm{ft} 4$ in. long. Each column contains four 5.25-in. holes on 8-in. centers to accommodate the fuel assemblies. There is a total of 232 fuel channels, each containing six fuel assemblies and two dummy assemblies.

A fuel assembly for the EGCR consists of a seven-element cluster of UO ${ }_{2}$ pellels clad with 0. U2U-in.thick type 304 stainless steel. The cluster is supported within a 1-in.-thick graphite sleeve (Fig. 1) that has an outside diameter of $5 \mathrm{in}$., an inside diameter of $3 \mathrm{in.}$, and a stacked length of $29 \mathrm{in}$. The top spider serves to support the cluster in the sleeve and also to locate the individual elements relative to one another and to the sleeve. The bottom spider does not carry any load, except a side reaction caused by temperature gradients in the cluster that tend to bow the elements. Only three of the seven elements, that is, alternate outer elements, are welded to the bottom spider. 


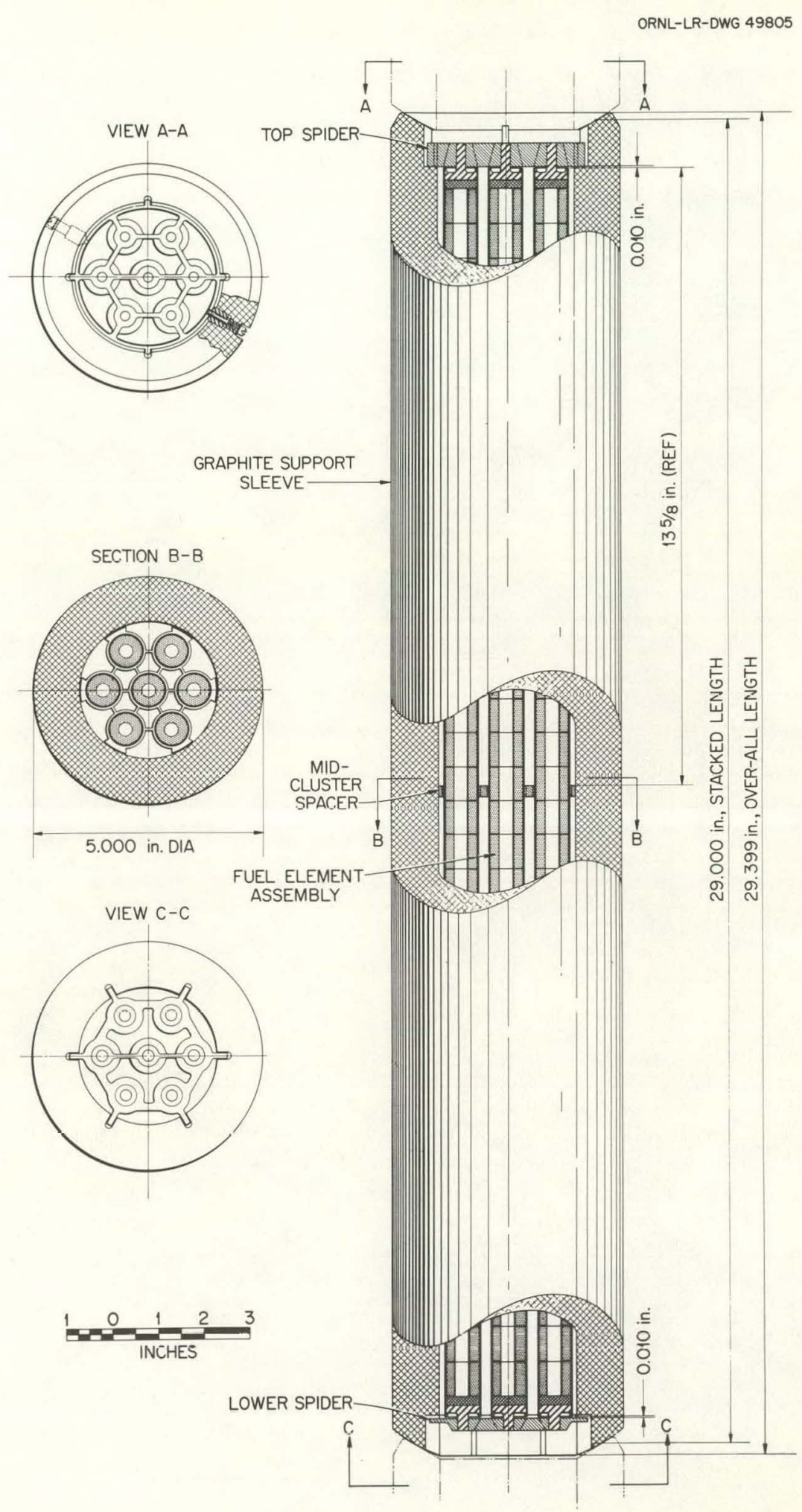

Fig. 1. EGCR Fuel Assembly. 
One of the six outer elements is shown in Fig. 2. The outer elements differ from the inner element only in the design of the spacer. The spacer for the central element is a thin ring that does not have the pad or the two protruding tabs. Each of the elements contains 36 cored 0.707 -in.-OD, 0.323-in.-ID UO ${ }_{2}$ pellets about 0.75 in. long. There is also an $\mathrm{MgO}$ pellet $3 / 16$ in. long at each end of the $\mathrm{UO}_{2}$ column to protect the stainless steel end caps from the high central $\mathrm{UO}_{2}$ temperatures. The end caps are pressed into and welded to the cladding. The primary purpose of the spacer is to prevent bowing of the rods due to thermal gradients within the cluster, and it thus adds thermal stability to the assembly.

One of the $\mathrm{UO}_{2}$ pellets is shown in Fig. 3. The nominal clearance between the pellets and the cladding is $0.004 \mathrm{in}$., and the tolerance on both the inside diameter of the cladding and the outside diameter of the pellet is 0.001 in.; thus the variation in diametral clearance will be from 0.002 to 0.006 in. These tight tolerances are necessary to prevent the formation of wrinkles in the cladding in the high-temperature region of the reactor where the cladding creeps and collapses onto the $\mathrm{UO}_{2}$. The small clearance will also reduce the temperature and, therefore, the fission-product release rate in the areas of the reactor where the clad-

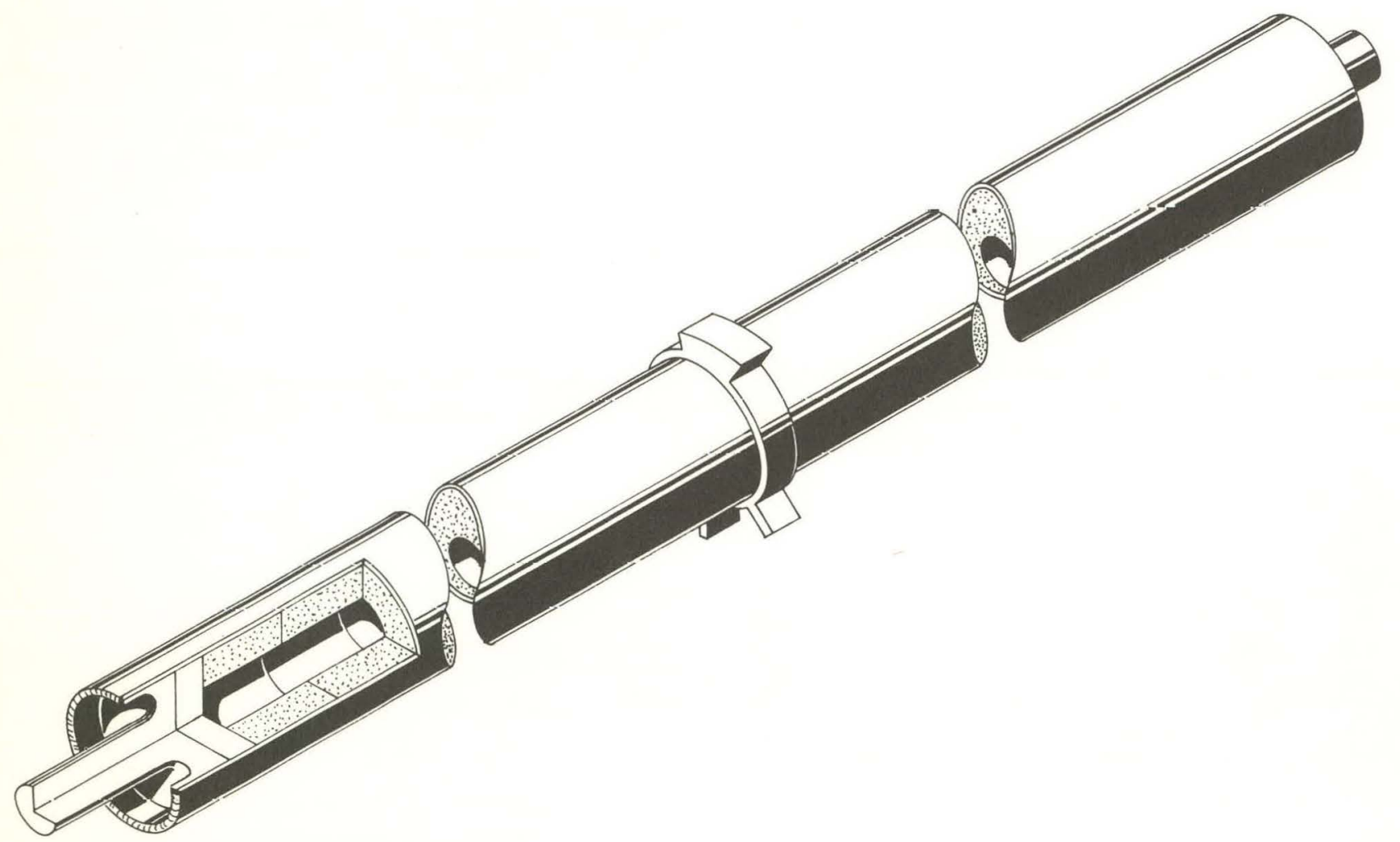

Fig. 2. EGCR Fuel Element. 
ding is not subject to creep. It has been found that the 0.002 -in. minimum clearance is necessary to assure easy loading of the pellets into the tube.

The hollow center in the $\mathrm{UO}_{2}$ fuel pellets serves to reduce the fission-gas-pressure buildup within the elements. For a given heat flux from an element, the removal of the central cores of the pellets reduces the temperature and, therefore, the fractional release of the fission products. The removal of the $\mathrm{UO}_{2}$ leaves a storage volume for the fission products that are released. This volume, although very inefficient because

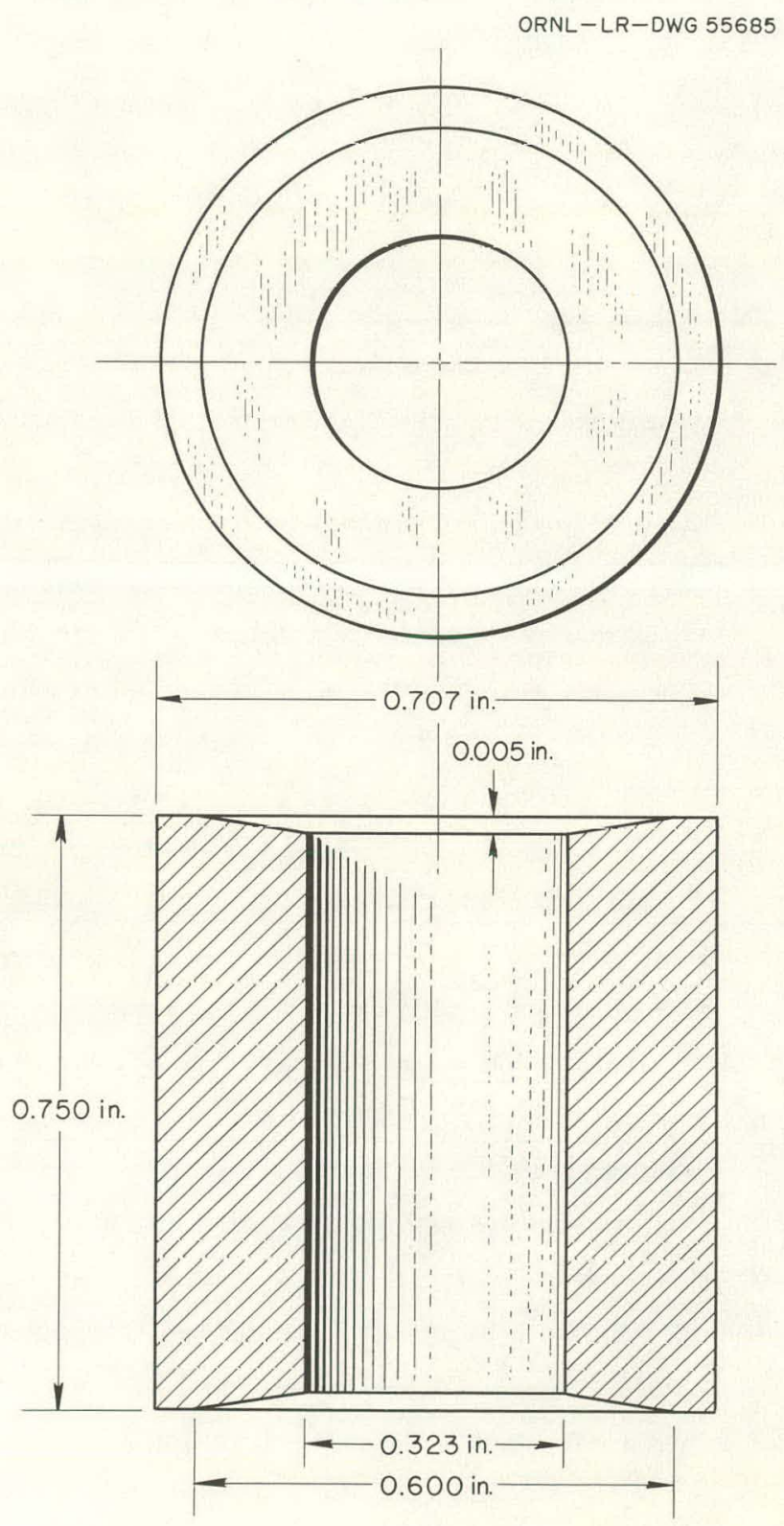

Fig. 3. EGCR Fuel Pellet. 
of its high temperature, is sufficient to prevent the pressure within the elements from exceeding the external coolant pressure of 300 psia for the design life of $10,000 \mathrm{Mwd} / \mathrm{metric}$ ton.

As shown in Fig. 3, the ends of the pellets are dished or chamfered to allow for axial expansion of the pellets in the higher-power regions of the core. The heat generation rate along a channel may vary as much as 40 to 1 . Under these conditions, the peak heat flux in the highest-power channel will be $173,000 \mathrm{Btu}$ $\mathrm{hr}^{-1} \mathrm{ft}^{-2}$ at a point one-third of the core length from the bottom of the reactor. The average flux in the top assembly in this channel will be about $4000 \mathrm{Btu} \mathrm{hr}^{-1} \mathrm{ft}^{-2}$. The axial coolant temperature variation for this case is such that, at the highest-flux point, the temperature will be about $850^{\circ} \mathrm{F}$ and, in the top assembly, the temperature will be $1075^{\circ} \mathrm{F}$. For these conditions the expansion of the pellets will be greater than that of the cladding at the peak flux point and less than that of the cladding in the top assembly. If a clearance were left at the top of the pellet column to allow for differential expansion, this clearance in the upper assemblies would become larger and might lead to the collapse of the unsupported length of cladding into the gap. Since the upper and lower three assemblies will be interchanged at their midlife, any circumference wrinkle into the gap would eliminate the original clearance and result in an axial strain on the cladding. The results of tests to investigate the behavior of a column of clad pellets have shown that for square-end pellets the axial growth depends on the central temperature of the pellets and that by dishing the pellets the axial growth is reduced. The use of the dished pellets then allows for the differential growth in the highest-power region of the core where the central temperature and, therefore, axial exparision is greatest, and no additional "head room" at the top of the element is necessary. As the central and outer temperatures of the pellets in the lowest-flux regions are very nearly the same, the effect of the dished ends on the relative growth is nil. The elimination of the initial clearance reduces the size of the end gap in the upper assemblies and no wrinkle is formed. The nominal depth of the chamfer at the inner surface of the pellet is 0.005 in., and the outside diameter of the chamfer is 0.600 in.

Three basic design criteria which have been applied to the fuel elements are (1) the maximum local hot spot temperature of the cladding will not exceed $1800^{\circ} \mathrm{F},(2)$ the $\mathrm{UO}_{2}$ pellets must have sufficient structural integrity to support the stainless steel cladding, and (3) the internal pressure in the elements will not exceed the external coolant pressure.

The gas and nominal fuel element surface temperatures for the highest-power channel with an exit gas temperature of $1075^{\circ} \mathrm{F}$ are shown in Fig. 4. This figure does not include the effects of local flux and heat transfer coefficient variations, gas temperature asymmetries, or hot spot factors. These items will lead to local surface temperatures in the range of 1650 to $1750^{\circ} \mathrm{F}$.

At these temperatures, the 0.020-in.-thick stainless steel cladding is not free standing and will collapse onto the $\mathrm{UO}_{2}$ in a short time. Thus, the $\mathrm{UO}_{2}$ pellets become the primary structural member and must maintain their shape. Cracking of the pellets is not serious so long as the pieces are wedged in place.

At high burnup or high fission-gas release rates, the high creep rate of the cladding becomes a major problem. A parametric study was made to determine the effect of the fission-gas release rate on the lifetime of the fuel elements. Figures 5 and 6 are typical of the results from this study. In both cases, the value of the apparent diffusion coefficient was assumed to be $10^{-9} \mathrm{sec}^{-1}$ at $1400^{\circ} \mathrm{C}$ with an activation

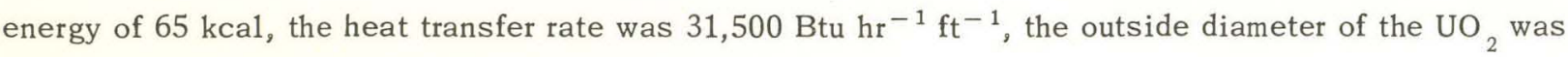




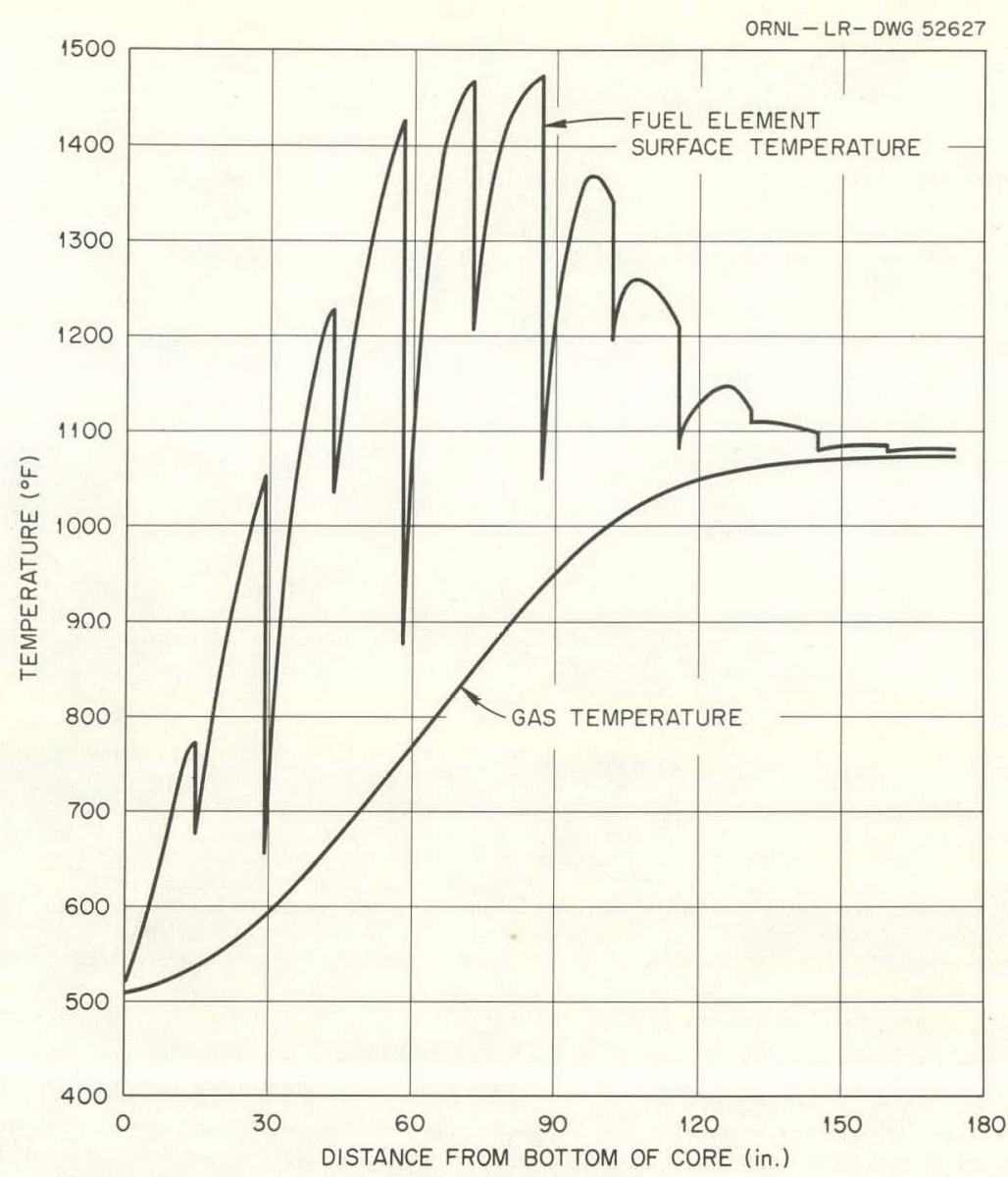

Fig. 4. Highest Power Channel (No. 4-20) Fuel Element Surface Temperature and Gas Temperature for a Uniform Exit Gas Temperature and Bank Insertion of Control Rods to a Depth of 62 in.

0.705 in., the inside diameter of the $\mathrm{UO}_{2}$ was 0.323 in., the stainless steel cladding was 0.020 in., and the initial gap between the $\mathrm{UO}_{2}$ and cladding was 0.0005 in. The element was initially filled with helium at $1 \mathrm{~atm}$.

In Fig. 5, the assumption is made that the pellet diameter remains constant so that as the initial pressure builds up and exceeds the external pressure, the cladding will creep and increase the clearance. Actually, as the clearance increases, the temperature of the $\mathrm{UO}_{2}$ will increase and the $\mathrm{UO}_{2}$ will expand and to some extent follow the cladding. Figure 6 shows the case in which the clearance remains constant at 0.0005 in. over the entire life. The true case lies somewhere between those shown in Figs. 5 and 6. It was obvious that either the fuel element design, fuel management, or lifetime must be such as to prevent any length of operation with the internal pressure above the external coolant pressure.

Thus, the primary goal of the irradiation program was to determine whether a design utilizing hollow $\mathrm{UO}_{2}$ pellets was feasible in a system in which the cladding, in many ways, was merely a barrier to contain the fission products. As a backup for the hollow pellet design, tests were also made with solid $\mathrm{UO}_{2}$ pellets and with hollow $\mathrm{UO}_{2}$ pellets which contained central $\mathrm{BeO}$ rods. 

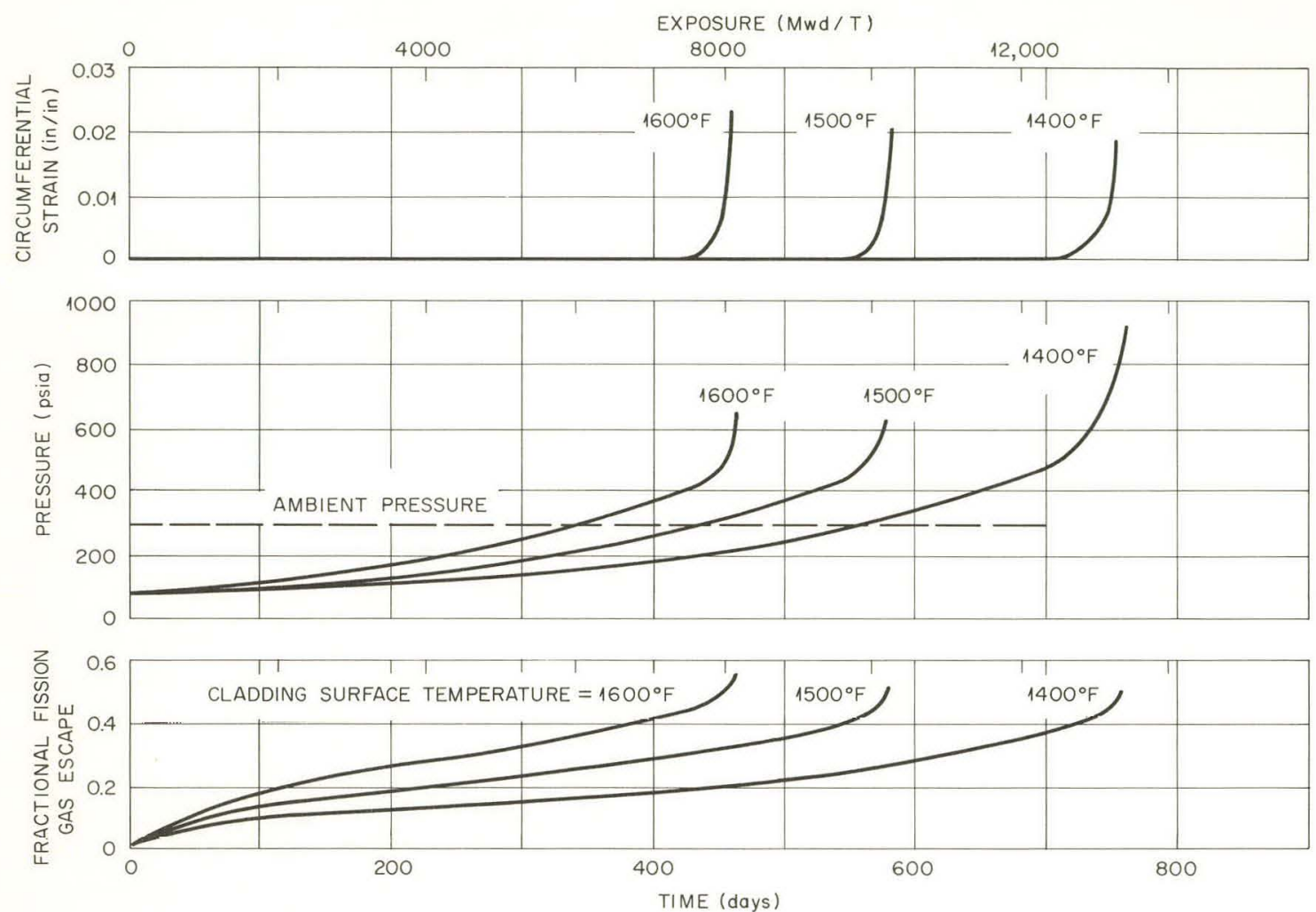

Fig. 5. Behavior of EGCR Fuel Element with Various Constant Surface Temperatures, Assuming Gap Increases as Cladding Expands.

ORNL-LR-DWG 45031A
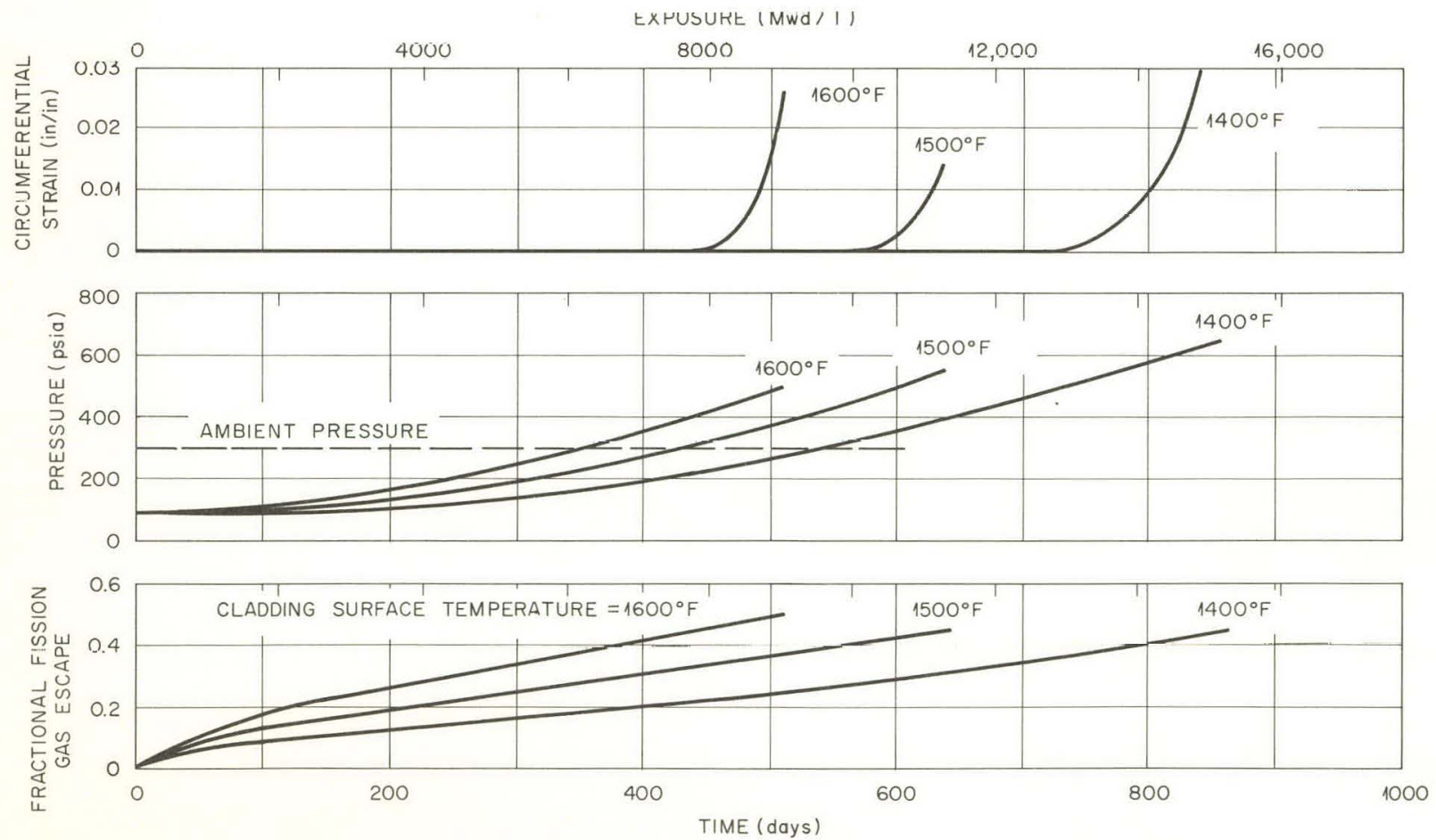

Fig. 6. Behavior of EGCR Fuel Element With Various Constant Surface Temperatures, Assuming Gap Remains Constant as Cladding Expands. 


\title{
2. DETAILS OF IRRADIATION PROGRAMS
}

\author{
D. B. Trauger
}

Although considerable information was available on the effects of irradiation on stainless-steel-clad $\mathrm{UO}_{2}$ from pressurized-water reactor programs, ${ }^{1-3}$ the higher surface temperature, larger diameter, and lower reactor coolant pressure for gas-cooled reactors necessitated additional developmental studies. While the major factors of concern in the irradiation program were the magnitude and effect of fission-gas release, the stability of $\mathrm{UO}_{2}$ under the proposed reactor operating conditions, the behavior of the stainless steel cladding, and the possibility of interaction between the fuel and the cladding, the specific objectives of the tests were: (1) to produce a basis for selecting one of several $\mathrm{UO}_{2}$ fuel pellet configurations, (2) to obtain fission-gas-release data, and (3) to provide adequate irradiation experience with fuel and cladding materials to justify their use in the reactor core.

The short time in the Experimental Gas-Cooled Reactor (EGCR) construction schedule allotted for development necessitated many concurrent irradiations in order to investigate the variables involved in detailed specification of the fuel elements. An extensive in-pile test program was necessary even though the irradiation testing was strictly limited to those variables closely associated with nuclear processes. Therefore, the tests were designed to obtain as nearly as possible the important fuel-element operating conditions. Test elements were chosen either to duplicate EGCR fuel-element dimensions or to bracket important variables, for example, fuel temperature, in specimens designed for convenience of experimental measurement.

Capsule-type irradiation assemblies were employed to initiate irradiation testing quickly and to provide the maximum test capacity and flexibility. No attempt was made to test a seven-element cluster under irradiation. Although such tests would be desirable to include effects of coolant flow distribution, no test reactor facility of a size adequate for this purpose was available. Furthermore, the time allotted for fuel specifications was not sufficient to permit the design and construction of the facilities and to conduct the necessary tests. As an alternative, out-of-pile heat transfer, pressure drop, and metallurgical experiments ${ }^{4,5}$ were coordinated with the irradiation program in order to provide a suitable prediction of the EGCR fuelelement characteristics. A forced-circulating loop has been completed in the Oak Ridge Research Reactor (ORR) for individual tests of helium-cooled 18-in.-long fuel-element segments. Although designed principally for tests of fuel for later EGCR cores, this loop is to be available for troubleshooting during first EGCR core procurement and during reactor startup.

Capsule irradiation test rigs were provided to utilize the ORR, Engineering Test Reactor (ETR), and Low-Intensity Test Reactor (LITR). Tests at the ETR, which are incomplete and therefore will be reported

\footnotetext{
${ }^{1} \mathrm{~J}$. D. Eichenberg et a1., Effects of Irradiation on Bulk UO ${ }_{2}$, WAPD-183 (October 1957).

${ }^{2}$ G. J. Belle and B. Lustman, Properties of $U_{2}$, WAPD-184 (September 1954).

${ }^{3}$ B. Iustman, Release of Fission Gases from UO ${ }_{2}$, WAPD-173 (March 1957).

${ }^{4}$ G. Samuels, Nuc1. Sci. Eng. 14, 37-52 (1962).

${ }^{5}$ J. H. Coobs, Nuc1. Sci. Eng. 14, 53-68 (1962).
} 
later, were conducted jointly with the Phillips Petroleum Company. ${ }^{6}$ All experimental assemblies irradiated in the ORR and ETR consisted of fuel elements of approximately EGCR size, except for length. Experiments conducted in the LITR utilized smaller hollow pellets and were designed rather specifically for obtaining data on fission-gas release as a function of burnup and fuel temperature.

\subsection{The Fuel Test Program (Miniature Capsules)}

The designs of the assemblies for irradiation of the miniature (LITR) capsules are shown in Fig. 7. The prime feature of these capsules is the reduced size, which permitted operation at considerably higher power density for a corresponding central temperature and fuel internal thermal stress, and, accordingly, much higher fuel enrichments were required. It was possible to attain greater burnup in these experiments; some burnups were in excess of 20,000 Mwd per metric ton of $\mathrm{UO}_{2}$.

The equipment for LITR miniature capsule irradiations utilizes forced-air cooling of the fuel container. Two designs of the capsule are shown in Fig. 7. These differ in that one accommodates a small fuel specimen directly encased in an Inconel container; the other utilizes a larger capsule, and the fueled body is surrounded by a ceramic insulating sleeve to obtain higher temperatures. The latter design reduces thermal gradients in the fuel and/or makes possible higher average fuel temperatures. In both cases, the metal container is air-cooled and temperature control is achieved by varying the velocity and corresponding heat transfer coefficient. Control is based on the lower capsule compartment; therefore the upper capsule operates at a lower equilibrium temperature.

The cladding for these capsules is designed only for convenience of the fuel irradiation, with no attempt to obtain significant information relative to encapsulation techniques. Closure of the capsule is achieved with a commercially available brazed metal-to-ceramic hermetic seal employing a nickel-cased, metallized aluminum oxide insulator through which the thermocouple lead wires pass. Although the seals have been reasonably satisfactory, their failures have accounted for most of the leaks that have occurred. In order to obtain a valid indication of the capsule wall temperature in the relatively cold, high-velocity cooling-air stream, the 1/16-in.-diam stainless-steel-sheathed Chromel-Alumel thermocouple assemblies were flattened and set in grooves $0.025 \mathrm{in}$. deep. The ends are inert-arc tack welded for strength and convenience in assembly, and the junction is brazed to the wall to obtain a good thermal bond.

An important and common feature of each LITR miniature capsule design is the center thermocouple for measuring the central temperature of the hollow cylindrical fuel specimens. This feature is discussed further in a later section.

Within 4 to 16 in. above the capsule, each of the sheathed thermocouples is connected to flexible lead wire through a connector seal. These lead wires are loosely attached to a 1/8-in.-OD aluminum push rod which is attached to the capsule support tube. For irradiation, the capsule is lowered into a semipermanent irradiation facility tube. This tube consists of two concentric aluminum tubes which penetrate the reactor tank cover and enters a reactor core position. The outer tube is sealed to the reactor tank at the

\footnotetext{
${ }^{6}$ W. C. Francis, J. R. McGeachin, and E. H. Porter, Trans. Am. Nucl. Soc. 3(2), Paper No. 38-3 (December 1960).
} 


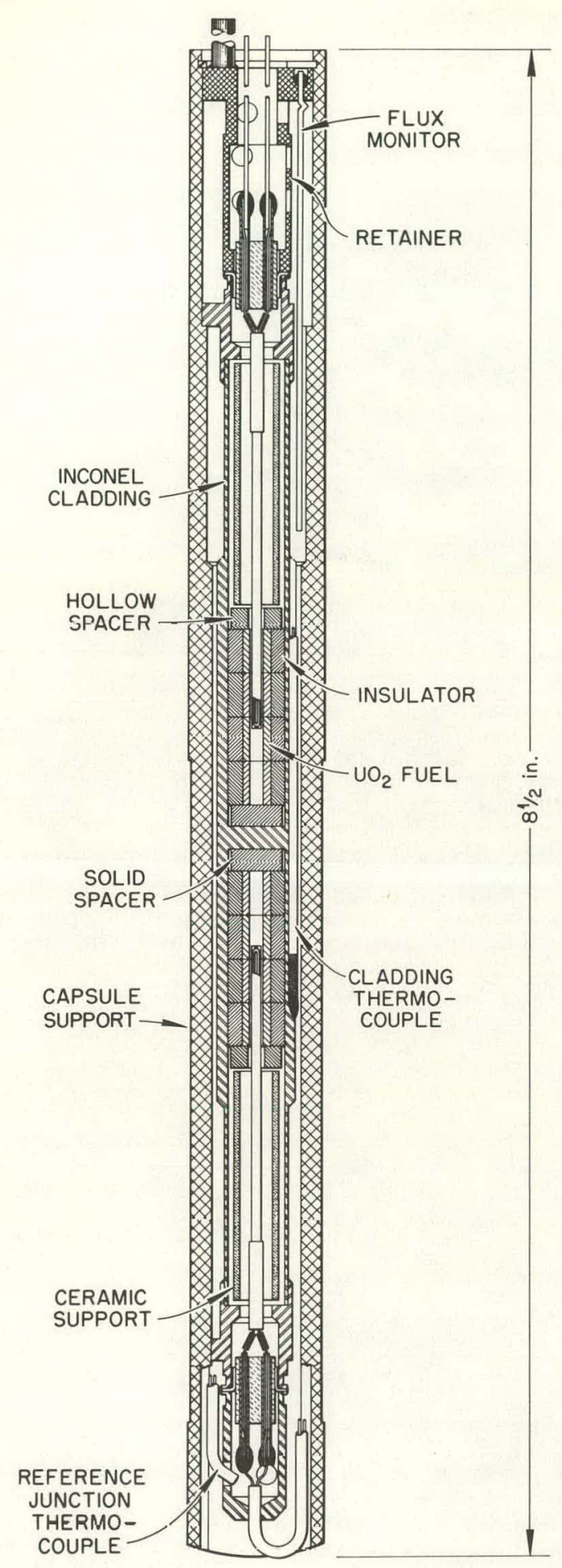

CERAMIC-INSULATED CAPSULE
ORNL - LR-DWG 40436R2

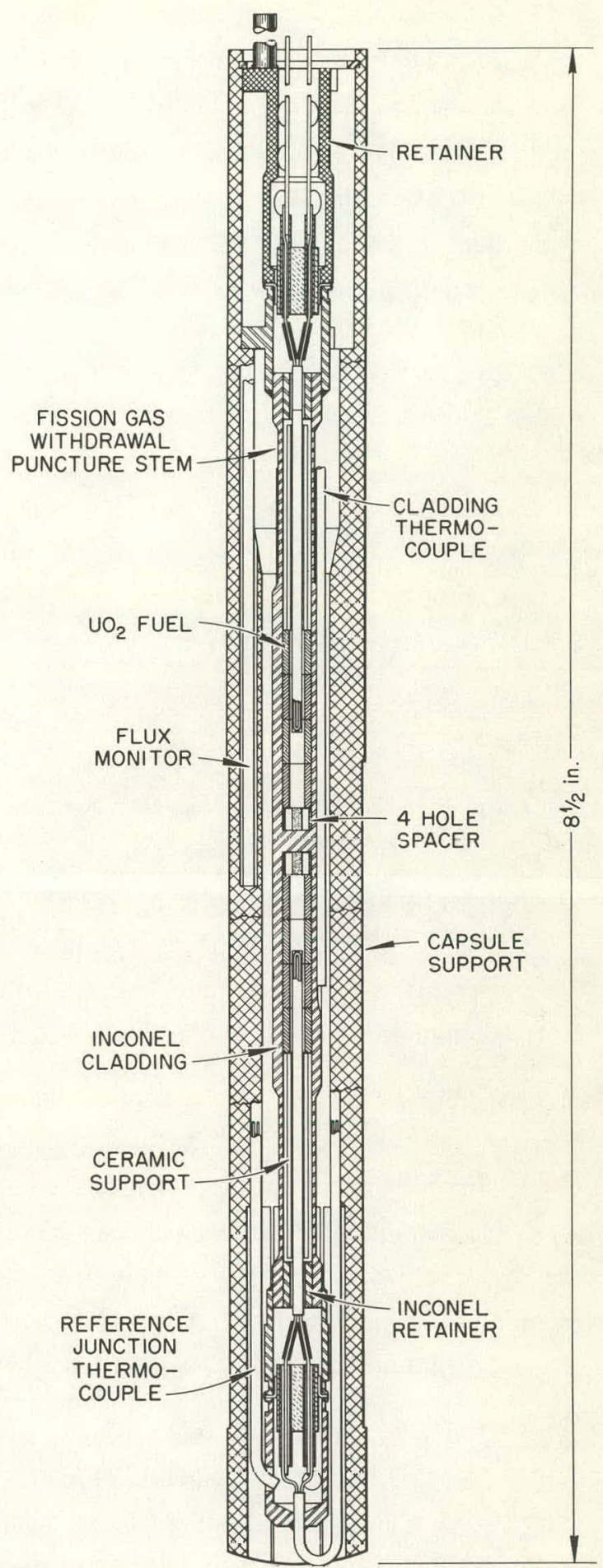

GAS-INSULATED CAPSULE

Fig. 7. Experimental Assembly for Irradiation of Miniature Fuel Capsules in LITR. 
top and is closed at the bottom end. Air nozzles are sealed to both tubes above the reactor tank so that cooling air admitted to the inner tube flows past the capsule within the inner tube and exits through the annulus between the tubes. Insertion and withdrawal of the capsule from the inner tube are facilitated by the push rod. The top seal of the inner tube contains connector pins for thermocouple connections. For withdrawal of a capsule, the push rod and thermocouple leads are threaded through a lead hole in a carrier above the facility tube. The capsule is then pulled up into the carrier, excess leads are cut off, and the carrier is vented and sealed. It is then ready for movement to a hot cell, where it is either prepared for long-distance shipment or is immediately subjected to postirradiation examination, depending upon where the examination is to be performed.

\subsection{The Prototype Capsule Test Program}

\subsubsection{Purpose}

The shape of the fuel pellets was one of the important variables affecting specification of the fuel. The shapes considered were a solid right cylinder, a hollow cylinder, and a hollow cylinder with a porous central plug. The hollow cylinders were considered as a means of eliminating the high-temperature central fuel region in the pellet and providing space for fission-gas accumulation. The possibility of $\mathrm{UO}_{2}$ flaking or chipping from the inner surface of a hollow cylindrical pellet was of particular concern, because this could lead to vertical redistribution of fuel within the element. Therefore, experimental capsules containing porous, low-density, sintered granular-BeO central plugs were irradiated to test this design as a corrective measure in the event mechanical stability of the hollow pellets was found to he unsatisfactory.

The choice of fuel geometry was an important factor in establishment of the test program scope. It was necessary to include sufficient specimens of each configuration to provide adequate confidence in the results for EGCR fuel specification, because the short time schedule would not permit sequential investigations. The distribution of specimens was weighted slightly in favor of the hollow pellet, since this was

the EGCR reference design. Spacing between the $\mathrm{UO}_{2}$ pellet surface and the cladding internal surface was included as a variable, and a few experiments are being conducted in the ETR at larger spacing than that now specified for the reactor fuel rods.

Most of the experiments were conducted at a cladding surface temperature of $1300^{\circ} \mathrm{F}$, but a substantial portion were conducted at temperatures up to $1600^{\circ} \mathrm{F}$ to include provision for EGCR "hot channel factors" and "hot spot factors." An external pressure of 315 psia was applied to prototype fuel capsules during irradiation. Thermal cycling of the fuel capsules was specified for some of the ORR experiments to simulate power variations expected for initial reactor startup and for startup after scheduled maintenance. shutdowns. In cycling, the thermal-neutron flux was varied with essentially constant thermal resistance in the heat sink to reduce cladding temperatures of 1300 and $1600^{\circ} \mathrm{F}$, respectively, to approximately 550 and $800^{\circ} \mathrm{F}$. The change in neutron flux was made quickly both for increases and decreases by insertion 
or removal of neutron-absorbing cadmium sheets between the specimens and the neutron source, as described below. Thermal cycles were scheduled at hourly intervals near the beginning and end of the irradiation periods. The significance of the imposed thermal cycling is somewhat questionable because of a rather large number of cycles to ambient temperature introduced by the ORR operating schedule. Smaller fluctuations also were introduced during capsule temperature adjustment and control.

Burnup of uranium was an important variable in the program. The specified burnups for the prototype capsules ranged from 2000 to $13,000 \mathrm{Mwd}$ per metric ton of $\mathrm{UO}_{2}$. Power generation rates up to 30,000 Btu $\mathrm{hr}^{-1} \mathrm{ft}^{-1}$ were specified for most experiments with prototype capsules, although some were set for 35,000 $\mathrm{Btu} \mathrm{hr}^{-1} \mathrm{ft}^{-1}$ to reduce the irradiation periods required for high burnup. These values approximate the greatest power densities predicted for any EGCR fuel element. ${ }^{4}$ Test reactor facilities having flux levels which would produce these power generation rates with a fuel enrichment of approximately $2 \%$ were sought. For convenience, however, the ${ }^{235} \mathrm{U}$ enrichment of some prototype capsules was as high as $7.5 \%$. The total power generation also was varied because of inadequacies in estimating flux and because the flux in a test reactor frequently changes at a given facility position.

Fuel enrichments were calculated from unperturbed thermal-neutron flux measurements made with cobalt or aluminum-cobalt alloy wires. The flux depression resulting from self-shielding of the $\mathrm{UO}_{2}$ and absorption of neutrons by the metal capsule parts was determined experimentally in two ORR locations and one ETR location. Complete capsule mockup assemblies containing flux monitor wires at the hollow $\mathrm{UO}_{2}$ pellet centers, in the $\mathrm{NaK}$, and on the outer surfaces were irradiated briefly. The ratios of pellet center flux to the flux at the other locations obtained from analysis of the wires agreed well (within $\pm 15 \%$ ) with those obtained by calculation using the SNG and $\mathrm{PDQ}^{7}$ computer codes. The SNG code was then used to calculate enrichments for the irradiation test fuel. However, burnup analyses obtained from capsules after irradiation indicated that the actual effective neutron fluxes were somewhat lower than predicted. Accordingly, empirical factors were applied for later experiments. The values presented in the tables are calculated by methods treating localized self-absorption factors.' 8,9 Agreement between the burnup predicted and that achieved, although quite approximate, has been commensurate with the precision of determination and the estimated flux changes at the facility positions.

\subsubsection{Detailed Discussion of Design and Operation of Experiments}

The principal tool for overall irradiation studies is the NaK-filled container used for the prototype (ORR and ETR) capsules shown in Fig. 8. The alkali-metal alloy is employed for convenience to conduct heat radially from the fueled capsule under irradiation. In addition to conducting heat to its containing vessel wall, the NaK-filled space includes six thermocouples to provide good measurement of the fueledcapsule wall temperature.

\footnotetext{
${ }^{7}$ G. G. Bilodeau et al., PDQ. An IBM-704 Code to Solve the Two-Dimensional Few-Group Neutron Diffusion Equation, WAPD-TM-70 (1957).

${ }^{8}$ W. J. C. Bartels, Self-Absorption of Monoenergetic Neutrons, KAPL-336 (May 1, 1950).

${ }^{9} \mathrm{~J}$. Dwork et al., Self-Shielding Factors for Infinitely Long, Hollow Cylinders, KAPL-1262 (Jan. 10, 1955).
} 


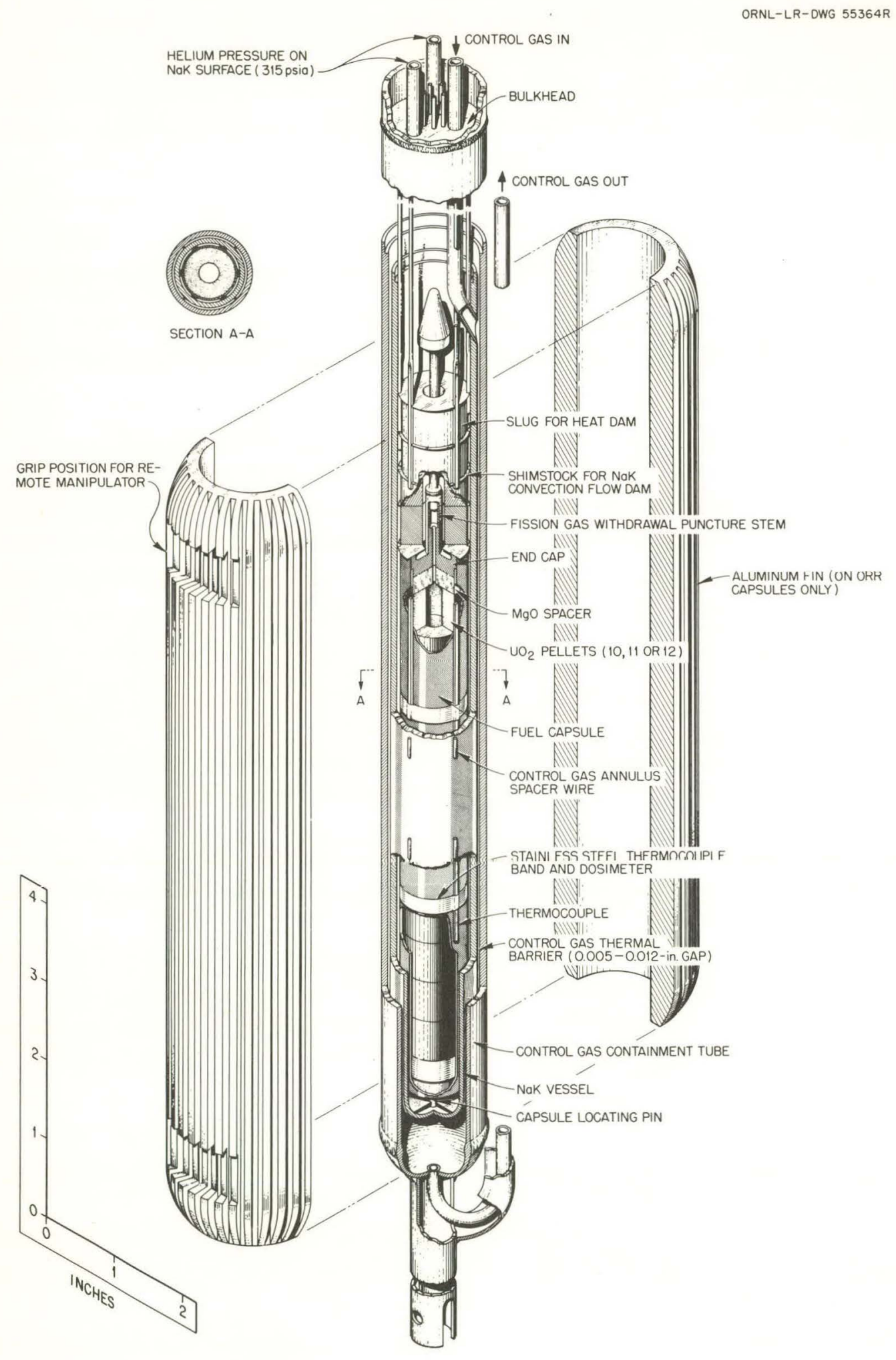

Fig. 8. Typical Experimental Assembly for Irradiation of Full-Diameter Prototype EGCR Fuel Capsules. 
The $\mathrm{NaK}$ vessel is enclosed in an outer vessel with uniform annular spacing to provide a gas gap. Variations of the thermal resistance of the gas gap are obtained by utilizing the appropriate mixture of helium and nitrogen or helium and argon to obtain the desired temperature. By varying the gas composition during irradiation, the temperature of the capsule can be adjusted over a range of several hundred degrees during irradiation at constant power. Conversely, as was the practice in these experiments, a capsule surface temperature of $1300^{\circ} \mathrm{F}$, for example, can be maintained when the power density varies by a factor of approximately 2. Final heat disposal is to the reactor pool (ORR) or core cooling water (ETR).

The concentric vessels that form the gas gap are closed by dual bulkheads that effect double containment of the radioactive fuel for safety purposes. Gas lines into each assembly provide means for applying a helium gas pressure of 315 psia to the NaK surface to match the EGCR operating pressure and for supplying mixed gases at a pressure of 300 psia to the gas annulus. The gas in the annulus is pressurized to reduce stresses that would produce metallurgical creep in the $\mathrm{NaK}$ vessel wall. By varying the gas gap and the gas mixture, fuel having heat generation rates between approximately 5000 and $50,000 \mathrm{Btu} / \mathrm{hr}$ per foot of length can be tested in this apparatus, which is described in greater detail in an ORNL report. ${ }^{10}$

The eight NaK-filled assemblies irradiated concurrently in the ORR were located in two sets of four at the poolside facility as shown in Fig. 9, which is a photograph of a mockup. The stainless-steel-clad cadmium shutters that were installed at six of the positions, so that both power and temperature for those capsules could be reduced periodically as desired, are also shown in the photograph. Each facility in the ORR was equipped with continuous temperature recording, suitable gas pressure and mixture controls, and reactor setback controls for high $\mathrm{NaK}$ (fuel) temperature and off-design pressure conditions. ${ }^{11}$

Insertion and withdrawal of capsule rigs irradiated in the ORR poolside facility are relatively simple. For insertion a rig is maneuvered into the proper standing position within the poolside facility and secured in appropriate mounting brackets. The double containment gas tubing connections are made below final reactor pool water operating level, thus connecting the gas lines to the permanent shielded gas valve box. Thermocouple leads penetrating the top end of the capsule rig above the final water operating level are connected to permanent instrument leads. Withdrawal of a rig is effected by (1) disconnecting the thermocouple leads, (2) partially lowering the reactor pool water level to allow shearing and weld-sealing of the gas lines, (3) raising the water level again for disengagement and maneuvering of the rig away from the reactor, and (4) underwater transfer of the rig to the ORR hot cell pool. Subsequently, the 28-ft-long rig is shortened to about $20 \mathrm{ft}$ by shearing off the upper end and charging the lower end into the ORR south hot cell by underwater transfer through the cell floor hatchway. Here the rig is further shortened, the NaK is removed, and the fuel element is extracted. The fuel element is then transferred to another hot cell for postirradiation examination.

\footnotetext{
${ }^{10}$ GCR Program Semiann. Progr. Rept. Dec. 31, 1958, ORNL-2676, pp. 105-20.

${ }^{11}$ GCR Proǵtam Quart. Progrt. Rept. Dec. 31, 1959, ORNL-2888, pp. 90-107.
} 


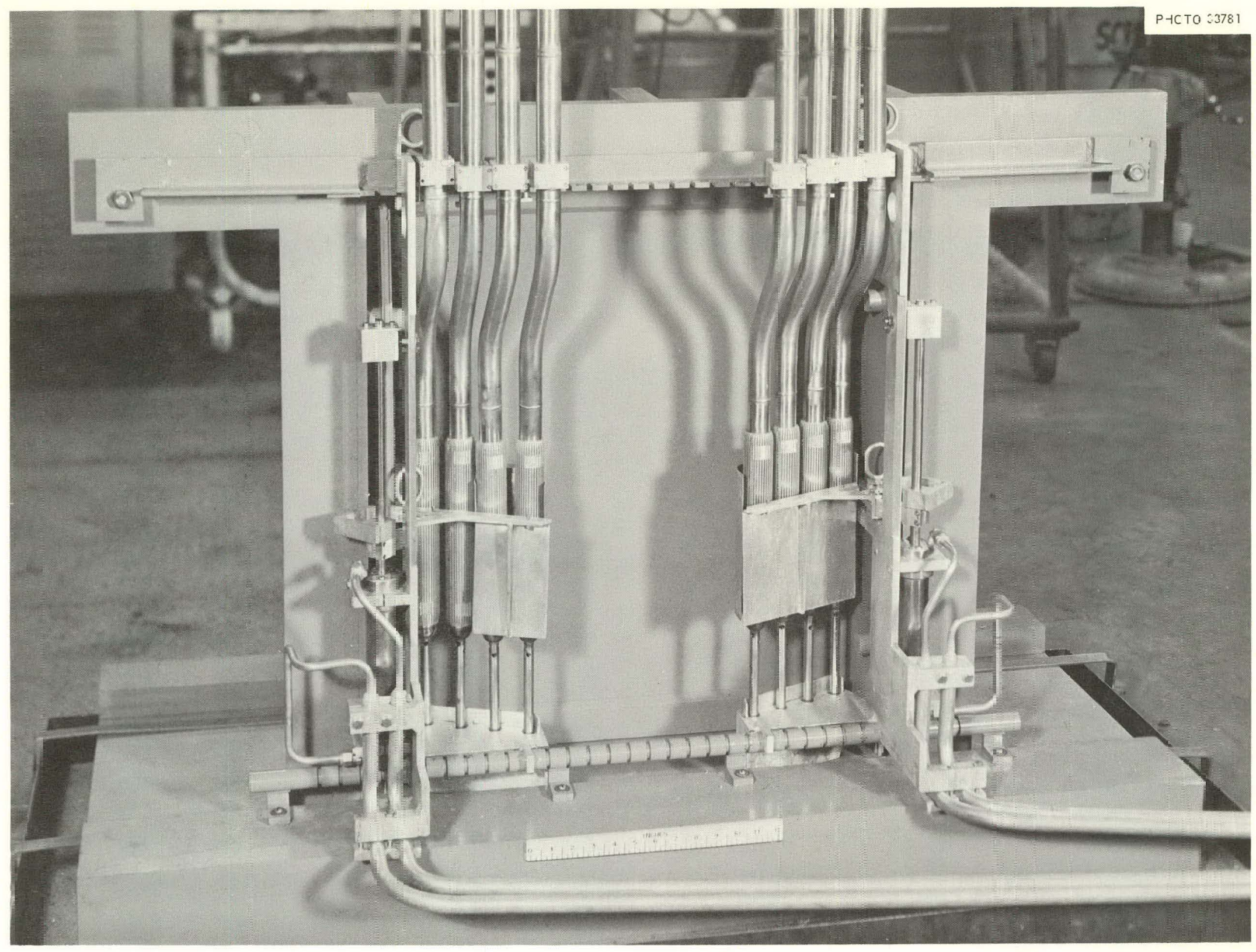

F g. 9. ORR Pocls de Irradiation Facility Mockup Illustrating Capsule Positions at the Reactor. 


\subsubsection{Specification and Inspection of Test Assemblies}

An attempt was made to envision, to the extent possible, the final specifications for the EGCR fuel in determining those for the test assemblies. The specifications used in handling, cleaning, welding, and atmosphere control did not always constitute the best possible laboratory technique, but rather were those considered practical for large-scale procurement. In contrast, the inspection procedures were as detailed as time and facilities permitted.

Tolerances for cladding dimensions, density, and stoichiometry are illustrated by the values given in Table B.2 (Appendix B). The 1/2-in.-long cylindrical fuel pellet had square ends, in contrast to the EGCR dished ends, since this feature was established after the irradiation specimens had been manufactured. The end clearance between the fuel column (including the $\mathrm{MgO}$ insulator pieces) and the end plugs was established as $0.040 \mathrm{in}$. when cold. This approximates that required to accommodate the calculated differential thermal expansion between the fuel column and the cladding wall. It was considered desirable to hold the end clearance to a minimum to avoid tubing collapse from the external pressures.

All $\mathrm{UO}_{2}$ pellets were prepared from special oxide batches by a simplified fabrication process ${ }^{5}$ and by sintering for 1 to $2 \mathrm{hr}$ at $1750^{\circ} \mathrm{C}$ in hydrogen. In many cases, the pellets were sintered directly to the required size and tolerances. Each $\mathrm{UO}_{2}$ pellet which had been ground to size or drilled (to provide for measurement of the central temperature in LITR experiments) was cleaned in carbon tetrachloride for 5 min with ultrasonic agitation. Following cleaning, the pellets were dried and outgassed at $300^{\circ} \mathrm{C}$ under a vacuum of $5 \times 10^{-4} \mathrm{~mm} \mathrm{Hg}$ or less and identified with an electric pencil scribe. Visual inspection usually was more stringent than would be required for reactor fuel procurement ${ }^{12}$ so that small cracks and chips that developed during irradiation could be more readily identified. Radial cracks exceeding one-fourth of the wall thickness or radius, circumferential or axial cracks, or chips exceeding 1/16 in. in lateral dimension or $0.010 \mathrm{in.}$ in depth were cause for rejection. In some instances, in order to utilize pellets of special isotopic enrichments, circumferential cracks up to $90^{\circ}$ of arc and axial cracks $1 / 4$ in. in length were accepted. Representative pellets were chosen from each set for chemical analyses and microscopic examinations. Acceptable pellets were weighed and measured. The surface areas of the pellets selected for given experiments were determined by the BET method ${ }^{13}$ and were found to vary widely, from about 5 to $89 \mathrm{~cm}^{2} / \mathrm{g}$, depending to some extent on the geometry and size of the pellets. Immersion densities were obtained by vacuum-filling pores in the pellets with carbon tetrachloride and weighing while suspended from a fine wire in a bath of carbon tetrachloride. After again drying and outgassing, the pellets were stored in desiccators until they were loaded into the capsules.

The $\mathrm{BeO}$ plugs used in the central holes of hollow pellets were made from GC-grade $\mathrm{BeO}$ powder by cold extrusion of a plasticized mix and firing for $1 \mathrm{hr}$ at $1650^{\circ} \mathrm{C}$. The plugs were then machined to the required size. The average calculated bulk density of these plugs was $1.40 \mathrm{~g} / \mathrm{cm}^{3}$, or about $46 \%$ of theoretical.

\footnotetext{
${ }^{12}$ Specifications for Fuel Assemblies for Core 1 of the Experimental Gas-Cooled Reactor, ORNL-CF-60-11-90 (Dec. 9. 1960).

${ }^{13}$ S. Brunauer, P. H. Emmett, and E. Teller, J. Am. Chem. Soc. 60, 309 (1938),
} 


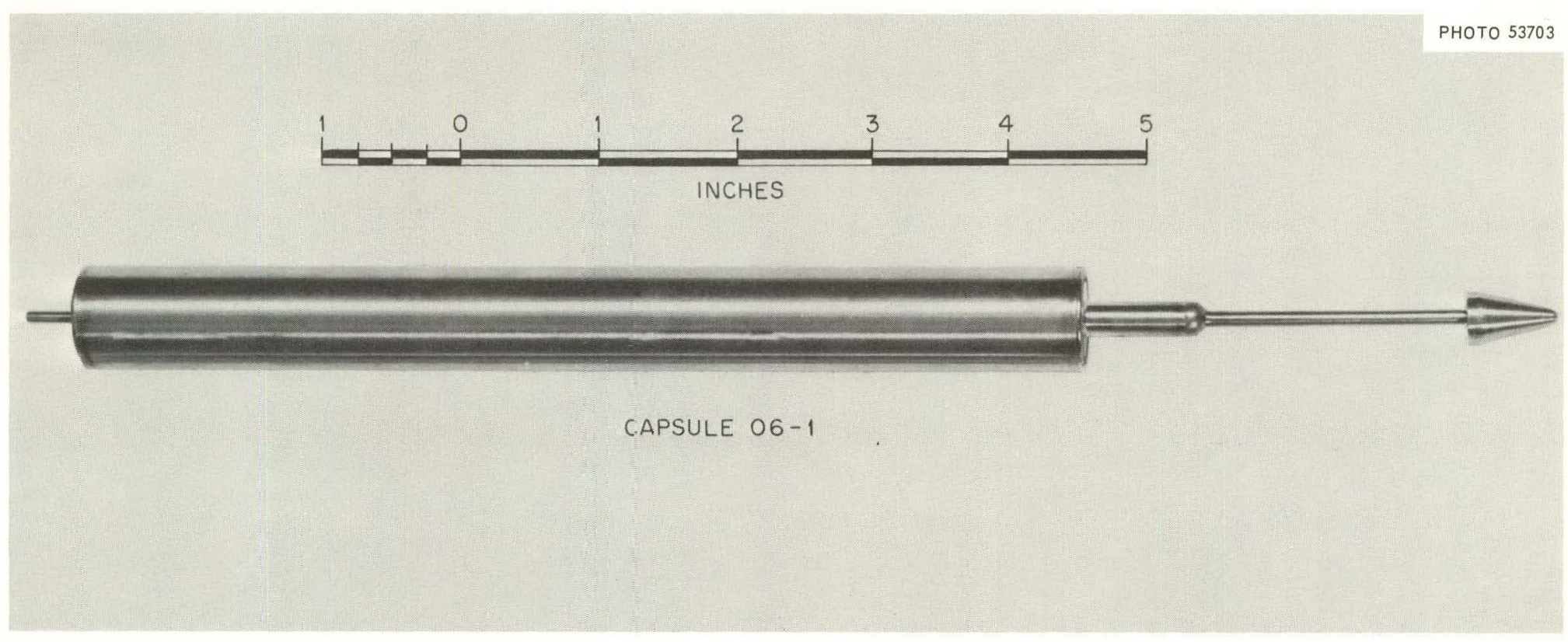

Fig. 10. Completed Prototype Capsule. 
Magnesium oxide pellets were prepared at ORNL to a special density of $2.6 \mathrm{~g} / \mathrm{cm}^{3}$. They were cleaned and degassed, dimensioned, and stored with essentially the same treatment as for $\mathrm{UO}_{2}$ pellets.

Tubing for cladding the fuel was procured commercially. Dimensional inspection included the use of air gages, and material integrity tests were made by dye penetrant, eddy current, and ultrasonic methods. End cap materials were inspected by x-ray and dye penetrant techniques; the latter was used both before and after fabrication.

Final assembly of the test specimens was made in a welding dry box filled with helium, which also provided the encapsulation atmosphere. Closure was made by semiautomatic inert-arc welding with rotation through $450^{\circ}$ and tapered current cutoff to obtain a smooth weld overlap. Fig. 10 is a photograph of a finished capsule, while Fig. 11 illustrates the differences in assembly for the three types of pellets used. No filler metal was added to the edge weld, which was made with the end cap having a ${ }_{-0.001}^{+0.000}$-in. press fit into the capsule tubing. Atmospheric purity was established by twice evacuating the dry box to $10^{-4}$ $\mathrm{mm} \mathrm{Hg}$ pressure and back filling with helium to a slightly positive pressure. The argon torch flow was restricted to $8 \mathrm{cfh}$ and to periods when welding was performed to limit the argon in the capsule to about 3 vol \%. Capsules selected for irradiation were measured for ovality and bowing, using apparatus consisting of a movable dial indicator mounted on a bed equipped with spindle ends to support and rotate the tubing. This equipment is identical with that used for postirradiation dimensional measurements. Although the specifications and inspections were somewhat more detailed than those outlined here, only those found relevant to postirradiation findings are of major interest.
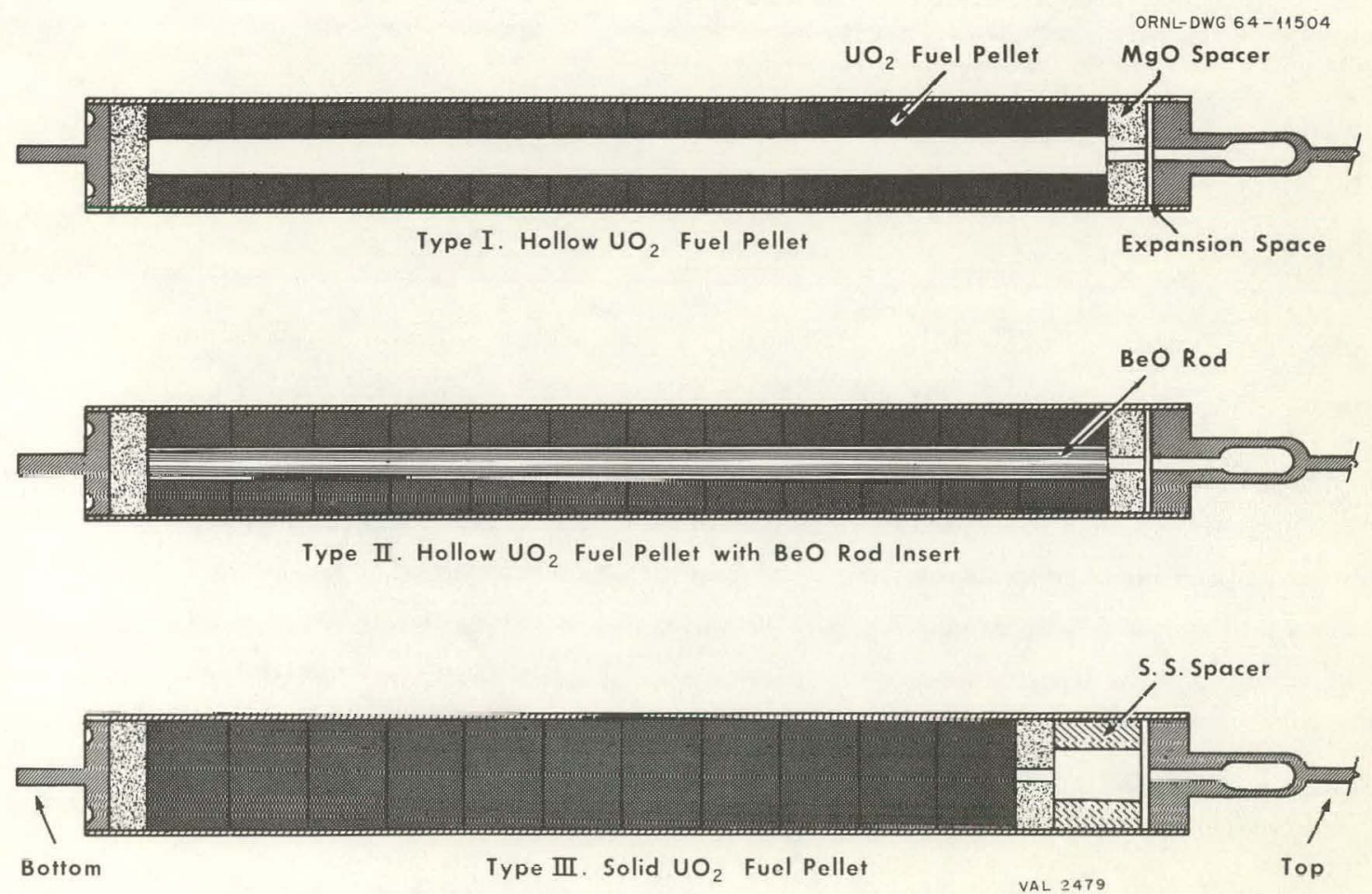

Fig. 11. Three Types of ORR Prototype Capsules. 


\section{POSTIRRADIATION MEASUREMENTS}

Postirradiation examinations of the prototype and miniature fuel elements were made at ORNL and at

the General Electric Company's Vallecitos Atomic Laboratory (GEVAL). The following examination procedures apply to the prototype elements generally. Only the fuel examination and fission gas release procedures apply to the miniature elements, since these experiments were designed primarily for fuel performance evaluation.

\subsection{Nondestructive Measurements}

Nondestructive examination of the irradiated fuel elements consisted of visual observation of surface characteristics of the cladding, gamma scanning of the element to obtain variations in burnup and fuel migration, and dimensional measurements of outside diameter, eccentricity, bowing, and wrinkling.

Monoculars, binoculars, and Kollmorgen periscopes aided visual examination of the elements. Photographs of the complete elements and points of special interest (such as weld zones) were also made.

A gamma scan is obtained by moving the capsule past a narrow collimating slit in a cell wall plug behind which is located a scintillation detector (Fig. 12). The output of the detector is recorded on a strip chart recorder which relates the gamma activity to position along the capsule.

Outside diameter measurements of the fuel element cladding were made at selected intervals with a micrometer or a comparator dial gage (Fig. 13). Out-of-roundness was determined by rotating the element on its axis. Generally four measurements, approximately $90^{\circ}$ apart, were made at each longitudinal position.

Bowing and profile measurements were made by a remotely controlled profilometer (Fig. 14), or by positioning the element in two V-blocks resting on a surface plate, and using a dial indicator gage (Fig. 15) to measure the height of the surface of the element above the surface plate.

\subsection{Fission Gas and Canning Atmos phere Sampling and Analysis}

Fission gas and canning atmosphere samples were obtained from the irradiated elements by piercing the cladding with a modified refrigeration-type needle valve and expanding the gas into an evacuated system of dilution tanks of known volume (Fig. 16 for ORNL method and Fig. 17 for GEVAL method). An estimate of the final volume and pressure of the gas in the element was obtained by making two or more successive expansions into known evacuated volumes and noting the equilibrium pressure at each expansion.

Aliquots of the gas were then taken for mass spectrometer and gamma spectrometer analyses. The activity of the long-lived ${ }^{85} \mathrm{Kr}$ was measured in all cases, and the shorter-lived ${ }^{85 \mathrm{~m}} \mathrm{Kr},{ }^{88} \mathrm{Kr},{ }^{133} \mathrm{Xe}$, and ${ }^{135} \mathrm{Xe}$ activities were obtained whenever possible. Mass spectrometer analyses were made for the stable krypton and xenon isotopes, $\mathrm{H}_{2}, \mathrm{He}, \mathrm{H}_{2} \mathrm{O}, \mathrm{CO}-\mathrm{N}_{2}, \mathrm{O}_{2}, \mathrm{Ar}, \mathrm{CO}_{2}$, and any other identifiable gases present. 


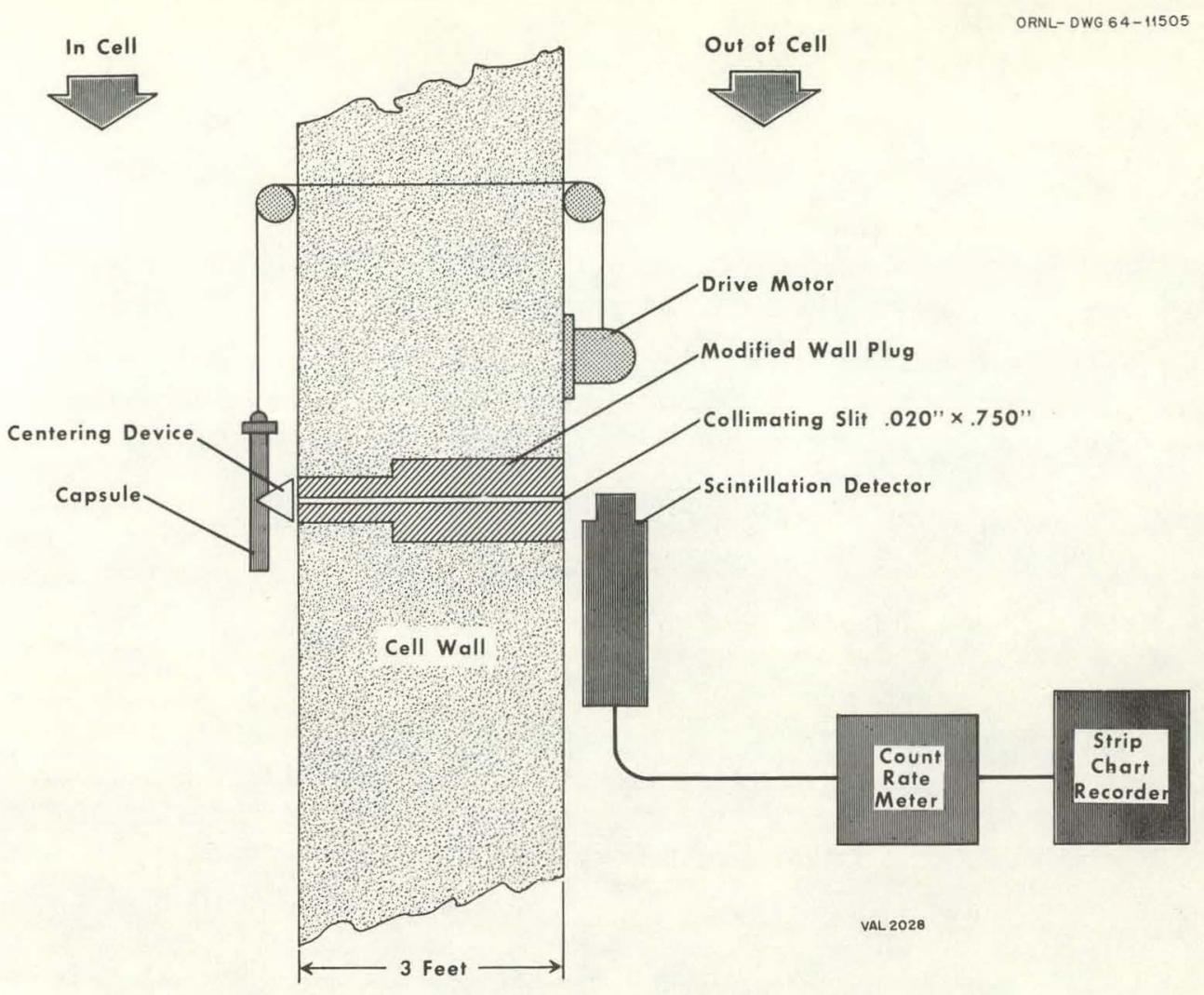

Fig. 12. Schematic Diagram of Gamma Scan Equipment.

Fig. 13. Outside Diameter Gage. 0.6×.

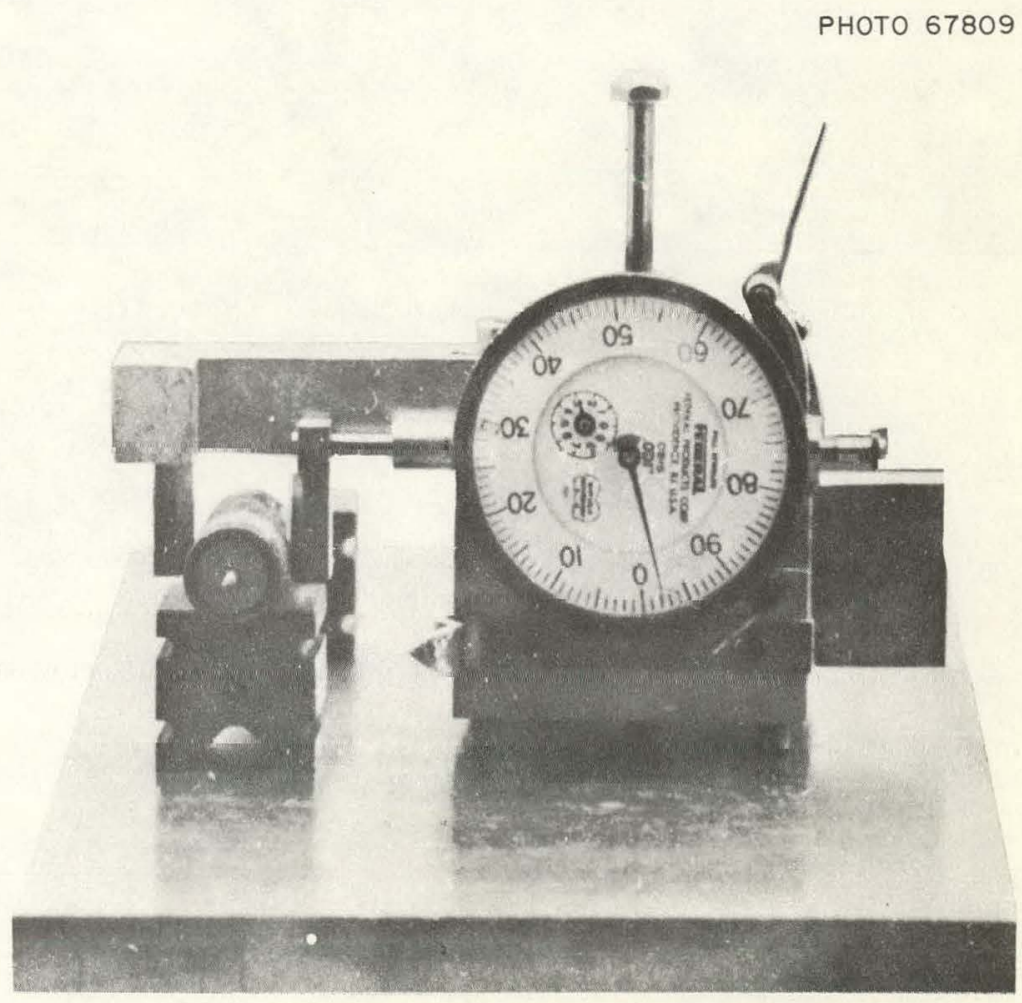




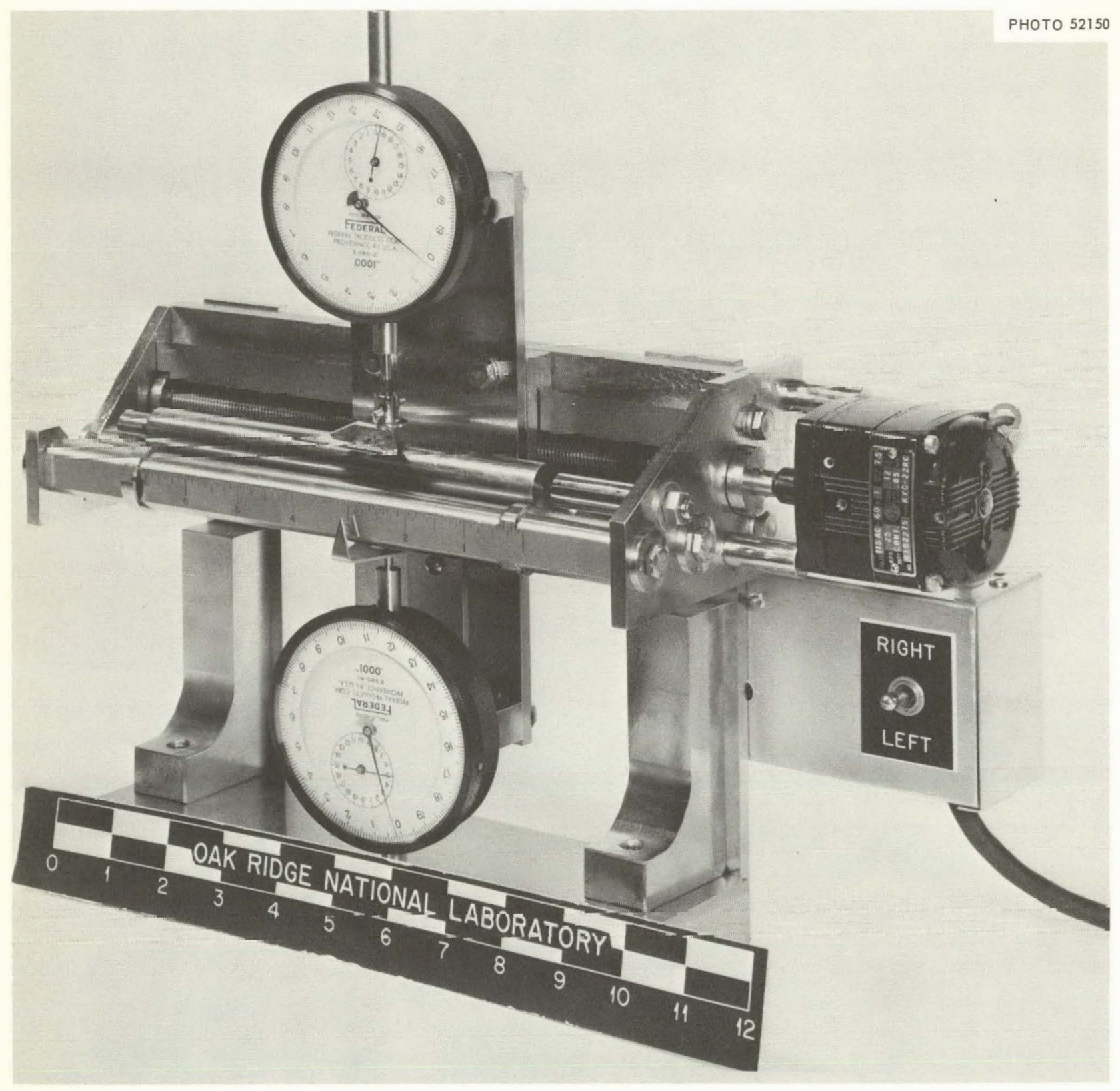

Fig. 14. Profilometer Used to Measure Bow and Eccentricity of EGCR Prototype Capsules. 


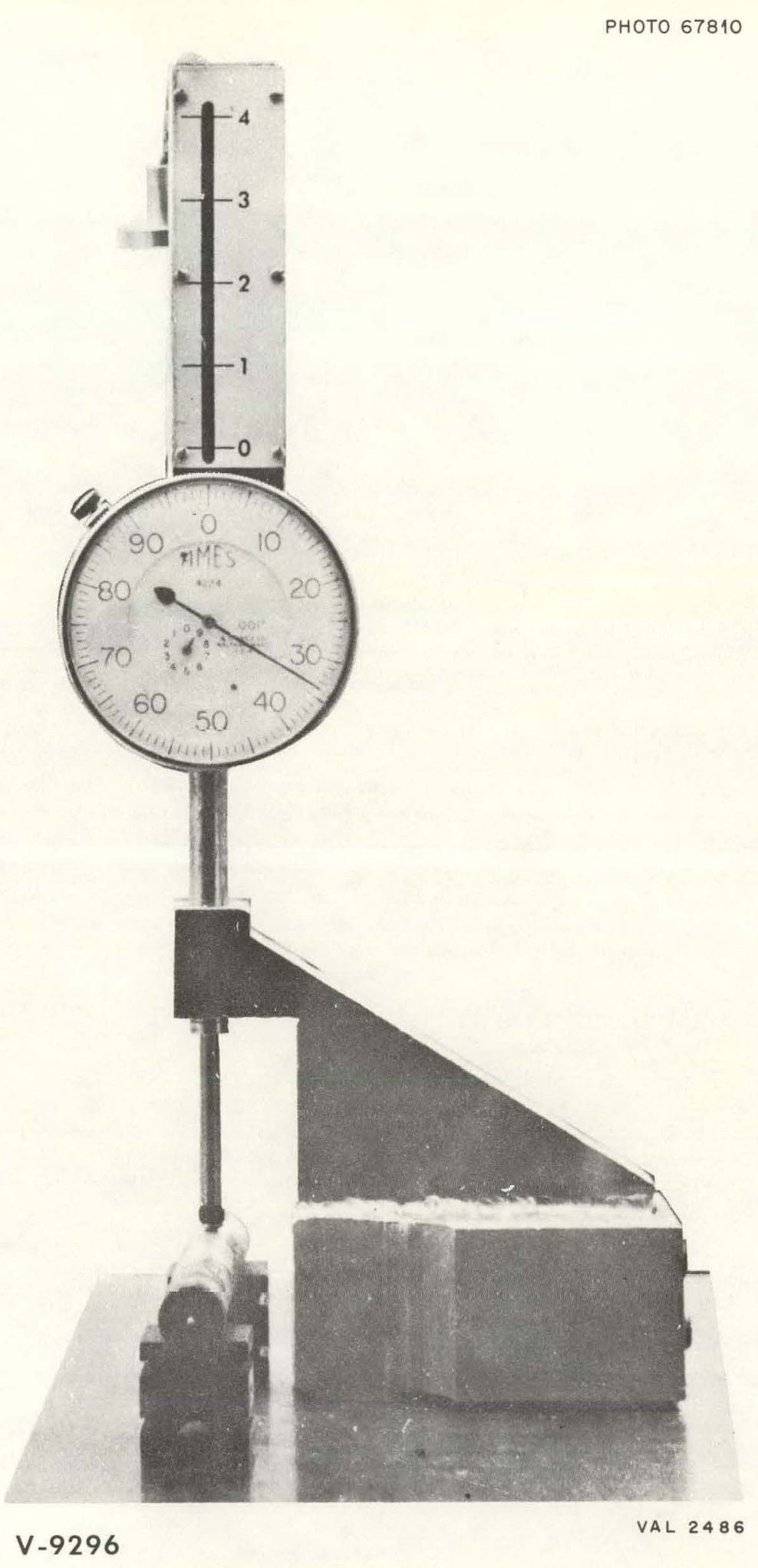

Fig. 15. Profile Gage. $0.6 \times$. 


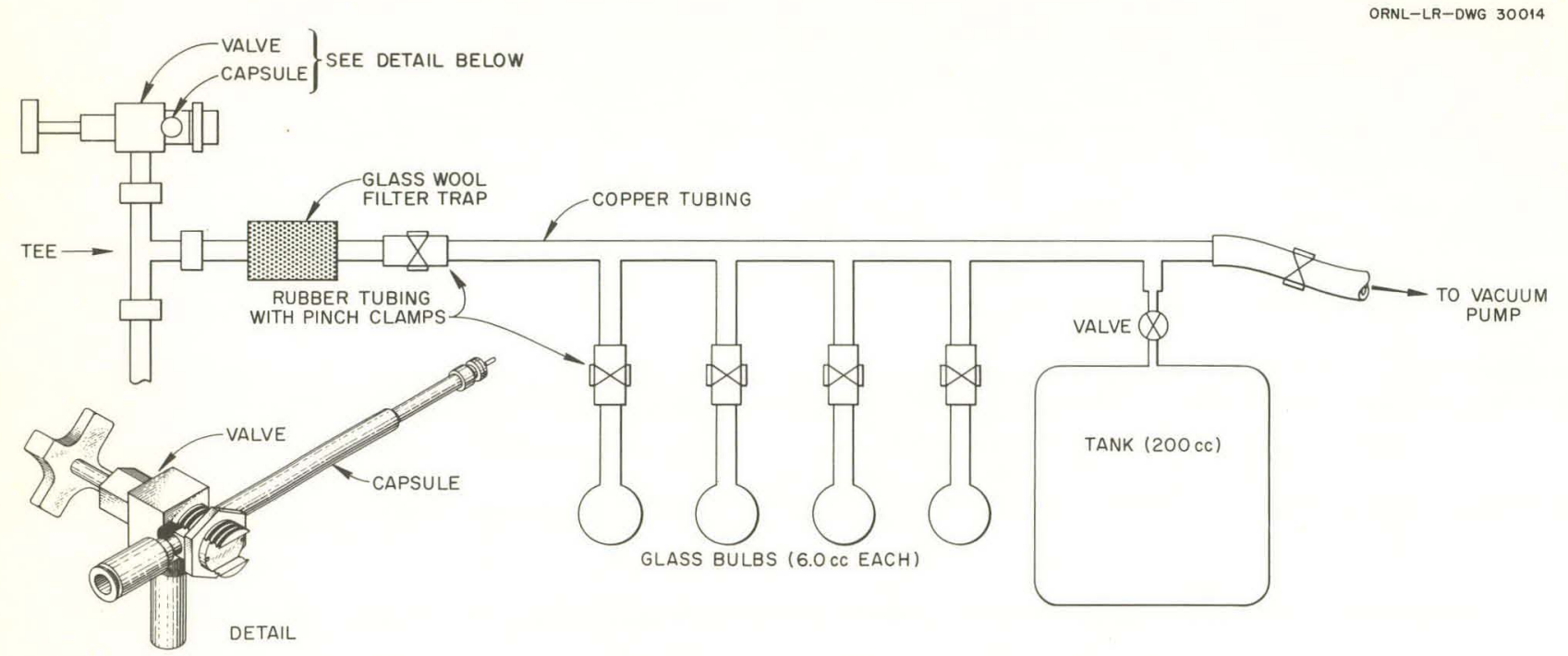

Fig. 16. Fission-Gas Collection Apparatus, ORNL.

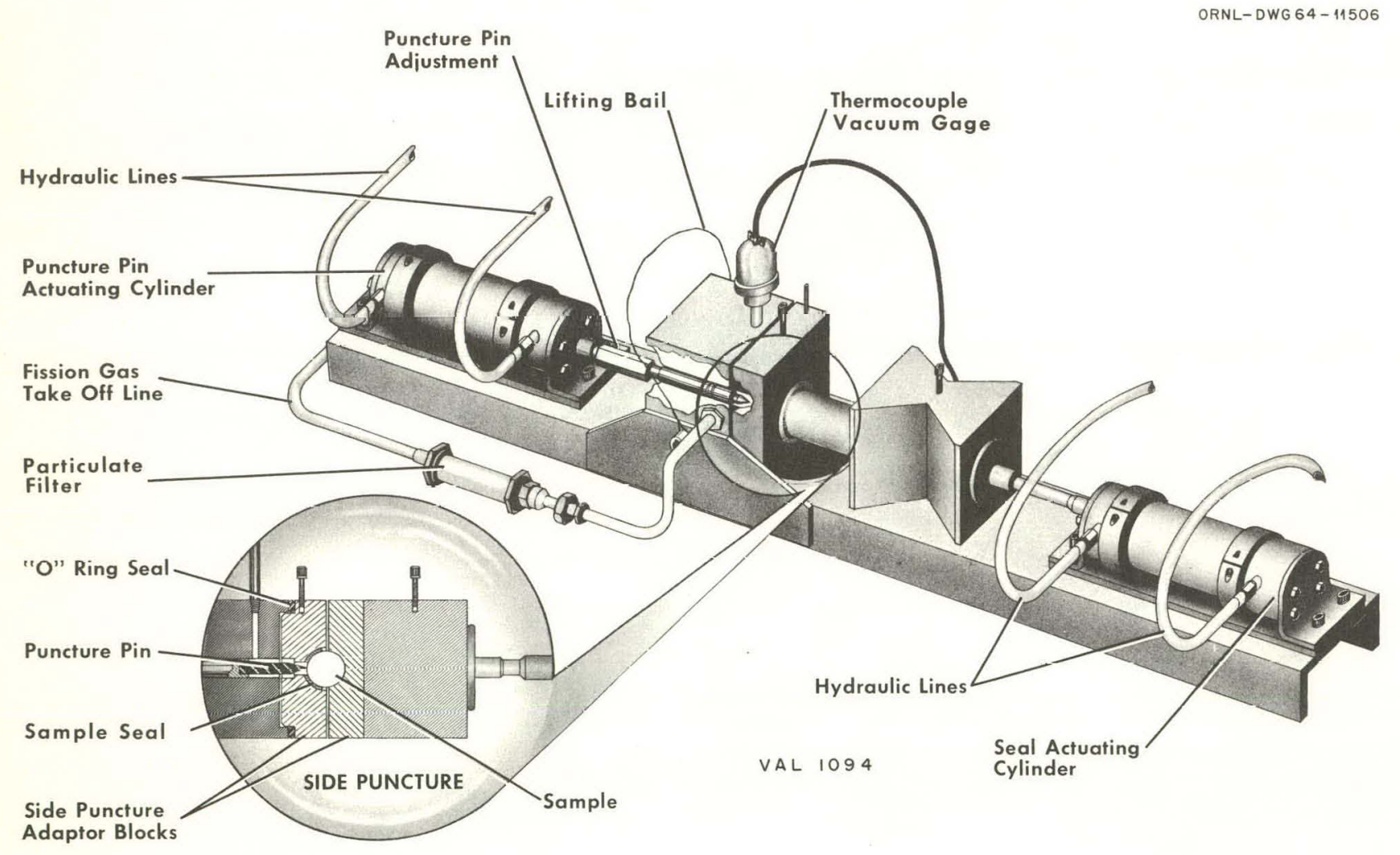

Fig. 17. Fission-Gas Puncture Mechanism, GEVAL. 


\subsection{Fuel Element Disassembly}

The fuel elements were opened by cutting off the end caps and slitting the cladding twice longitudinally about $180^{\circ}$ apart, using a high-speed air motor and abrasive wheel. The contents of some elements, or half elements, were immobilized prior to opening by impregnation (or vacuum "potting") with an epoxy resin (e.g., "Hysol" mounting compound). One half of the split cladding was removed to expose the components and inside of the cladding to visual examination. Sections for metallographic examination, either transverse or longitudinal, were obtained by use of the ceramic cutoff wheel. These samples of fuel, ceramic components, and cladding were mounted and prepared for metallurgical examination using standard hot cell techniques.

\subsection{Fuel Pellet Examination}

Pellets which had not fractured too severely were selected for dimensional measurements (outside diameter and length) by micrometers and then were weighed. Bulk density was obtained from the weight and calculated volume.

Immersion density measurements in carbon tetrachloride and mercury were made in various pycnometers (Fig. 18), using whole pellets if obtainable. Generally the carbon tetrachloride measurement was made after evacuating the pellet in the pycnometer. In this way an indication of the extent of open and closed porosity was obtained (since mercury does not wet $\mathrm{UO}_{2}$, and the carbon tetrachloride would enter previously evacuated pores whose size approached that of the carbon tetrachloride molecule).

Selected pellets, or portions of pellets, were then mounted and prepared for metallographical examination using routine hot cell techniques. Samples were also selected for burnup determinations (by standard fission product and total uranium analyses or mass spectrographical uranium isotopic analyses), and for oxygen-to-uranium ratio measurements.

\subsection{Effect. of Low-Boiling-Point Alkali-Metal Fission Products on Pressure Buildup}

The effect of low-boiling-point alkali-metal fission products (principally cesium and $\mathrm{r} u b i$ dium) on the pressure buildup in several prototype elements was investigated by means of the apparatus shown in Fig. 19. The pressure of the contained gas vs the temperature was obtained while heating the assembly to approximately $1700^{\circ} \mathrm{F}$. Pressure vs temperature measurements were also obtained while cooling to ambient temperature. A change in slope or nonlinearity of the pressure-temperature curve above approximately $1200^{\circ} \mathrm{F}$ would indicate the presence of alkali-metal vapor. These measurements were made before aliquots of the gas were obtained for gamma and mass spectrometer analyses.

\subsection{Component Examinations}

The $\mathrm{BeO}$ bushings, $\mathrm{MgO}$ spacers, and thermocouples were removed from the opened assembly and visually examined. Dimensions of the bushings and spacers were obtained with micrometers. Selected samples were obtained by means of the ceramic cutoff wheel and were mounted for metallographic examination. 


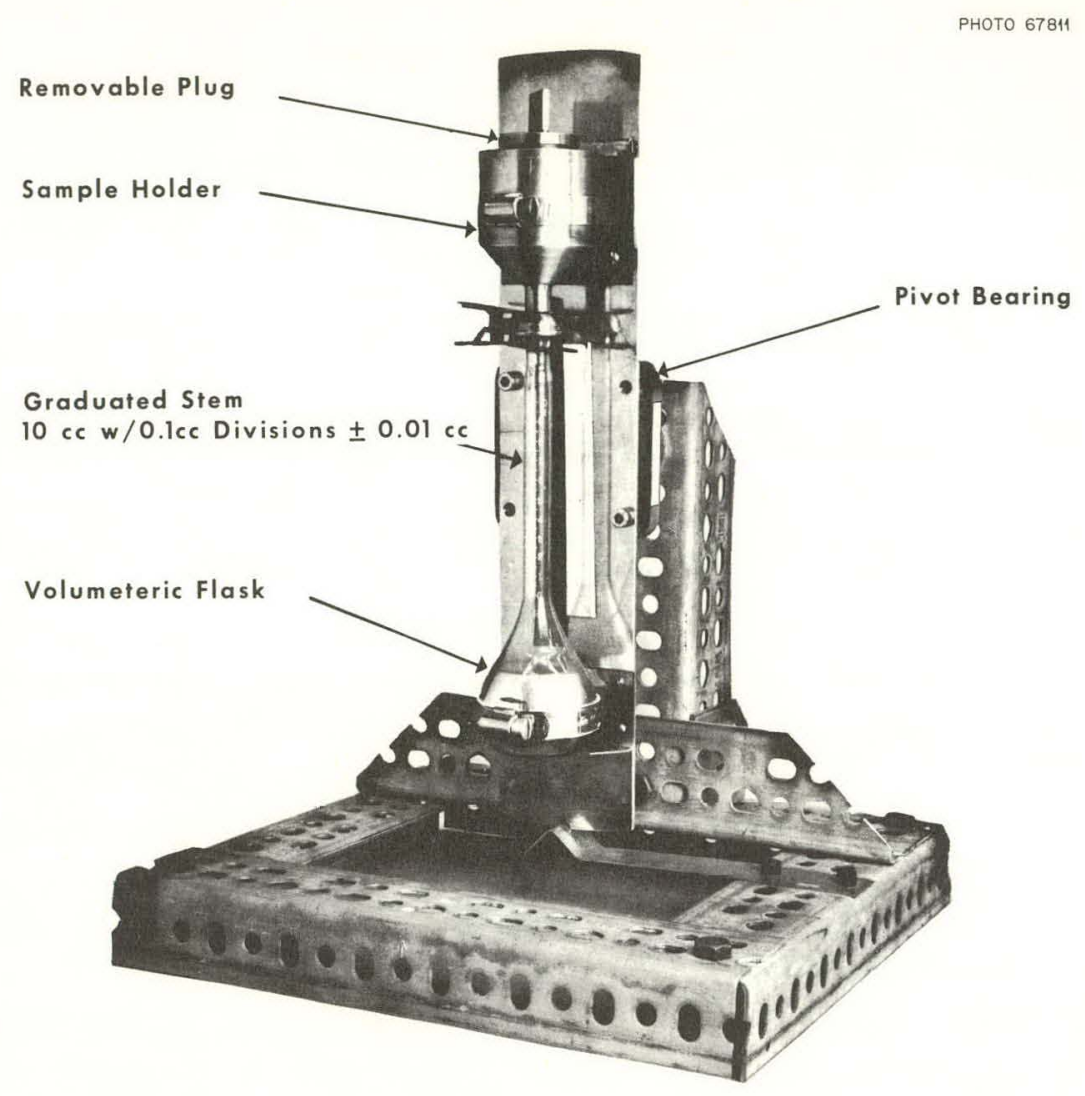

Fig. 18. Apparatus Used to Determine Volume by Mercury Immersion.

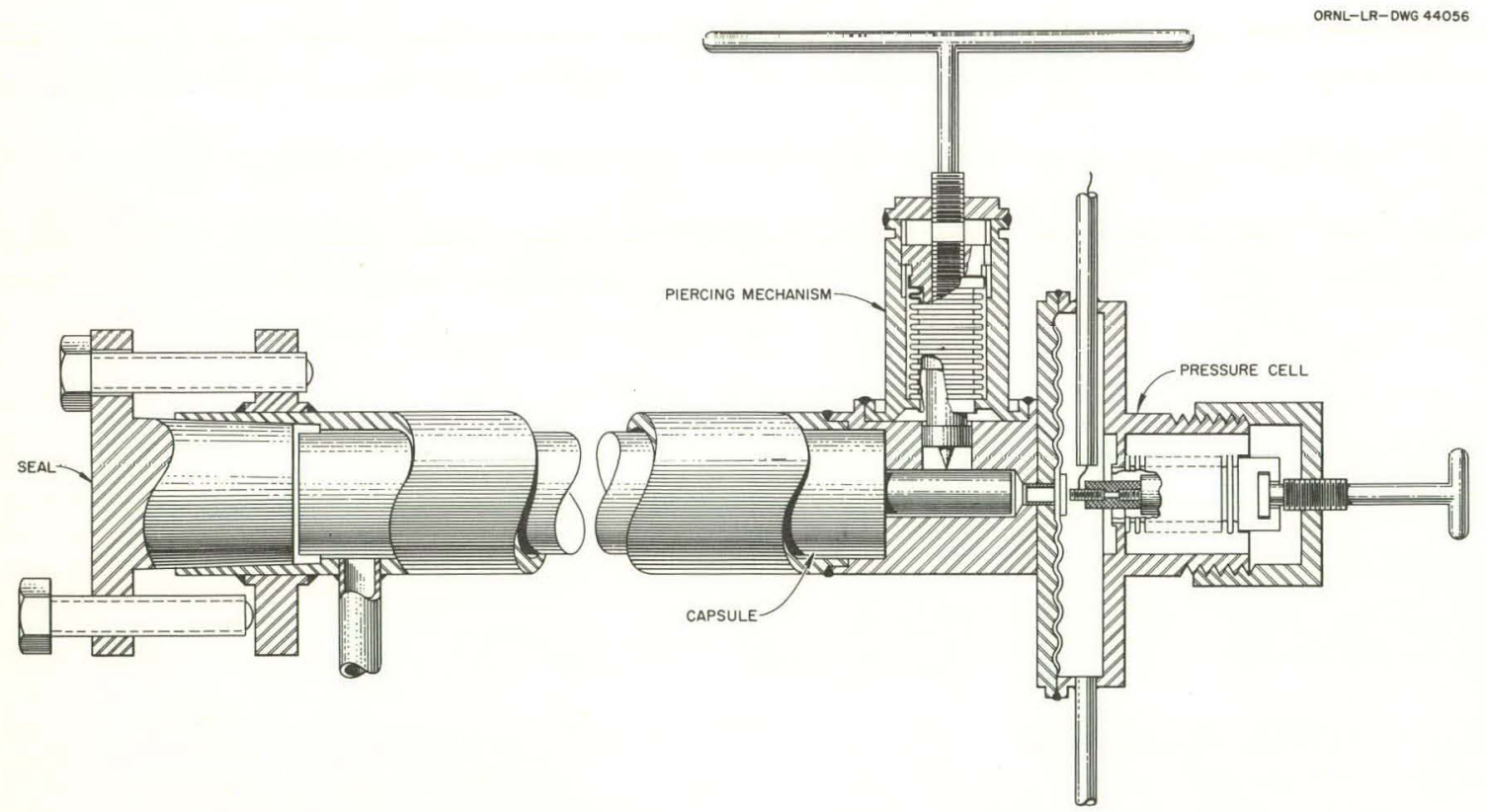

Fig. 19. Apparatus for High-Temperature Measurements of Fission-Gas Pressure in Irradiated Capsules. 


\section{DISCUSSION OF RESULTS}

\subsection{Effect of Pellet Geometry on Redistribution of Fuel, Ratchetting, and Wrinkling of Can}

It is desirable to use a hollow cylindrical pellet because (1) this eliminates the extremely high central temperature portion of a solid pellet, thus reducing fission gas release without much reduction in overall power output; and (2) the central void provides a free space for accumulation of fission gas thus reducing the internal pressure of the element.

The main possible disadvantage of a hollow pellet is that it may crack up during operation to such an extent that portions of the fuel will fall to the bottom of the central hole of the element. This would increase the localized power output at the bottom of the element, which would, in turn, produce localized hot spots, create bowing problems, etc.

The three different pellet geometries used in the prototype experiments were solid pellets, hollow pellets, and hollow pellets with $\mathrm{BeO}$ bushings filling the central void.

All the pellets had the same nominal outside diameter as that specified for the EGCR $(0.705$ in. $)$ and all the hollow pellets had the same nominal inside diameter as the EGCR (0.323 in.). The BeO bushing was inscrted into the central hole of the hollow pellets of some experiments to prevent fuel shifting.

It appears that redistribution of the fuel in the hollow pellets is not a problem in these relatively lowburnup and low-powered experiments. The pellets had cracked, but had not powdered or spalled. The gamma scans show some peaking at the bottom, and in some cases at the top, of an element, but this is normal and due to the flux peaking expected at the ends of a cylindrical absorber.

Generally the top and bottom pellets of an element were more severely fractured than the other pellets. This is probably due to unsymmetrical thermal expansion and contraction because the temperature gradients in the end pellets are not predominantly radial.

It was also feared that ratchetting might take place in a fuel element. Ratchetting is the "keying" of a fragment of fuel between a pellet and the cladding so as to prevent free relative motion of the cladding and fuel (due to unequal thermal expansion). It appears that some ratchetting has occurred - but only to a minor degree. Figure 20 shows some $\mathrm{UO}_{2}$ embedded in the inside surtace of the cladding of element 5-2. Figure 21 indicates that one of the pellets is slightly tilted and that the corners of the pellets are broken. It would be possible for the resulting fragments of fuel to become wedged between the pellets and cladding. There was no visual evidence of gouging on the inner surface of any of the claddings.

In element $2-2$ a fragment of fuel became mechanically embedded in the cladding opposite the top pellet (Fig. 22). This occurred prior to, or during, irradiation, because the cladding exterior was discolored in this area. A metallographic examination of the cladding at this spot showed a slight reaction between the $\mathrm{UO}_{2}$ and the cladding.

These prototype elements are two-ninths the length of an actual EGCR fuel element. It is possible that ratchetting in a full-size element would be more of a problem because of the greater differential expansion. Howcver, it is expected that dishing the ends of the pellets will reduce the gap between 
adjacent pellets at operating temperature, minimizing the relative differential expansion between fuel and cladding, and thus reduce the probability of ratchetting.

It was found that wrinkling of the cladding was more a function of cladding operating temperature than pellet geometry (all the pellets had flat ends). In the elements which operated with cladding temperature of $1500^{\circ} \mathrm{F}$ or greater, the cladding collapsed around the pellets and circumferential ridges were formed at the pellet interfaces. The characteristics of these ridges will be discussed in the section concerning cladding.
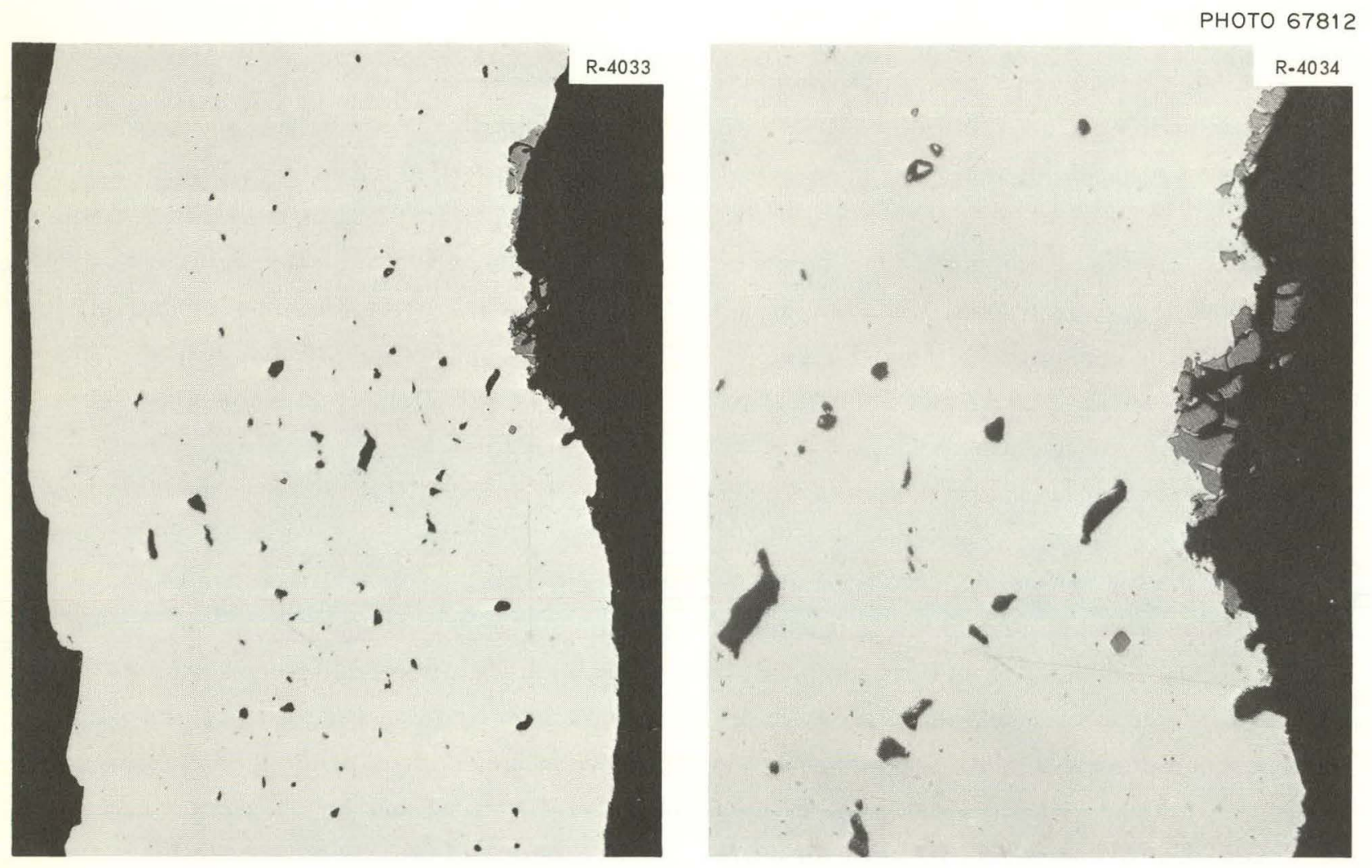

Fig. 20. Section Through Wrinkle at Pellet Interface from Capsule 05.2 Cladding, Showing Distribution of Voids and $\mathrm{UO}_{2}$ Embedded in Inside Surface. 

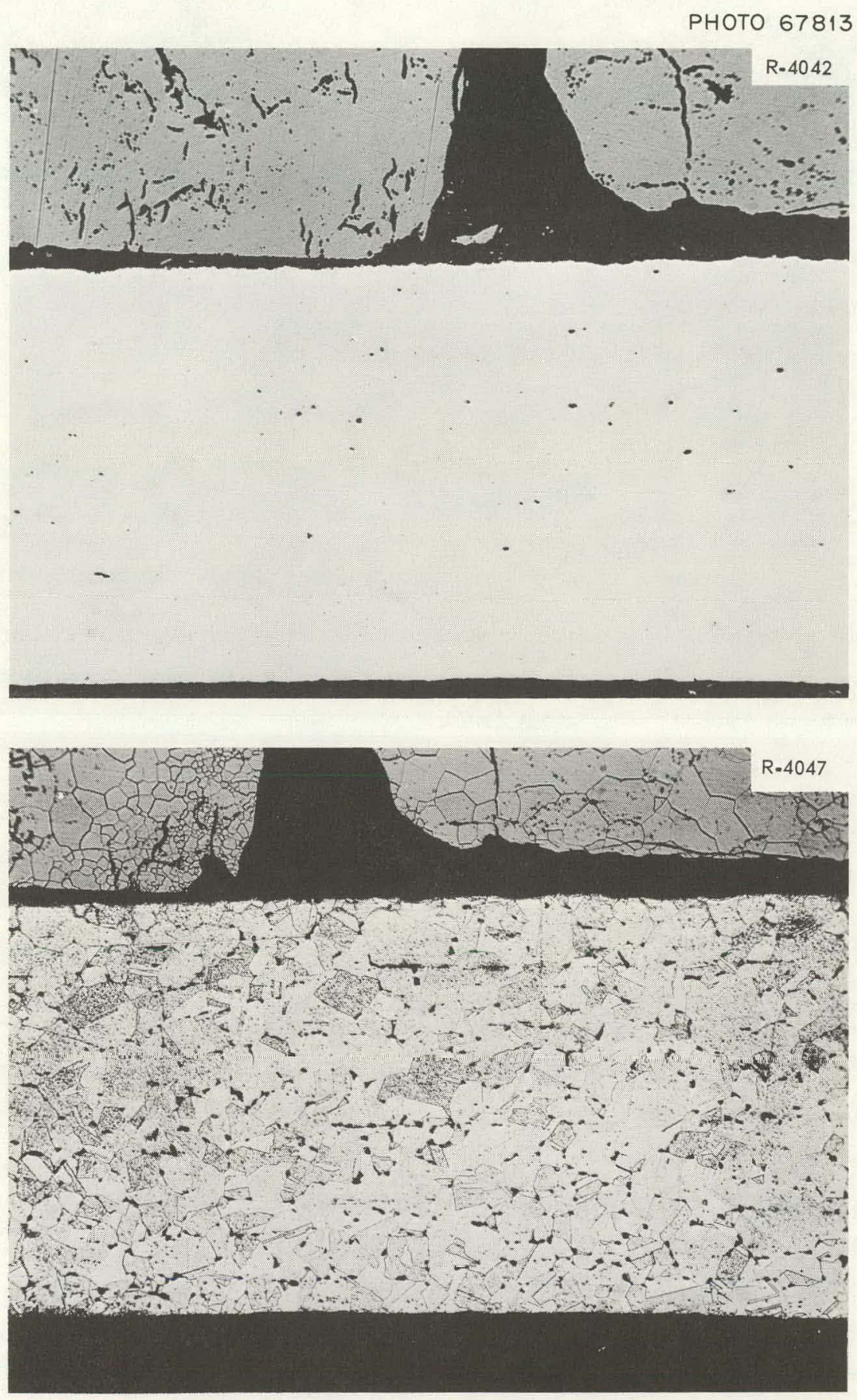

Fig. 21. Section of Cladding at Pellet Interface from Irradiated Capsule 06-2, Showing Appearance After Etching to Remove Sigma-Phase Material. Note tilted pellet and broken corners of pellets. 100x. 


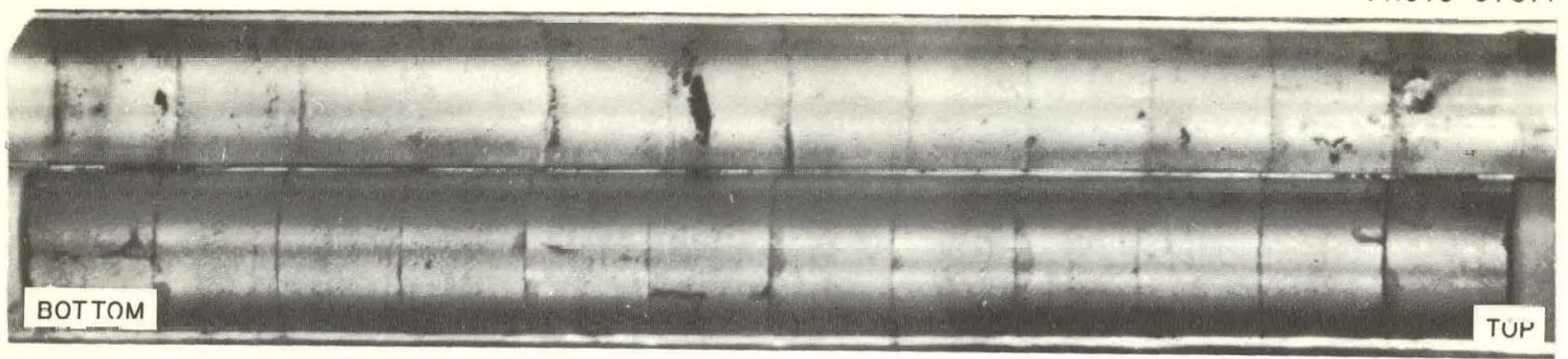

V-13288

$\checkmark A L \quad 2495$

Fig. 22. As-Opened Capsule 02-2. Note UO 2 mechanically embedded in cladding opposite top pellet. $1 \times$.

\subsection{Fission Gas and Volatile Fission Product Release}

\subsubsection{Stable Isotopes}

Gas samples from the prototype elements could be obtained only after several weeks had elapsed after termination of irradiation. This limited radioactive fission gas analyses by gamma counting to the 10.3-year ${ }^{85} \mathrm{Kr}$ isotope. The ${ }^{85} \mathrm{Kr}$ fractional release and the mass spectrometer analyses of gas obtained from the prototype fuel elements are listed in Table 1.

The mass spectrometer analyses provide relative data only. The ratios of total krypton to total xenon in the elements are also listed in Table 1 and are about the value one would expect for the average irradiation neutron flux of $5 \times 10^{12}$, namely 0.164 . The ${ }^{136} \mathrm{Xe}$ fraction is greatly influenced by the amount of neutron capture by ${ }^{135} \mathrm{Xe}$, which, in turn, depends upon the neutron flux during irradiation. The experimentally obtained ratios listed in Table 1 are not quite consistent with the average neutron irradiation for the individual element, but the deviations are relatively small considering all the experimental uncertainties involved. This, then, is an indication that the fractional release of krypton is about the same as that of xenon and certainly does not differ by as much as a factor of 2 .

Table 1 also lists the composition of the fuel element atmosphere. It appears that element 01-1 was accidentally sealed in an argon atmosphere rather than helium.

The mass spectrometer does not readily differentiate between different kinds of molecules of the same molecular weight, for example, $\mathrm{N}_{2}$ and CO. If one assumes that all the $\mathrm{N}_{2}$ and $\mathrm{CO}$ in element 04-2 is really $\mathrm{N}_{2}$, then the $\mathrm{O}_{2}$ and $\mathrm{N}_{2}$ components are very nearly the same in proportion as that of normal air (i.e., $20.99 \%$ and $78.06 \%$ respectively for an $\mathrm{O}_{2} / \mathrm{N}_{2}$ of 0.269 ). Since the total amount of fission gases recovered in this element was so small, it appears that either (1) the element developed a leak between termination of irradiation and sampling, (2) a leak occurred during sampling, or (3) the sample itself leaked prior to analysis.

Elements 05-2, 07-2, 08-2, and possibly 01-1 show excess $\mathrm{N}_{2}$. However, here the $\mathrm{O}_{2}$ to $\mathrm{N}_{2}$ ratio is much less than that of normal air. A plausible explanation is that these elements were sealed (welded) 
in an atmosphere contaminated with air. During irradiation the $\mathrm{O}_{2}$ would react with either the $\mathrm{UO}_{2}$ or the stainless cladding much more rapidly than would the $\mathrm{N}_{2}$, hence decreasing the $\mathrm{O}_{2}$ to $\mathrm{N}_{2}$ ratio below that of normal air. Calculations show that if the fill gas of a typical element was all air at atmospheric pressure, and if all the $\mathrm{O}_{2}$ reacted only with the $\mathrm{UO}_{2}$, the $\mathrm{O} / \mathrm{U}$ ratio would increase only 0.00016 (e.g., go from 2.0000 to 2.00016) - an insignificant amount. It does not appear logical that the $\mathrm{N}_{2}$ came from the $\mathrm{UO}_{2}$ because (1) the hollow group 1 series pellets were sintered in an $\mathrm{N}_{2}+\mathrm{H}_{2}$ atmosphere and thus had appreciably higher $\mathrm{N}_{2}$ content than the group 2 pellets (which were sintered in $\mathrm{H}_{2}$ ) - yet the $\mathrm{N}_{2}$ content of the fill gas from the group 1 elements was much less than the 2 elements (save perhaps 01-1), and (2) if all the impurity $\mathrm{N}_{2}$ of the group 1 pellets were released during irradiation to the void volume of the element, the resulting pressure (at standard temperature) due to this alone would be of the order of 25 atm. The amounts of gas collected thus indicate that most of the impurity $\mathrm{N}_{2}$ remained bound to the fuel during irradiation.

Table 1. Krypton-85 Release and Mass Spectrometer Analysis of Gases from ORR Prototype Fuel Elements After Irradiation

\begin{tabular}{|c|c|c|c|c|c|c|c|c|c|c|c|}
\hline & \multicolumn{11}{|c|}{ Element No. } \\
\hline & $01-1$ & O2-1 & $03-1$ & O5-1 & $\mathrm{O}-2$ & 02.2 & $03-2$ & O1-2 & O5-2 & $07-2$ & $08-2$ \\
\hline $\begin{array}{l}\text { Total gas in element, } \\
\text { moles }\left(10^{-4}\right)\end{array}$ & & & & & 4.27 & 4.15 & 4.09 & 2.73 & 3.89 & 1.66 & 1.62 \\
\hline $\begin{array}{l}\text { Measured void } \\
\text { volume, } \mathrm{cm}^{3}\end{array}$ & & & & & & 9.6 & 10.2 & 0.7 & 10.0 & & 3.6 \\
\hline \multicolumn{12}{|l|}{ Gas analysis, vol \% } \\
\hline $1 \mathrm{He}$ & & 97.9 & 98.9 & 93.7 & 97.19 & 98.33 & 93.44 & & 74.09 & 12.37 & 11.30 \\
\hline $2 \mathrm{Ar}$ & 96.5 & 0.03 & 0.02 & 0.06 & 0.56 & 0.45 & 1.97 & 1.07 & 0.95 & 4.08 & 2.58 \\
\hline $3 \mathrm{O}_{2}$ & 0.20 & 0.02 & 0.01 & 0.02 & 0.27 & 0.13 & 0.23 & 19.14 & 0.40 & 0.26 & 3.99 \\
\hline $4 \mathrm{~N}_{2}+\mathrm{CO}$ & 3.2 & 0.07 & 0.05 & 0.06 & 0.98 & 0.50 & 2.18 & 78.28 & 20.65 & 82.12 & 81.35 \\
\hline $5 \mathrm{H}_{2} \mathrm{O}$ & 0.10 & 0.36 & 0.40 & 0.48 & & & 0.44 & 1.22 & 1.96 & & \\
\hline $6 \mathrm{CO}_{2}$ & & 0.005 & 0.01 & 0.02 & 0.07 & 0.04 & 0.02 & 0.09 & 0.07 & 0.08 & 0.15 \\
\hline $7^{86} \mathrm{Kr}$ & & & & & 0.06 & 0.05 & 0.08 & trace & 0.14 & 0.08 & 0.08 \\
\hline${ }^{85} \mathrm{Kr}$ & & & & & 0.01 & 0.01 & 0.01 & & 0.02 & 0.01 & 0.01 \\
\hline${ }^{84} \mathrm{Kr}$ & & & & & 0.04 & 0.02 & 0.11 & trace & 0.11 & 0.04 & 0.04 \\
\hline${ }^{83} \mathrm{Kr}$ & & & & & 0.02 & 0.02 & 0.03 & trace & 0.04 & 0.02 & 0.03 \\
\hline${ }^{82} \mathrm{Kr}$ & & & - & & & & 0.01 & trace & & & \\
\hline Total $\mathrm{Kr}$ & & 0.32 & 0.13 & 1.15 & 0.13 & 0.10 & 0.24 & trace & 0.31 & 0.15 & 0.16 \\
\hline $8^{136} \mathrm{Xe}$ & & & & & 0.31 & 0.16 & 0.30 & 0.08 & 0.62 & 0.32 & 0.16 \\
\hline${ }^{1.34} \mathrm{Xe}$ & & & & & 0.24 & 0.15 & 0.28 & 0.06 & 0.49 & 0.31 & 0.15 \\
\hline${ }^{132} \mathrm{Xe}$ & & & & & 0.15 & 0.09 & 0.34 & 0.04 & 0.30 & 0.19 & 0.10 \\
\hline${ }^{131} \mathrm{Xe}_{e}$ & & & & & u. vy & 0.05 & 0.27 & 0.02 & 0.17 & 0.11 & 0.06 \\
\hline $128,129,130 \mathrm{Xe}$ & & & & & & & 0.28 & & & & \\
\hline Thtal Xe & & 1.29 & 0.52 & 4.54 & 0.79 & 0.45 & 1.47 & 0.20 & 1.58 & 0.93 & 0.47 \\
\hline 9 Total $\mathrm{Kr}+\mathrm{Xe}$ & & 1.61 & 0.65 & 5.69 & 0.92 & 0.55 & 1.71 & 0.20 & 1.89 & 1.08 & 0.63 \\
\hline 10 Ratio $\mathrm{Kr} / \mathrm{Xe}^{a}$ & & 0.248 & 0.250 & 0.256 & 0.165 & 0.222 & 0.163 & & 0.196 & 0.161 & 0.340 \\
\hline${ }^{85} \mathrm{Kr}$ release, $\%^{b}$ & 0.68 & 1.6 & 0.74 & 1.6 & 0.39 & 0.48 & 0.64 & 0.06 & 1.3 & 0.33 & 0.21 \\
\hline
\end{tabular}

${ }^{a}$ Ratin of fission product total krypton to total xenon $\approx 0.164$ for $\phi=5 \times 10^{12}$.

${ }^{b}$ Based on measured burnup by ${ }^{144} \mathrm{Ce},{ }^{85} \mathrm{Kr}$ fission yield of $0.3 \%$, and ${ }^{85} \mathrm{Kr} \rightarrow{ }^{85} \mathrm{Rb}$ gamma branching ratio of $0.37 \%$. 
The relative isotopic yields of the stable krypton and xenon isotopes are listed in Table 2. Considering that the total xenon and krypton was such a relatively small fraction of the total gas recovered from the fuel elements, the measured relative yields of the various isotopes are in remarkably good agreement with the theoretical yields (excepting possibly element O3-2). The ${ }^{136} \mathrm{Xe}$ fraction includes the ${ }^{136} \mathrm{Xe}$ produced from neutron capture by ${ }^{135} \mathrm{Xe}$ for a neutron flux of $5 \times 10^{12}$ (i.e., 2.6 atoms of ${ }^{136} \mathrm{Xe}$ per 100 fissions from ${ }^{135} \mathrm{Xe}$ plus the 6.4 atoms of ${ }^{136} \mathrm{Xe}$ per 100 fissions chain yield).

Only a few mass spectrometer analyses of the fill gas from LITR type elements were made because of the very small total amount of gas available. Table 3 lists results of the analyses which were made, and Table 4 lists the measured and theoretical relative yields of the various krypton and xenon isotopes. The xenon theoretical relative yields are different for each element because of the great dependence of the ${ }^{135} \mathrm{Xe}(n, y){ }^{136} \mathrm{Xe}$ process upon the neutron flux (which varied from $0.94 \times 10^{13}$ to $1.6 \times 10^{13}$ for these elements).

Again, save for the krypton in elements L-27b and L-28a, there appears to be remarkably good agreement between the measured and theoretical relative yields for the various krypton and xenon isotopes, indicating no isotopic separation due to the release mechanism.

The ratio of total krypton to total xenon release (excepting L-27b and L-28a) is again about equal to their theoretical fission yields, which indicates that the fractional release of each of the stable gases is about the same. This is further supported by the measured ratio of ${ }^{86} \mathrm{Kr}$ to ${ }^{134} \mathrm{Xe}$ being approximately equal to the ratio of their fission yields (again excepting L-27b and L-28a).

Table 2. Relative Isotopic Yields of Stable Fission Gas for ORR Experiments

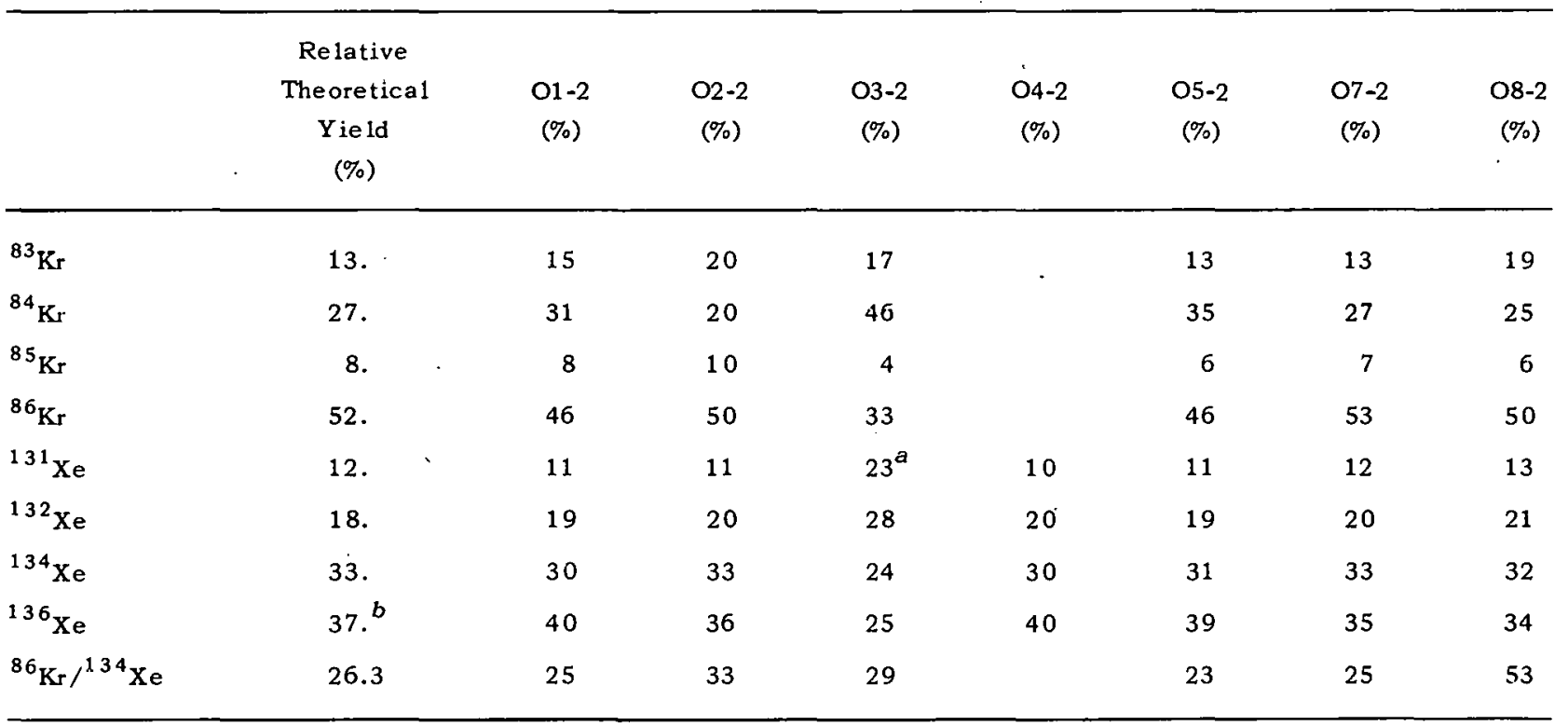

\footnotetext{
${ }^{a}$ Neglecting ${ }^{128,129,130} \mathrm{Xe}$ contribution.

${ }^{b}$ Includes ${ }^{136} \mathrm{Xe}$ produced by neutron capture of ${ }^{135} \mathrm{Xe}$ for $\phi=5 \times 10^{12}$.
} 
Table 3. Mass Spectrometer Analys is of Gas from LITR Type Fuel Elements After Irradiation

\begin{tabular}{|c|c|c|c|c|c|}
\hline & \multicolumn{5}{|c|}{ Element No. } \\
\hline & L-24a & $L-27 b$ & L-28a & L-32a & $L-32 b$ \\
\hline Total gas volume (STP), $\mathrm{cm}^{3}$ & 2.22 & 1.43 & 1.09 & 1.43 & 1.59 \\
\hline \multicolumn{6}{|l|}{ Gas analysis, vol \% } \\
\hline${ }^{136} \mathrm{Xe}$ & 13.18 & 1.01 & 0.084 & 1.59 & 6.73 \\
\hline${ }^{134} \mathrm{Xe}$ & 9.53 & 0.73 & 0.064 & 1.22 & 5.09 \\
\hline${ }^{132} \mathrm{Xe}$ & 5.46 & 0.43 & 0.036 & 0.74 & 3.04 \\
\hline${ }^{131} \mathrm{Xe}$ & 3.57 & 0.30 & 0.026 & 0.44 & 1.89 \\
\hline Total Xe & 31.74 & 2.47 & 0.210 & 3.99 & 16.75 \\
\hline${ }^{86} \mathrm{Kr}$ & 2.49 & 0.08 & 0.019 & 0.35 & 1.35 \\
\hline${ }^{85} \mathrm{Kr}$ & 0.36 & 0.01 & 0.002 & 0.05 & 0.18 \\
\hline${ }^{84} \mathrm{Kr}$ & 1.32 & 0.04 & 0.012 & 0.18 & 0.69 \\
\hline${ }^{83} \mathrm{Kr}$ & 0.64 & 0.01 & 0.010 & 0.09 & 0.38 \\
\hline Total $\mathbf{K r}$ & 4.81 & 0.14 & 0.043 & 0.67 & 2.60 \\
\hline Tota $1 \mathrm{Xe}$ and $\mathrm{Kr}$ & 36.55 & 2.61 & 0.253 & 4.66 & 19.35 \\
\hline $\mathrm{H}_{2} \mathrm{O}$ & & & 0.618 & & \\
\hline $\mathrm{CO}_{2}$ & & & 0.048 & 0.09 & \\
\hline Ar & 0.08 & 0.54 & 0.153 & 0.04 & 0.21 \\
\hline $\mathrm{O}_{2}$ & 0.21 & 1.23 & 0.511 & 0.16 & 0.21 \\
\hline $\mathrm{N}_{2}^{2}+\mathrm{CO}$ & 1.11 & 12.15 & 1.96 & 0.87 & 0.76 \\
\hline $\mathrm{He}$ & 62.05 & 83.45 & 96.45 & 91.17 & 79.48 \\
\hline Ratio ${ }^{86} \mathrm{Kr} /{ }^{134} \mathrm{Xe} e^{a}$ & 0.261 & 0.110 & 0.297 & 0.287 & 0.265 \\
\hline Ratio $\mathrm{O}_{2} / \mathrm{N}_{2}+\mathrm{CO}^{b}$ & 0.189 & 0.101 & 0.261 & 0.184 & 0.276 \\
\hline Percent ${ }^{85} \mathrm{Kr}$ release & 39. & 1.7 & 0.21 & 5.1 & 31. \\
\hline
\end{tabular}

${ }^{a}$ Theoretical ratio ${ }^{86} \mathrm{Kr} /{ }^{134} \mathrm{Xe}=0.263$.

${ }^{b}$ Ratio $\mathrm{O}_{2} / \mathrm{N}_{2}$ for normal air $=0.269$.

Tablo 1. Rolative Fissinn Gns Yields from LITR Type Elements

\begin{tabular}{|c|c|c|c|c|c|c|c|c|c|c|}
\hline & \multicolumn{10}{|c|}{ Element No. } \\
\hline & \multicolumn{2}{|c|}{ L-24a } & \multicolumn{2}{|c|}{ L-27b } & \multicolumn{2}{|c|}{$\mathrm{L}-28 \mathrm{a}$} & \multicolumn{2}{|c|}{ L-32a } & \multicolumn{2}{|c|}{$L-32 b$} \\
\hline & $\begin{array}{c}\text { Measured } \\
(\%)\end{array}$ & $\begin{array}{c}\text { Theoretica } 1 \\
(\%)\end{array}$ & $\begin{array}{c}\text { Measured } \\
(\%)\end{array}$ & $\begin{array}{c}\text { Theoretical } \\
(\%)\end{array}$ & $\begin{array}{c}\text { Measured } \\
(\%)\end{array}$ & $\begin{array}{c}\text { The oretical } \\
(\%)\end{array}$ & $\begin{array}{c}\text { Measured } \\
(\%)\end{array}$ & $\begin{array}{c}\text { Theoretical } \\
(\%)\end{array}$ & $\begin{array}{c}\text { Measured } \\
\text { (\%) }\end{array}$ & $\begin{array}{c}\text { The oretica } 1 \\
(\%)\end{array}$ \\
\hline${ }^{136} \mathrm{Xe}$ & 41.5 & 41.2 & 40.9 & 41.2 & 40.0 & 39.9 & 39.8 & 39.3 & 40.2 & 39.3 \\
\hline${ }^{134} \mathrm{Xe}$ & 30.0 & 30.4 & 29.6 & 30.4 & 30.5 & 31.1 & 30.6 & 31.4 & 30.4 & 31.4 \\
\hline${ }^{1.32} \mathrm{Xe}$ & 17.2 & 17.1 & 17.4 & 17,1 & 17.1 & 17,4 & 18.5 & 17.6 & 18.1 & 17.6 \\
\hline${ }^{131} \mathrm{Xe}$ & 11.2 & 11.3 & 12.1 & 11.3 & 12.4 & 11.6 & 11.1 & 11.7 & 11.3 & 11.7 \\
\hline${ }^{86} \mathrm{Kr}$ & 51.8 & 52.1 & 57.1 & 52.1 & 44.2 & 52.1 & 52.3 & 52.1 & 51.9 & 52.1 \\
\hline${ }^{85} \mathrm{Kr}$ & 7.5 & 8.4 & 7.1 & 8.4 & 4.7 & 8.4 & 7.5 & 8.4 & 6.9 & 8.4 \\
\hline${ }^{84} \mathrm{Kr}$ & 27.4 & 26.6 & 28.6 & 26.6 & 27.9 & 26.6 & 26.9 & 26.6 & 26.5 & 26.6 \\
\hline${ }^{83} \mathrm{Kr}$ & 13.3 & 12.9 & 7.1 & 12.9 & 23.2 & 12.9 & 1.3 .4 & 12.9 & 14.6 & 12.9 \\
\hline Tulal Kr/lülal Xe & 15.2 & 15.3 & 5.7 & 1.5 .3 & 20.5 & 15.7 & 16.8 & 15.8 & 15.5 & 15.8 \\
\hline Ratio ${ }^{86} \mathrm{Kr} /{ }^{134} \mathrm{Xe}$ & 26.1 & 26.3 & 11.0 & 26.3 & 29.7 & 26.3 & 28.7 & 26.3 & 26.5 & 26.3 \\
\hline
\end{tabular}


The anomalous results for L-27b and L-28a might be explained as follows: L-27b has rather high $\mathrm{N}_{2}$ and $\mathrm{O}_{2}$ analyses in comparison to the other elements, and the $\mathrm{O}_{2} / \mathrm{N}_{2}$ ratio is much less than normal air. Thus, it appears that there may have been some air contaminating the fill gas when the element was sealed (welded). The oxygen in the fill gas could then react with either the $\mathrm{UO}_{2}$ or other components of the element during irradiation, thus reducing the $\mathrm{O}_{2} / \mathrm{N}_{2}$ below that of normal air. There is also the possibility of a slight leak during operation (al though the measured preirradiation helium leak rate was low) which would account for the abnormally low krypton/xenon ratios (krypton would leak more rapidly from an element than xenon because of its lower atomic weight). The abnormal L-28a results may be due to the low release, for example, $0.21 \%$ total of four isotopes for xenon and $0.043 \%$ total for four krypton isotopes.

The theoretical relative yield of the 10.3 -year ${ }^{85} \mathrm{Kr}$ was obtained on the assumption that it behaved as a stable isotope. The actual relative yield should be somewhat lower than the theoretical yield (stable isotope basis) because the actual irradiation time ranged from 73 to 228 days and a cooling period of about a half year (so short-lived activity would have decayed) elapsed before the mass spectrometric analyses were made.

\subsubsection{Radioactive Isotopes}

Theory. - The rate-controlling process for release of fission gas from the fuel to the free space in the element is assumed to be the diffusion of the fission-gas atom through the solid matrix (i.e., other processes such as recoils and surface evaporation are neglected). After the atom passes from the solid to an open pore (a pore which connects to the free space surrounding the fuel) it is assumed that the gas atom reaches equilibrium with the free gas so rapidly that this process is negligible in comparison to diffusion.

This analysis of the radioactive fission-gas release from a cylindrical pellet is based on the classical equivalent sphere model. The model assumes the fuel to consist of identical hypothetical spheres of radius $a$, where

and

$$
a=3\left(\frac{\rho_{b}}{\rho_{i}}\right) \frac{1}{s_{v}}
$$

$$
\begin{aligned}
& \rho_{b}=\text { bulk density, } \\
& \rho_{i}=\text { immersion density, and } \\
& S_{v}=\text { surface area per unit gross volume of fuel. }
\end{aligned}
$$

The total surface area of these spheres is equal to the BET surface area ${ }^{13}$ of the fuel.

S. D. Beck ${ }^{14}$ gives an exact time-dependent solution of the Fickian diffusion equations for diffusion of a radioactive fission product through a solid sphere (assuming the characteristic diffusion coefficient

\footnotetext{
$18,1960)$.

${ }^{14}$ S. D. Beck, The Diffusion of Radioactive Fission Products from Porous Fuel Elements, BME-1433 (Apr.
} 
to be constant). He evaluates the release rate and the accumulation of nondecayed atoms external to the fuel, and presents the results in numerical tables for a wide range of values of two dimensionless parameters: $\mu=\lambda a^{2} / D$ and $\tau=D t / a^{2}$, where $\lambda$ is the radioactive decay coefficient, $D$ the diffusion coefficient, $a$ the radius of the hypothetical sphere, and $t$ the irradiation time. Thus, by measuring the fractional release (the accumulation) of a gaseous fission product from a fuel element, and knowing $\lambda$ and $t$, one can obtain a value of $D / a^{2}$ (or $D$, if a is known) characteristic of the whole element.

The classical variation of $D$ with temperature $T\left({ }^{\circ} \mathrm{K}\right)$ is given as

$$
D(T)=D_{0} e^{-E / R T},
$$

where $D_{0}$ is a constant characteristic of the material, $E$ an activation energy, and $R$ the molar gas constant. Experiments show that for $\mathrm{UO}_{2}, 15,000^{\circ} \mathrm{K}<E / R<50,000^{\circ} \mathrm{K}$; so that the variation of $D$ with temperature is quite drastic. Similarly, the temperature of the fuel in an element can also vary greatly. The question arises as to how to interpret the $\bar{D}$ (the whole-element $D$ ) obtained from fission-gas release measurements of a whole fuel element.

The whole-element $\bar{D}$ should be equal to the volume-averaged $D$ of the whole element. However, the equations describing the fission-gas release are functions of $\sqrt{D}$ (rather than just $D$ ). Thus, the wholeelement $\bar{D}$ should be equal to the square of the volume-averaged $\sqrt{D}$, that is,

$$
\bar{D}(\text { whole element })=(\sqrt{\bar{D}} \text { vol av })^{2},
$$

where

$$
\sqrt{\bar{D}}=\frac{\int_{\mathrm{v} 01} \sqrt{D_{v}} d V}{\int_{\mathrm{v} 01} d V}=\frac{\int_{\mathrm{v} 01}\left(D_{0} e^{-E / R T}\right)^{1 / 2} d V}{\int_{\mathrm{v} 01} d V}
$$

and $D_{v}$ and $T_{v}$ refer to the diffusion coefficient and temperature $\left({ }^{\circ} \mathrm{K}\right)$ of the volume element $d V$. The $\sqrt{\bar{D}}$ for solid and hollow cylindrical pellets are derived with the assumption that (1) there is no axial variation of temperature in the pellet, (2) the heat generation per unit volume $q$ is constant (implies constant neutron flux thrnighnut the pellet, that is, no flux depression and no axial variation in flux), and (3) the thermal conductivity $k$ is constant. The effects of deviations from these assumptions will be discussed later.

The temperature distribution across a solid pellet is

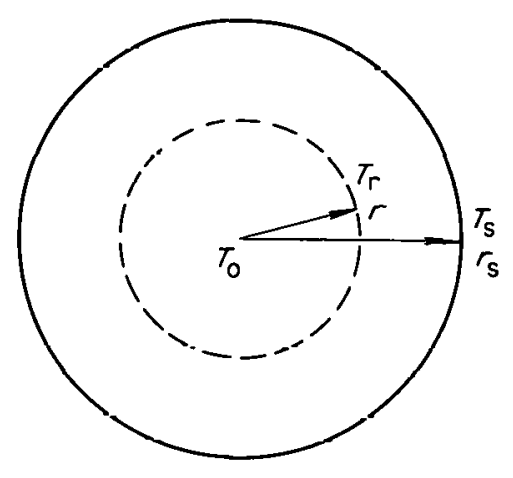




$$
T_{\mathrm{r}}=T_{0}-\frac{q}{4 k} \mathrm{r}^{2}=T_{0}-\Delta T\left(\frac{\mathrm{r}}{t_{s}}\right)^{2}
$$

or

$$
T_{x}=T_{0}-\Delta T x^{2},
$$

where.

$$
\Delta T=T_{0}-T_{s} \text { and } x=\frac{r}{r_{s}}
$$

For a hollow pellet, the temperature distribution is

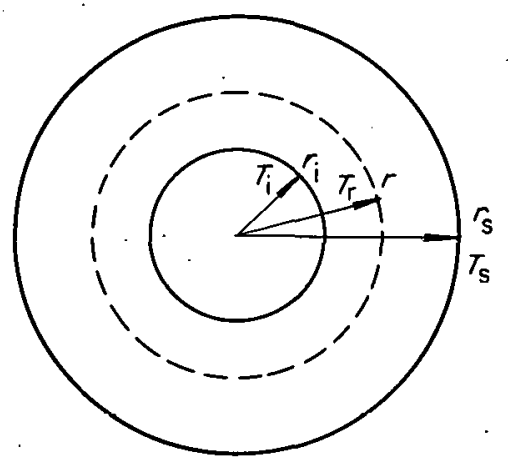

$$
T_{r .}=T_{i}-\frac{q r_{i}^{2}}{4 k}\left[\left(\frac{r}{r_{i}}\right)^{2}-1-\ln \left(\frac{r}{r_{i}}\right)^{2}\right]
$$

or

$$
T_{y}=T_{i}-\frac{\Delta T}{y_{s}{ }^{2}-1-\ln y_{s}^{2}}\left(y^{2}-1-\ln y^{2}\right),
$$

where

$$
\begin{aligned}
\Delta T & =T_{i}-T_{s}, \\
y & =\frac{r}{r_{i}}, \text { and } \\
y_{s} & =\frac{r_{s}}{r_{i}} .
\end{aligned}
$$

Then for the solid pellet

$$
\overline{\sqrt{D}}=\frac{\int_{0}^{r_{s}}\left(D_{0} e^{-E / R T_{r}}\right)^{1 / 2}(2 \pi r l d r)}{\int_{0}^{r_{s}}(2 \pi r l d r)}=D_{0}^{1 / 2}\left(\frac{E}{2 R \Delta T}\right)\left[\frac{e^{-t}}{t}+\int \frac{e^{-t} d t}{t}\right]_{E / 2 R T_{s}}^{E / 2 R T_{0}}
$$


where

$$
l=\text { length of pellet and } t=\frac{E}{2 R T_{0}\left[1-\Delta T / T_{0}\left(r / r_{s}\right)^{2}\right]} .
$$

The integral inside the brackets is a form of the exponential integral and may be numerically evaluated by means of published tables. ${ }^{15,16}$ However, the results may be simplified by (1) making use of the asymptotic expansion of the exponential integral for large values of $t,{ }^{16}$ and (2) noting that normally $e^{-E / 2 R T s}<e^{-E / 2 R T_{0}}$. Thus

$$
\overline{\sqrt{D}} \approx D_{0}{ }^{1 / 2}\left(\frac{T_{0}}{\Delta T}\right) \mathrm{e}^{-E / 2 R T_{0}} \sum_{n=1}^{\infty}(-)^{n+1} \frac{n !}{\left(E / 2 R T_{0}\right)^{n}} .
$$

Since $E / 2 R T_{0}$ is usually large, the series summation may be approximated by only the first term. Then

$$
\overline{\sqrt{D}} \approx D_{0}^{1 / 2}\left(\frac{T_{0}^{2}}{\Delta T}\right) \frac{e^{-E / 2 R T_{0}}}{E / 2 R}
$$

Finally,

$$
\bar{D}=(\overline{\sqrt{D}})^{2} \approx\left(\frac{T_{0}^{2}}{\Delta T}\right)^{2} \frac{D_{0} e^{-E / R T_{0}}}{(E / 2 R)^{2}} .
$$

By recognizing that $D\left(T_{0}\right)=D_{0} e^{-E / R T_{0}}$ is the center-line diffusion coefficient, one can then relate the pellet center-line diffusion coefficient to the $\bar{D}$ obtained from the measured fission-gas release. However, since $E$ may not be well known, it would be better to examine the data in the following form when analyzing a particular fuel performance:

$$
\frac{D\left(T_{0}\right)}{(E / 2 R)^{2}}=\frac{D_{0} e^{-E / R T_{0}}}{(E / 2 R)^{2}} \approx\left(\frac{\Delta T}{T_{0}^{2}}\right)^{2} \bar{D}
$$

Thus if an Arrhenius plot of $\ln \left(\Delta T / T_{0}{ }^{2}\right)^{2} \bar{D}$ vs $\frac{1}{T_{0}}$ for several experiments (i.e., different $T_{0}$ ) results in a straight line, the model is validated. A value for $E$ can be obtained from the slope of the line, and $D_{0}$ extracted from the magnitude of the function at any particular value of $T_{0}$.

For the hollow pellet

$$
\overline{\sqrt{D}}=\frac{\int_{r_{i}}^{r_{s}}\left(D_{0} e^{-E / R T_{r}}\right)^{1 / 2}(2 \pi r l d r)}{\int_{r_{1}}^{r_{\theta}}(2 \pi r l d r)} .
$$

\footnotetext{
${ }^{15}$ E. Jahnke and F. Emde, Tables of Functions, 4th ed., Dover, New York, 1945.

${ }^{16}$ Nalivinal Düreau of Standard3, Tabloo of Sine, Cosine and Exponential Integrals, val. 1, 1940.
} 
Upon substituting the temperature distribution for $T_{r}$, Eq. (7) or (8), the integral may be evaluated by means of Laplace's method (as suggested by W. Gautschi of the ORNL Mathematics Division) for the asymptotic evaluation of an integral. ${ }^{17,18}$ Thus

$$
\overline{\sqrt{D}} \approx \frac{\sqrt{\pi / 2}\left(y_{s}^{2}-1-\ln y_{s}^{2}\right)^{1 / 2}}{y_{s}^{2}-1} \frac{T_{i}}{\sqrt{\Delta T}} \frac{D_{0}^{1 / 2} e^{-E / 2 R T_{i}}}{\sqrt{E / 2 R}},
$$

or

$$
\bar{D}=(\overline{\sqrt{D}})^{2} \approx \frac{\pi / 2\left(y_{s}^{2}-1-\ln y_{s}^{2}\right)}{\left(y_{s}^{2}-1\right)^{2}} \frac{T_{i}^{2}}{\Delta T} \frac{D_{0} e^{-E / R T_{1}}}{E / 2 R}
$$

And, similar to the solid pellet,

$$
\frac{D\left(T_{i}\right)}{E / 2 R}=\frac{D_{0} \mathrm{e}^{-E / R T_{1}}}{E / 2 R} \approx \frac{\left(y_{s}^{2}-1\right)^{2}}{(\pi / 2)\left(y_{s}^{2}-1-\ln y_{s}^{2}\right)} \frac{\Delta T}{T_{i}^{2}} \bar{D} .
$$

By making use of an Arrhenius plot of

$$
\ln \frac{\left(y_{s}^{2}-1\right)^{2}}{(\pi / 2)\left(y_{s}^{2}-1-\ln y_{s}^{2}\right)}\left(\frac{\Delta T}{T_{i}^{2}}\right) \bar{D}
$$

vs $1 / T_{i}$, one can check the validity of the model, and obtain values of $E$ and $D_{0}$ as in the solid pellet case.

Results for LITR Type Experiments. - Tables 5-10 list the items believed pertinent to the fissiongas release of the LITR type experiments. The experiments have been separated into twn arbitrary groups - one with preirradiation $O / U$ ratio $<2.02$, and the other with $O / U$ ratio $\geqq 2.02$.

R. M. Evans ${ }^{19}$ has established the best values of $O / U$ ratio and chemical analyses from the several analyses made on the preirradiated material as reported earlier. ${ }^{20}$ The best values for both the LITR and ORR experiments, along with the original data, ${ }^{20}$ are listed in appendix $A$. The pertinent best values are listed in Tables 5 and 8.

It was found that determinations of $\mathrm{O} / \mathrm{U}$ ratio and carbon content varied considerably, depending upon whether the sample had been outgassed (at $300^{\circ} \mathrm{C}$ in vacuum) prior to analysis. Generally, the outgassed $\mathrm{O} / \mathrm{U}$ ratios were lower than the values for the nonoutgassed pellets, and are believed to be the more nearly correct values.

${ }^{17}$ A. Erdélyi, Asymptotic Expansions, p. 36, Dover, New York, 1956.

${ }^{18}$ D. V. Widder, The Laplace Transform, p. 277, Princeton University Press, Princeton, N.J., 1946.

${ }^{19}$ R. M. Evans, personal communication (Jan. 4, 1963). 1960).

${ }^{20}$ R. M. Evans and R. L. Heestand, GCR Irradiation Program Fuel Data Summary, ORNL CF-59-12-1 (Apr. 7, 
Table 5. Fuel Characterization of LITR Experiments: Oxygen-to-Uranium Ratio $<2.020$

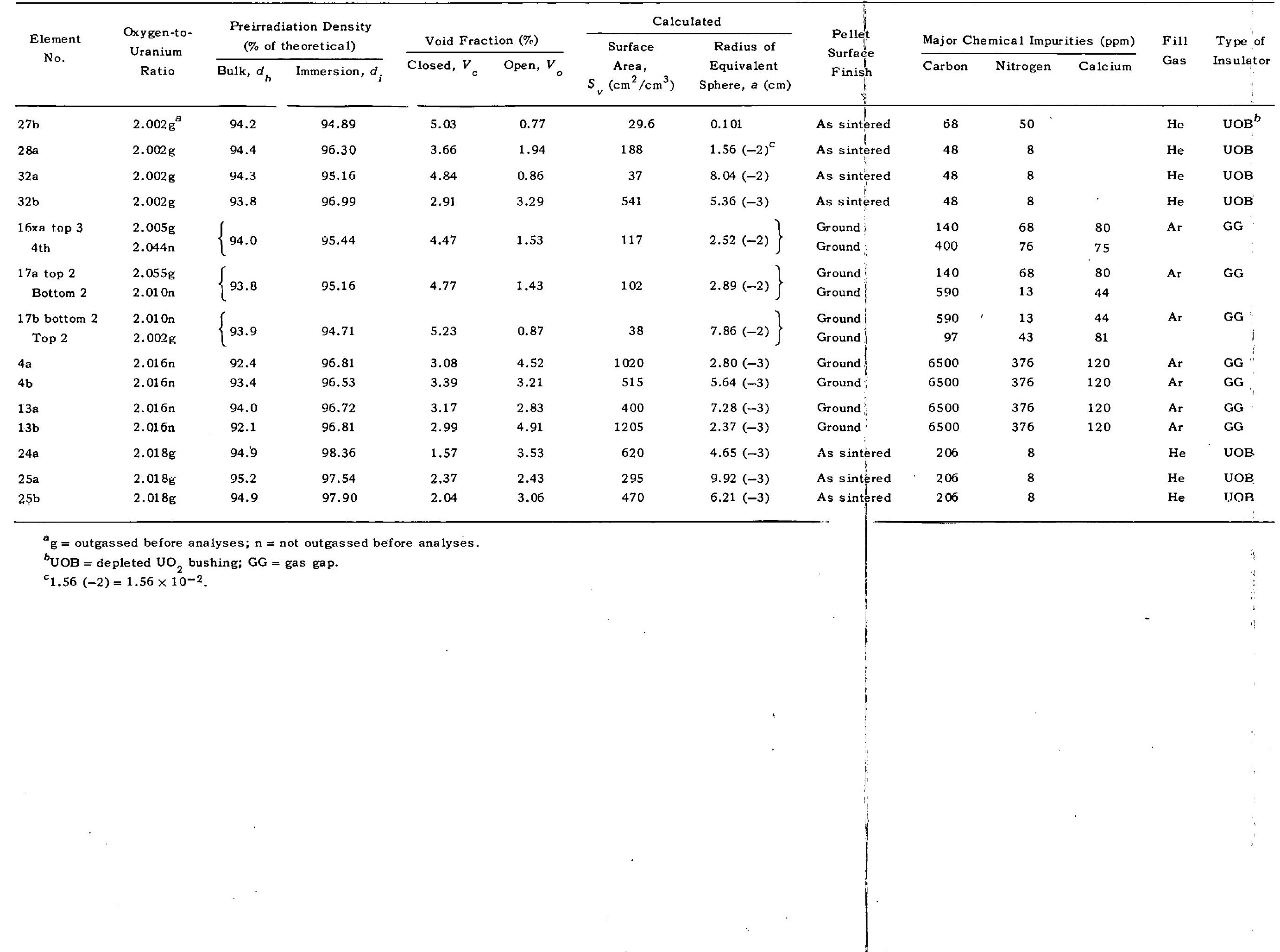


Table 6. Operating Conditions and Fission Gas Fractional Release of LITR Experiments: Oxygen-to-Uranium Ratio $<2.020$

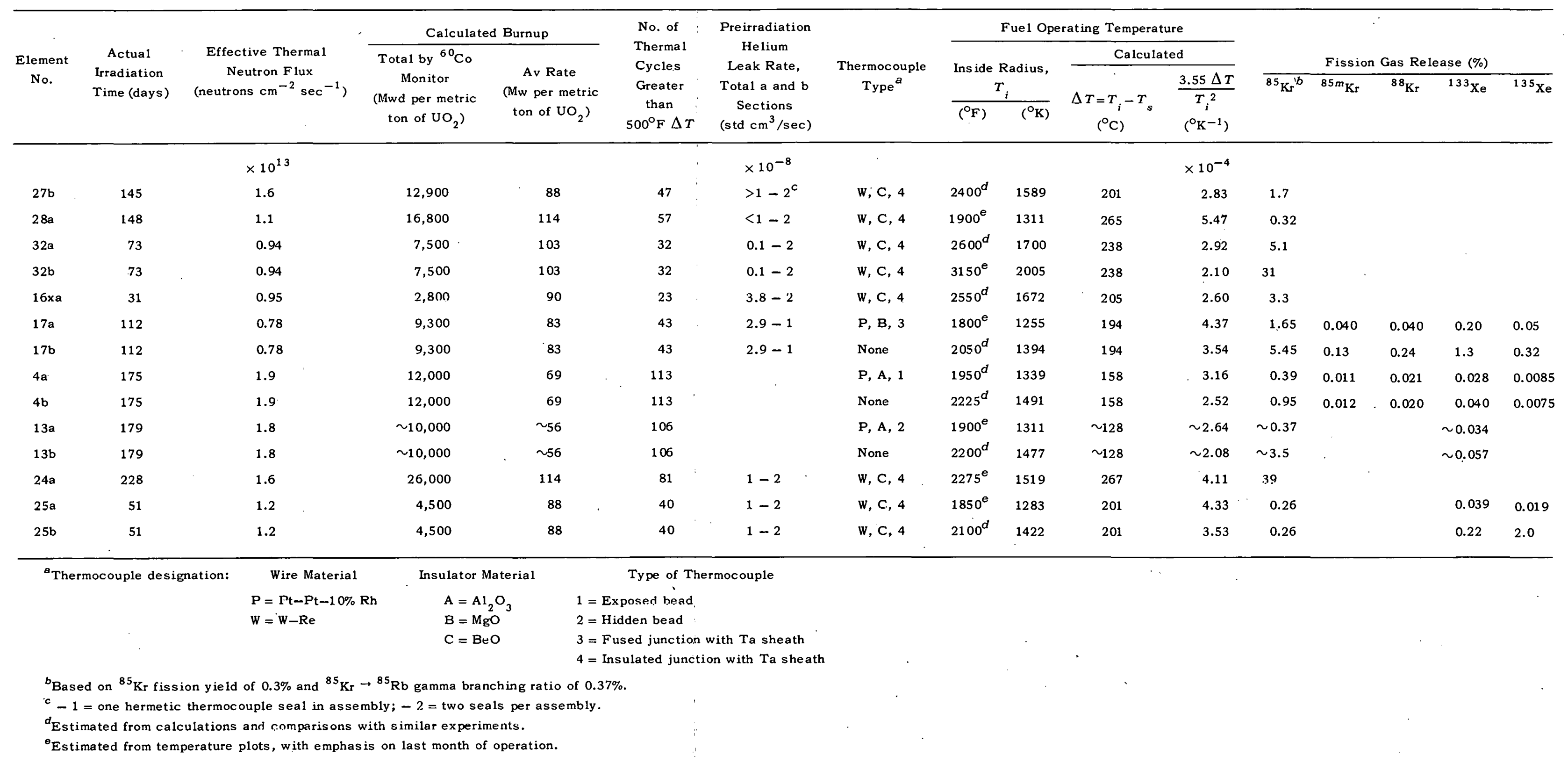


Table 7. Diffusion Coefficients Obtained from Fission Gas Release of LITR Experiments: Oxygen-to-Uranium Ratio $<2.020$

\begin{tabular}{|c|c|c|c|c|c|c|c|c|c|c|c|c|c|c|c|c|}
\hline \multirow{2}{*}{$\begin{array}{c}\text { Element } \\
\text { No. }\end{array}$} & \multirow{2}{*}{$\begin{array}{c}1 / T \\
\left({ }^{\circ} K^{-1}\right)\end{array}$} & \multicolumn{5}{|c|}{$\bar{D}^{\prime}\left(\sec ^{-1}\right)$} & \multicolumn{3}{|c|}{$\frac{D_{0}^{\prime} e^{-E / R T_{i}}}{E / 2 R} \approx \frac{3.55 \Delta T}{T_{i}^{2}} \bar{D}^{\prime}$} & \multicolumn{2}{|l|}{$\left.\sec ^{-10} \mathrm{~K}^{-1}\right)$} & \multicolumn{5}{|c|}{$\frac{D_{0} e^{-E / R T_{i}}}{E / 2 R}=\frac{a^{2} D_{0}^{\prime} e^{-E / R T_{i}}}{E / 2 R}\left(\mathrm{~cm}^{2} \mathrm{sec}^{\left.-1{ }^{\circ} \mathrm{K}^{-1}\right)}\right.$} \\
\hline & & ${ }^{85} \mathrm{Kr}$ & ${ }^{85 m} \mathrm{Kr}$ & ${ }^{88} \mathrm{Kr}$ & ${ }^{133} \mathrm{Xe}$ & ${ }^{135} \mathrm{Xe}$ & ${ }^{85} \mathrm{Kr}$ & & & ${ }^{133} \mathrm{Xe}$ & ${ }^{135} \mathrm{Xe}$ & $85_{\mathrm{Kr}}$ & $\frac{2 R}{85 m_{\mathrm{Kr}}}$ & & ${ }^{133} \mathrm{Xe}$ & ${ }^{135} \mathrm{Xe}$ \\
\hline & $\times 10^{-4}$ & & & & & & & & & & & & & & & \\
\hline $27 \mathrm{~b}$ & 6.29 & $4.8(-12)^{a}$ & & & & & $1.36(-15)$ & & & & & $1.38(-17)$ & & & & \\
\hline $28 \mathrm{a}$ & 7.63 & $1.5(-13)$ & & & & & $8.2(-17)$ & & & & & $2.0(-20)$ & & & & \\
\hline $32 a$ & 5.88 & $9.0(-11)$ & & & & & $2.6(-14)$ & & & & & $1.7(-16)$ & & & & \\
\hline $32 \mathrm{~b}$ & 4.99 & $4.4(-9)$ & & & & & $9.3(-13)$ & & & & & $2.7(-17)$ & & & & \\
\hline $16 x a$ & 5.98 & $8.0(-11)$ & & & & & $2.1(-14)$ & & & & & $1.3(-17)$ & & & & \\
\hline $17 a$ & 7.97 & $5.8(-12)$ & $7.9(-13)$ & $1.3(-12)$ & $6.9(-13)$ & $1.2(-12)$ & $2.5(-15)$ & $3.5(-16)$ & $5.5(-16)$ & $3.0(-16)$ & $5.3(-16)$ & $2.1(-18)$ & $2.9(-19)$ & $4.6(-19)$ & $2.5(-19)$ & $4.4(-19)$ \\
\hline $17 b$ & 7.17 & $6.3(-11)$ & $8.4(-12)$ & $4.5(-11)$ & $2.9(-11)$ & $5.0(-11)$ & $2.2(-14)$ & $2.9(-15)$ & $1.6(-14)$ & $9.9(-15)$ & $1.7(-14)$ & $1.3(-16)$ & $1.8(-17)$ & $9.6(-17)$ & $6.1(-17)$ & $1.1(-16)$ \\
\hline $4 a$ & 7.47 & $2.0(-13)$ & $6.0(-14)$ & $3.4(-13)$ & $1.4(-14)$ & $5.9(-14)$ & $6.3(-17)$ & $1.90(-17)$ & $1.07(-16)$ & $4.4(-18)$ & $1.87(-17)$ & $4.9(-22)$ & $1.49(-22)$ & $8.4(-22)$ & $3.45(-23)$ & $1.48(-2.2)$ \\
\hline $4 b$ & 6.71 & $1.3(-12)$ & $7.1(-14)$ & $3.1(-13)$ & $2.8(-14)$ & $4.6(-14)$ & $3.3(-16)$ & $1.79(-17)$ & $7.8(-17)$ & $7.1(-18)$ & $1.16(-17)$ & $1.05(-20)$ & $5.7(-22)$ & $2.5(-21)$ & $2.3(-22)$ & $3.7(-22)$ \\
\hline $13 a$ & $\sim 7.63$ & $\sim_{1.7(-13)}$ & & & $22.0(-14)$ & & $\sim 4.5(-17)$ & & & $\sim 5.3(-18)$ & & $\sim 2.4(-21)$ & & & $\sim 2.8(-22)$ & \\
\hline $13 b$ & $\sim 6.77$ & $\sim 1.7(-11)$ & & & $\sim 5.6(-14)$ & & $\sim 3.5(-15)$ & & & $\sim 1.2(-17)$ & & $\sim 2.0(-20)$ & & & $\sim 6.6(-23)$ & \\
\hline $24 a$ & 6.58 & $2.1(-9)$ & & & & . & $8.6(-13)$ & & & & & $1.9(-17)$ & & & & \\
\hline $25 \mathrm{a}$ & 7.79 & $2.8(-13)$ & & & $2.6(-14)$ & $2.2(-13)$ & $1.2(-16)$ & & & $1.1(-17)$ & $9.5(-17)$ & $1.2(-20)$ & & & $1.1(-21)^{\circ}$ & $9.4(-21)$ \\
\hline $25 b$ & 7.03 & $2.8(-13)$ & & & $8.3(-13)$ & $2.4(-9)$ & $9.7(-17)$ & & & $2.9(-16)$ & $8.5(-13)$ & $3.7(-21)$ & & & $1.1(-20)$ & $3.3(-17)$ \\
\hline
\end{tabular}

$a_{4.8(-12)}=4.8 \times 10^{-12}$. 
Table 8. Fuel Characterization of LITR Experiments: Oxygen-to-Uranium Ratio $>2.020$

\begin{tabular}{|c|c|c|c|c|c|c|c|c|c|c|c|c|c|c|}
\hline \multirow{2}{*}{$\begin{array}{l}\text { Element } \\
\text { No. }\end{array}$} & \multirow{2}{*}{$\begin{array}{l}\text { Oxygen-to- } \\
\text { Uranium } \\
\text { Ratio }\end{array}$} & \multicolumn{3}{|c|}{$\begin{array}{l}\text { Preirradiation Density } \\
\text { (\% of the oretical) }\end{array}$} & \multicolumn{2}{|c|}{ Void Fraction (\%) } & \multicolumn{2}{|c|}{ Calculated } & \multirow{2}{*}{$\begin{array}{l}\text { Pellet } \\
\text { Surface } \\
\text { Finish }\end{array}$} & \multicolumn{3}{|c|}{ Major Chemical Impurities (ppm) } & \multirow{2}{*}{$\begin{array}{l}\text { Fill } \\
\text { Gas }\end{array}$} & \multirow{2}{*}{$\begin{array}{l}\text { Type of } \\
\text { Insulator }\end{array}$} \\
\hline & & Bulk, $d_{b}$ & Immers ion, $d_{i}$ & & Closed, $V_{c}$ & Open, $V_{0}$ & $\begin{array}{l}\text { Surface Area, } \\
S_{v}\left(\mathrm{~cm}^{2} / \mathrm{cm}^{3}\right)\end{array}$ & $\begin{array}{c}\text { Radius of } \\
\text { Equivalent } \\
\text { Sphere, } a(\mathrm{~cm})\end{array}$ & & Carbon & Nitrogen & Calcium & & \\
\hline $6 a$ & $2.024^{a}$ & 73.6 & 95.62 & $\therefore$ & 3.4 & 23.0 & 26,450 & $8.73(-5)^{b}$ & Ground & & & & Ar & $\mathrm{GG}^{\mathrm{c}}$ \\
\hline $6 \mathrm{~b}$ & 2.024 & 74.2 & 95.99 & & 3.1 & 22.7 & 25,810 & $8.98(-5)$ & Ground & & & & Ar & GG \\
\hline $\mathbf{3 a}$ & 2.118 & 75.0 & 97.26 & & 2.1 & 22.9 & 26,170 & $8.84(-5)$ & Ground & 2400 & 29 & & Ar & GG \\
\hline $3 \mathrm{~b}$ & 2.118 & 74.9 & 97.26 & $"$ & 2.1 & 23.0 & 26,500 & $8.72(-5)$ & Ground & 2400 & 29 & & Ar & GG \\
\hline $18 \mathrm{~b}$ & 2.082 & 85.2 & 94.89 & & 4.6 & 10.2 & 5,220 & $5.16(-4)$ & Ground & 3100 & 20 & 59 & Ar & GG \\
\hline $2 b$ & 2.130 & 84.4 & 91.79 & & 7.6 & 8.0 & 3,230 & $8.54(-4)$ & Ground & 2500 & 20 & & $\mathrm{Ar}$ & $\mathrm{GG}$ \\
\hline $8 a$ & 2.133 & 84.6 & 92.97 & & 6.4 & 9.0 & 4,070 & $6.71(-4)$ & Ground & 3000 & 20 & & $\mathrm{Ar}$ & GG \\
\hline $8 b$ & 2.133 & 85.0 & 92.88 & . & 6.5 & 8.5 & 3,590 & $7.66(-4)$ & Ground & 3000 & 20 & & $\mathrm{Ar}$ & GG \\
\hline $11 \mathrm{~b}$ & 2.140 & 85.2 & 95.44 & $\vdots$ & 4.1 & 10.7 & 5,720 & $4.68(-4)$ & Ground & 630 & 16 & 590 & Ar & GG \\
\hline $14 a$ & 2.028 & 88.7 & 94.07 & 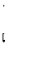 & 5.6 & 5.7 & 1,600 & $1.77(-3)$ & Ground & 690 & 633 & 1100 & Ar & GG \\
\hline $14 \mathrm{~b}$ & 2.028 & 90.3 & 95.4 & 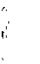 & 4.3 & 5.4 & 1,470 & $1.92(-3)$ & Ground & 690 & 633 & 1100 & Ar & GG \\
\hline $15 a$ & 2.028 & 91.4 & 91.70 & & 8.3 & 0.29 & 4.2 & 0.711 & Ground & 690 & 633 & 1100 & Ar & GG \\
\hline $7 b$ & 2.041 & 95.15 & 96.17 & & 3.79 & 1.06 & 56.2 & $5.28(-2)$ & Ground & & & & Ar & GG \\
\hline $7 x a$ & 2.041 & 95.0 & 95.89 & & 4.06 & 0.94 & 44.2 & $6.72^{\prime}(-2)$ & Ground & & & & $\mathrm{Ar}$ & GG \\
\hline $7 \times b$ & 2.041 & 94.85 & 95.80 & & 4.16 & 0.99 & 49.0 & $6.06(-2)$ & Ground & & & & $\mathrm{Ar}$ & GG \\
\hline $10 \mathrm{~b}$ & 2.041 & 95.2 & 95.62 & $\because$ & 4.35 & 0.45 & 10.1 & 0.2 .96 & Ground & & & & $\mathrm{He}$ & GG \\
\hline $16 a$ & 2.044 & 94.4 & 95.57 & ' & 4.41 & 1.19 & 70.8 & $4.19(-2)$ & Ground & 400 & 76 & 75 & Ar & GG \\
\hline $16 \mathrm{xb}$ & 2.044 & 94.35 & 95.62 & & 4.32 & 1.33 & 88.4 & $3.35(-2)$ & Ground & 400 & 76 & 75 & Ar & GG \\
\hline $17 \mathrm{xa}$ & 2.044 & 94.7 & 95.62 & : & 4.40 & 0.90 & 40.5 & $7.34(-2)$ & Ground & 400 & 76 & 75 & Ar & GG \\
\hline $17 \times b$ & 2.044 & 94.8 & 95.35 & $?$ & 4.65 & 0.55 & 15.1 & 0.198 & Ground & 400 & 76 & 75 & $A_{r}$ & GG \\
\hline
\end{tabular}

${ }^{a}$ Not outgassed before analyses.

${ }^{6} 8.73(-5)=8.73 \times 10^{-5}$.

${ }^{\mathrm{C}} \mathrm{GG}=$ gas gap. 
Table 9. Operating Conditions and Fission Gas Fractional Release of LITR Experiments: Oxygen-to-Uranium Ratio >2.02

\begin{tabular}{|c|c|c|c|c|c|c|c|c|c|c|c|c|c|c|c|c|}
\hline \multirow{4}{*}{$\begin{array}{l}\text { Element } \\
\text { No. }\end{array}$} & \multirow{4}{*}{$\begin{array}{c}\text { Actual } \\
\text { Irradiation } \\
\text { Time (days) }\end{array}$} & \multirow{4}{*}{$\begin{array}{l}\text { Effective Thermal } \\
\text { Neutron Flux } \\
\text { (neutrons } \mathrm{cm}^{-2} \mathrm{sec}^{-1} \text { ) }\end{array}$} & \multicolumn{2}{|c|}{ Calculated Burnup } & \multirow{4}{*}{$\begin{array}{l}\text { No. of } \\
\text { Therma } 1 \\
\text { Cycles } \\
\text { Greater } \\
\text { than } \\
500^{\circ} \mathrm{F} \Delta T\end{array}$} & \multirow{4}{*}{$\begin{array}{l}\text { Preirradiation } \\
\text { Helium } \\
\text { Leak Rate, } \\
\text { Total a and b } \\
\text { Sections } \\
\left(\mathrm{std}^{3} \mathrm{~cm}^{3} / \mathrm{sec}\right)\end{array}$} & \multirow{4}{*}{$\begin{array}{c}\text { Thermocouple } \\
\text { Type }^{a}\end{array}$} & \multicolumn{4}{|c|}{ Fuel Operating Temperature } & \multirow{2}{*}{\multicolumn{5}{|c|}{ Fission Gas Release $(\%)$}} \\
\hline & & & \multirow{3}{*}{$\begin{array}{c}\text { Total by }{ }^{60} \mathrm{Co} \\
\text { Monitor } \\
\text { (Mwd per metric } \\
\text { ton of } \mathrm{UO}_{2} \text { ) }\end{array}$} & \multirow{3}{*}{$\begin{array}{c}\text { Av Rate } \\
(\text { Mw per metric } \\
\left.\text { ton of } \mathrm{UO}_{2}\right)\end{array}$} & & & & \multirow{2}{*}{\multicolumn{2}{|c|}{$\begin{array}{c}\text { Inside Radius, } \\
T_{i}\end{array}$}} & \multicolumn{2}{|c|}{ Calculated } & & & & & \\
\hline & & & & & & & & & & & $3.55 \Delta T$ & \multirow{2}{*}{$85 \mathrm{Kr}^{b}$} & \multirow{2}{*}{${ }^{85 m} \mathrm{Kr}$} & \multirow{2}{*}{${ }^{88} \mathrm{Kr}$} & \multirow{2}{*}{${ }^{133} \mathrm{Xe}$} & \multirow[t]{2}{*}{${ }^{135} \mathrm{Xe}$} \\
\hline & & & & & & & & $\overline{\left({ }^{\circ} \mathrm{F}\right)}$ & $\left({ }^{\circ} \mathrm{K}\right)$ & $\begin{array}{c}\Delta T=T_{i}-T_{s} \\
\quad\left({ }^{\circ} \mathrm{C}\right)\end{array}$ & $\begin{array}{c}T_{i}^{2} \\
\left({ }^{\circ} K^{-1}\right)\end{array}$ & & & & & \\
\hline & & $\times 10^{13}$ & & & & $\times 10^{-8}$ & & & & & $\times 10^{-4}$ & i & & & & \\
\hline $6 a$ & 175 & 1.8 & 12,000 & 69 & 111 & & $\mathrm{P}, \mathrm{A}, 1$ & $2100^{c}$ & 1422 & 153 & 2.69 & 3.3 & 0.091 & & 0.293 & 0.049 \\
\hline $6 \mathrm{~b}$ & 175 & 1.8 & 12,000 & 69 & 111 & & None & $2350^{c}$ & 1561 & 153 & 2.26 & 3.7 & 0.035 & & 0.132 & 0.026 \\
\hline $3 a$ & 76 & 1.6 & 4,100 & 54 & 22 & $0.36-1^{d}$ & $w, c, 3$ & $2500^{\mathrm{c}}$ & 1644 & 128 & 1.68 & 2.6 & & & 0.42 & \\
\hline $3 b$ & 76 & 1.6 & 4,100 & 54 & 22 & $0.36-1$ & None & $2600^{c}$ & 1700 & 128 & 1.57 & 42 & & & 19 & \\
\hline $18 \mathrm{~b}$ & 55 & 0.95 & 5,600 & 102 & 2.1 & $0.03-1$ & Nòne & $2800^{C}$ & 1811 & 239 & 2.59 & 67 & & & 16 & \\
\hline $2 b$ & 30 & 1.4 & 3,200 & 107 & 22 & $1.5-1$ & None & $2400^{c}$ & 1589 & 245 & 3.45 & 23 & & & 9.0 & \\
\hline $8 \mathrm{a}$ & 55 & 1.5 & 6,300 & 115 & 21 & $0.6-1$ & $w, c, 3$ & $2300^{e}$ & 1533 & 261 & 3.94 & 8.1 & & & 0.007 & \\
\hline $8 b$ & 55 & 1.5 & 6,300 & 115 & 21 & $0.6-1$ & None & $2500^{\mathrm{C}}$ & 1644 & 261 & 3.43 & 32 & & & 4.0 & \\
\hline $11 \mathrm{~b}$ & 195 & 1.3 & 19,000 & 97 & 87 & $0.2-2$ & $\mathrm{w}, \mathrm{C}, 3$ & $2225^{\mathrm{e}}$ & 1491 & 226 & 3.61 & 70 & & & 5.3 & 2.1 \\
\hline $14 a$ & 69 & 0.91 & 4,500 & 65 & 33 & & $\mathrm{P}, \mathrm{A}, 2$ & $1950^{e}$. & 1339 & 156 & 3.09 & 0.13 & 0.029 & 0.011 & 0.014 & 0.006 \\
\hline $14 \mathrm{~b}$ & 69 & 0.91 & 4,500 & 65 & 33 & & None & $2200^{c}$ & 1477 & 156 & 2.54 & 0.23 & 0.057 & 0.019 & 0.029 & 0.017 \\
\hline $15 a$ & 90 & 0.79 & 5,200 & 58 & 43 & $1.1-1$ & $\mathbf{P} ; \mathbf{A}, 2$ & $1700^{e}$ & 1200 & 135 & 3.33 & 0.10 & 0.019 & 0.004 & 0.010 & 0.004 \\
\hline $7 \mathrm{~b}$ & 73 & 1.0 & 5,400 & 74 & 47 & $2.8-1$ & None & $2200^{C}$ & 1477 & 172 & 2.80 & 0.13 & 0.019 & 0.033 & 0.066 & 0.035 \\
\hline $7 \times a$ & 126 & 1.5 & 14,000 & 111 & 66 & $1.0-2$ & P;C, 4 & $2000^{c}$ & 1367 & 253 & 4.81 & 0.13 & & & 0.16 & \\
\hline $7 \times b$ & 126 & 1.5 & 14,000 & 111 & 66 & $1.0-2$ & $\mathrm{w}, \mathrm{C}, 3$ & $2300^{e}$ & 1533 & 253 & 3.82 & 8.6 & & & 0.85 & \\
\hline $10 b$ & 30 & 1.5 & 1,400 & 47 & 14 & $16-?$ & W, C, 4 & $2600^{e}$ & 1700 & 261 & 3.21 & 28 & & & 30 & 27 \\
\hline $16 \mathbf{a}$ & 88 & 0.71 & 2,500 & 28 & 26 & $7-2$ & $\mathrm{P}, \mathrm{C}, 2$ & $1900^{\circ}$ & 1311 & 04 & 1.32 & 0.35 & & & 0.078 & 0.021 \\
\hline $16 \mathrm{xb}$ & 31 & 0.95 & 2,800 & 90 & 23 & $3.8-2$ & $w ; c, 3$ & $2800^{e}$ & 1811 & 205 & 2.22 & 11.2 & & & & \\
\hline $17 \times a$ & 30 & 0.84 & 2,700 & 90 & 14 & $0.47-2$ & $\mathrm{P}, \mathrm{C}, 4$ & $2650^{c}$ & 1727 & 205 & 2.44 & $\therefore$ & & & 30 & 4.5 \\
\hline $17 \times b$ & 30 & 0.84 & 2,700 & 90 & 14 & $0.47-2$ & w C, 4 & $2950^{e}$ & 1894 & 205 & 2.03 & 42 & & & 61 & 20 \\
\hline
\end{tabular}

D.'Thermoc ouple destgnation:

\begin{tabular}{lll} 
Wire Malerial & Inoulator Material & \multicolumn{1}{c}{ Tyne nf Thermocouple } \\
$\mathrm{P}=\mathrm{Pt}-\mathrm{Pt}-10 \% \mathrm{Rh}$ & $\mathrm{A}=\mathrm{Al}_{2} \mathrm{O}_{3}$ & $1=$ Exposed bead \\
$\mathrm{W}=\mathrm{W}-\mathrm{Re}$ & $\mathrm{B}=\mathrm{MgO}$ & $2=$ II idlen bead \\
& $\mathrm{C}=\mathrm{BeO}$ & $3=$ Fused junction with Ta sheath
\end{tabular}

4 - Insulated junction with sheath

${ }^{b}$ Based on ${ }^{85} \mathrm{Kr}$ fission yield of $0.3 \%$ and ${ }^{85} \mathrm{Kr}_{\mathrm{r}} \rightarrow{ }^{85} \mathrm{Rb}$ gamma branching ratio of $0.37 \%$.

Estimated from calculatiuns and comparizons with $\varepsilon$ imilar experiments.

$-1=$ one hermetic thermocouple seal in assembly; $-2=$ two seals per assembly.

${ }^{e}$ Estimated from temperature plots, with emphasis on last month of operation. 
Table 10. Diffusion Coefficients Obtained from Fission Gas Release of LITR Experiments: Oxygen-to-Uranium Ratio $>2.02$

\begin{tabular}{|c|c|c|c|c|c|c|c|c|c|c|c|c|c|c|c|c|}
\hline \multirow{2}{*}{$\begin{array}{l}\text { Element } \\
\text { No. }\end{array}$} & \multirow{2}{*}{$\begin{array}{c}1 / T_{i} \\
\left({ }^{\circ} K^{-1}\right)\end{array}$} & \multicolumn{5}{|c|}{$\bar{D}^{\prime}\left(\sec ^{-1}\right)$} & \multicolumn{5}{|c|}{$\frac{D_{0}^{\prime} \mathrm{e}^{-E / R T_{i}}}{E / 2 R} \approx \frac{3.55 \Delta T}{T_{i}^{2}} \bar{D}^{\prime}\left(\mathrm{sec}^{\left.-1{ }^{\circ} \mathrm{K}^{-1}\right)}\right.$} & \multicolumn{5}{|c|}{$\frac{D_{0} \mathrm{e}^{-E / R T_{i}}}{E / 2 R}=\frac{a^{2} D_{0}^{\prime} \mathrm{e}^{-E / R T_{i}}}{E / 2 R}\left(\mathrm{~cm}^{2} \sec ^{-1 \circ^{-1}} \mathrm{~K}^{-1}\right)$} \\
\hline & & ${ }^{85} \mathrm{Kr}$ & ${ }^{85 m} \mathrm{Kr}$ & ${ }^{88} \mathrm{Kr}$ & ${ }^{133} \mathrm{Xe}$ & ${ }^{135} \mathrm{xe}$ & $8{ }^{85} \mathrm{Kr}$ & ${ }^{85 m} \mathrm{Kr}$ & ${ }^{88} \mathrm{Kr}$ & ${ }^{133} \mathrm{Xe}$ & ${ }^{135} \mathrm{Xe}$ & $85_{\mathrm{Kr}}$ & $85 m_{\mathrm{Kr}}$ & ${ }^{88} \mathrm{Kr}$ & ${ }^{133} \mathrm{Xe}_{\mathrm{e}}$ & ${ }^{135} \mathrm{Xe}$ \\
\hline & $\times 10^{-4}$ & & & & & & & & & & & & & & & \\
\hline $6 a$ & 7.03 & $1.5(-11)^{a}$ & $4.1(-12)$ & & $1.5(-12)$ & $1.9(-12)$ & $4.0(-15)$ & $1.1(-15)$ & & $4.0(-16)$ & $5.1(-16)$ & $3.1(-23)$ & $8.4(-24)$ & & $3.0(-24)$ & $3.9(-24)$ \\
\hline $6 \mathrm{~b}$ & 6.41 & $1.9(-11)$ & $6.0(-13)$ & & $3: 0(-13)$ & $5.3(-13)$ & $4.3(-15)$ & $1.4(-16)$ & & $6.8(-17)$ & $1.2(-16)$ & $3.5(-23)$ & $1.1(-24)$ & & $5.5(-25)$ & $9.7(-25)$ \\
\hline $3 a$ & 6.08 & $2.1(-11)$ & & & $3.0(-12)$ & & $3.5(-15)$ & & & $5.0(-16)$ & & $2.7(-23)$ & & & $3.9(-24)$ & \\
\hline $3 b$ & 5.88 & $8.0(-9)$ & & & $6.9(-9)$ & & $1.3(-12)$ & & & $1.08(-12)$ & & $9.9(-21)$ & & & $8.2(-21)$ & \\
\hline $18 \mathrm{~b}$ & 5.52 & $5.0(-8)$ & & & $4.8(-9)$ & & $1.3(-11)$ & & & $1.2(-12)$ & & $3.4(-18)$ & & & $3.3(-19)$ & \\
\hline $2 b$ & 6.29 & $5.0(-9)$ & & & $1.4(-9)$ & & $1.7(-12)$ & & & $4.8(-13)$ & & $1.3(-18)$ & & & $3.5(-19)$ & \\
\hline $8 a$ & 6.52 & $3.0(-10)$ & & & $8.4(-16)$ & & $1.2(-13)$ & & & $3.3(-19)$ & & $5.2(-20)$ & & & $1.5(-25)$ & \\
\hline $8 b$ & 6.08 & $5.8(-9)$ & & & $2.8(-10)$ & : & $2.0(-12)$ & & & $9.5(-14)$ & & $1.2(-18)$ & & & $5.5(-20)$ & \\
\hline $11 \mathrm{~b}$ & 6.71 & $1.8(-8)$ & & & $4.9(-10)$ & $2.8(-9)$ & $6.5(-12)$ & & & $1.8(-13)$ & $1.0(-12)$ & $1.4(-18)$ & & & $3.9(-20)$ & $2.2(-19)$ \\
\hline $14 a$ & 7.47 & $5.0(-14)$ & $4.2(-13)$ & $9.4(-14)$ & $3.4(-15)$ & $1.8(-14)$ & $1.5(-17)$ & $1.3(-16)$ & $2.9(-17)$ & $1.0(-18)$ & $5.7(-18)$ & $4.7(-23)$ & $3.9(-22)$ & $8.7(-23)$ & $3.1(-24)$ & $1.7(-23)$ \\
\hline $14 \mathrm{~b}$ & 6.77 & $1.7(-13)$ & $1.6(-12)$ & $2.8(-13)$ & $1.4(-14)$ & $1.5(-1.3)$ & $4.3(-17)$ & $4.1(-16)$ & $7.1(-17)$ & $3.7(-18)$ & $3.8(-17)$ & $1.6(-22)$ & $1.5(-21)$ & $2.6(-22)$ & $1.4(-23)$ & $1.4(-22)$ \\
\hline $15 a$ & 8.33 & $2.7(-14)$ & $1.8(-13)$ & $1.2(-14)$ & $1.7(-15)$ & $7.0(-15)$ & $9.0(-18)$ & $6.0(-17)$ & $4.1(-18)$ & $5.7(-19)$ & $2.5(-18)$ & $4.5(-18)$ & $3.0(-17)$ & $2.1(-18)$ & $2.9(-19)$ & $1.3(-18)$ \\
\hline $7 \mathrm{~b}$ & 6.77 & $5.2(-14)$ & $1.8(-13)$ & $8.4(-13)$ & $7.5(-14)$ & $6.6(-13)$ & $1.5(-17)$ & $5.0(-17)$ & $2.4(-16)$ & $2.1(-17)$ & $1.8(-16)$ & $4.1(-20)$ & $1.4(-19)$ & $6.6(-19)$ & $5.9(-20)$ & $5.2(-19)$ \\
\hline $7 \times a$ & 7.32 & $3.9(-14)$ & & & $4.4(-13)$ & & $1.9(-17)$ & & & $2.1(-16)$ & & $8.5(-20)$ & & & $9.5(-19)$ & \\
\hline $7 \mathrm{xb}$ & 6.52 & $1.5(-10)$ & & & $1.2(-11)$ & & $5.6(-14)$ & & & $4.7(-15)$ & & $2.1(-16)$ & & & $1.7(-17)$ & \\
\hline $10 \mathrm{~b}$ & 5.88 & $7.8(-9)$ & & & $1.8(-8)$ & $6.3(-7)$ & $1.04(-12)$ & & & $2.4(-12)$ & $8.4(-11)$ & $9.1(-14)$ & & & $2.1(-13)$ & $7.4(-12)$ \\
\hline $16 \mathrm{a}$ & 7.63 & $2.8(-13)$ & & & $1.1(-13)$ & $2.0(-13)$ & $3.7(-17)$ & & & $1.45(-17)$ & $2.6(-17)$ & $6.5(-20)$ & & & $2.5(-20)$ & $4.6(-20)$ \\
\hline $16 \times b$ & 5.52 & $1.1(-9)$ & & & & & $2.44(-13)$ & & & & & $2.7(-16)$ & & & & \\
\hline $17 \times a$ & 5.79 & & & & $1.8(-8)$ & $1.0(-8)$ & & & & $4.4(-12)$ & $2.44(-12)$ & & & & $2.37(-14)$ & $1.32(-14)$ \\
\hline $17 \times b$ & 5.28 & $1.7(-8)$ & & & $1.2(-7)$ & $2.2(-7)$ & $3.45(-12)$ & & & $2.44(-11)$ & $4.47(-11)$ & $1.35(-13)$ & & & $9.57(-13)$ & $1.75(-12)$ \\
\hline
\end{tabular}

$a_{1.5(-11)}=1.5 \times 10^{-11}$. 
The listed preirradiation density measurements are the averages of all the individual pellet densities for a given experiment. In some cases, the densities of the individual pellets varied greatly within an experiment. Bulk density was obtained from dimensions and weight. Immersion density is a carbon tetrachloride immersion density.

The void and solid fractions were calculated from the densities as follows:

$$
\begin{gathered}
V_{\text {closed }}=V_{c}=\frac{\rho_{b}}{\rho_{i}}-\frac{\rho_{b}}{\rho_{T}}=\frac{d_{b}}{d_{i}}-d_{b}, \\
V_{\text {open }}=V_{o}=1-\frac{\rho_{b}}{\rho_{i}}=1-\frac{d_{b}}{d_{i}}, \text { and } \\
V_{\text {solid }}=V_{s}=\frac{\rho_{b}}{\rho_{T}}=d_{b},
\end{gathered}
$$

where $\rho_{b}, \rho_{i}$, and $\rho_{T}$ are the bulk, immersion, and theoretical densities respectively; $d_{b}$ and $d_{i}$ are the fractional bulk and immersion densities respectively (i.e., $d_{b}=\rho_{b} / \rho_{T}$ and $d_{i}=\rho_{i} / \rho_{T}$ ). Also $V_{s}+V_{c}+$ $V_{0}=1$ (or $100 \%$ if the $V$ 's are expressed in percent).

The surface area measurements are calculated from

$$
S_{v}\left(\frac{\mathrm{cm}^{2}}{\mathrm{~cm}^{3}}\right)=50 V_{o}^{2}
$$

where $V_{0}$ is expressed in percent.

The original surface area measurements for the LITR experiments ${ }^{20}$ are not consistent, mainly because large enough samples of the very low surface area materials were not made available for measurement. However, a plot of $S_{v}$ vs $V_{o}$ for the ORR type pellets (data obtained from ref. 20) was reasonably consistent. Some excess pellets from five LITR experiments were still available, and surface area measurements were then made on these samples. The $S_{v} v s V_{o}$ for these samples (except for one of very low surface area) are surprisingly consistent with the ORR data as shown in Fig. 23. This indicates that the surface roughness of the open porosity did not vary greatly between the ORR and LITR type fuels, even though the open void fraction of the latter varied by a factor of about 15 .

The results of the recent surface area measurements for the low open void fraction of LITR samples were given to only one significant figure and thus may be in error as much as $100 \%$.

The fractional bulk density, $d_{b}$, for ORR pellets ranged from 94.2 to $96.1 \%$ while the open void fraction $V_{o}$, ranged from 0.8 to $4.2 \%$. It was found that $S_{y}$ correlated much better with $V_{o}$ than with $d_{b}$. The surface area per unit volume $\left(S_{V}\right)$ should vary with $V_{0}$ in some consistent manner as long as the surface roughness of the elementary sintered particles does not change with $V_{o}$. A universal $S_{v} v s V_{o}$ relationship cannot be expected for $\mathrm{UO}_{2}$ compacts because both surface roughness and particle size distribution affect $S_{v}$ measurements. One would expect that these two factors would vary from one type of $\mathrm{UO}_{2}$ to another. 


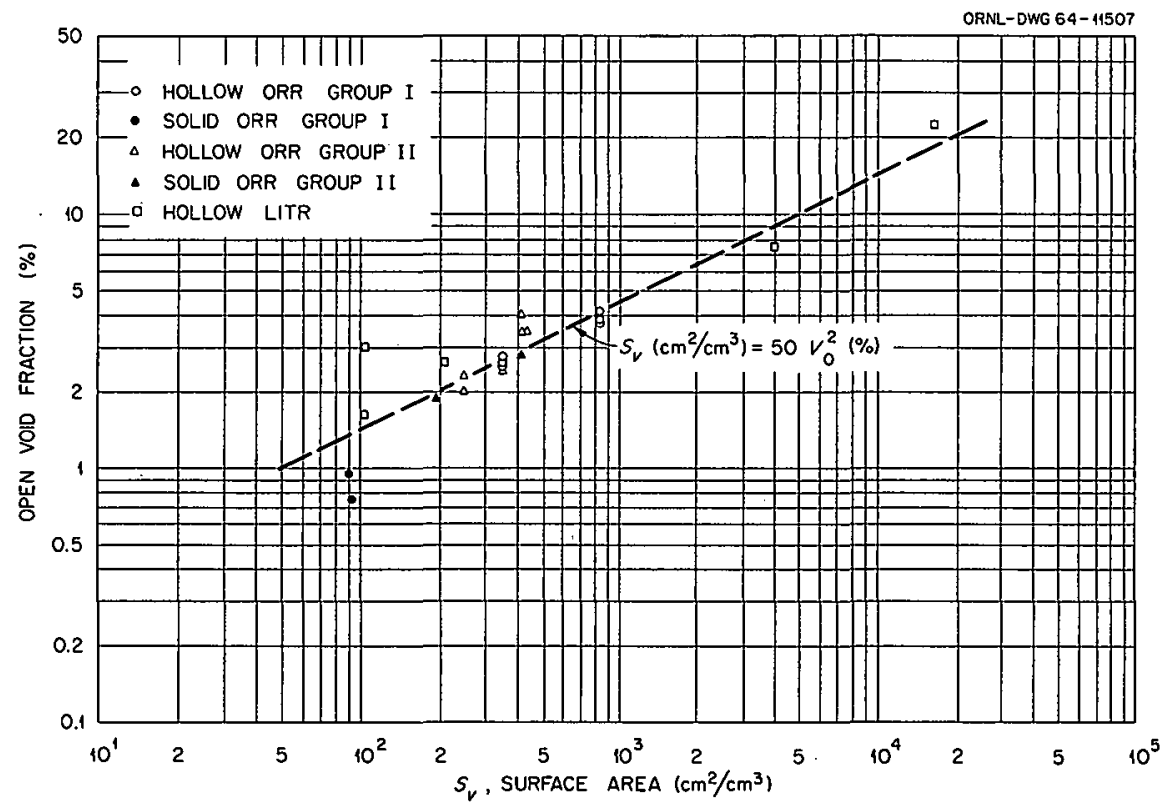

Fig. 23. Surface Area vs Percent Open Voids of $\mathrm{UO}_{2}$ Pellets.

The radius of the equivalent hypothetical sphere was calculated from

$$
a=3\left(\frac{\rho_{b}}{\rho_{i}}\right)\left(\frac{1}{S_{v}}\right)=3\left(\frac{d_{b}}{d_{i}}\right) \frac{1}{S_{v}}
$$

rather than from

$$
a=3\left(\frac{\rho_{b}}{\rho_{T}}\right)\left(\frac{1}{S_{v}}\right)=3\left(\frac{d_{b}}{S_{v}}\right)
$$

because the former takes into account the effect of closed porosity - the latter does not.

The fuel operating temperatures were estimated from operating temperature plots with emphasis on the last month of operation. The pellet inside surface operating temperature plots generally showed a gradual downward drift with irradiation time, even though the element outer surface temperature was maintained more or less constant. For the $\mathrm{Pt} / \mathrm{Pt}-10 \%$ rhodium thermocouples, the drift was usually several times greater than the error in thermocouple output expected from burnup of the rhodium. The error in output vs $n v t$ for tungsten-rhenium thermocouples is not known. The temperatures were estimated to the nearest $50^{\circ} \mathrm{F}$ with no correction for $n v t$ error in thermocouple output.

Some experiments had no thermocouple; in others the thermocouple failed or malfunctioned during the course of the experiment. The temperatures assigned to these experiments were obtained from calculations and comparison with similar experiments in the same, or nearby, reactor position.

The listed $\Delta T$ is calculated from the power rating of the experiment with the assumption of constant $\mathrm{UO}_{2}$ thermal conductivity (i.e., independent of temperature and burnup). This is, of course, probably in 
error; but the other temperature measurements are also so much in error that a $\Delta T$ obtained as the difference between the inside surface and the outside surface pellet temperatures would probably be much greater in error than a $\Delta T$ calculated from the power output.

The coefficient of $\Delta T / T_{i}^{2}$ in Tables 6 and $9,3.55$, is equal to

$$
\frac{\left(y_{s}^{2}-1\right)^{2}}{\pi / 2\left(y_{s}^{2}-1-\ln y_{s}^{2}\right)}
$$

for the nominal pellet dimensions, rather than being calculated for each experiment. The resulting error is much less than the error associated with the temperature measurements.

The $\bar{D}^{\cdot}\left(=\bar{D} / a^{2}\right)$ of Tables 7 and 10 were obtained from the fission-gas release measurements of Tables 6 and 9 by means of Beck's ${ }^{14}$ tables. The

$$
\frac{D_{0}^{\prime} e^{-E / R T_{i}}}{E / 2 R}=3.55 \frac{\Delta T \bar{D}^{\prime}}{T_{i}^{2}} \text { and } \frac{D_{0} e^{-E / R T_{i}}}{E / 2 R}=\frac{a^{2} D_{0}^{\prime} e^{-E / R T_{i}}}{E / 2 R}
$$

in Tables 7 and 10 were calculated on the basis of the foregoing theory.

Plots of $\log \left(D_{0}^{\circ} e^{-E / R T_{i}} / E / 2 R\right)$ vs $1 / T_{i}$ and of $\log \left(D_{0} \mathrm{e}^{\left.-E / R T_{i} / E / 2 R\right)}\right.$ vs $1 / T_{i}$ are shown in Figs. $24-28$.

The sloping line in these figures is arbitrarily drawn in the same position in each group of figures with a slope of $70,000 \mathrm{cal} / \mathrm{mole}$. It is presented to facilitate interfigure comparison. It is emphasized that this curve is not drawn to be a fit of the data, but for a basis of intercomparison only.

Figure 26 is the 90 and $95 \% \rho_{b}$ data extracted from Fig. 25. This was done so that density effects might be eliminated when stoichiometric, etc., effects are being examined.

Generally the spread of $\bar{D}^{\prime}$ in any one experiment for the five gases measured is about an order of magnitude. Usually $\bar{D}^{+85} \mathrm{Kr}$ is greatest and $\bar{D}^{\prime 133} \mathrm{Xe}$ is lowest. Ordinarily the experiments operated long enough so that steady-state release was attained for all isotopes except ${ }^{85} \mathrm{Kr}$.

The reason for the high $\bar{D} \cdot{ }^{85} \mathrm{Kr}$ may be bursts due to rapid temperature changes and/or consistent errors in measurement (i.e., yield constants, counting errors, etc.). Only those bursts which occur during the last few half-lives of an irradiation should have an effect on the fission-gas accumulation of radioactive isotopes. Thus, only ${ }^{85} \mathrm{Kr}$ accumulation should be affected appreciably, unless a series of large bursts occurred near the end of irradiation.

The $\bar{D}$ "'s were obtained from the fission-gas accumulation as though the isotopes were born directly from fission, that is, the diffusion of any relatively long-lived parents was neglected. This is satisfactory for the kryptons, but the xenons have relatively long-lived iodine parents.

For steary-state parent-daughter diffusion, the $\bar{D}^{-133} \mathrm{Xe}$ corrected for parent diffusion would be approx $0.8 \bar{D}^{\prime}$ uncorrected, with the assumption that $D^{\circ}$ iodine is the same as $D^{\prime}$ xenon. ${ }^{21}$ The $\vec{D}^{\circ}$ ${ }^{135} \mathrm{Xe}$ corrected would range from about $3 / 8$ to $\frac{1}{4} \bar{D}^{\prime}$ uncorrected, depending upon the flux.

\footnotetext{
${ }^{21}$ J. W. Prados and J. I.. Scott. Models for Fission-Gas Release from Coated Fuel Particles, ORNL-3421A.
} 


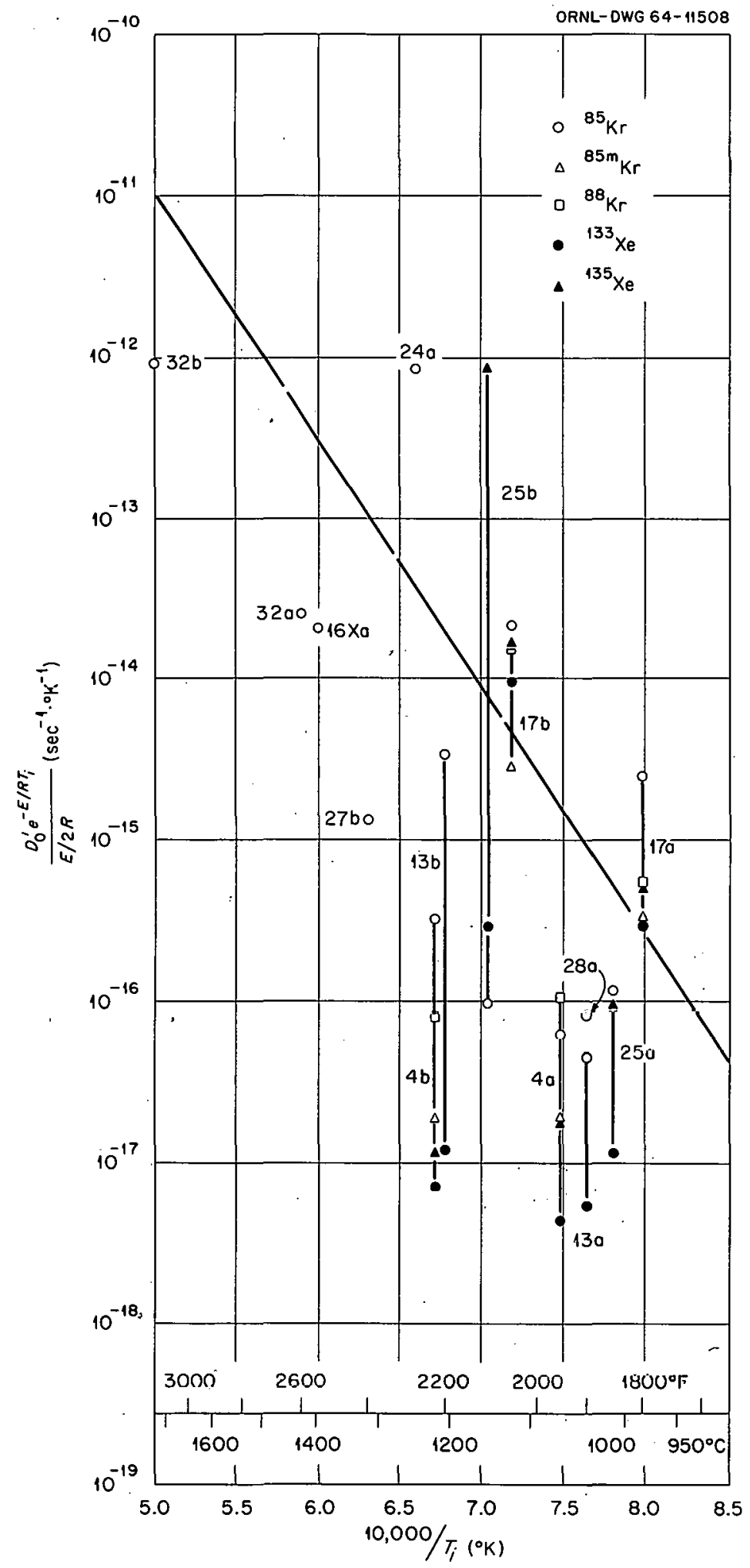

Fig. 24. $\frac{D_{0}^{\prime} e^{-E / R T} i}{E / 2 R}$ vs $\frac{1}{T_{i}}$ for LITR $0 / U<2.02$ Experiments, $\rho_{b} \approx 95 \%$. 


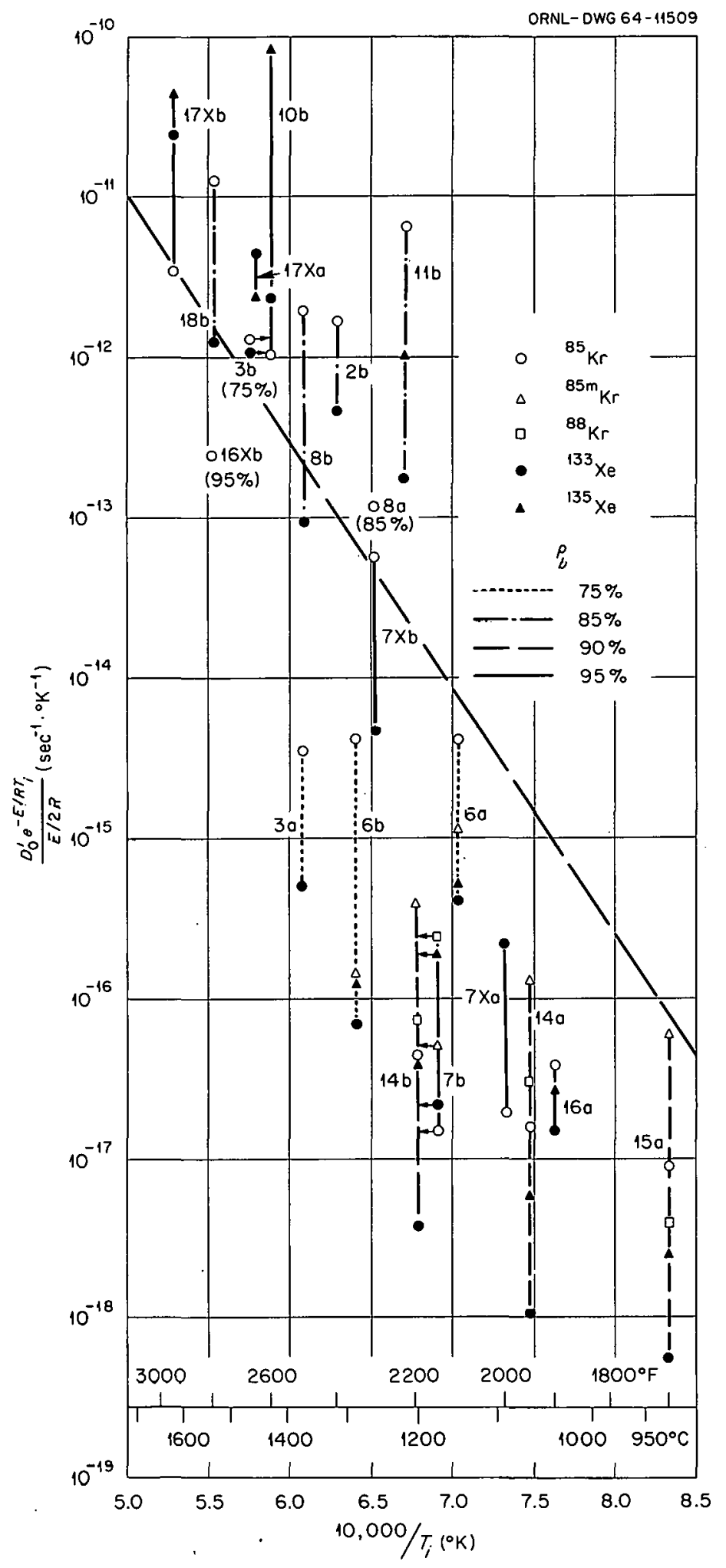

Fig. 25. $\frac{D_{0}^{\prime} e^{-E / R T_{i}}}{E / 2 R}$ vs $\frac{1}{T_{i}}$ for LITR $O / U \geqq 2.02$ Experiments. 


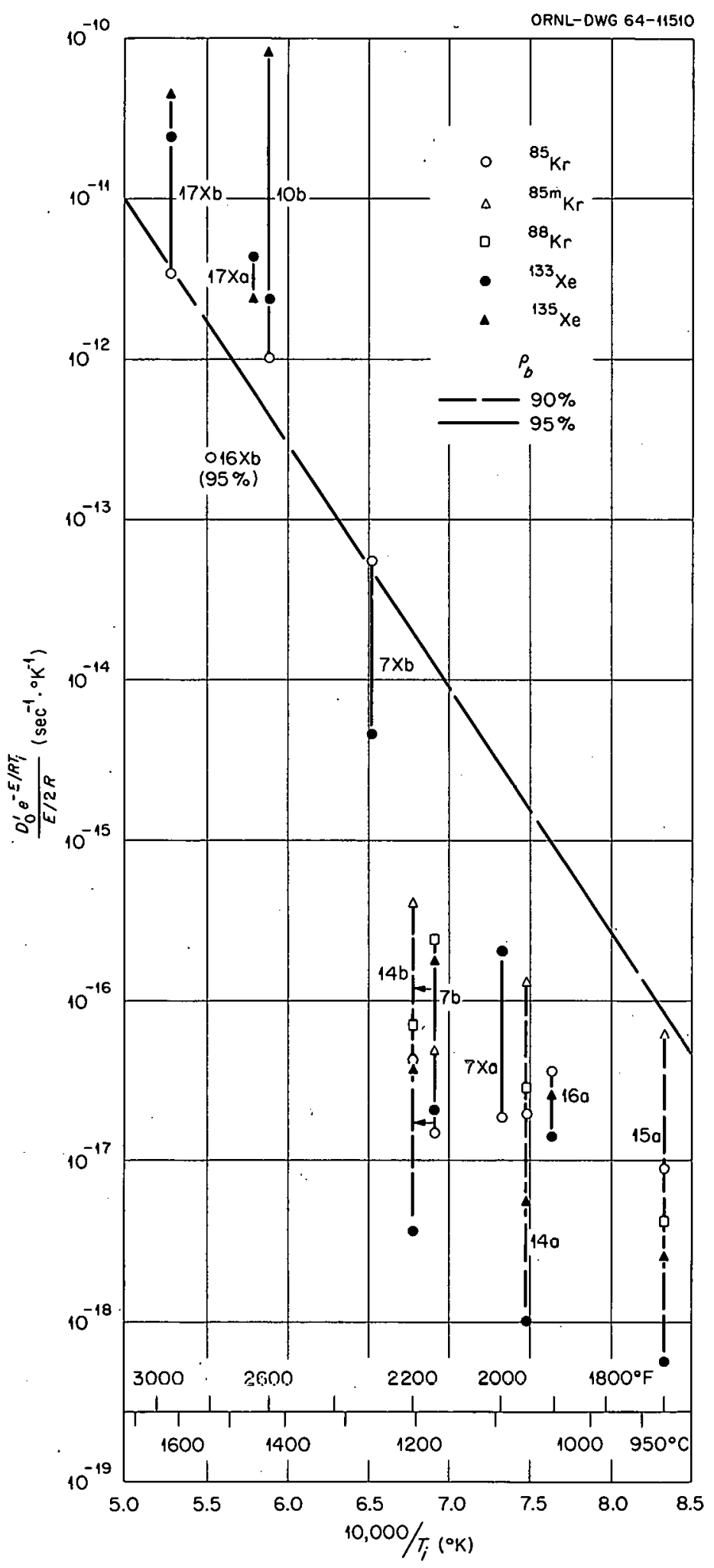

Fig. 26. $\frac{D_{0}^{e} e^{-E / R T}}{E / 2 R}$ vs $\frac{1}{T_{i}}$ for LITR $0 / U \geq 2.02$ Experiments, $\rho_{b}=90$ and $95 \%$. 


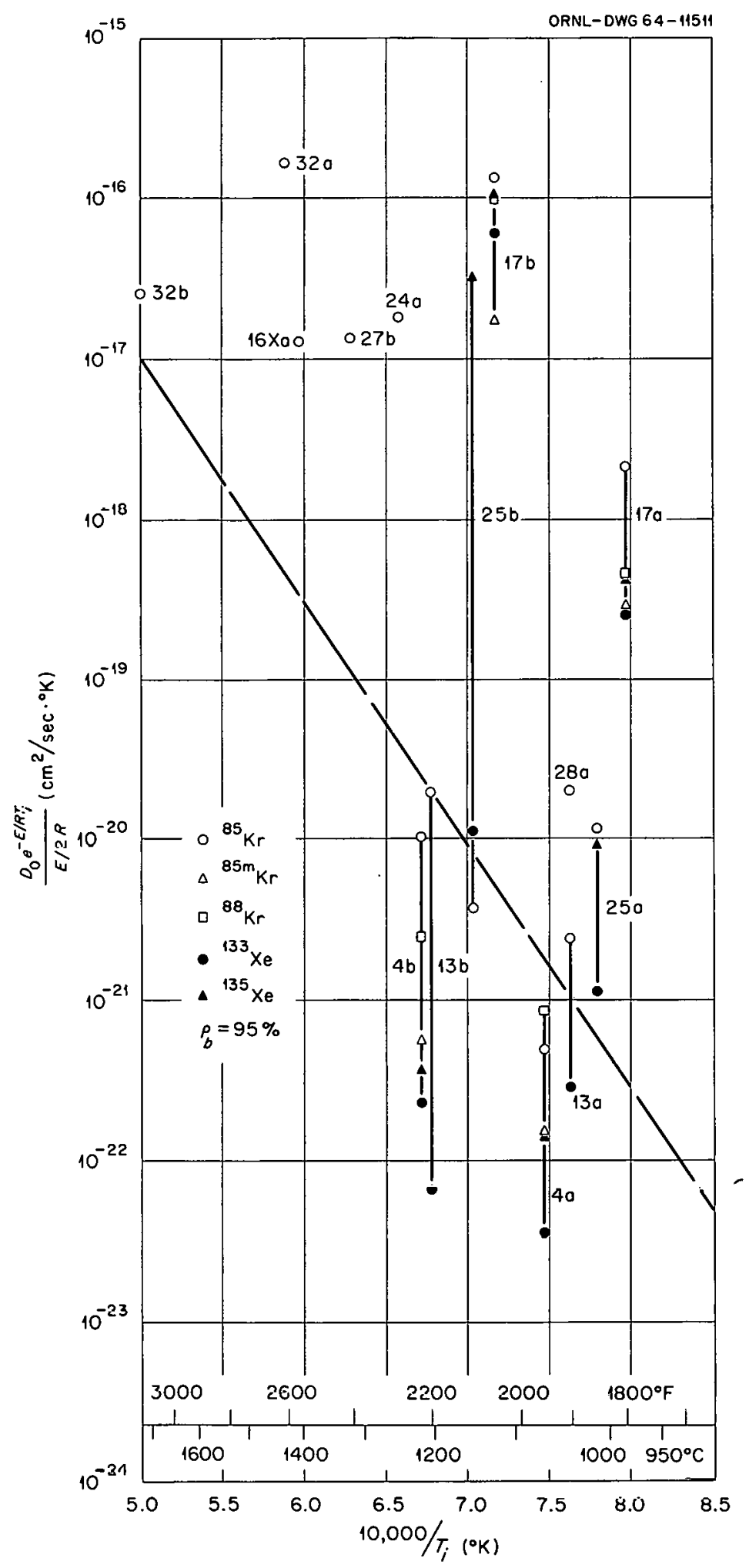

Fig. 27. $\frac{D_{0} \mathrm{e}^{-E / R T_{i}}}{E / 2 R}$ vs $\frac{1}{T_{i}}$ for LITR $0 / \mathrm{U}<2.02$ Experiments, $\rho_{b} \approx 95 \%$. 


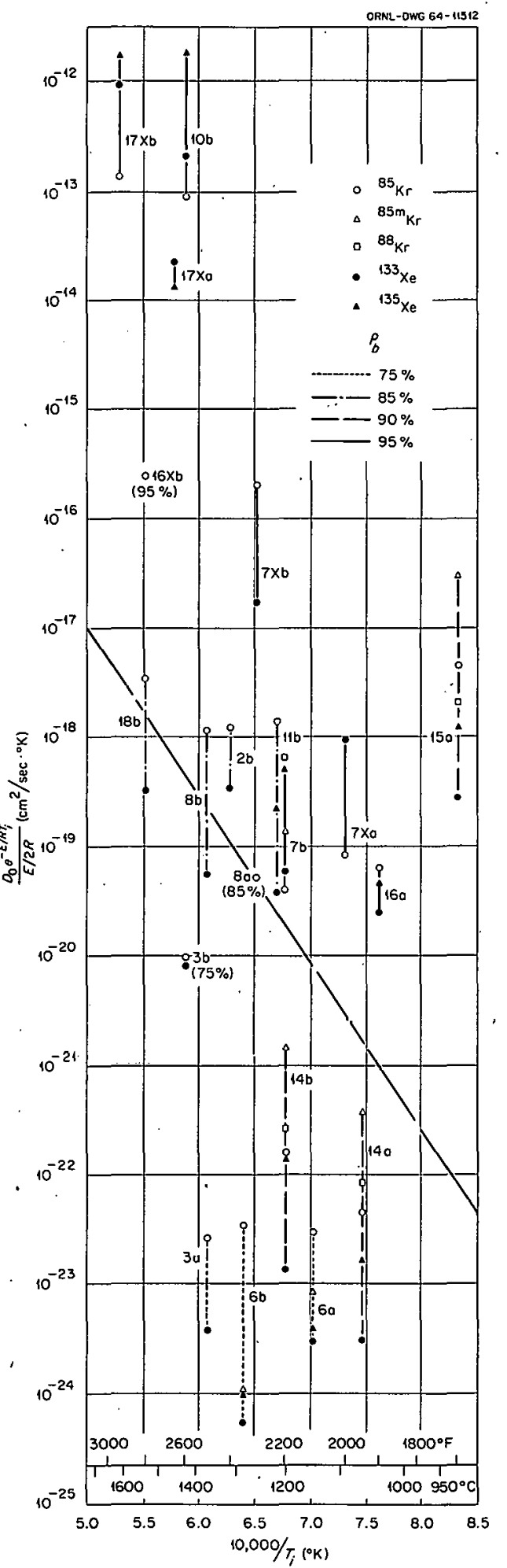

Fig. 28. $\frac{D_{0} \mathrm{e}^{-E / R T}}{E / 2 R}$ vs $\frac{1}{T_{i}}$ for LITR $O / U \geqq 2.02$ Experiments. 
If the foregoing analysis and measurements are correct, then generally the $\bar{D}^{\prime} \mathrm{Xe}$ 's are about an order of magnitude lower than $\bar{D}^{\cdot}{ }^{85} \mathrm{Kr}$, with the other $\bar{D}^{\prime} \mathrm{Kr}$ 's between those of the Xe's and ${ }^{85} \mathrm{Kr}$.

It should be emphasized that the $\bar{D}^{\prime}$ ohtained are functions of many variables (the values of many of these are not well known, e.g., operating temperatures, neutron flux, burnup, etc.); and that the operating conditions were not maintained constant throughout the irradiation period. In addition, the model itself contains many simplifying assumptions, and any effects due to recoil, etc., are considered as diffusion.

Table 11 lists the calculated $D^{\prime}\left(1400^{\circ} \mathrm{C}\right)=D_{0}^{\prime} e^{-E / R \cdot 1673}$ and $D\left(1400^{\circ} \mathrm{C}\right)=a^{2} D^{\prime} \cdot\left(1400^{\circ} \mathrm{C}\right)$ for ${ }^{85} \mathrm{Kr}$ on the assumption that $E=70,000 \mathrm{cal} / \mathrm{g}$-mole.

Table 11. ${ }^{85} \mathrm{Kr} D^{\prime}\left(1400^{\circ} \mathrm{C}\right)$ and $D\left(1400^{\circ} \mathrm{C}\right)$ for LITR Experiments

$$
E=70,000 \mathrm{ca} 1 / \mathrm{g} \text { mole }
$$

\begin{tabular}{|c|c|c|c|c|c|}
\hline \multicolumn{3}{|c|}{ Oxygen-to-Uranium Ratio $<2.02$} & \multicolumn{3}{|c|}{ Oxygen-to-Uranium Ratio $>2.02$} \\
\hline $\begin{array}{c}\text { Element } \\
\text { No. }\end{array}$ & $\begin{array}{c}D^{\prime}\left(1400^{\circ} \mathrm{C}\right) \\
\left(\sec ^{-1}\right)\end{array}$ & $\begin{array}{l}D\left(1400^{\circ} \mathrm{C}\right) \\
\left(\mathrm{cm}^{2} / \mathrm{sec}\right)\end{array}$ & $\begin{array}{c}\text { Element } \\
\text { No. }\end{array}$ & $\begin{array}{c}D^{\prime}\left(1400^{\circ} \mathrm{C}\right) \\
\left(\sec ^{-1}\right)\end{array}$ & $\begin{array}{l}D\left(1400^{\circ} \mathrm{C}\right) \\
\left(\mathrm{cm}^{2} / \mathrm{sec}\right)\end{array}$ \\
\hline $27 \mathrm{~b}$ & $4.8(-11)^{a}$ & $4.9(-13)$ & $3 \mathbf{a}$ & $9.0(-11)$ & $7.0(-19)$ \\
\hline 28 a & $4.9(-10)$ & $1.2(-13)$ & $3 \mathrm{~b}$ & $1.6(-8)$ & 1..2(-16) \\
\hline $32 a$ & $3.3(-10)$ & $2.1(-12)$ & $18 \mathrm{~b}$ & $4.5(-8)$ & $1.2(-14)$ \\
\hline $32 \mathrm{~b}$ & $5.0(-10)$ & $1.4(-14)$ & $2 \mathrm{~b}$ & $9.1(-8)$. & $6.6(-14)$ \\
\hline $16 \mathrm{xa}$ & $3.75(-10)$ & $2.4(-13)$ & $\begin{array}{l}8 a \\
8 b\end{array}$ & $\begin{array}{l}1.45(-8) \\
5.1(-8)\end{array}$ & $\begin{array}{l}6.5(-15) \\
3.0(-14)\end{array}$ \\
\hline $17 a$ & $4.9(-8)$ & $4.1(-11)$ & $11 \mathrm{~b}$ & $1.5(-6)$ & $3.3(-13)$ \\
\hline $17 \mathrm{~b}$ & $2.6(-8)$ & $1.6(-10)$ & $14 a$ & $5.1(-11)$ & $1.6(-16)$ \\
\hline $4 a$ & $2.1(-10)$ & $1.7(-15)$ & $14 \mathrm{~b}$ & $1.2(-11)$ & $4.6(-17)$ \\
\hline $4 b$ & $7.7(-10)$ & $2.4(-14)$ & $15 a$ & $6.4(-10)$ & $3.2(-10)$ \\
\hline $13 \mathbf{a}$ & $\sim 2.7(-10)$ & $\sim 1.4(-14)$ & 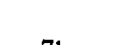 & $12(10)$ & 10 \\
\hline $13 \mathrm{~b}$ & $\sim 1.01(-9)$ & $\sim 5.7(-15)$ & $7 \times a$ & $3.7(-11)$ & $1.7(-13)$ \\
\hline $24 a$ & $1.28(-7)$ & $2.8(-12)$ & $7 \times b$ & $6.8(-9)$ & $2.5(-11)$ \\
\hline $25 a$ & $1.29(-9)$ & $1.3(-13)$ & $10 b$ & $1.31(-8)$ & $1.2(-9)$ \\
\hline $25 b$ & $7.0(-11)$ & $2.7(-15)$ & $16 a$ & $1.60(-10)$ & $2.8(-13)$ \\
\hline $6 a$ & $2.9(-9)$ & $2.2(-17)$ & $16 \times 4$ & $4.6(-10)$ & $9.7(-13)$ \\
\hline $6 \mathrm{~b}$ & $3.4(-10)$ & $2.8(-18)$ & $17 \mathrm{xb}$ & $1.88(-8)$ & $2.0(-10)$ \\
\hline
\end{tabular}

\footnotetext{
$4.8(-11)=4.8 \times 10^{-11}$.
} 
Density Effects. - It is surprising that bulk density effects upon $D^{\prime}$ are not more noticeable in Fig. 25. One would expect the less-dense fuels to have appreciably higher $D^{\prime \prime}$ s than the high-density fuels. In fact, the $75 \% \rho_{b}$ experiments indicate rather good $D^{\prime}$ performance if it were not for L3b. However, since leakage during operation and gas release measurement errors would all usually be in the direction of making the experimental performance look better than it actually is, it is not safe to make a general conclusion on just three out of four experiments.

Presumably the density effects may be removed from the $D^{\prime}$ measurements by evaluating $a$, the radius of the hypothetical equivalent sphere. Figures 27 and 28 show the variation of $D\left(T_{i}\right)$ with $1 / T_{i}$ obtained on this basis.

Rather than reduce the spread of the data, the density corrections seem to separate the $D$ into groups

characterized by the bulk density. While one would expect the characteristic $D_{0}\left(\right.$ in $D=D_{0} e^{-E / R T I}$ ) to be somewhat different for each batch of $\mathrm{UO}_{2}$ the spread in data is so great as to make one question the validity of the model. However, the precision of density measurements and the possible effects of $\mathrm{O} / \mathrm{U}$ ratio cannot be ignored. Unfortunately, most of the $\rho_{b}<90 \%$ experiments had high $\mathrm{O} / \mathrm{U}$ ratios (confused further by these samples not being outgassed prior to $O / U$ analyses). There were no experiments with $O / U<2.02$ which had $\rho_{b}<92 \%$.

The precision of measurement of the inside diameter of the LITR pellets has a marked effect upon the bulk density as obtained from weight and dimensional measurements. The fractional error in bulk density, $\left(\Delta \rho_{b} / \rho_{b}\right)$ due to an error, $\Delta d_{i}$ in., in inside diameter is $\Delta \rho_{b} / \rho_{b}=8.55 \Delta d_{i}$ on the assumption that there is no error in the outside diameter, the length, or the weight of the pellet. Thus, each mil error in inside diameter results in about $0.9 \%$ error in bulk density.

The fractional error in $D, \Delta D / D$, varies even more drastically with $\Delta d_{i}$, depending upon the ratio of bulk to immersion density, that is,

$$
\frac{\Delta D}{D}=\frac{2\left(1+\rho_{b} / \rho_{i}\right)}{1-\rho_{b} / \rho_{i}} \times 8.55 \Delta d_{i}
$$

Since $\rho_{b} / \rho_{i}$ varies from 0.77 to 0.995 for these LITR experiments, the $\Delta D / D$ varies from 13 to $680 \%$ per mil error in inside diameter. The quite high $\rho_{b} / \rho_{i}$ of 0.995 may itself be due to an error in $\Delta d_{i}$.

As an example of the drastic effects of density measurements upon the results, consider experiments L-14ab and L-15a. They are from the same basic fuel, yet the void fractions of L-15a differ markedly from L-14, probably because the immersion density of L-15a is so close to the bulk density. The $D^{\prime}$ performance of L-14ab and L-15a are about the same, as one would expect if they came from the same material. However, the differences in density characteristics result in the $D$ of L-15a being about $10^{5}$ times that of L-14ab. This certainly is not logical. It appears that the immersion density measurement of $\mathrm{L}-15$ is in error.

Most of the central holes of the LITR pellets were drilled ultrasonically. In some of the pellets the holes were not round, or the diameter was not constant throughout the length of the hole. Thus the selection of the typical diameter to use in volume calculations for bulk density required judgment, and may have resulted in error. 


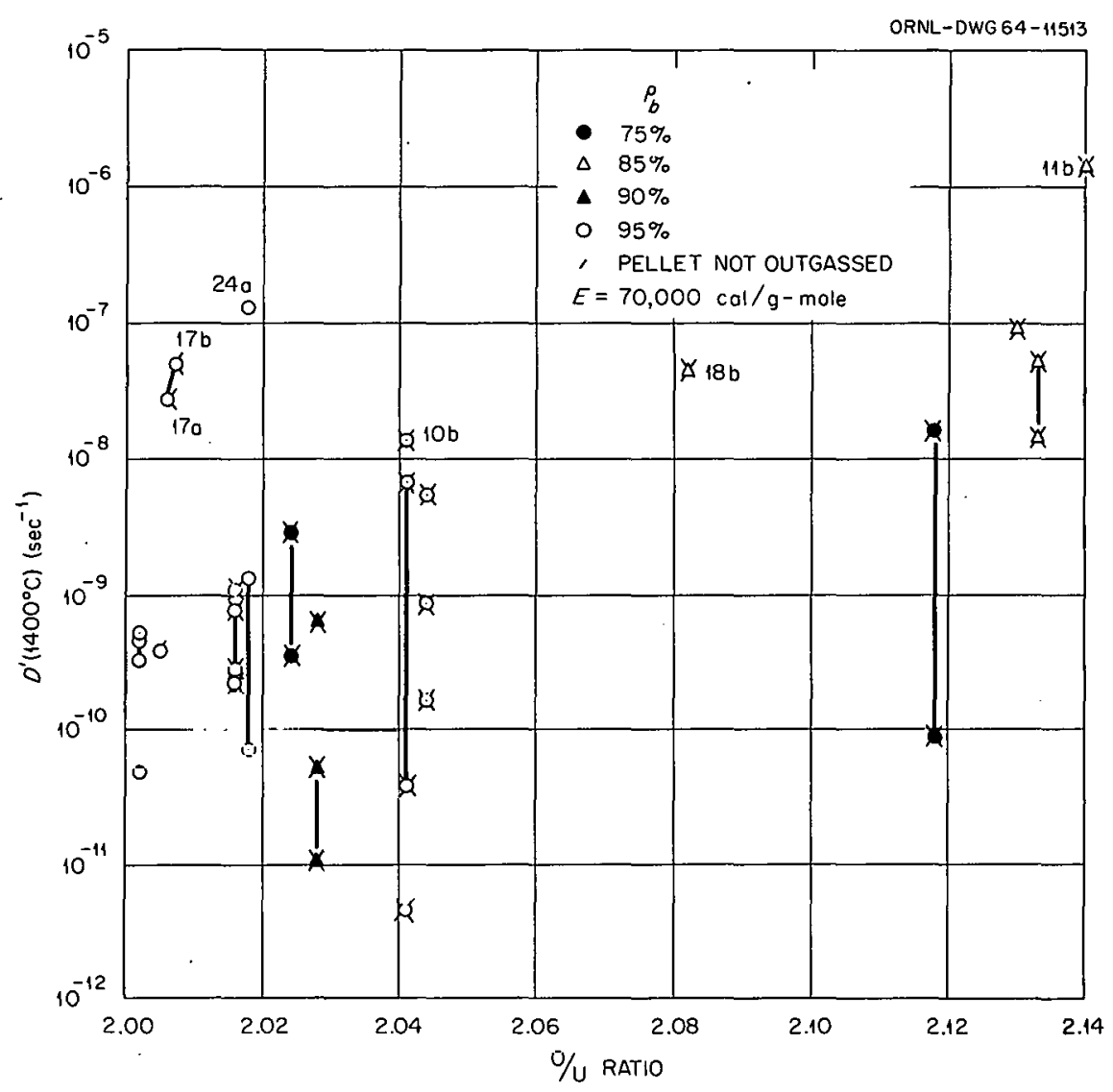

Fig. 29. ${ }^{85} \mathrm{Kr} D^{\prime}\left(1400^{\circ} \mathrm{C}\right)$ vs $\mathrm{O} / \mathrm{U}$ Ratio for LITR Experiments.

While the bulk density of $\mathrm{O} / \mathrm{U}<2.02$ experiments ranged only from 92 to $\sim 95 \%$, the $V_{c}$ ranged from about $1 \frac{1}{2}$ to $\sim 5 \%$, and the $V_{o}$ ranged from $\frac{3}{4}$ to $\sim 5 \%$. The ratio of $V_{o} / V_{c}$ ranged from 0.153 to 2.25 , so it is apparent that the detailed structure of these experiments varied considerably. A further indication of this is the range of the surface area $S_{v}\left(\mathrm{~cm}^{2} / \mathrm{cm}^{3}\right)$ and radius of equivalent sphere as listed in Table .5 .

Bulk densities obtained from immersion in a liquid.which did not wet the $\mathrm{UO}_{2}$ would eliminate the errors due to dimensional measurements. Mercury was tried, but it was found that some mercury remained inside the larger pores after the measurement had been made. Since there was no assurance that all the mercury would be removed from the pellet prior to usage, this method of measuring bulk density was abandoned (except for postirradiation measurements).

Stoichiometric Effects. - The stoichiometric effects are inconcilusive even though there is an apparent dependence of $D^{\prime}\left(1400^{\circ} \mathrm{C}\right)$ on $\mathrm{O} / \mathrm{U}$ ratio as shown in Fig. 29. This is because

(1) None of the samples from experiments with $\mathrm{O} / \mathrm{U}$ ratio $>2.02$ had been outgassed prior to analyses, whereas most of the samples with $O / U$ ratio $<2.02$ had heen outgassed. As shown previously, ${ }^{20}$ outgassing the sample prior to analysis in some cases markedly reduced the measured $O / U$ ratio. 
In order to rule out density effects, if only the $O / U$ ratio $>2.02$ experiments with 90 to $95 \%$ bulk density are compared with the $\mathrm{O} / \mathrm{U}<2.02$ experiments (all were 90 to $95 \%$ bulk density), the question arises whether these samples would not also have $O / U<2.02$ if they had been outgassed prior to analysis, for their measured $\mathrm{O} / \mathrm{U}$ ratios were 2.044 or less.

(2) The experiments with high $\mathrm{O} / \mathrm{U}$ ratio had bulk densities of $75^{-}$or $85 \%$. Thus any fission-gas release comparisons with stoichiometric fuels would also involve density effects.

The $D\left(1400^{\circ} \mathrm{C}\right)$ vs $\mathrm{O} / \mathrm{U}$ ratio, as shown in Fig. 30, indicates that factors other than $\mathrm{O} / \mathrm{U}$ ratio greatly affect $D\left(1400^{\circ} \mathrm{C}\right)$, especially at low $\mathrm{O} / \mathrm{U}$ ratios; and that the rather poor performance of the $85 \% \rho_{b}$ experiments may be due to their high $\mathrm{O} / \mathrm{U}$ ratio.

Burnup Effects. - The effect of burnup appears to be small, if any, for the range studied here. It is essentially impossible to separate the bu mup effect from other variables. The two experiments ( $\mathrm{L}-11 \mathrm{~b}$ and L-24a) having bumups greater than $17,000 \mathrm{Mwd}$ per metric ton of $\mathrm{UO}_{2}$ had rather poor fission-gas release performance. Below 17,000 Mwd per metric ton of $\mathrm{UO}_{2}$ the burnup did not seem to have as much influence upon the fission-gas release as other variables; for example, L-10b had the lowest burnup of the LITR type experiments, $1400 \mathrm{Mwd}$ per metric ton of $\mathrm{UO}_{2}$, but still its performance was very poor.

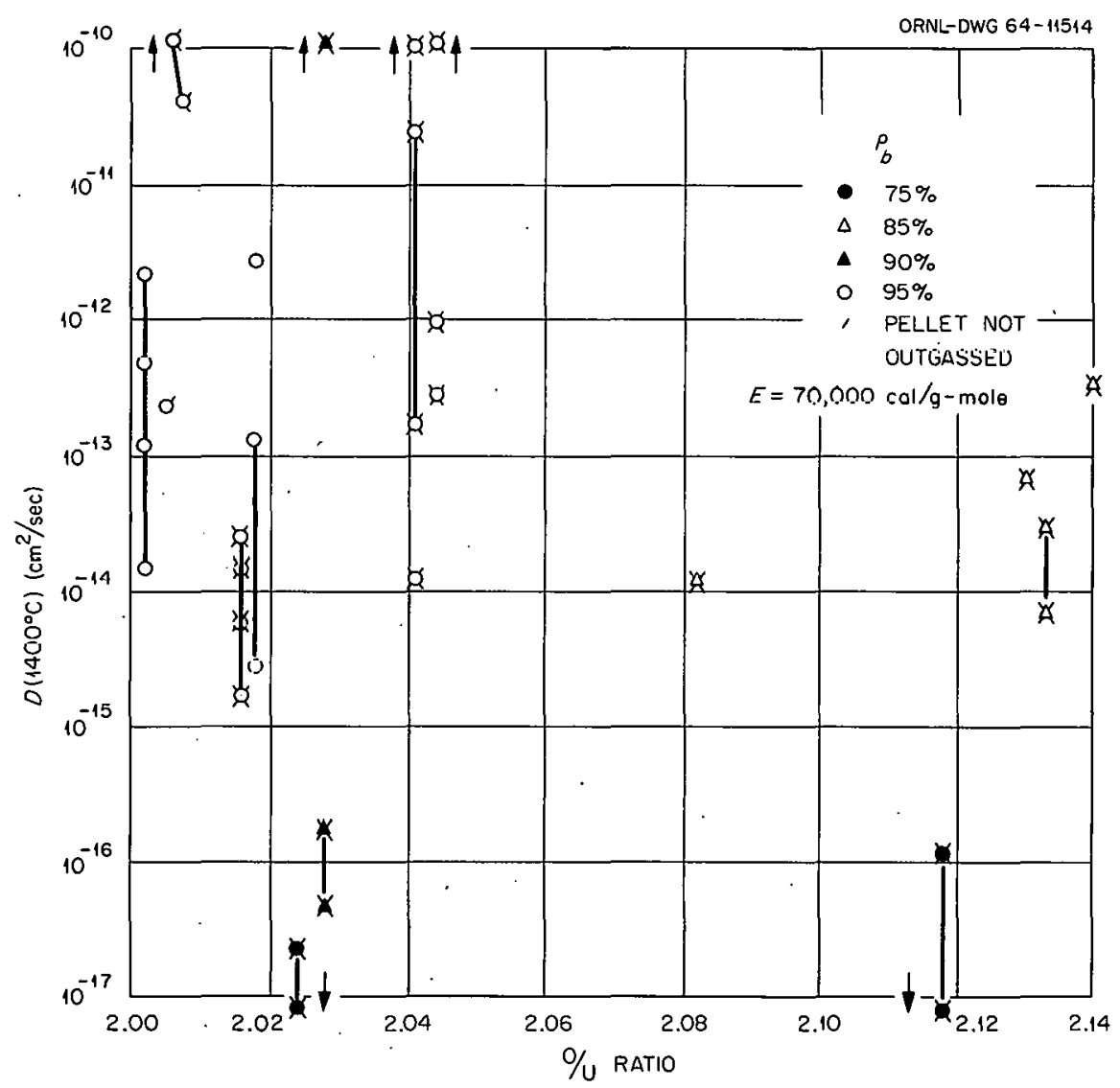

Fig. 30. ${ }^{85} \mathrm{Kr} D\left(1400^{\circ} \mathrm{C}\right)$ vs $0 / \mathrm{U}$ Ratio for LITR Experiments. 
Leak Rate. - Rough calculations indicate that of the five radioactive fission gases considered, only the ${ }^{85} \mathrm{Kr}$ release might be affected by leak rates of the order of $10^{-8} \mathrm{std} \mathrm{cc} / \mathrm{sec}$. The half-1ives of the other fission gases considered are short enough so that it is much more probable that the gas atom would undergo radioactive decay than leak from the element. Therefore, lower $D^{\prime}\left({ }^{85} \mathrm{Kr}\right)$ in comparison with $D^{\prime \prime}$ s for other isotopes would be expected as the leak rate increased. It appears that the leak rates were not great enough for this to occur.

Evidently, the leak rates did not increase sufficiently at operating temperatures (the leak rates in Tables 6 and 9 are at room temperature) to affect the performance of the element, as no correlation of performance with leak rate was found, except for possibly L-10b, which had the highest leak rate $(16 \times$ $10^{-8} \mathrm{std} \mathrm{cc} / \mathrm{sec}$ at ambient temperature) and rather poor performance.

Surface Finish. - It is believed that grinding a pellet to dimensions may open some closed pores and thus increase fission-gas release above that which would occur for a similar as-sintered pellet. The as-sintered pellets were used only in some of the $\mathrm{O} / \mathrm{U}<2.02$ experiments. While some of the ground pellets in $\mathrm{O} / \mathrm{U}<2.02$ experiments had surface areas (a measure of open porosity) greater than the assintered pellets, other ground pellets had surface areas about as low as the as-sintered pellets. It appears that grinding does not greatly affect the void volume distribution; the closed pores that are opened by grinding are negligible in comparison to the normally open pores.

Fill Gas. - All experiments that contained helium as the fill gas had as-sintered pellets for the fuel, save one experiment, L-10b, which had ground pellets. All experiments that contained argon as the fill gas had ground pellets for the fuel. Hence, any difference in performance between the two groups cannot be ascribed definitely either to the fill gas or to the surface finish. Comparing the performance of the two groups for $\mathrm{O} / \mathrm{U}<2.02$ experiments only (to eliminate possible stoichiometric effects), there does not seem to be any significant difference between the two groups.

Possible Reasons for Unusual Performance. - Below are listed possible reasons for the performance of those experiments which were not within a nominal scatter band.

1. $\mathrm{O} / \mathrm{U}<2.02$ Experiments

L-25b - From Fig. 24 it appears that $D^{\prime}\left({ }^{85} \mathrm{Kr}\right)$ is inconsistently low in comparison with $D^{\prime}\left({ }^{133} \mathrm{Xe}\right)$ and $D^{\prime}\left({ }^{135} \mathrm{Xe}\right)$ much too high. This experiment should probably be within the scatter band.

L-24a - This experiment had the greatest burnup and burnup rate of any of the experiments.

L-17ab - The eight pellets in this experiment were made from three different batches of fuel. Except for possibly the rather low $V_{o}$ in comparison to $V_{c}$, it is not apparent why this experiment had such poor performance.

\section{2. $\mathrm{O} / \mathrm{U}>2.02$ Experiments}

L-3a,6b - The fissinn-gas release from these experiments is not consistent with the release from $\mathrm{L}-3 \mathrm{~b}$ and $6 \mathrm{a}$, probably due to incomplete fission-gas recovery or to leaks during or after operation. If the releases were consistent with $\mathrm{L}-3 \mathrm{~b}$ and $6 \mathrm{a}$, they would fall within the scatter band.

L-14ab - This, along with L-15, was designed to be a $95 \%$ bulk density fuel, but after fabrication the bulk density was approximately $90 \%$. The relatively nonstringent operating conditions may contribute to the good performancc, but certainly they are not the complete answer. 
L-15a - This is the same basic fuel as L-14, but the average immersion density of the pellets is much lower than that of L-14. It appears that the immersion density measurements are in error. The ${ }^{85 \mathrm{~m}} \mathrm{Kr}$ release compared with the ${ }^{85} \mathrm{Kr}$ release was much greater for L-14ab and L-15a than for the $\mathrm{O} / \mathrm{U}$ $<2.02$ experiments.

$\mathrm{L}-7 \mathrm{~b}$ - This has about the same nonsevere operating conditions and same performance as L-14b. However, the basic fuels are quite different.

All $85 \% \rho_{b}$ Experiments - The relatively poor performance of this group as a whole appears to be due to a combination of structural $\left[V_{c} /\left(V_{c}+V_{o}\right)\right]$ and chemical (highest $O / U$ ratios) properties. It appears that some reaction between the tantalum-clad thermocouple and the fuel took place in L-11b.

L-7Xab - It appears that the ${ }^{85} \mathrm{Kr}$ release of L-7 Xa is low in comparison to its ${ }^{133} \mathrm{Xe}$ release and also in comparison to the ${ }^{85} \mathrm{Kr}$ of $\mathrm{L}-7 \mathrm{Xb}$. This experiment had rather high burnup and burnup rate with unusually low $V_{o}$ in comparison to $V_{c}$.

L-10b - This experiment had the highest preirradiation leak rate of any measured, and was the only $\mathrm{O} / \mathrm{U}>2.02$ experiment to be filled with helium (the others were filled with argon). Only L-15a had smaller $V_{o}$. This results in a large value for $V_{c} /\left(V_{c}+V_{o}\right)$. The operating conditions were not severe. Very fine crystal-like particles were detected on the fuel during postirradiation examinations.

L-17Xab - The operating temperatures were rather high. This experiment also had an unusually low $V_{o}$ in comparison to $V_{c}$.

It also appears that the activation energy for fission-gas diffusion in the $O / U>2.02$ experiments may be greater than the assumed value of $70,000 \mathrm{cal} / \mathrm{g}$-mole.

\subsection{Results for EGCR Prototype Experiments}

Table 12 lists the items believed pertinent to the fuel characterization for the EGCR prototype experiments. The values listed for the various analyses are the best values as established by $R$. M. Evans ${ }^{19}$ from those listed earlier. ${ }^{20}$

The preirradiation calculated radius of equivalent sphere was obtained from the measured surface area. Figure 31 is a plot of the preirradiation measured surface area vs the open void fraction. The calculated curve $S_{v}=50\left(V_{o} \%\right)^{2}$ is also drawn in Fig. 31 for comparison. The postirradiation calculated radius of the equivalent sphere was obtained on the assumption that $S_{v}\left(\mathrm{~cm}^{2} / \mathrm{cm}^{3}\right)=50\left(V_{o} \%\right)^{2}$ was applicable to irradiated $\mathrm{UO}_{2}$. The postirradiated values of $V_{0}$ used in these calculations were obtained from postitradiation bulk density measurements made by immersion in mercury, and carbon tetrachloride immersion density measurements on a single pellet from each element. In some of the group 1 experiments the two measurements were not made on the same pellet. In these cases $V_{o}$ was calculated as though the density measurements were made on the same pellet.

The fission-gas release was analyzed using the same theory as developed for the LITR experiments. Since only the outside surface element sheath temperatures were measured, the inside surface (or center line) and outside surface temperatures had to be calculated. These were calculated from the average 
Table 12. Fuel Characterization for EGCR Prototype Fuel Elements

\begin{tabular}{|c|c|c|c|c|c|c|c|c|c|c|c|c|c|c|c|}
\hline \multirow{2}{*}{$\begin{array}{l}\text { Element } \\
\text { No. }\end{array}$} & \multirow{2}{*}{$\begin{array}{c}\text { Pellet } \\
\text { Geometry }\end{array}$} & \multirow{2}{*}{$\begin{array}{l}\text { Oxygen- } \\
\text { to- } \\
\text { Uranium } \\
\text { Ratio }^{b}\end{array}$} & \multicolumn{2}{|c|}{$\begin{array}{l}\text { Preirradiation Density } \\
\text { (\% of theoretical) }\end{array}$} & \multicolumn{2}{|c|}{ Void Fractions } & \multirow{2}{*}{$\begin{array}{c}\text { BET } \\
\text { Surface } \\
\text { Area, }{ }^{c} \\
\text { Measured } \\
S_{\&}\left(\mathrm{~cm}^{2} / g\right)\end{array}$} & \multicolumn{2}{|c|}{$\begin{array}{l}\text { Calculated Radius of } \\
\text { Equivalent Sphere }(\mathrm{cm})\end{array}$} & \multicolumn{4}{|c|}{ Major Impurity Content (ppm) } & \multirow{2}{*}{$\begin{array}{c}\text {-Pellet } \\
\text { Sintering } \\
\text { Atmosphere }\end{array}$} & \multirow{2}{*}{$\begin{array}{l}\text { Major } \\
\text { Fill } \\
\text { Gas }\end{array}$} \\
\hline & & & Bulk, $d_{b}$ & $\frac{\text { eoretical) }}{\text { Immersion, } d_{i}}$ & $\begin{array}{l}\text { Closed, } \\
V_{c}(\%)\end{array}$ & $\begin{array}{l}\text { Open, } \\
V_{0}(\%)\end{array}$ & & $\begin{array}{l}\text { Preirradiation, } \\
\qquad a=\frac{3}{\rho_{i} S_{s}}\end{array}$ & $\begin{array}{l}\text { Postirradiation, } \\
\qquad a=\frac{3 \rho_{b}}{S_{v} \rho_{i}}\end{array}$ & Carbon & Nitrogen & Fluorine & Iron & & \\
\hline $01-1$ & $\mathrm{H}$ & 2.007 & 94.77 & 97.35 & 2.60 & 2.63 & $33.8 \mathrm{G}$ & $8.32(-3)^{d}$ & $1.85(-3)$ & 100 & 760 & 390 & 87 & $\mathrm{~N}_{2}: \mathrm{H}_{2}$ & $\mathrm{Ar}$ \\
\hline O2-1 & $\mathrm{H}$ & 2.017 & 94.27 & 97.94 & 1.98 & 3.75 & $80.7 \mathrm{As}$ & $3.56(-3)$ & $2.45(-3)$ & 30 & 1900 & 206 & 130 & $\mathrm{~N}_{2}: \mathrm{H}_{2}$ & $\mathrm{He}$ \\
\hline O3-1 & $\mathbf{H}$ & 2.007 & 94.91 & 97.38 & 2.55 & 2.54 & $33.8 \mathrm{G}$ & $8.32(-3)$ & $3.27(-3)$ & 100 & 760 & 390 & 87 & $\mathrm{~N}_{2}: \mathrm{H}_{2}$ & $\mathrm{He}$ \\
\hline O4-1 & H-B & 2.007 & 94.73 & 97.43 & 2.50 & 2.77 & $33.8 \mathrm{G}$ & $8.31(-3)$ & & 100 & 760 & 390 & 87 & $\mathrm{~N}_{2}: \mathrm{H}_{2}$ & \\
\hline O5-1 & $\mathrm{H}$ & 2.017 & 94.23 & 98.08 & 1.84 & 3.93 & $80.7 \mathrm{As}$ & $3.56(-3)$ & $1.62(-3)$ & 30 & 1900 & 206 & 130 & $\mathrm{~N}_{2}: \mathrm{H}_{2}$ & $\mathrm{He}$ \\
\hline $06-1$ & $\mathrm{H}-\mathrm{B}$ & 2.017 & 94.18 & 98.27 & 1.65 & 4.17 & $8.07 \mathrm{As}$ & $3.45(-3)$ & & 30 & 1900 & 206 & 130 & $\mathrm{~N}_{2}: \mathrm{H}_{2}$ & \\
\hline $07-1$ & s & 2.004 & 96.09 & 96.83 & 3.15 & 0.76 & $8.78 \mathrm{G}$ & $3.22(-2)$ & & 100 & 743 & 109 & 395 & $\mathrm{H}_{2}$ & \\
\hline O8-1 & s & 2.004 & 95.31 & 96.23 & 3.73 & 0.96 & $8.78 \mathrm{G}$ & $3.24(-2)$ & & 100 & 743 & 109 & 395 & $\mathrm{H}_{2}$ & \\
\hline $01-2$ & $\mathrm{H}$ & 2.004 & 95.73 & 97.97 & 1.98 & 2.29 & $23.65 \mathrm{As}$ & $1.18(-2)$ & $5.20(-3)$ & 105 & 7 & $<10$ & 70 & $\mathrm{H}_{2}$ & $\mathrm{He}$ \\
\hline $\mathrm{O} 2-2$ & $\mathrm{H}$ & 2.004 & 95.85 & 97.80 & 2.15 & 2.00 & $23.65 \mathrm{As}$ & $1.18(-2)$ & $1.01(-2)$ & 105 & 7 & $<10$ & 70 & $\mathrm{H}_{2}$ & $\mathrm{He}$ \\
\hline O3-2 & $\mathbf{H}$ & 2.001 & 94.33 & 97.73 & 2.20 & 3.47 & $40.6 \mathrm{As}$ & $6.90(-3)$ & $3.14(-3)$ & 91 & 14 & $<15$ & 115 & $\mathrm{H}_{2}$ & $\mathrm{He}$ \\
\hline O4-2 & $\mathrm{H}-\mathrm{B}$ & 2.002 & 94.42 & 97.83 & 2.09 & 3.49 & $41.9 \mathrm{As}$ & $6.68(-3)$ & & 57 & 10 & $<10$ & 125 & $\mathrm{H}_{2}$ & $\mathrm{~N}_{2}+\mathrm{O}_{2}$ \\
\hline $05-2$ & $\mathrm{H}$ & 2.001 & 94.91 & 97.35 & 2.59 & 2.50 & $34.3 \mathrm{G}$ & $8.20(-3)$ & $1.26(-3)$ & 156 & 7 & $<10$ & 49 & $\mathrm{H}_{2}$ & $\mathrm{He}+\mathrm{N}_{2}$ \\
\hline O6-2 & $\mathrm{H}-\mathrm{B}$ & 2.003 & 94.37 & 98.29 & 1.64 & 3.99 & $40.0 \mathrm{G}$ & $6.96(-3)$ & & 56 & 6 & $<10$ & 117 & $\mathrm{H}_{2}$ & \\
\hline $07-2$ & $\mathbf{s}$ & 2.004 & 95.30 & 97.13 & 2.82 & 1.88 & $18.4 \mathrm{As}$ & $1.53(-2)$ & $3.06(-3)$ & 49 & $<5$ & $<10$ & 122 & $\mathrm{H}_{2}$ & $\mathrm{~N}_{2}+\mathrm{He}$ \\
\hline $08-2$ & s & 2.004 & 95.53 & 98.26 & 1.69 & 2.78 & $39.8 \mathrm{As}$ & $7.00(-3)$ & $3.03(-3)$ & 87 & 10 & $<10$ & 100 & $\mathrm{H}_{2}$ & $\mathrm{~N}_{2}+\mathrm{He}$ \\
\hline
\end{tabular}

${ }^{a_{H}}=$ hollow pellet; $\mathrm{H}-\mathrm{B}=$ hollow pellet with BeO rod in void; $\mathrm{S}=$ solid pellet.

${ }^{b} A 11$ samples outgassed prior to analysis.

${ }^{\mathrm{C}}$ Pellet surface: As $=$ as sintered; $G=$ ground.

$d_{8.32(-3)}=8.32 \times 10^{-3}$. 


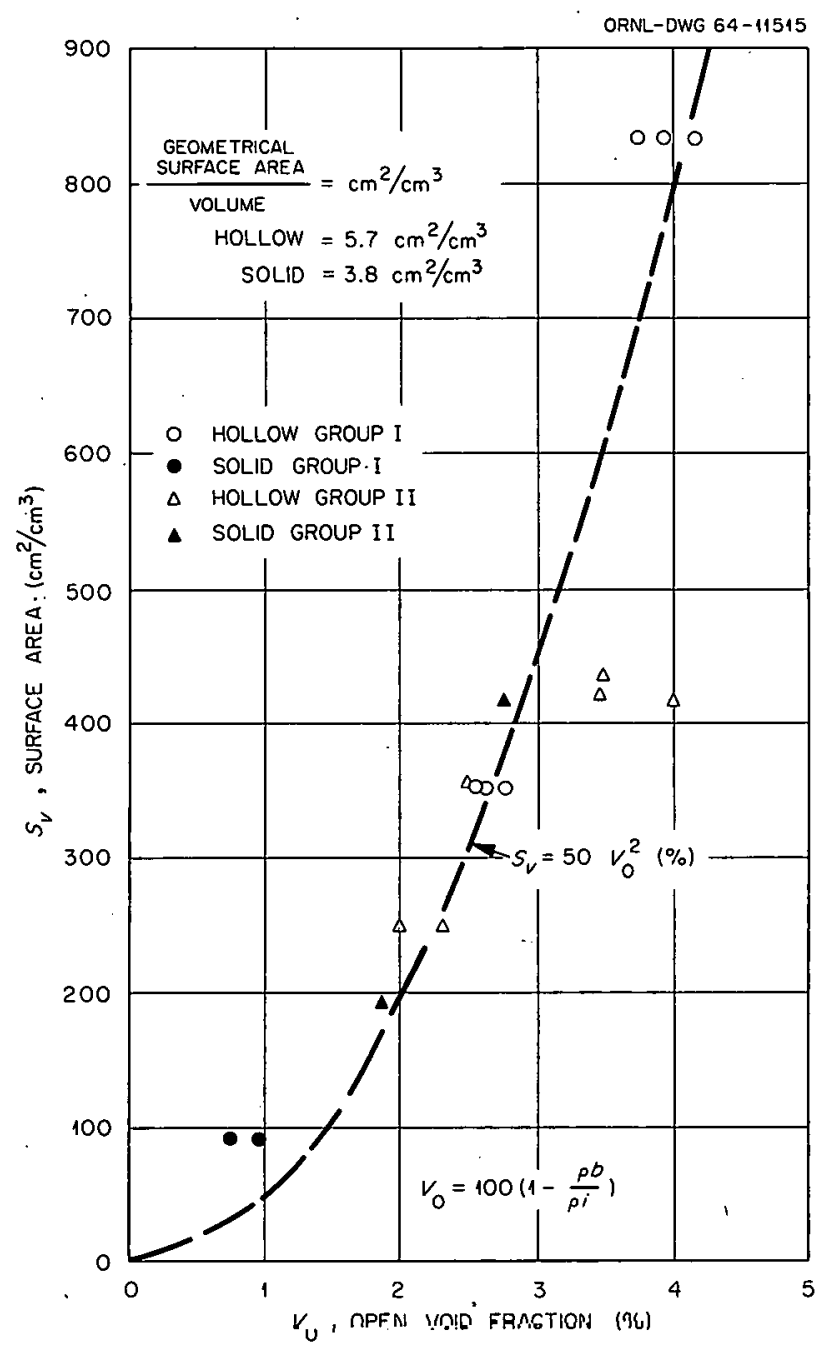

Fig. 31. Surface Area vs Open Void Fraction of ORR Pellets (Preirradiated).

burnup rates using the integral $k(\theta) d \theta$ values ${ }^{22}$ of the corrected Hedge and Fieldhouse data. However, the burnup as determined by neutron-flux measurements, by ${ }^{235} \mathrm{U}$ to ${ }^{236} \mathrm{U}$ isotopic ratios, and by fission product ${ }^{137} \mathrm{Cs}$ and ${ }^{144} \mathrm{Ce}$ measurements (see Table 13) differed considerably. Two sets of operating temperature and fission-yas release were calculated, one for burnup rate obtained from neutron flux monitor measurements, the second from ${ }^{144} \mathrm{Ce}$ fission product measurements. These are listed in Tables 14 and 15 respectively.

The low results for element 5-2 may be due to the element leaking. The mass spectrogram of the fill gas (Table 1) indicates roughly $20 \% \mathrm{~N}_{2}$ (or CO) to be present. The mass spectrogram of the fill gas for element 5-1 does not indicate a leak.

${ }^{22}$ J. A. L. Robertson, $\int k d \theta$ in Fuel Irradiations, CRFD-835 (April 1959). 
The apparently low gas release of the solid pellet elements 7-2 and 8-2 may be because the elements might have leaked after irradiation but prior to fission-gas sampling. The postirradiation mass spectrographic analyses of the fill gas indicate over $80 \%$ nitrogen present. Of course some, or all, of this nitrogen may have been present from the beginning of irradiation.

It appears from the $D^{\prime}$ measurements that the group 2 fuels were slightly better in performance than the group 1 fuels.

- The $D\left(=a^{2} D^{\prime}\right)$ results for the ORR experiments are about the same as some of the better LITR experiments. The postirradiated $a$ is often quite a bit smaller than the preirradiated a, so the $D$ was calculated using both the preirradiated and the postirradiated a. A $D$ based on preirradiation density measurements would be characteristic of initial performance, while the $D$ based on postirradiation density measurements would be characteristic of performance near the end of irradiation.

\subsubsection{Pressure Buildup Effects of Volatile Fission Products}

The high mobility, low boiling points (below $\left.1275^{\circ} \mathrm{F}\right)$, and relatively high fission yields $(62 \%$ of that of krypton and xenon) of the fission product alkali metals, cesium and rubidium, could result in a significant contribution to the intemal pressure of a fuel element operating at high temperatures. Figure 19

Table 13. Comparison of Burnup Data for EGCR Prototype Fuel Elements

\begin{tabular}{|c|c|c|c|c|}
\hline \multirow{2}{*}{$\begin{array}{c}\text { Element } \\
\text { No. }\end{array}$} & \multicolumn{4}{|c|}{ Burnup (Mwd per metric ton of $\mathrm{UO}_{2}$ ) } \\
\hline & $\begin{array}{c}\text { Flux } \\
\text { Monitor }\end{array}$ & ${ }^{137} \mathrm{Cs}$ & ${ }^{144} \mathrm{Ce}$ & ${ }^{235} \mathrm{U} /{ }^{236} \mathrm{U}$ \\
\hline $01-1$ & 1000 & & 1510 & 1660 \\
\hline $\mathrm{O} 2-1$ & 1100 & & 1600 & 1560 \\
\hline O3-1 & 900 & & 1350 & 1940 \\
\hline O4-1 & 1400 & 1550 & 1510 & \\
\hline O5-1 & 1900 & & 2380 & 2330 \\
\hline O6-1 & 1100 & & & 1740 \\
\hline $07: 1$ & 550 & 680 & 650 & \\
\hline O8-1 & 550 & 680 & 630 & \\
\hline $01-2$ & 1400 & & 1470 & \\
\hline $\mathrm{O} 2-2$ & 1400 & & 1230 & \\
\hline $03-2$ & 1400 & & 12.90 & \\
\hline O4-2 & 1700 & & 1480 & \\
\hline $05-2$ & 2200 & & 2200 & \\
\hline $06-2$ & 1500 & & 1490 & \\
\hline $07-2$ & 1000 & & 1150 & \\
\hline O8-2 & 900 & & 980 & \\
\hline
\end{tabular}


Table 14. EGCR Prototype Fuel Element Operating Conditions and Fission-Gas Release (Based on ${ }^{144} \mathrm{Ce}$ Burnup)

\begin{tabular}{|c|c|c|c|c|c|c|c|c|c|c|c|c|c|c|c|c|}
\hline \multirow[b]{2}{*}{$\begin{array}{l}\text { Element } \\
\text { No. }\end{array}$} & \multirow{2}{*}{$\begin{array}{c}\text { Effective } \\
\text { Therma1 } \\
\text { Neutron Flux } \\
\text { (neutrons } \mathrm{cm}^{-2} \sec ^{-1} \text { ) }\end{array}$} & \multirow{2}{*}{$\begin{array}{l}\text { No. of } \\
\text { Thermal } \\
\text { Cycles } \\
>200^{\circ} \mathrm{F}\end{array}$} & \multirow{2}{*}{$\begin{array}{c}\text { Average: } \\
\text { Cladd ing oD } \\
\text { Temperature } \\
\quad\left({ }^{\circ} \mathrm{F}\right)\end{array}$} & \multirow{2}{*}{$\begin{array}{c}\text { Calculated } \\
\text { Average } \\
\text { Pellet OD } \\
\text { Temperature, } \\
T_{s} \\
\left(^{\circ} \mathrm{C}\right)\end{array}$} & \multirow{2}{*}{$\begin{array}{c}{ }^{85} \mathrm{Kr} \\
\text { Reiease } \\
\quad \%\end{array}$} & \multirow{2}{*}{$\begin{array}{l}\left.\bar{D}^{\prime} \cdot{ }^{85} \mathrm{Kr}\right) \\
\text { Whole- } \\
\text { Element } \\
\left(\sec ^{-1}\right)\end{array}$} & \multicolumn{2}{|c|}{ Burnup (from ${ }^{144} \mathrm{Ce}$ ) } & \multirow{2}{*}{$\begin{array}{c}\int_{T_{s}}^{T_{i}} k(\theta) d \theta \\
(w / \mathrm{cm})\end{array}$} & \multirow{2}{*}{$\begin{array}{c}\text { Pellet D } \\
\text { (or Center-Line) } \\
\text { Temperature, } \\
T_{i} \\
\left({ }^{\circ} \mathrm{C}\right)\end{array}$} & \multirow[b]{2}{*}{$\begin{array}{c}\Delta T=T_{i}-T_{s} \\
\quad\left({ }^{\circ} \mathrm{C}\right)\end{array}$} & \multirow{2}{*}{$\begin{array}{c}\frac{1}{r_{i}} \\
\left({ }^{\circ} K^{-1}\right)\end{array}$} & \multirow{2}{*}{$\frac{D_{0}^{\prime} \mathrm{e}^{-E / R T_{i}}}{E / 2 R} \frac{\left(\mathrm{sec}^{-1 \mathrm{o}_{\mathrm{K}}-1}\right)}{}$} & \multirow{2}{*}{$\frac{\frac{D_{0} \mathrm{e}^{-E / R T_{i}}}{E / 2 R}}{\frac{E}{\text { Preirradiation }}}=$} & \multirow{2}{*}{ 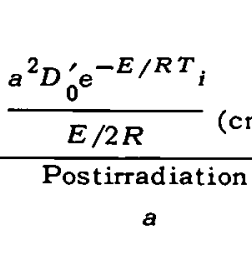 } & \multirow{2}{*}{$\frac{\left.{ }^{2} \sec ^{-1} o_{K^{-1}}\right)}{\text { Geometric Av }}$} \\
\hline & & & & & & & $\begin{array}{c}\text { Total } \\
\text { (Mwd per metric } \\
\text { ton of } \mathrm{UO}_{2} \text { ) }\end{array}$ & $\begin{array}{l}\text { Rate }^{b} \\
(w / g)\end{array}$ & & & & & & & & \\
\hline & $\times 10^{12}$ & & & & & & & & & & & $\times 10^{-4}$ & & & & \\
\hline O1-1 & 4.1 & 135 & 1320 & 739 & 0.68 & $7.2(-13)^{\mathrm{c}}$ & 1510 & 10.8 & 10.45 & 1130 & 391 & 7.12 & $5.83(-16)$ & $4.04(-20)$ & $2.00(-21)$ & $8.96(-21)$ \\
\hline $02-1$ & 4.4 & 229 & 1510 & 844 & 1.6 & $4.2(-12)$ & 1600 & 11.4 & 10.95 & 1300 & 456 & 6.36 & $3.16(-15)$ & 4. $02(-20)$ & $1.90(-20)$ & $2.76(-20)$ \\
\hline 03-1 & 3.7 & 255 & 1300 & 724 & 0.74 & $8.6(-13)$ & 1350 & 9.7 & 9.39 & 1058 & 334 & 7.52 & $6.62(-16)$ & $4.58(-20)$ & $7.08(-21)$ & $1.80(-20)$ \\
\hline C4-1, & 5.8 & 192 & 13201 & & & & 1510 & 10.8 & 10.34 & & & & & & & \\
\hline $05-1$ & $7: 5$ & 357 & 1450 & 825 & 1.6 & $4.2(-12)$ & 2380 & 16.7 & 16.0 & 1535 & 710 & 5.53 & $3.73(-15)$ & $4.73(-20)$ & $9.80(-21)$ & $2.15(-20)$ \\
\hline $06-1$ & 4.6 & 330 & 1480 & & & & $1740^{d}$ & 12.3 & & & & & & & & \\
\hline SO $7-1^{e}$ & 4.3 & $299^{\circ}$ & 1250 & & & & 650 & 1.9 & & & & & & & & \\
\hline so8-1 & 4.1 & 287 & 1500 & & & & 630 & 4.7 & & & & & & & & \\
\hline $01 \cdot 2$ & 3.6 & 109 & 1310 & 740 & 0.39 & $2.18(-13)$ & 1470 & 10.5 & 10.25 & 1120 & 380 & 7.18 & $1.74(-16)$ & $2.43(-20)$ & $4.72(-21)$ & $1.07(-20)$ \\
\hline $02-2$ & 3.6 & 116 & 1460 & 823 & 0.48 & $3.44(-13)$ & 1230 & 8.9 & 8.69 & 1165 & 342 & 6.95 & $2.33(-16)$ & $3.25(-2.0)$ & $2.35(-20)$ & $2.77(-20)$ \\
\hline O3-2 & 3.6 & 269 & 1320 & 742 & 0.64 & $6.42(-13)$ & 1290 & 9.3 & 8.96 & 1070 & 328 & $7: 44$ & $4.77(-16)$ & $2.27(-20)$ & $4.70(-21)$ & $1.03(-20)$ \\
\hline $04-2$ & 4.5 & 258 & 1.320 & & & & 1400 & $10.0^{\circ}$ & & & & & & & & \\
\hline $05-2$ & 7.9 & 225 & 1480 & 845 & 1.3 & $2.78(-12)$ & 2200 & 15.6 & 15.09 & 1520 & 675 & 5.58 & $2.385(-15)$ & $1.60(-19)$ & $3.79(-21)$ & $2.46(-20)$ \\
\hline O6-2 & 4.1 & 196 & 1490 & 840 & 0.84 & $1.14(-12)$ & 1490 & 10.7 & 10.29 & 1265 & 425 & 6.50 & $8.37(-16)$ & $4.05(-20)$ & & \\
\hline SO7-2 & 2.3 & 165 & 1290 & 726 & 0.33 & $1.56(-13)$ & 1150 & 8.3 & 17.43 & 1455 & 729 & 5.79 & $1.64(-16)^{f}$ & $3.84(-2.0)^{b}$ & $1,54(-2.1)^{f}$ & $7.70(-21)^{f}$ \\
\hline sO8.2 & 2.2 & 195 & 1490 & 830 & 0.21 & $6.59(-14)$ & 980 & 7.2 & 15.20 & 1510 & 680 & 5.61 & $5.58(-17)^{f}$ & $2.14(-21){ }^{f}$ & $5.14(-22)^{t}$ & $1.19(-21)^{f}$ \\
\hline
\end{tabular}

${ }^{a}$ Based on measured burnup by ${ }^{144} \mathrm{Ce},{ }^{85} \mathrm{Kr}$ fission yield of $0.3 \%$, and ${ }^{85} \mathrm{Kr} \rightarrow{ }^{85} \mathrm{Rb}$ gamma branching ratio of $0.37 \%$.

${ }^{b}$ Includes $0.37 \mathrm{w} / \mathrm{g}$ gamma heating; the elements were at power approximately 145 days.

$7.2(-13)=7.2 \times 10^{-13}$.

From $=$ solid pellets.

I On basis $E=70,000$ cal $/$ mole 
Table 15. EGCR Prototype Fuel Element Operating Conditions and Fission-Gas Release (Based on Flux Monitor Burnup)

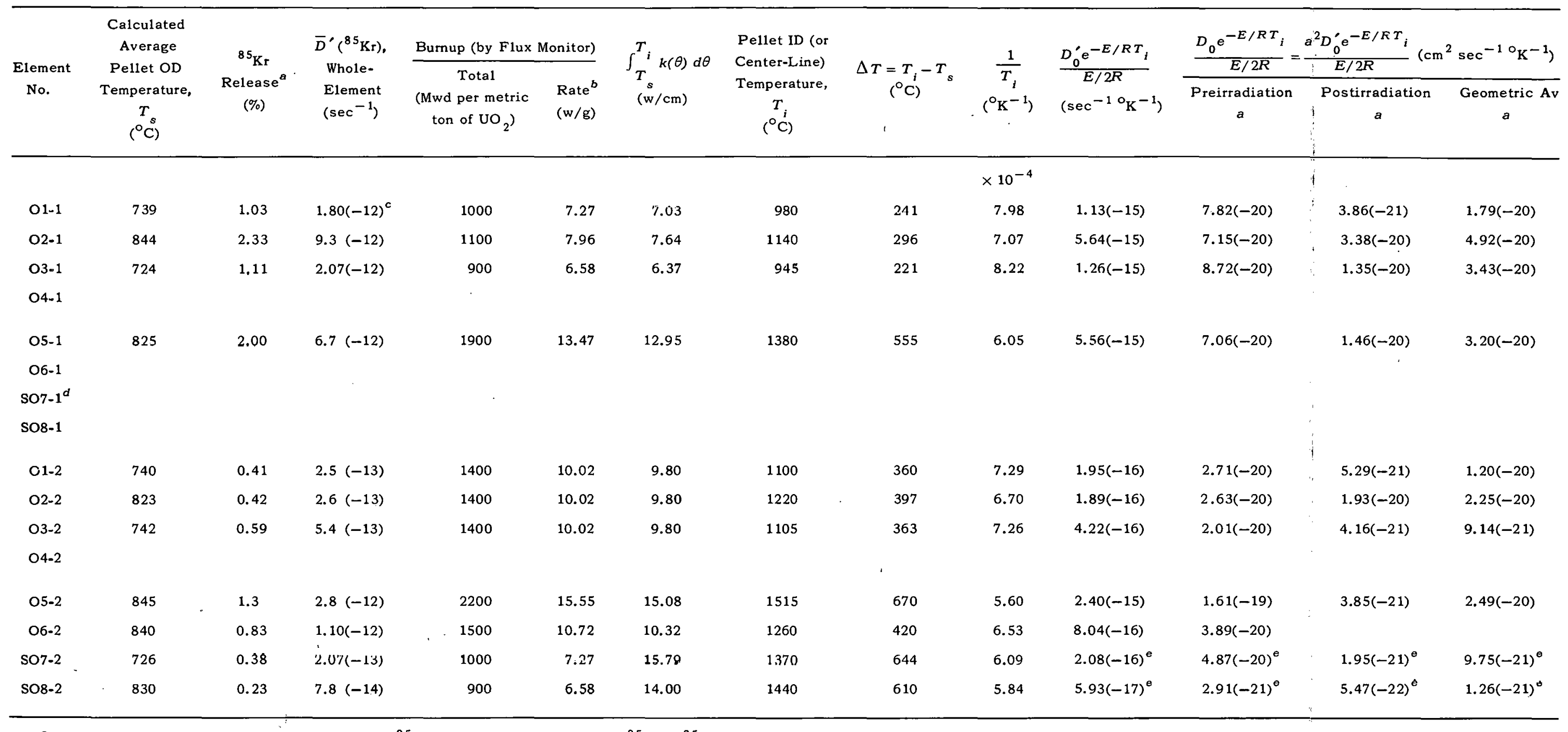

${ }^{a}$ Based on burnup calculated frồm flux monitors, ${ }^{85} \mathrm{Kr}$ fission yield of $0,3 \%$, and ${ }^{85} \mathrm{Kr} \rightarrow{ }^{85} \mathrm{Rb}$ gamma branching ratio of $0.37 \%$.

${ }^{b}$ Includes $0.37 \mathrm{w} / \mathrm{g}$ gamma heating; the elements were at power approximately 145 days.

${ }^{c} 1.80(-12)=1.80 \times 10^{-12}$.

us $=$ solid pellets.

${ }^{\circ}$ On basis $E=70,000 \mathrm{cal} / \mathrm{mole}$. 
illustrates the apparatus used for high-temperature measurements of the pressure of the gas inside a prototype fuel element after irradiation. Figures 32-35 are the results of measurements on four elements. The accuracy of measurement is $\pm 15 \mathrm{~mm} \mathrm{Hg}$ at $1700^{\circ} \mathrm{F}$.

Since the slope of the pressure-temperature curves did not change above $1250^{\circ} \mathrm{F}$ - the approximate boiling point of rubidium and cesium - it appears that metallic fission product rubidium and cesium do not contribute significantly to the pressure inside the elements at temperatures up to $1700^{\circ} \mathrm{F}$. The vapor pressure of metallic cesium is 46 psia and that of rubidium is 52 psia. In any event, the lowest temperature inside a normally operating EGCR fuel element should be below $1250^{\circ} \mathrm{F}$, and thus the vapor pressures of any metallic rubidium and cesium present would be less than $1 \mathrm{~atm}$.

The pressures indicated in Figs. 32-35 are for the gas inside an element expanded into a volume totaling that of the free space in the element plus the "dead" volume of the pressure measuring device. The data as presented are the pressures for the total volume and are not what one would expect inside the fuel element at these temperatures. However, an estimate of the actual operating pressures at elevated temperatures may be made on the basis that the pressure of the fuel element fill gas is approximately $1 \mathrm{~atm}$ at normal ambient temperature as based on calculations from data in Tables 1 and 16 for the group 2 elements.

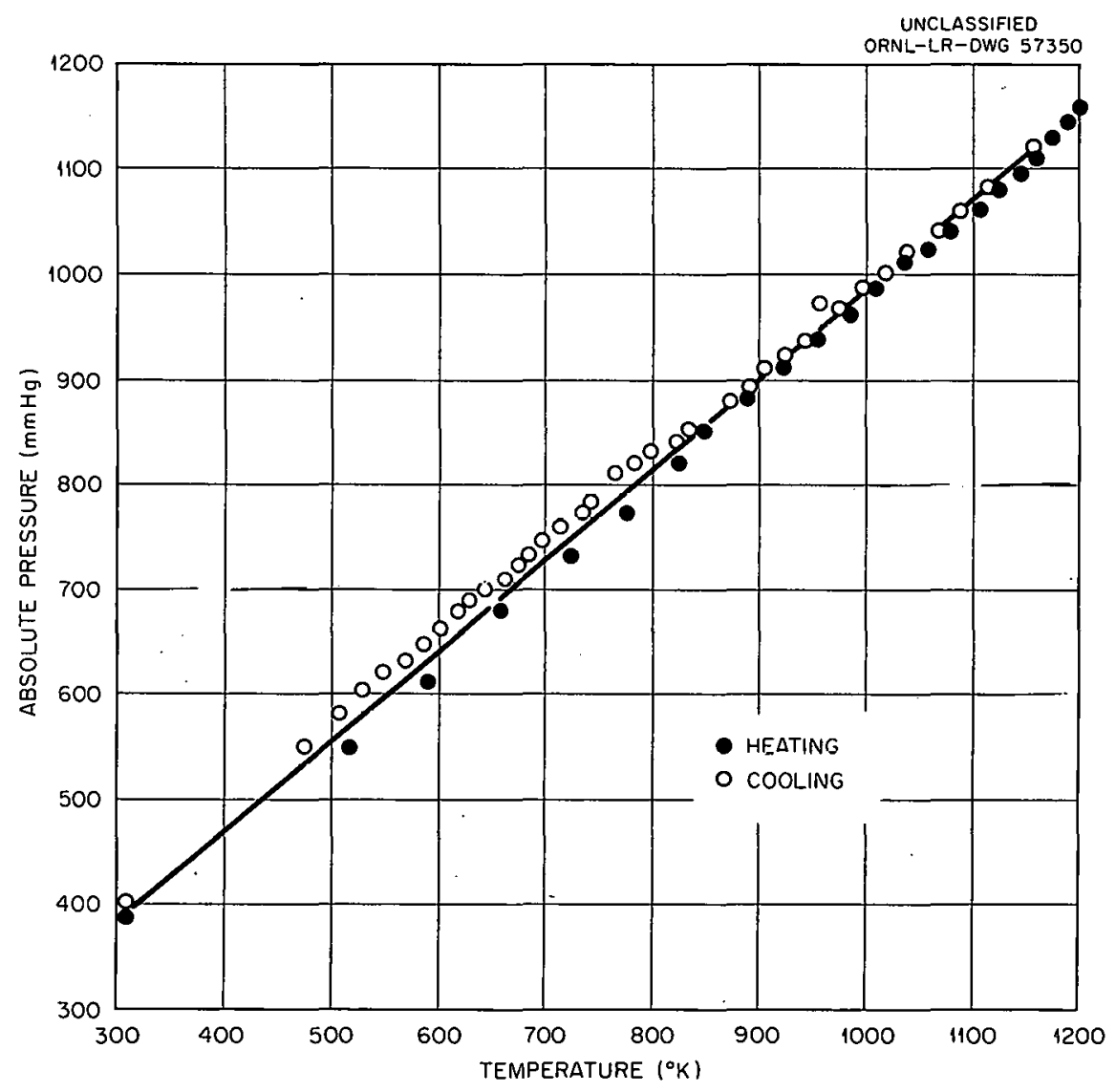

Fig. 32. Postirradiation Measurement of Fission-Gas Pressure in ORR Capsule O4-1. 


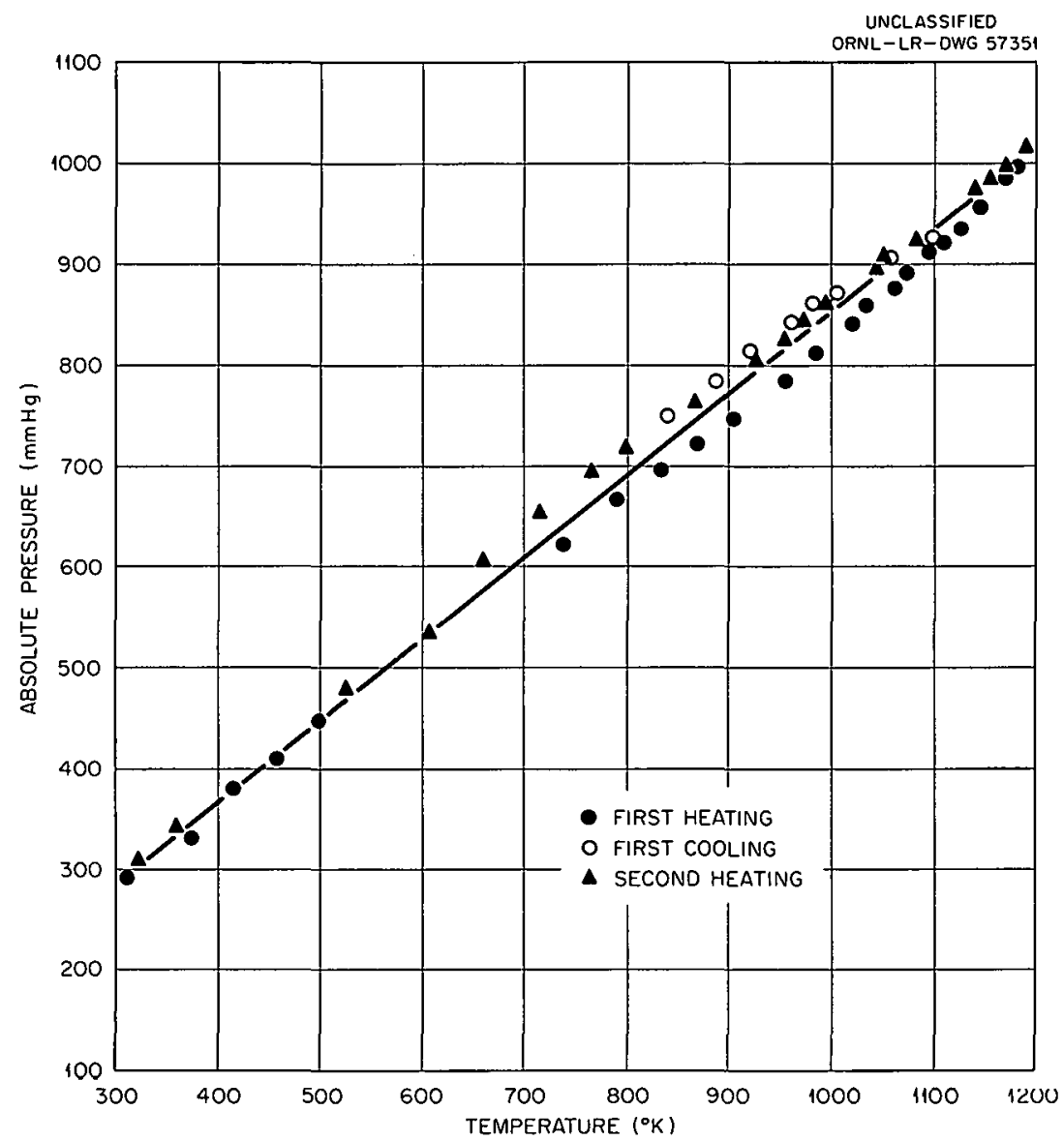

Fig. 33. Postirradiation Measurement of Fission-Gas Pressure in ORR Capsule O6-1.

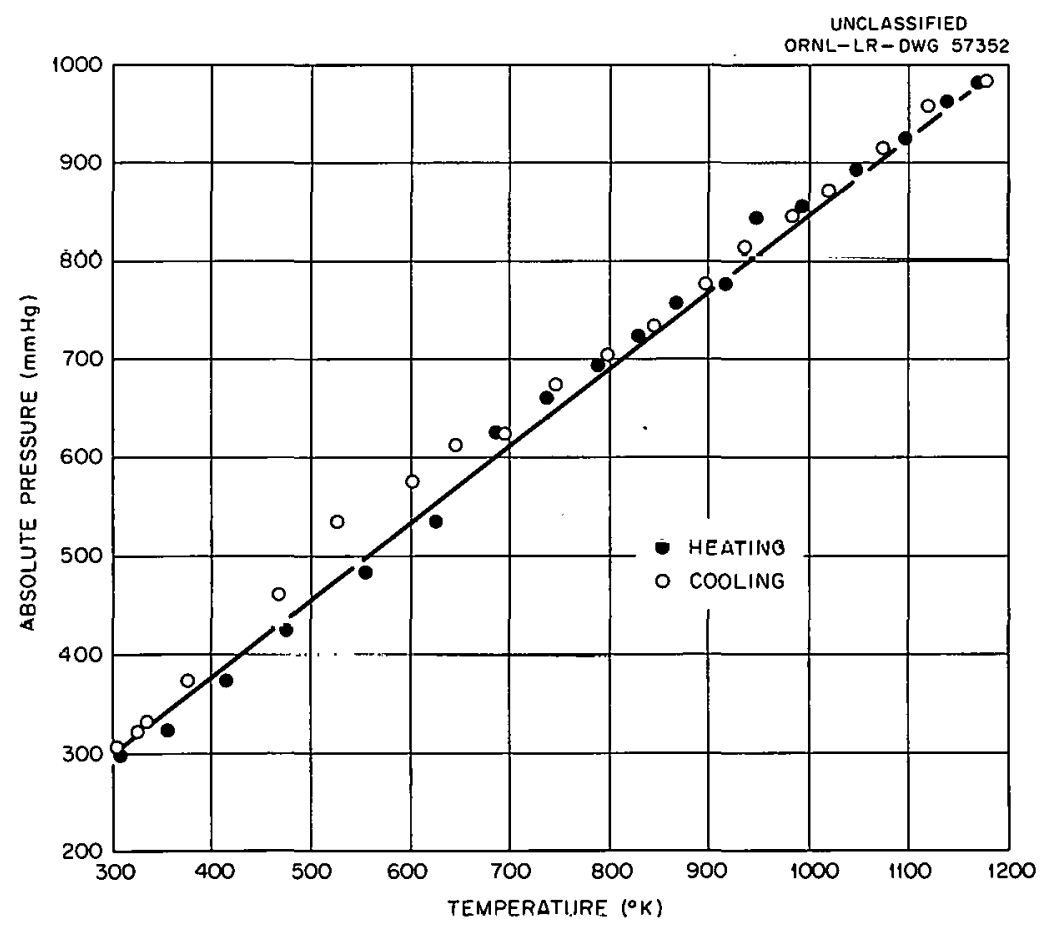

Fig. 34. Postirradiation Measurement of Fission-Gas Pressure in ORR Capsule 07-1. 


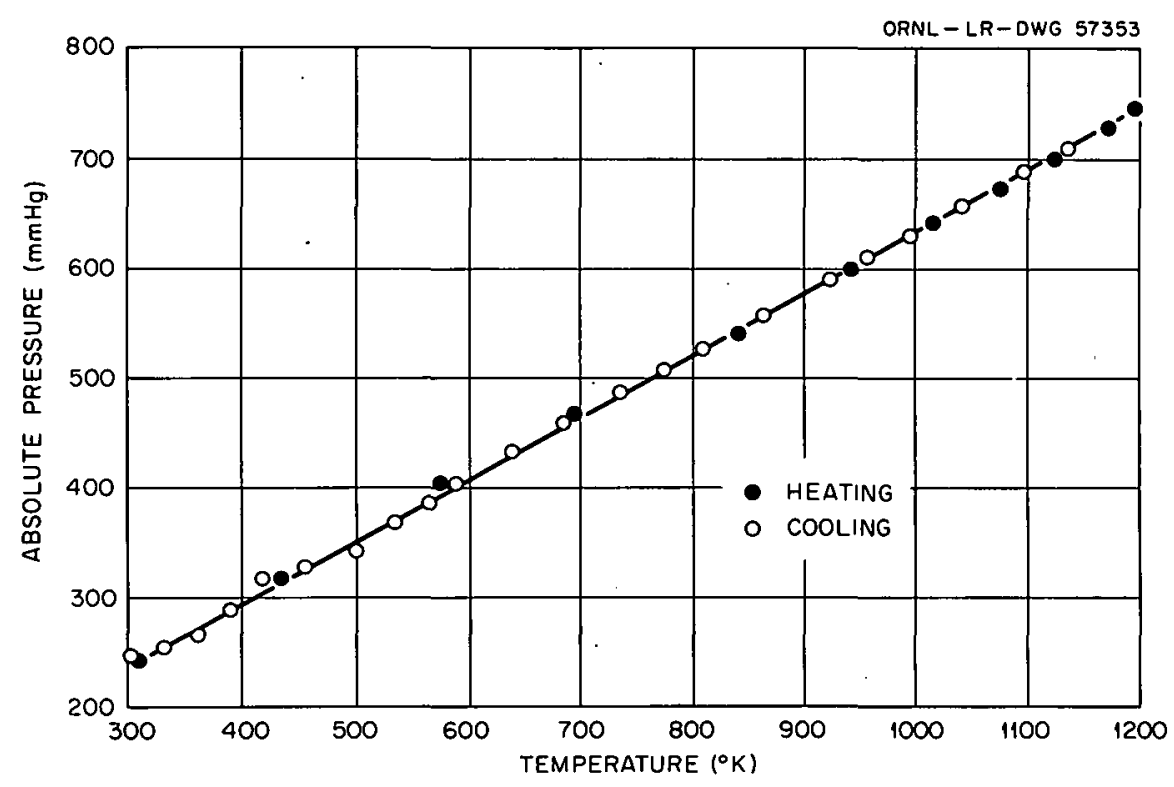

Fig. 35. Postirradiation Measurement of Fission-Gas Pressure in ORR Capsule 08-1.

Table 16. Internal Void Volume and Fill Gas Pressure of Irradiated Group 2 Elements at Ambient Temperature $\left(31^{\circ} \mathrm{C}\right)$

\begin{tabular}{|c|c|c|c|c|c|}
\hline \multirow{2}{*}{$\begin{array}{c}\text { Element } \\
\text { No. }\end{array}$} & \multirow{2}{*}{$\begin{array}{c}\text { Pellet } \\
\text { Geometry }^{a}\end{array}$} & \multicolumn{2}{|c|}{ Void Volume $\left(\mathrm{cm}^{3}\right)$} & \multirow{2}{*}{$\begin{array}{l}\text { Moles of } \\
\text { Fill Gas }\end{array}$} & \multirow{2}{*}{$\begin{array}{c}\text { Calculated } \\
\text { Pressure (atm) a } \\
\text { Standard } \\
\text { Temperature }\end{array}$} \\
\hline & & Calculated $^{b}$ & $\overline{\text { Measured }^{c}}$ & & \\
\hline & & & & $\times 10^{-4}$ & \\
\hline $01-2$ & $\mathbf{H}$ & 9.8 & & 4.27 & $0.98^{d}$ \\
\hline $\mathrm{O} 2-2$ & $\mathbf{H}$ & 9.8 & 9.6 & 4.15 & 0.97 \\
\hline O3.2 & $\mathbf{H}$ & 9.8 & 10.2 & 4.09 & 0.90 \\
\hline O4-2 & $\mathrm{H}-\mathrm{B}$ & 2.1 & 6.7 & 2.73 & 0.91 \\
\hline $05-2$ & $\mathbf{H}$ & 9.8 & 10.0 & 3.89 & 0.87 \\
\hline $06-2$ & $\mathrm{II}-\mathrm{B}$ & 2.1 & 0.7 & & \\
\hline $07-2$ & $s$ & 3.1 & & 1.66 & $1.20^{d}$ \\
\hline $08-2$ & $\mathrm{~s}$ & 3.1 & 3.6 & 1.62 & 1.01 \\
\hline
\end{tabular}

${ }^{a} \mathrm{H}=$ hollow pellet; $\mathrm{H}-\mathrm{B}=$ hollow pellet with $\mathrm{BeO}$ rod in void; $\mathrm{S}=$ solid pellet.

${ }^{b} \mathrm{UO}$ and $\mathrm{MgO}$ spacers (and $\mathrm{BeO}$ rods) considered $100 \%$ solid. BeO rods contain approximately $4 \mathrm{~cm}^{3}$ open porosity (from ${ }^{2}$ immersion density measurements).

"Includes "open" porosity of $\mathrm{UO}_{2}$ and $\mathrm{MgO}$ spacers (and BeO rods).

${ }^{d}$ Based on calculated void volume; others on measured void volume. 


\subsubsection{Internal Void Volume and Fill Gas Pressure in ORR Prototype Fuel Elements}

The moles of fill gas present in a fuel element after termination of irradiation was obtained by piercing the fuel element and making successive expansions of the fill gas into evacuated tanks of known volume and measuring the system pressure at each expansion. After the fill gas had been removed from the element, the fuel element was filled with ambient air (at atmospheric pressure) and the original piercing hole sealed. The internal void volume was then obtained by repiercing the element and expanding the contained air into evacuated tanks and measuring the pressure at each expansion as before. The measured volumes thus obtained are probably correct to within $\pm 0.2 \mathrm{cc}$. The results are listed in Table 16.

The calculated (i.e., geometric) void volumes considered the $\mathrm{UO}_{2}, \mathrm{MgO}$, and $\mathrm{BeO}$ to be $100 \%$ solid. The void volumes as measured include the open porosity of the $\mathrm{UO}_{2}, \mathrm{MgO}$, and $\mathrm{BeO}$. The $\mathrm{BeO}$ rods were found to contain about $4 \mathrm{~cm}^{3}$ of open porosity from immersion density measurements.

\subsection{Fuel Damage}

\subsubsection{Micro and Macro Cracking of the Fuel}

All the pellets exhibited micro cracking and generally were quite fragile. In some cases the collapsed cladding prevented the cracks from opening up as shown in Fig. 36. Generally the group 1 pellets were much more severely cracked than the group 2 pellets. In fact, the outer surfaces of many of

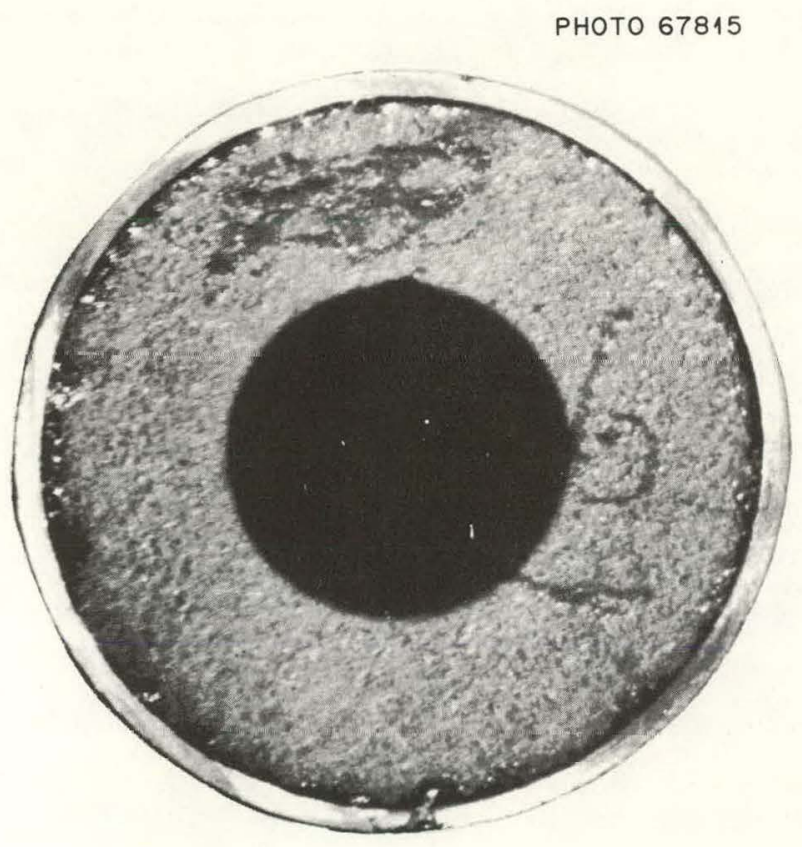

\section{V-13262}

Fig. 36. Collapsed Cladding Prevents Cracks in Pellet from Opening. $4.4 \times$. 
Table 17. Fracturing of Fuel and MgO Spacers

As removed from cladding

\begin{tabular}{|c|c|c|c|c|c|c|c|c|}
\hline & $01-2$ & $\mathrm{O} 2-2$ & O3-2 & $04-2$ & O5-2 & O6-2 & $07-2$ & $08-2$ \\
\hline Top MgO spacer & (2), D & w & & w & (2), D & \multirow{13}{*}{ 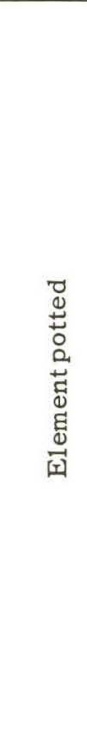 } & (5) & (4) \\
\hline Pellet No. 12 & (8) & w, $\mathrm{R}$ & & (12) & (3) & & & \\
\hline 11 & (4) & $\mathrm{W}, \mathrm{R}$ & 离 & (2), D & (3) & & (8) & $\mathrm{w}, \mathrm{R}$ \\
\hline 10 & (2), D & w, D & a & (2), D & $\mathrm{w}$ & & $\mathrm{w}$ & (2), D \\
\hline 9 & (2), D & $\mathrm{W}, \mathrm{R}, \mathrm{L}$ & 芯 & w & $\mathrm{w}$ & & (5) & (2), D \\
\hline 8 & (4) & $\mathrm{w}, \mathrm{R}$ & & (2), D & $\mathrm{W}, \mathrm{R}, \mathrm{L}$ & & (2), D & (2), D \\
\hline 7 & $\mathrm{w}, \mathrm{R}$ & W, R & & w & W & & W, D & $\mathrm{w}$ \\
\hline 6 & (2), D & (2), D & (2), D & (3) & \multirow{7}{*}{ 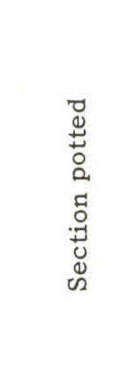 } & & $\mathrm{W}, \mathrm{R}$ & W, D \\
\hline 5 & w, D & (2), D & (2), D & (4) & & & w, D & $\mathrm{w}$ \\
\hline 4 & W, D & $\mathrm{W}, \mathrm{R}$ & (5), D & $\mathrm{W}, \mathrm{R}$ & & & $\mathrm{W}, \mathrm{R}$ & $\mathrm{W}, \mathrm{R}$ \\
\hline 3 & w, D & W, R & $\mathrm{w}$ & W, L & & & $\mathrm{W}, \mathrm{R}, \mathrm{L}$ & W, R \\
\hline 2 & w, D & $\mathrm{W}, \mathrm{R}$ & (3) & (2), D & & & $\mathrm{W}, \mathrm{R}, \mathrm{L}$ & $\mathrm{W}, \mathrm{R}$ \\
\hline 1 & (3) & (6) & (6) & (3) & & & W, R & (2), D \\
\hline Bottom $\mathrm{MgO}$ spacer & $\mathrm{w}$ & w & $\mathrm{w}$ & $\mathrm{w}$ & & & w & $\mathrm{w}$ \\
\hline
\end{tabular}

()$=$ number of pieces when pellet fractured.

$\mathrm{W}=$ pellet removed intact.

$\mathrm{R}=$ radial crack.

$\mathrm{L}=$ longitudinal crack.

$\mathrm{D}=$ diametral crack.

the group 2 pellets did not appear to be fractured. A fracture analysis of the pellets and top and bottom $\mathrm{MgO}$ spacers in the group 2 experiments is presented in Table 17.

Usually the top and bottom pellets in an element exhibited more macro cracking than other pellets. This is probably associated with the flux peaking at the ends of an element and the resulting unsymmetrical thermal expansion, because the temperature gradients are then not predominantly radial. However, usually the pellets near the center of the element underwent a greater amount of intergranular cracking (micro cracks), especially at the outer surface, than the pellets located at the bottom of an element. The intergranular cracking appears to be temperature dependent because the two highest-temperature hollow-pellet experiments (05-1 and 05-2) showed the greatest tendency toward fracturing.

There was no great difference in fracture behavior between the three types of pellets - hollow, hollow with bushings, and solid.

\subsubsection{Dimensional Changes of Pellets}

Generally the change in dimensions of the prototype pellets (Table 18) was small, usually less than one mil, that is, less than $0.2 \%$. Length changes were usually decreases, while diameter changes were about equally divided between increases and decreases. The resulting change in bulk density (assuming the mass of the pellet did not change during irradiation) would be less than $\frac{1}{2} \%$ for solid pellets. 
Table 18. Dimensional Changes of Pellets After Irrodiation

\begin{tabular}{|c|c|c|c|c|c|c|c|}
\hline \multirow{2}{*}{$\begin{array}{c}\text { Element } \\
\text { No. }\end{array}$} & \multirow{2}{*}{$\begin{array}{c}\text { Pellet } \\
\text { No. }\end{array}$} & \multicolumn{3}{|c|}{ Outside Diameter (in.) } & \multicolumn{3}{|c|}{ Length (in.) } \\
\hline & & Preirradiation & Postirradiation & Change & Preirradiation & Postirradiation & Change \\
\hline \multirow[t]{9}{*}{$02-1$} & 2 & & & & 0.4975 & 0.4972 & -0.0003 \\
\hline & 4 & & & & 0.4975 & 0.4980 & +0.0005 \\
\hline & 5 & & & & 0.5010 & 0.5014 & +0.0004 \\
\hline & 6 & 0.7055 & 0.7052 & -0.0003 & 0.4970 & 0.4969 & -0.0001 \\
\hline & 7 & & & & 0.5005 & 0.5000 & -0.0005 \\
\hline & 8 & & & & 0.5010 & 0.5000 & -0.0010 \\
\hline & 9 & & & & 0.5010 & 0.5010 & 0.0000 \\
\hline & 11 & & & & 0.5025 & 0.5020 & -0.0005 \\
\hline & 12 & 0.7062 & 0.7035 & -0.0027 & 0.4955 & 0.4955 & $0: 0000$ \\
\hline \multirow[t]{2}{*}{ 04-1 } & 2 & & & & 0.5019 & 0.5015 & -0.0004 \\
\hline & 7 & & & & 0.5012 & 0.4990 & -0.0022 \\
\hline \multirow[t]{4}{*}{ O5-1 } & 2 & & & & 0.5005 & 0.5000 & -0.0005 \\
\hline & 4 & & & & 0.4967 & 0.4965 & -0.0002 \\
\hline & 5 & & & & 0.5015 & 0.5015 & 0.0000 \\
\hline & 9 & . & & & 0.5010 & 0.5010 & 0.0000 \\
\hline \multirow{4}{*}{ O7-1 } & 3 & & & & 0.5009 & 0.5000 & -0.0009 \\
\hline & 5 & & & & 0.5007 & 0.4950 & -0.0057 \\
\hline & 8 & & & & 0.5005 & 0.5005 & 0.0000 \\
\hline & 10 & & & & 0.4996 & 0.1995 & -0.0001 \\
\hline \multirow[t]{7}{*}{ O8-1 } & 1 & & & & 0.5008 & 0.5000 & -0.0008 \\
\hline & 2 & & & & 0.5006 & 0.5000 & -0.0006 \\
\hline & 3 & & & & 0.5010 & 0.4995 & -0.0015 \\
\hline & 4 & & & & 0.5008 & 0.4995 & -0.0013 \\
\hline & 5 & & & & 0.5004 & 0.4990 & -0.0014 \\
\hline & 7 & 0.7062 & 0.7060 & -0.0002 & 0.5012 & 0.5015 & +0.0003 \\
\hline & 9 & 0.7060 & 0.7040 & -0.0020 & 0,5017 & 0.4995 & -0.0022 \\
\hline $\begin{array}{l}-2 \\
\text { expts. }\end{array}$ & $\begin{array}{l}\text { All that were } \\
\text { recovered } \\
\text { intact }\end{array}$ & \multicolumn{6}{|c|}{ All dimens ional changes less than one mil } \\
\hline \multirow[t]{2}{*}{$L-3$} & $10-10$ & 0.1542 & 0.142 & -0.012 & & & \\
\hline & $10-12$ & 0.1540 & 0.141 & -0.013 & & & \\
\hline \multirow[t]{2}{*}{$L-27 b$} & $39-37$ & 0.1551 & 0.1565 & +0.0014 & 0.2513 & 0.2550 & +0.0037 \\
\hline & $39-41$ & 0.1552 & 0.1570 & +0.0018 & & & \\
\hline
\end{tabular}

Most of the LITR type pellets were fractured during irradiation to such an extent that postirradiation dimensional measurements could not be madc. However, the postirradiated outside diameter of the pellets from the $75 \%$ bulk density experiments (L3 and L6) was appreciably less than the preirradiated outside diameler. Two pelleto from L.3a were rerovered almost intact. As shown in Table 18 their postirradiated outside diameter was 8 to $8 \frac{1}{2} \%$ less than the preirradiated. The fractured pellets from L6 easily slid from the element after a circumferential cut had been made - indicating a reduction in outside diameter. 


\subsubsection{Density Changes}

Prototype Pellets. - Preirradiation bulk density measurements were made by weighing an individual pellet and calculating its volume from dimensional measurements made with a micrometer. Postirradiation bulk density was obtained by means of a mercury pycnometer (Fig. 18) on the supposition that the mercury (which was not under pressure) would not enter the open pores. The precision of measurement is approximately $\pm 0.5 \%$ for preirradiation and approximately $\pm 0.7 \%$ for the postirradiation measurements.

Pre- and postirradiation carbon tetrachloride immersion densities were obtained by first evacuating the pycnometer with the sample in place before admitting the carbon tetrachloride. Under these conditions the carbon tetrachloride should enter open pores approaching the size of the carbon tetrachloride molecule.

"Total porosity" is defined as the difference in percent between the bulk density (expressed in percent) and theoretical density (i.e., 100\%). Total porosity consists of "closed porosity" and "open porosity." Closed porosity is assumed to be the difference between carbon tetrachloride immersion density and theoretical density expressed in percent. It thus consists of micro pores which will not admit carbon tetrachloride and pores which do not extend to a free surface, hence "closed" pores. Open porosity is obtained by subtracting the closed porosity from the total porosity. Open porosity consists of those pores which extend to a free surface.

The results of the density measurements of prototype pellets are presented in Table 19, and a comparison of the pre- and postirradiation porosity is shown in Fig. 37.

The data were examined to determine if a correlation existed between change in porosity and burnup, initial total porosity, or initial open or closed porosity. The results are summarized in Table 20. It should be emphasized that

1. The pre- and postirradiation bulk densities (hence the total and deduced open porosities) were obtained by two different methods of measurements.

2. Dimensional changes on pellets which remained somewhat intact after irradiation were generally small and would result in changes in total porosity ranging from $+0.1 \%$ to $-0.5 \%$ (assuming the mass of the pellet remained constant).

3. The geometrical dependence of the group 1 solid pellets is complicated by their being the most dense (i.e., smallest total porosity) of any of the pellets used in these experiments. Yet they have the largest closed porosity. This results in an extremely low value for the open porosity.

It may be concluded that the major change is a relatively large increase in open porosity due to a small increase in total porosity and a slight decrease in closed porosity. This indicates the formation and enlargement of micro cracks, and the extension of closed pores to a free surface during irradiation.

LITR Type Pellets. - Tables 21 and 22 list the results of the density measurements expressed as porosities for LITR experiment pellets.

Preirradiation bulk density was obtained by weight and dimensional measurements with a precision of $\pm 1.4 \%$. The precision of carbon tetrachloride immersion densities is $\pm 2 \%$. Individual pellets in any 
Table 19. Pre- and Postirradiation Density Meosurements of Protosype Fuel Element Pellets

\begin{tabular}{|c|c|c|c|c|c|c|c|c|c|c|c|c|c|c|}
\hline \multirow[t]{2}{*}{$\begin{array}{c}\text { Element } \\
\text { No. }\end{array}$} & \multirow[t]{2}{*}{$\begin{array}{c}\text { Pellet } \\
\text { No. }\end{array}$} & \multirow[t]{2}{*}{$\begin{array}{c}\text { Pellet } \\
\text { Geometry }^{\theta}\end{array}$} & \multirow{2}{*}{$\begin{array}{l}\text { Preirradiation } \\
\text { (Feight and } \\
\text { Dimensions) }\end{array}$} & \multirow{2}{*}{$\begin{array}{l}\text { Pos ti:radiation } \\
\text { (Mercury } \\
\text { Immersion) }\end{array}$} & \multirow{2}{*}{ Change } & \multicolumn{3}{|c|}{$\begin{array}{c}\mathrm{CCl}_{4} \text { Immersion Density } \\
(\% \text { of theoretical) } \\
\end{array}$} & \multicolumn{3}{|c|}{$\begin{array}{l}\text { Open Porosity (\% of theoretical density) } \\
\qquad\left(\mathrm{CCl}_{4} \rho-\text { Bulk } \rho\right)\end{array}$} & \multicolumn{3}{|c|}{$\begin{array}{l}\text { Closed Porosity } \\
\text { (\% of theoretical density) } \\
\left(100 \%-\mathrm{CCl}_{4} \rho\right)\end{array}$} \\
\hline & & & & & & Preirradiation & Postirradiation & Change & Preị rradiation & Postirradiation & Change & Preirradiation & Postimradiation & Change \\
\hline \multirow[t]{2}{*}{ 01-1 } & 7 & $\mathbf{H}$ & 95.07 & & & 97.35 & 98.08 & +0.73 & & & & 2.65 & 1.92 & -0.73 \\
\hline & 9 & H & 94.89 & 92.52 & -237 & 97.35 & & & 2.46 & 5.56 & 3.10 & & & \\
\hline \multirow[t]{2}{*}{$02-1$} & 8 & $\mathrm{H}$ & 93.89 & & & 98.08 & 98.27 & 0.19 & & & & 1.92 & 1.73 & -0.19 \\
\hline & 9 & $\mathrm{H}$ & 93.80 & 93.52 & -0.28 & 97.81 & & & 4.01 & 4.75 & 0.74 & & & \\
\hline 03-1 & 6 & $\mathrm{H}$ & 94.98 & 94.07 & $-c .91$ & 97.45 & 98.18 & 0.73 & 2.47 & 4.11 & 1.64 & 2.55 & 1.82 & -0.73 \\
\hline $04-1$ & 8 & $\mathrm{H}-\mathrm{B}$ & 94.71 & 92.79 & -11.92 & 97.35 & 97.90 & 0.55 & 2.64 & 5.11 & 2.47 & 2.65 & 2.10 & -0.55 \\
\hline \multirow[t]{2}{*}{$05-1$} & 7 & $\mathrm{H}$ & 94.07 & & & 98.18 & $97.26^{b}$ & $-0.92^{b}$ & & & & 1.82 & $2.74^{b}$ & $+0.92^{b}$ \\
\hline & 9 & $\mathrm{H}$ & 93.89 & 91.51 & $-\tau .38$ & 98.18 & & & 4.29 & $5.75^{b}$ & $1.46^{b}$ & & & \\
\hline 06-1 & 1 & H-B & 94.16 & c & & 98.27 & 98.54 & +0.27 & 4.11 & & & 1.73 & 1.46 & -0.27 \\
\hline $07-1$ & 6 & $s$ & 96.35 & 95.26 & $-i .09$ & 96.81 & 97.63 & 0.82 & 0.46 & 2.37 & 1.91 & 3.19 & 2.37 & -0.82 \\
\hline $08-1$ & 7 & $\mathrm{~s}$ & 96.44 & 93.52 & -2.92 & 96.90 & 97.63 & 0.73 & 0.46 & 4.11 & 3.65 & 3.10 & 2.37 & -0.73 \\
\hline $01-2$ & 7 & $\mathrm{H}$ & 95.89 & 95.07 & -0.82 & 97.99 & 98.36 & 0.37 & 2.10 & 3.29 & 1.19 & 2.01 & 1.64 & -0.37 \\
\hline $02-2$ & 9 & $\mathrm{H}$ & 95.89 & 95.99 & +0.10 & 97.81 & 98.36 & 0.55 & 1.92 & 2.37 & 0.45 & 2.19 & 1.64 & -0.55 \\
\hline 03.2 & 3 & $\mathrm{H}$ & 94.43 & 93.98 & -0.45 & 97.72 & 98.18 & 0.46 & 3.29 & 4.20 & 0.91 & 2.28 & 1.82 & -0.46 \\
\hline $04-2$ & 7 & H-B & 94.43 & 94.34 & -0.09 & 97.90 & 98.36 & 0.46 & 3.47 & 4.02 & 0.55 & 2.10 & 1.64 & -0.46 \\
\hline $05-2$ & 7 & H & 94.71 & 92.15 & -1.56 & 96.44 & 98.72 & 2.28 & 1.73 & 6.57 & 4.84 & 3.56 & 1.28 & -2.28 \\
\hline $06-2$ & \multicolumn{2}{|c|}{ Element potted } & & & & & & & & & & & & \\
\hline $07-2$ & 2 & $S$ & 95.35 & 94.53 & -0.82 & 96.99 & 98.81 & 1.82 & 1.64 & 4.28 & 2.64 & 3.01 & 1.19 & -1.82 \\
\hline 08.2 & 3 & $\mathrm{~s}$ & 95.26 & 94.43 & -0.83 & 98.18 & 98.72 & 0.54 & 2.92 & 4.29 & 1.37 & 1.82 & 1.28 & -0.54 \\
\hline
\end{tabular}

${ }^{a_{H}} \mathrm{H}=$ hollow pellet; $\mathrm{H}-\mathrm{B}=$ soilow pel let with $\mathrm{BeO}$ rod in void; $\mathrm{s}=$ solid pellet.

${ }_{\text {Surfaces o: }}$ pellet contained deposits of extraneous material.

c pellet fragments too small for measurement. 


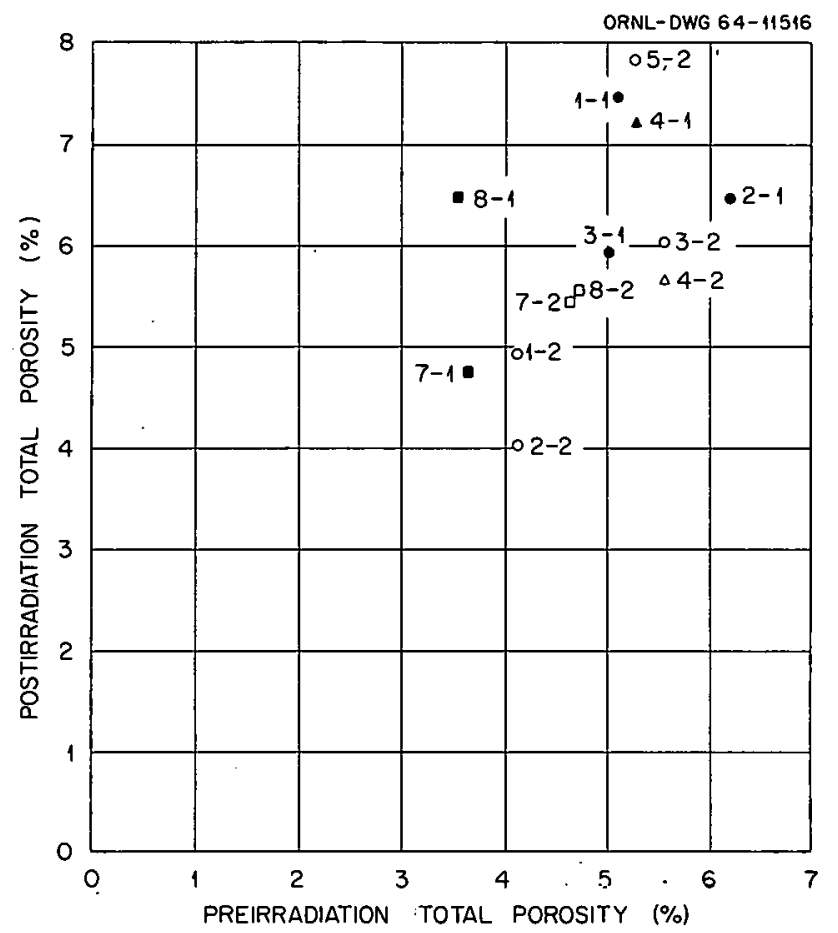

Fig. 37. ORR Capsule Postirradiation Total Porosity vs Preirradiation Total Porosity.

Table 20. Effect of Irradiation on Porosity of ORR Type Pellets

\begin{tabular}{|c|c|c|c|c|c|c|}
\hline & \multirow{2}{*}{\multicolumn{2}{|c|}{$\begin{array}{l}\text { Relative Change } \\
\text { After Irradiation }\end{array}$}} & \multicolumn{4}{|c|}{ Varies with ${ }^{b}$} \\
\hline & & & \multirow{2}{*}{ Burnup } & \multicolumn{3}{|c|}{ Initial Porosity } \\
\hline & $>$ or $<$ & Degree & & Tota 1 & Closed & Open \\
\hline Change in Porosity & & & & & & \\
\hline Tota1 & $>$ & $\mathbf{S}$ & $N$ & $\mathbf{N}$ & I & $\mathrm{D}$ \\
\hline Closed & $<$ & $\mathbf{S}$ & $\mathrm{D}$ & D & $\mathbf{I}$ & $\mathrm{D}$ \\
\hline Open & $>$ & $\mathbf{L}$ & $\mathbf{N}$ & $\mathbf{N}$ & I & $\mathrm{D}$ \\
\hline
\end{tabular}

${ }^{a}>=$ postirradiation value greater than preirradiation.

$<=$ postirradiation value less than preirradiation.

$\mathrm{S}=$ small relative change.

$\mathrm{L}=$ large relative change.

${ }^{b} \mathrm{I}=$ absolute value of change increases as independent variable increases.

$\mathrm{D}=$ absolute value of change decreases as independent variable increases.

$\mathrm{N}=$ no apparent dependence. 
Table 21. Pre. cnd Postirradiotion Density Measurements of LITR Type Fuel Pellets: Oxygen-to-Uranium Ratio $\leqq 2.02$

\begin{tabular}{|c|c|c|c|c|c|c|c|c|c|c|c|c|}
\hline \multirow{3}{*}{$\begin{array}{c}\text { Element } \\
\text { No. }\end{array}$} & \multicolumn{5}{|c|}{ Preirradiation } & \multicolumn{2}{|c|}{ Postirradiation } & \multirow{3}{*}{$\begin{array}{c}\text { Change in } \\
\text { Closed } \\
\text { Porosity } \\
(\%)\end{array}$} & \multirow{3}{*}{$\begin{array}{c}\text { Fractional Change } \\
\text { in Closed } \\
\text { Porosity }\end{array}$} & \multicolumn{3}{|c|}{ Average of Duplicated Measurements } \\
\hline & Bulk & Sity & \multicolumn{3}{|c|}{ Porosity (\%) } & \multirow{2}{*}{$\begin{array}{l}\mathrm{CCl}_{4} \\
\text { Immersion Density } \\
\text { (\% of theoretical) }\end{array}$} & \multirow{2}{*}{$\begin{array}{c}\text { Closed } \\
\text { Porosity } \\
(\%)\end{array}$} & & & \multirow{2}{*}{$\begin{array}{l}\text { Closed } \\
\text { Porosity } \\
(\%)\end{array}$} & \multirow{2}{*}{$\begin{array}{c}\text { Change in } \\
\text { Closed } \\
\text { Porosity } \\
(\%)\end{array}$} & \multirow{2}{*}{$\begin{array}{c}\text { Fractional Change } \\
\text { in Closed } \\
\text { Porosity }\end{array}$} \\
\hline & $\begin{array}{c}\text { (height and } \\
\text { Dimensions) } \\
\text { (\% o: theoretical) }\end{array}$ & $\begin{array}{c}\text { Immersion } \\
\text { (\% of theoretical) }\end{array}$ & Total & Closed & Open & & & & & & & \\
\hline \multirow[t]{2}{*}{ L-4a } & \multirow[t]{2}{*}{92.43} & \multirow[t]{2}{*}{96.81} & \multirow[t]{2}{*}{7.57} & \multirow[t]{2}{*}{3.19} & \multirow[t]{2}{*}{4.38} & 96.17 & 3.83 & +0.64 & +0.20 & \multirow{2}{*}{\}+4.33} & \multirow{2}{*}{+1.14} & \multirow{2}{*}{+0.36} \\
\hline & & & & & & 95.16 & 4.84 & +1.65 & +0.52 & & & \\
\hline \multirow[t]{2}{*}{ b } & \multirow[t]{2}{*}{93.43} & \multirow[t]{2}{*}{96.53} & \multirow[t]{2}{*}{6.57} & \multirow[t]{2}{*}{3.47} & \multirow[t]{2}{*}{3.10} & 95.53 & 4.47 & +1.00 & +0.29 & \multirow[t]{2}{*}{+5.02} & \multirow[t]{2}{*}{+1.55} & \multirow[t]{2}{*}{+0.44} \\
\hline & & & & & & 94.43 & 5.57 & +2.10 & +0.60 & & & \\
\hline$-13 a$ & 93.98 & 96.72 & 6.02 & 3.28 & 2.74 & 97.35 & 2.65 & -0.63 & -0.19 & & & \\
\hline $\mathrm{b}$ & 92.06 & 96.81 & 7.94 & 3.19 & 4.75 & 97.45 & 2.55 & -0.64 & -0.20 & & & \\
\hline$-16 a^{a}$ & 94.43 & 95.57 & 5.57 & 4.43 & 1.14 & $\begin{array}{l}97.26 \\
96.53\end{array}$ & $\begin{array}{l}2.74 \\
3.47\end{array}$ & $\begin{array}{l}-1.69 \\
-0.96\end{array}$ & $\begin{array}{l}-0.33 \\
-0.22\end{array}$ & 3.10 & -1.33 & -0.30 \\
\hline $\left.\begin{array}{c}-16 \times a^{a} \\
b\end{array}\right\}$ & 94.25 & 95.53 & 5.75 & 4.47 & 1.28 & $\begin{array}{l}96.62 \\
96.90\end{array}$ & $\begin{array}{l}3.38 \\
3.10\end{array}$ & $\begin{array}{l}-1.09 \\
-1.37\end{array}$ & $\begin{array}{l}-0.24 \\
-0.31\end{array}$ & 3.24 & -1.23 & -0.27 \\
\hline $\begin{array}{r}-17 a \\
b\end{array}$ & $\begin{array}{l}93.80 \\
93.89\end{array}$ & $\begin{array}{l}95.16 \\
94.71\end{array}$ & $\begin{array}{l}6.20 \\
6.11\end{array}$ & $\begin{array}{l}4.84 \\
5.29\end{array}$ & $\begin{array}{l}1.36 \\
0.82\end{array}$ & $\begin{array}{l}95.99 \\
95.44\end{array}$ & $\begin{array}{l}4.01 \\
4.56\end{array}$ & $\begin{array}{l}-0.83 \\
-0.73\end{array}$ & $\begin{array}{l}-0.17 \\
-0.14\end{array}$ & & & \\
\hline$-24 a$ & 94.89 & 98.36 & 5.11 & 1.64 & 3.47 & 95.80 & 4.20 & +2.56 & +1.56 & & & \\
\hline$-27 b$ & 94.16 & 94.89 & 5.84 & $5.1 \mathrm{i}$ & 0.73 & 94.89 & 5.11 & 0.00 & 0.60 & & & \\
\hline$-28 a$ & 94.43 & 96.26 & 5.57 & 3.74 & 1.83 & $\begin{array}{l}96.35 \\
95.99\end{array}$ & $\begin{array}{l}3.65 \\
4.01\end{array}$ & $\begin{array}{l}-0.09 \\
+0.27\end{array}$ & $\begin{array}{l}-0.02 \\
+0.07\end{array}$ & 3.83 & +0.09 & +0.03 \\
\hline$-32 a$ & 94.34 & 95.16 & 5.66 & 4.84 & 0.82 & 95.80 & 4.20 & -0.64 & -0.13 & & & \\
\hline b & 93.80 & 96.99 & 6.20 & 3.01 & 3.19 & 95.80 & 4.20 & +1.19 & +0.40 & & & \\
\hline
\end{tabular}

${ }^{a}$ Composite sample from a and $b$ sections. 
Table 22. Pre- and Postirradiation Density Measurements of LITR Type Fuel Pellets: Oxygen-to-Uranium Ratio $>2.02$

\begin{tabular}{|c|c|c|c|c|c|c|c|c|c|c|c|c|}
\hline \multirow{4}{*}{$\begin{array}{c}\text { Element } \\
\text { No. }\end{array}$} & \multicolumn{5}{|c|}{ Preirradiation } & \multirow{2}{*}{\multicolumn{2}{|c|}{ Postirradiation }} & \multirow{4}{*}{$\begin{array}{l}\text { Change in } \\
\text { Closed } \\
\text { Porosity } \\
(\%)\end{array}$} & \multirow[b]{4}{*}{$\begin{array}{l}\text { Fractional Change } \\
\text { in Closed } \\
\text { Porosity }\end{array}$} & \multirow{2}{*}{\multicolumn{3}{|c|}{ Average of Duplicated Measurements }} \\
\hline & \multicolumn{2}{|c|}{ Density } & \multirow{2}{*}{\multicolumn{3}{|c|}{ Porosity (\%) }} & & & & & & & \\
\hline & & & & & & \multirow{2}{*}{$\begin{array}{c}\mathrm{CCl}_{4} \\
\text { Immersion Density } \\
(\% \text { of theoretical) }\end{array}$} & \multirow[b]{2}{*}{$\begin{array}{c}\text { Closed } \\
\text { Porosity } \\
(\%)\end{array}$} & & & \multirow[b]{2}{*}{$\begin{array}{l}\text { Closed } \\
\text { Porosity } \\
(\%)\end{array}$} & \multirow{2}{*}{$\begin{array}{c}\text { Change in } \\
\text { Closed } \\
\text { Porosity } \\
(\%)\end{array}$} & \multirow[b]{2}{*}{$\begin{array}{l}\text { Fractional Change } \\
\text { in Closed } \\
\text { Porosity }\end{array}$} \\
\hline & $\begin{array}{l}\text { (Weight and } \\
\text { Dimensions) } \\
\text { (\% of theoretical) }\end{array}$ & $\begin{array}{l}\mathrm{CCl}_{4} \text { Immersion } \\
(\% \text { of theoretical) }\end{array}$ & Total & Closed & Open & & & & & & & \\
\hline \multirow[t]{2}{*}{$L-2 b$} & 84.49 & 91.79 & 15.51 & 8.21 & 7.30 & 93.25 & 6.75 & -1.46 & -0.18 & \multirow{2}{*}{\} 5.97} & \multirow{2}{*}{-2.24} & \multirow{2}{*}{-0.27} \\
\hline & & & & & & 94.80 & 5.20 & -3.01 & -0.37 & & & \\
\hline$-3 a$ & 75.09 & 97.26 & 24.91 & 2.74 & 22.17 & 96.81 & 3.19 & +0.45 & +0.16 & & & \\
\hline$b$ & 74.91 & 97.26 & 25.09 & 2.74 & 22.35 & 94.89 & 5.11 & +2.37 & +0.94 & . & & \\
\hline \multirow[t]{2}{*}{$-6 a$} & \multirow[t]{2}{*}{73.54} & \multirow[t]{2}{*}{95.71} & \multirow[t]{2}{*}{26.46} & \multirow[t]{2}{*}{4.29} & \multirow[t]{2}{*}{22.17} & 95.62 & 4.38 & +0.09 & +0.02 & \multirow{2}{*}{\} 4.47} & \multirow{2}{*}{+0.18} & \multirow{2}{*}{+0.04} \\
\hline & & & & & & 95.44 & 4.56 & +0.27 & +0.06 & & & \\
\hline \multirow[t]{2}{*}{$\cdot b$} & \multirow[t]{2}{*}{74.36} & \multirow[t]{2}{*}{95.89} & \multirow[t]{2}{*}{26.64} & 4.11 & 22.53 & 96.81 & 3.19 & -0.92 & -0.22 & & $-0,10$ & -005 \\
\hline & & & & & . & 95.35 & 4.65 & +0.54 & +0.13 & & -0.19 & -0.05 \\
\hline $7 x a$ & 95.07 & 95.89 & 4.93 & 4.11 & 0.82 & 93.98 & 6.02 & +1.91 & +0.46 & & & \\
\hline $\mathrm{b}$ & 94.94 & 95.80 & 5.06 & 4.20 & 0.85 & 93.98 & 6.02 & +1.82 & +0.43 & & & \\
\hline $8 a$ & 84.67 & 92.97 & 15.33 & 7.03 & 8.30 & 92.43 & 7.57 & +0.54 & +0.08 & & & \\
\hline$b$ & 85.13 & 92.88 & 14.87 & 7.12 & 7.75 & 94.25 & 5.75 & -1.37 & -0.19 & & & \\
\hline $10 \mathrm{~b}$ & 95.26 & 95.62 & 4.74 & 4.38 & 0.36 & $94.25^{a}$ & 5.75 & +1.37 & +0.31 & 6543 & 205 & 4.44 \\
\hline & & & & & & 92.88 & 7.12 & +2.74 & +0.58 & 0.43 & 2.05 & +0.44 \\
\hline $11 a$ & 85.13 & 95.53 & 14.87 & 4.47 & 10.40 & 94.89 & 5.11 & +0.64 & +0.14 & & & \\
\hline $17 \mathrm{xa}^{b}$ & 94.80 & 9548 & 5.20 & 452 & 6.68 & 96.35 & 3.65 & -0.87 & -0.19 & & & 017 \\
\hline b J & 94.80 & 93.48 & 3.20 & 4.52 & 0.08 & 96.17 & 3.83 & -0.69 & -0.15 & 3.74 & -0.78 & -0.17 \\
\hline $18 b$ & 85.31 & 94.89 & 14.59 & 5.11 & 9.58 & 95.53 & 4.47 & -0.64 & -0.13 & & & \\
\hline $18 \mathrm{xa}$ & 84.76 & 94.80 & 15.24 & 5.20 & 10.04 & 96.90 & 3.10 & -2.10 & -0.40 & & & \\
\hline
\end{tabular}

${ }^{a}$ Very fine crystalline particles on fuel surface after irradiation.

${ }^{b}$ Composite sample from a and $b$ sections. 
one experiment varied considerably in both bulk and carbon tetrachloride immersion densities. The preirradiation density value listed is the average of all the pellets in an experiment because the individual pellets used in postirradiation measurements were not identifiable. Postirradiation bulk density measurements were not made because of extreme extent of fracture of the pellets.

The bulk density is very sensitive to an error in inside diameter measurement; each mil error in inside diameter results in an $0.86 \%$ error in bulk density. The central hole of the LITR pellets was drilled ultrasonically. Some of the holes were out of round, or were not constant in diameter throughout the length of the pellet. If the mean diameter was not selected correctly, an appreciable error in bulk density could result.

Again the open porosity is subject to the sum of errors in total porosity and closed porosity measurements, since open porosity is obtained from the difference of bulk and carbon tetrachloride immersion densities. The apparent changes in closed porosity as a function of initial porosity, burnup, and operating temperature are shown in Table 23.

These apparent trends are consistent with those of the prototype pellets. However, the latter did not attain as large burnups as the LITR type experiments, and this is probably the reason why the change in closed porosity for the ORR pellets did not attain a postirradiation value greater than the preirradiation value.

It appears that the nonstoichiometric fuel has a much larger variation than the stoichiometric fuel. However, it must be remembered that the variation in preirradiation densities of the nonstoichiometric fuel was much greater than for the stoichiometric fuel. The ratio of closed to open porosity ranged from approx 0.12 to 12 (or a factor of 100 ) for nonstoichiometric fuels whereas that of stoichiometric fuels ranged from 0.47 to 7 (or a factor of 15 ).

Table 23. Variation of LITR Closed Porosity

\begin{tabular}{|c|c|c|c|c|c|}
\hline & \multicolumn{5}{|c|}{ Varies with } \\
\hline & \multirow{2}{*}{$\begin{array}{l}\text { Operating } \\
\text { Temperature }\end{array}$} & \multirow{2}{*}{ Burnup } & \multicolumn{3}{|c|}{ Initial Porosity } \\
\hline & & & Total & Closed & Open \\
\hline \multicolumn{6}{|l|}{ Change in closed porosity } \\
\hline Stoichiometric fuel & $\mathbf{N}$ & $\underline{I}$ & I & $\mathrm{D}$ & I \\
\hline Nonstoichiometric fuel & $\mathbf{N}$ & $\mathbf{N}$ & $\mathbf{N}$ & $\mathbf{N}$ & $\mathbf{N}$ \\
\hline
\end{tabular}

$I=$ increases from negative to positive as independent variable increases.

$\mathrm{D}=$ decreases from positive to negative as independent variable increases.

$\mathrm{N}=\mathrm{n} \cap$ apparent dependence. 


\subsubsection{Measurements of O/U Ratio}

The $\mathrm{O} / \mathrm{U}$ ratio is one of the important items in the characterization of $\mathrm{UO}_{2}$. Ratios greater than 2.000 denote oxygen in excess of the stoichiometric amount, presumably as $\mathrm{UO}_{3}$. Early experiments ${ }^{23}$ indicated that oxygen markedly in excess of stoichiometric would have an adverse effect upon the performance of the fuel; fission-gas release would increase, and thermal conductivity decrease.

Early $\mathrm{O} / \mathrm{U}$ ratio measurements on unirradiated fuel were not reliable, but with experience, better techniques were developed, and the analyses became more consistent. Postirradiation $\mathrm{O} / \mathrm{U}$ measurements were made first at ORNL and then continued at GEVAL. Some representative unirradiated pellets were analyzed at ORNL by the same hot-cell techniques as the irradiated pellets in order to see if the slight changes in technique necessitated by hot-cell limitations would affect the analyses. Table 24 lists the measurements made at the ORNL and GEVAL hot cells.

The ORNL measurements indicate that irradiated fuels tend to become more stoichiometric. This is not unexpected, since thermodynamic considerations ${ }^{24}$ in dicate that some of the fission products which occur in relatively high yields (i.e., $\mathrm{Zr}$, La, rare earths, $\mathrm{Y}, \mathrm{Sr}, \mathrm{Ba}$, and $\mathrm{Mo}$ ) would effectively take up all the available oxygen under equilibrium conditions. Any available oxygen in the free gas space in the element would react preferentially with the cladding at operating temperatures.

If the fill gas in the element was normal air rather than argon or helium, and if the fuel would react with all the $\mathrm{O}_{2}$ present, the average $\mathrm{O} / \mathrm{U}$ ratio would increase only 0.00016 for a typical ORR element (i.e., go from 2.000 to 2.00016 for stoichiomețic fuel) and increase 0.00066 for a typical LITR element. This should not imply that an oxygen-free atmosphere is not important. The oxygen present could react with the surface of the fuel to form a layer of $\mathrm{U}_{3} \mathrm{O}_{8}(\mathrm{O} / \mathrm{U}$ ratio of 2.667), which, it is believed, would greatly increase the release rate of the fission product gases.

\subsubsection{Burnup Determinations}

Accurate determinations of burnup of a fuel element are highly desirable but are also quite difficult to make. The advantages and disadvantages of the various methods of determination as used for these elements are as follows:

1. Flux monitors - The gamma activity of ${ }^{60} \mathrm{Co}$ from the activation of the stainless steel thermocouple retainers was used to obtain an effective neutron flux. One must calculate the flux depression due to the element itself and calculate the bumup from enrichment analyses, estimating the plutonium contribution.

2. Pre-and postirradiation ${ }^{235} \mathrm{U} /{ }^{236} \mathrm{U}$ isotopic ratios - Here one actually has a measure of the depletion of a fissionable species, but the validity of the analysis depends upon getting a truly representative sample for postirradiation measurements. Also, the precision becomes quite poor for small burnups (where the isotopic ratios will not change much) and the plutonium contribution must again be estimated.

\footnotetext{
23 J. A. L. Robertson, The Effects of Excess $O$ in $U O_{2}$, CRFD-973 (October 1960).

${ }^{24}$ GCR Proj. Quart. Progr. Rept. Dec. 31, 1959, ORNL-2888, p. 162.
} 
Table 24. Measurements of O/U Ratio

\begin{tabular}{|c|c|c|c|c|c|}
\hline \multirow{3}{*}{$\begin{array}{l}\text { Experiment } \\
\text { No. }\end{array}$} & \multirow{3}{*}{$\begin{array}{c}\text { Burnup } \\
\text { (Mwd per metric ton of } \mathrm{UO}_{2} \text { ) }\end{array}$} & \multirow{3}{*}{$\begin{array}{l}\text { Preirradiation } \\
\mathrm{O} / \mathrm{U}\end{array}$} & \multicolumn{3}{|c|}{ Hot Cell Measurements } \\
\hline & & & \multicolumn{2}{|c|}{ ORNL } & \multirow{2}{*}{$\begin{array}{c}\text { GEVAL } \\
\text { Postirradiation } \\
\mathrm{O} / \mathrm{U}\end{array}$} \\
\hline & & & $\begin{array}{c}\text { Preirradiation } \\
\mathrm{O} / \mathrm{U}\end{array}$ & $\begin{array}{c}\text { Postirradiation } \\
\mathrm{O} / \mathrm{U}\end{array}$ & \\
\hline $01-1$ & 1710 & 2.007 & $2.007^{-}$ & $2.007^{+}$ & 2.009 \\
\hline $02-1$ & 1820 & 2.017 & & & 2.010 \\
\hline $03-1$ & 1530 & 2.007 & & & 2.018 \\
\hline $04-1$ & 1710 & 2.007 & & & 2.013 \\
\hline $05-1$ & 2700 & 2.017 & 2.015 & 2.002 & 2.006 \\
\hline $06-1$ & 1970 & 2.017 & & & 2.039 \\
\hline $07-1$ & 740 & 2.004 & & & 2.012 \\
\hline $08-1$ & 710 & 2.004 & & & 2.042 \\
\hline $01-2$ & 1670 & 2.004 & & & 2.014 \\
\hline $\mathrm{O} 2-2$ & 1400 & 2.004 & $<2.001$ & $2.000^{+}$ & 2.012 \\
\hline $03-2$ & 1460 & 2.001 & & & 2.081 \\
\hline O4-2 & 1680 & 2.002 & 2.001 & 2.002 & 2.021 \\
\hline 05.2 & 2500 & 2.001 & & & 2.018 \\
\hline $06-2$ & 1690 & 2.003 & & & 2.021 \\
\hline $07-2$ & 1310 & 2.004 & & & 2.049 \\
\hline $08 \cdot 2$ & 1110 & 2.004 & & & 2.030 \\
\hline$L-7 x b$ & 16,000 & 2.041 & & 2.001 & \\
\hline$-11 b$ & 22,000 & 2.140 & 2.116 & 2.008 & \\
\hline$-25 b$ & 5,100 & 2.020 & & 2.003 & \\
\hline$-32 b$ & 8,500 & 2.004 & $2.003^{-}$ & $2.003 t$ & \\
\hline
\end{tabular}

3. Fission product analyses - This, on the surface, would appear to be one of the most attractive means of measurement, because one measures a direct result of the. fission (whether due to ${ }^{235} \mathrm{U},{ }^{239} \mathrm{Pu}$, or any uthei fissilc species). However, in addition to the problem of obtaining a representative sample, one has the problems of analytical procedures. Cesium-137 and ${ }^{144} \mathrm{Ce}$ were selected for burnup determinations for these experiments because of their reasonable yields, half-lives, and decay schemes. However, it was found that cesium tended to migrate at the elevated temperatures in the fuel - so the concentration of cesium in a particular sample was not necessarily directly proportional to the number of fissions that took place in the sample. Also, the recovery of cesium was very sensitive to the method of discolving the firel and the subsequent radiochemical analyses. These difficulties were not as serious 
with ${ }^{144} \mathrm{Ce}$, and for this reason the ${ }^{144} \mathrm{Ce}$ analyses are probably more reliable. However, for high burnups, the plutonium contribution must still be estimated because of the relatively large difference in ${ }^{144} \mathrm{Ce}$ fission yields of ${ }^{235} \mathrm{U}$ and ${ }^{239} \mathrm{Pu}$.

Tables 13 and 25 list the results of the various methods of measuring bumup for the EGCR prototype elements and for some of the LITR type elements.

\subsubsection{Metallographic Results}

Metallographic examination of the fuel in the prototype elements showed that generally there was little change as a result of irradiátion.

The group 1 elements had an appreciable nitrogen impurity con tent (up to $1900 \mathrm{ppm}$ ) which appeared as a second phase (UN ${ }_{2}$ with traces of UN) in the unirradiated fuel (see Figs. 38 and 39). The secondphase material in the central regions of the pellets apparently went into solution during irradiation and precipitated out on the slip planes of the $\mathrm{UO}_{2}$ in an acicular form. This needle-like precipitate was identified by $x$-ray diffraction as a hexagonal form of $U_{2} N_{3}$. The concentration of the $U_{2} N_{3}$ seems to be proportional to the temperature and may extend from the inside surface of the pellet as far as halfway through the pellet (Fig. 40).

Table 25. Comparison of Burnup

Data for LITR Type Elements

\begin{tabular}{|c|c|c|c|c|}
\hline \multirow{2}{*}{$\begin{array}{c}\text { Element } \\
\text { No. }\end{array}$} & \multicolumn{4}{|c|}{ Burnup (Mwd per metric ton of $\mathrm{UO}_{2}$ ) } \\
\hline & $\begin{array}{c}\text { Flux } \\
\text { Monitor }\end{array}$ & ${ }^{137} \mathrm{Cs}$ & ${ }^{144} \mathrm{Ce}$ & ${ }^{235} \mathrm{U} /{ }^{236} \mathrm{U}$ \\
\hline \multirow[t]{2}{*}{$L-2$} & 3,200 & 2,100 & 3,360 & \\
\hline & & 1,920 & $3, T \cup \cup u$ & \\
\hline \multirow[t]{2}{*}{$L-4$} & 12,000 & 10,700 & 12,800 & \\
\hline & & 10,900 & 11,900 & \\
\hline \multirow[t]{2}{*}{ L-6 } & 12,000 & 9,700 & 11,000 & \\
\hline & & 11,100 & 12,600 & \\
\hline L-7xa & $: 14,000$ & & 12,900 & 13,500 \\
\hline$b$ & 14,000 & & 12,900 & 12,000 \\
\hline$L-11 b$ & 19,000 & & 17,700 & 21,300 \\
\hline L-15 & 5,200 & 5,700 & 5,500 & \\
\hline$L-24 a$ & 26,000 & & & 25,400 \\
\hline b & 26,000 & . & & 25,900 \\
\hline L-25a & 4,500 & & & 5,600 \\
\hline$b$ & 4,500 & & & 5,900 \\
\hline$L-27 b$ & 12,900 & & & 12,200 \\
\hline $\mathrm{L}-28$ & 16,800 & & & 17,500 \\
\hline \multirow[t]{2}{*}{$L=32 b$} & 7,500 & & 9,600 & 15,000 \\
\hline & & & 10,200 & \\
\hline
\end{tabular}



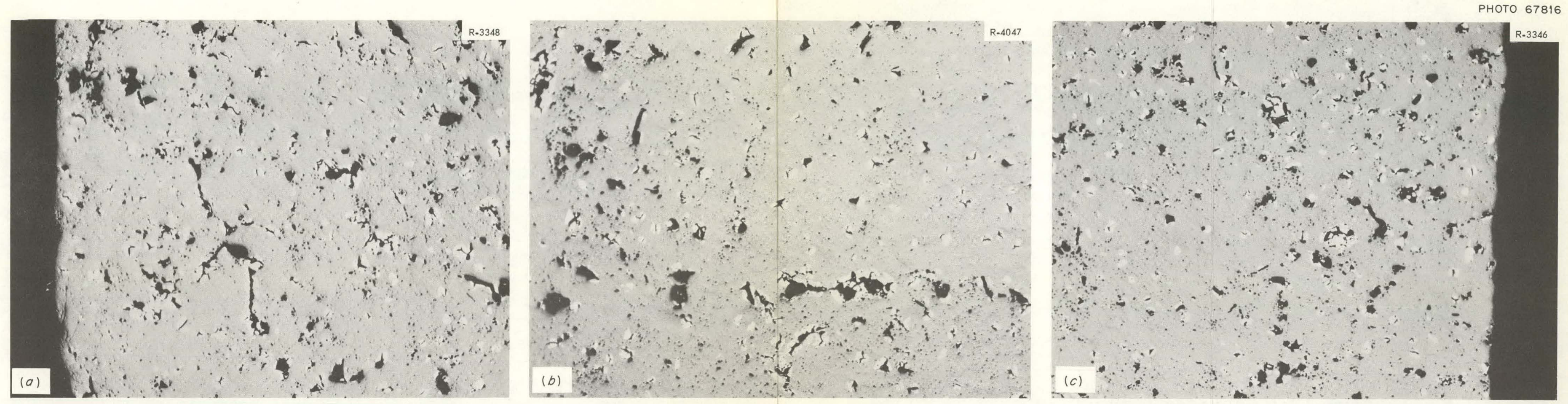

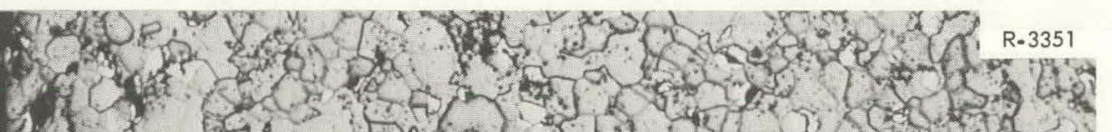
s.

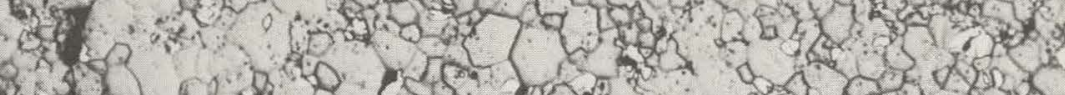

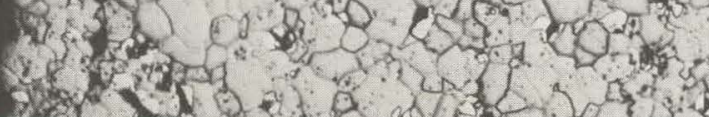

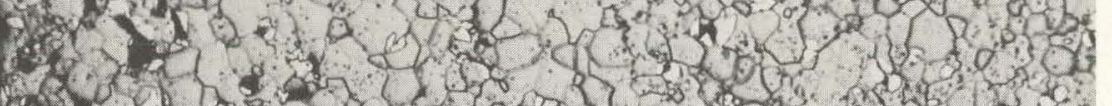

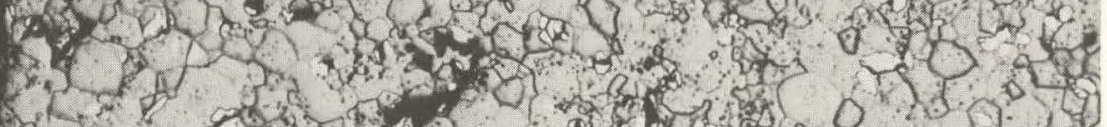

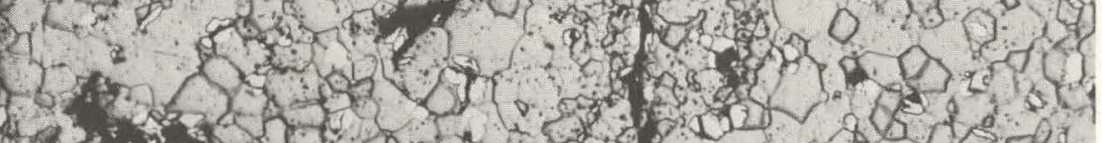

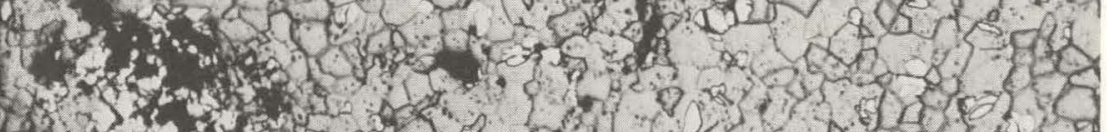

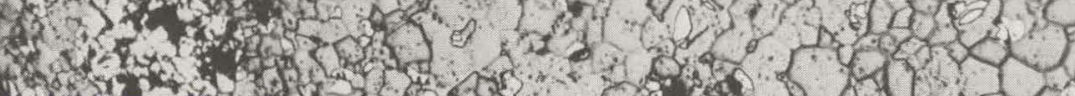

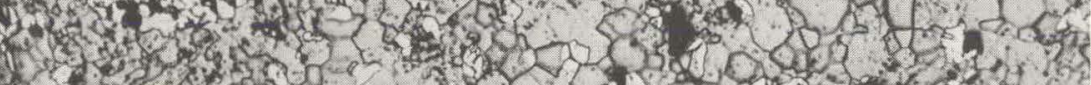

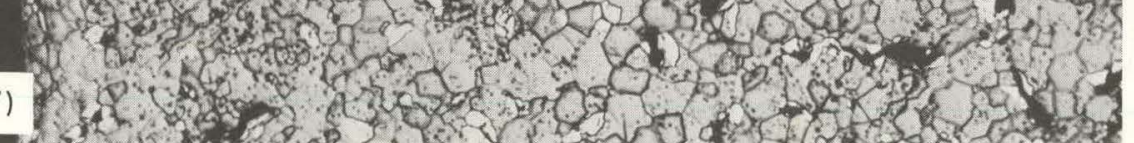
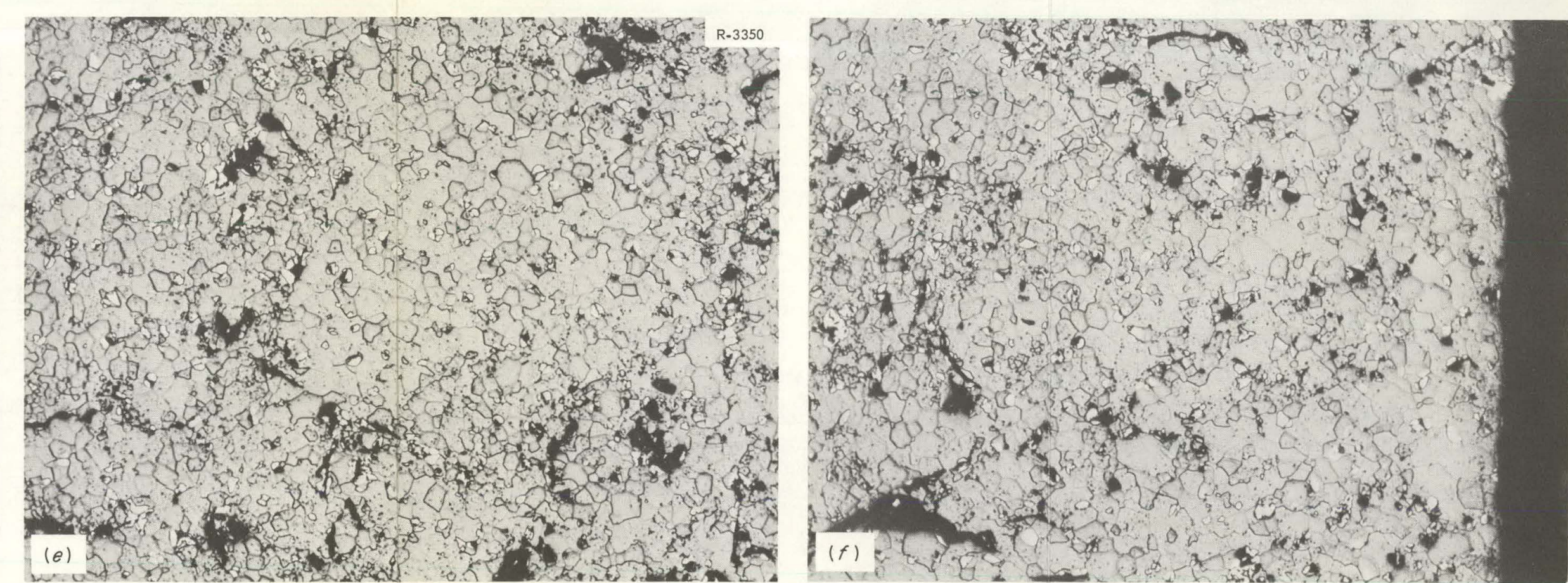

Fig. 38. Metullugruplic Sections of Unirradiatod Un, Enntral Snmple Representative of Fuel Pellets in Group 1 Capsules $01-1$ and 03-1. $(a)$, (b), and (c) show outer, central, and inner areas, respectively, of hollow pellet as polished. (d), (e), and (f) show same sections after etching. The light, second phase distributed throughout the microstructure has been identified as $U_{2}$. The grain-boundary pliase has not been dentified. Note porosity a 

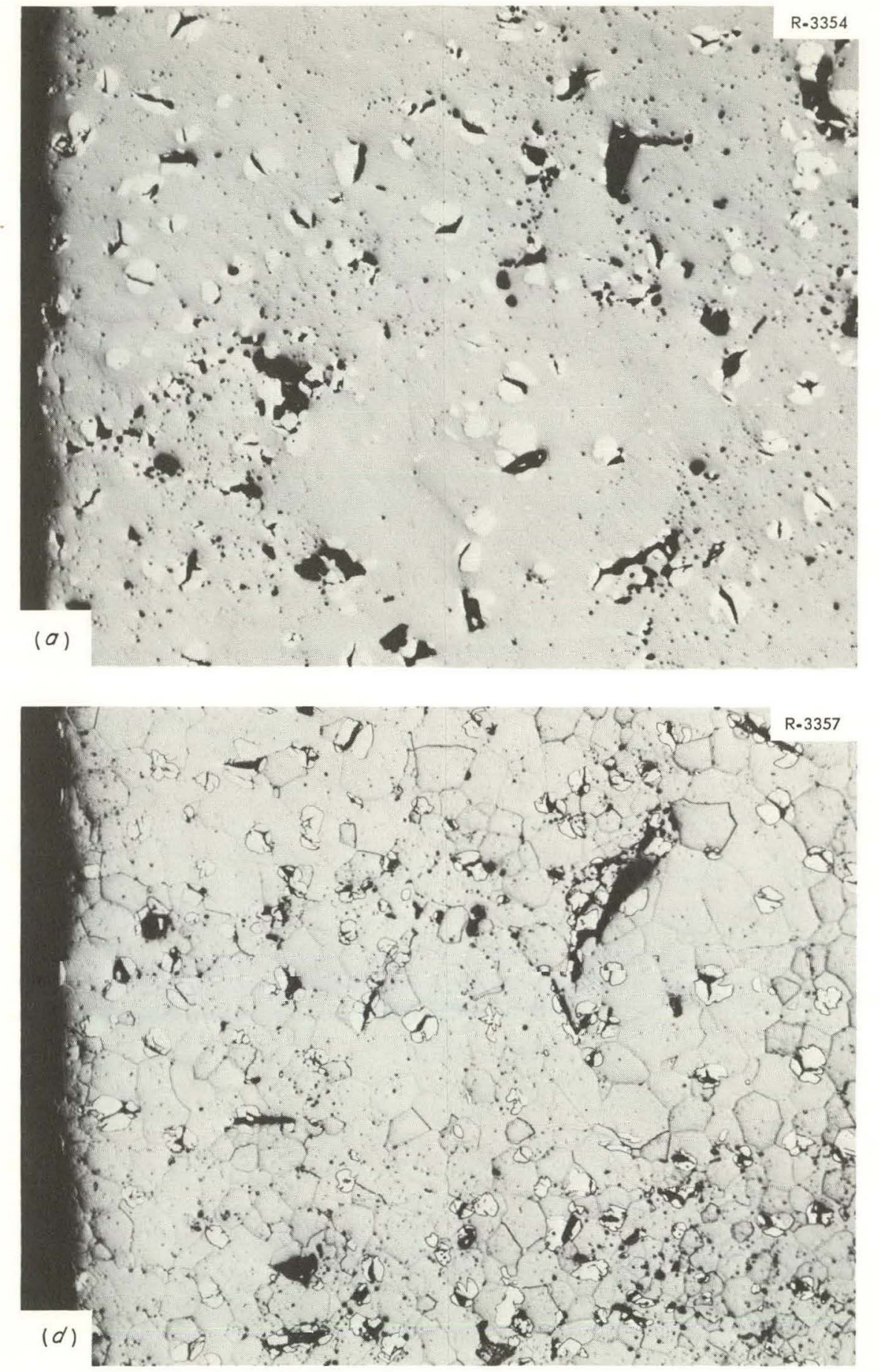
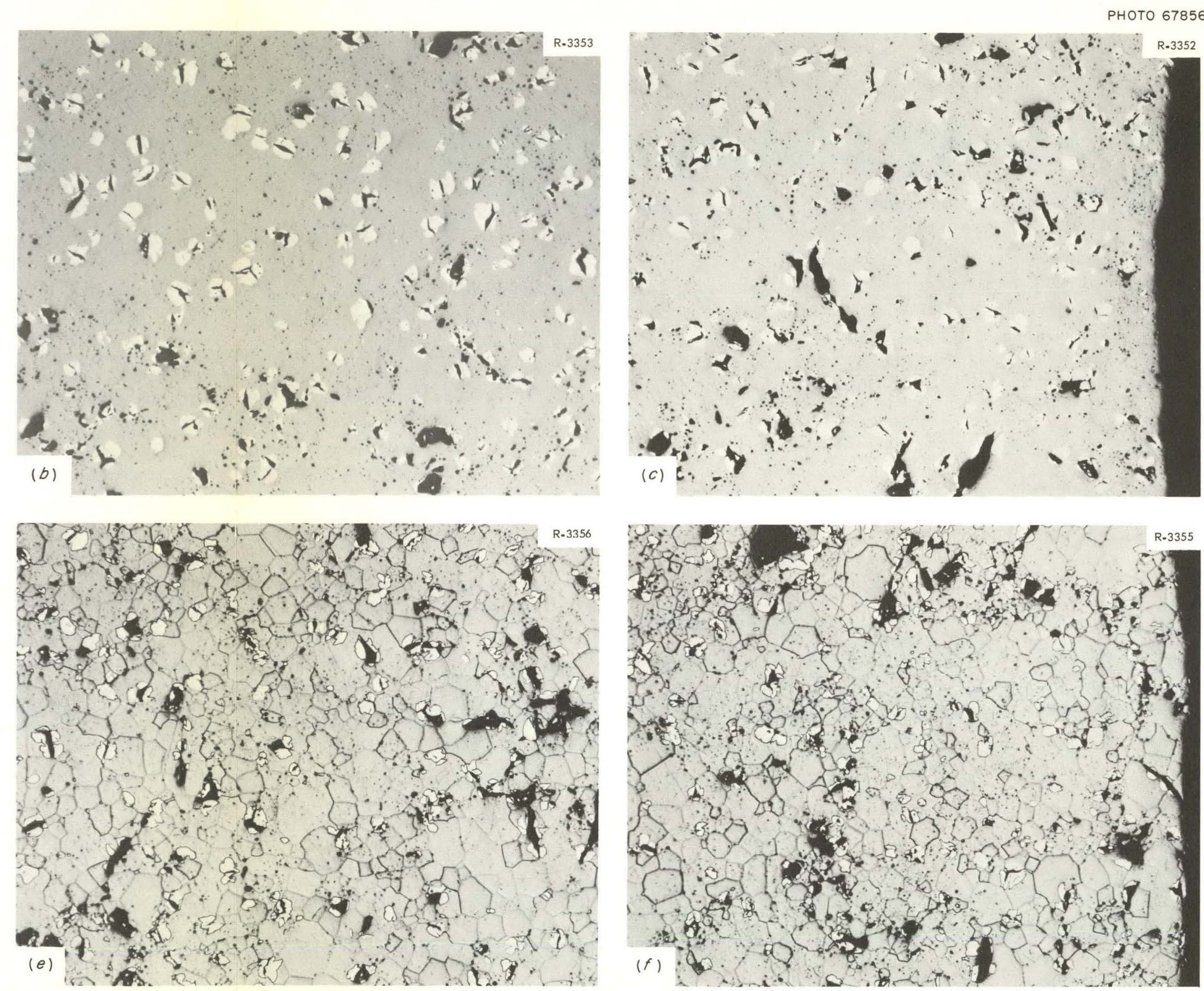

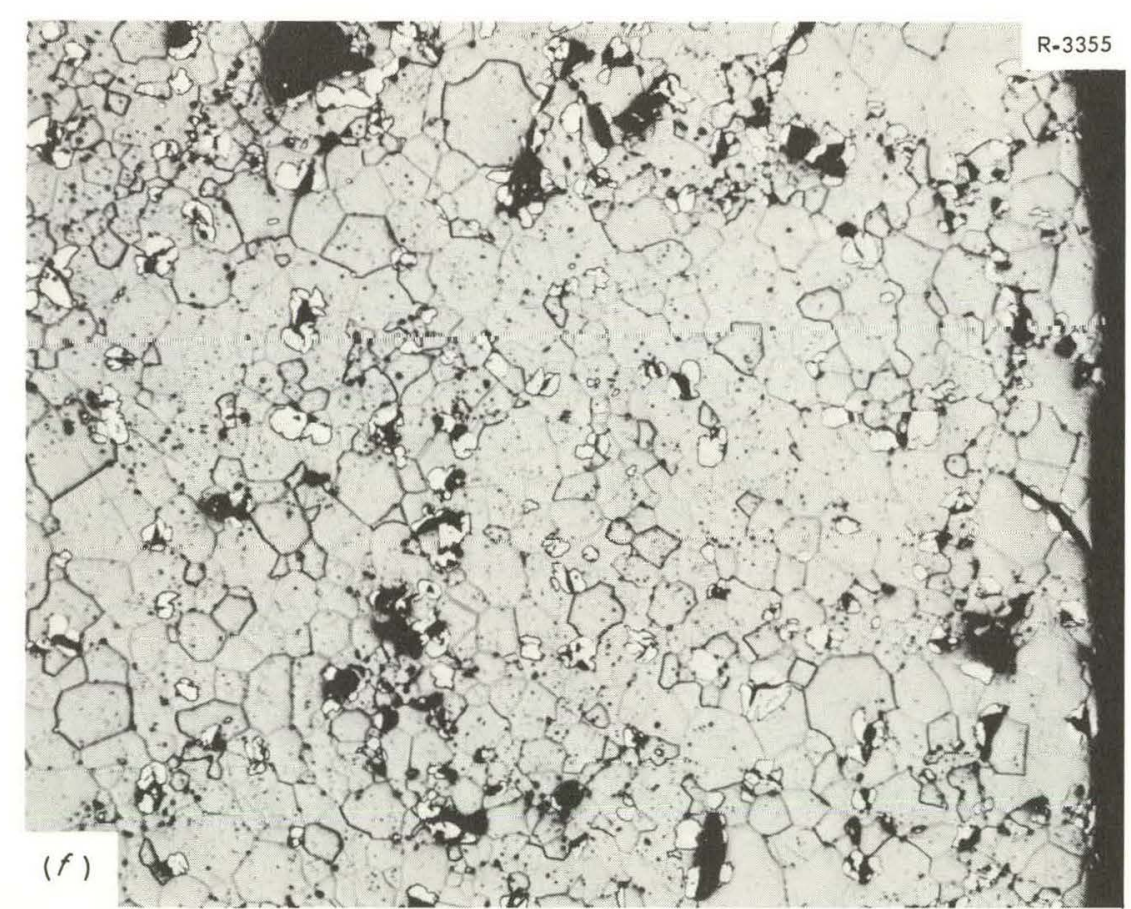

Fig. 39. Metallogite $(b)$, and $(c)$ show outer, central, and inner areas, respectively, of hollow pellet as polished. $(d)$, (e), and $(f)$ show same sections after etching. The light second phase distributed throughout microstructure has heen identified as $\mathrm{UN}_{2}$. The grain-boundury phase has not been identified. Note porosity and uniform, equiaxed grains. 250x. Reduced $12 \%$. 


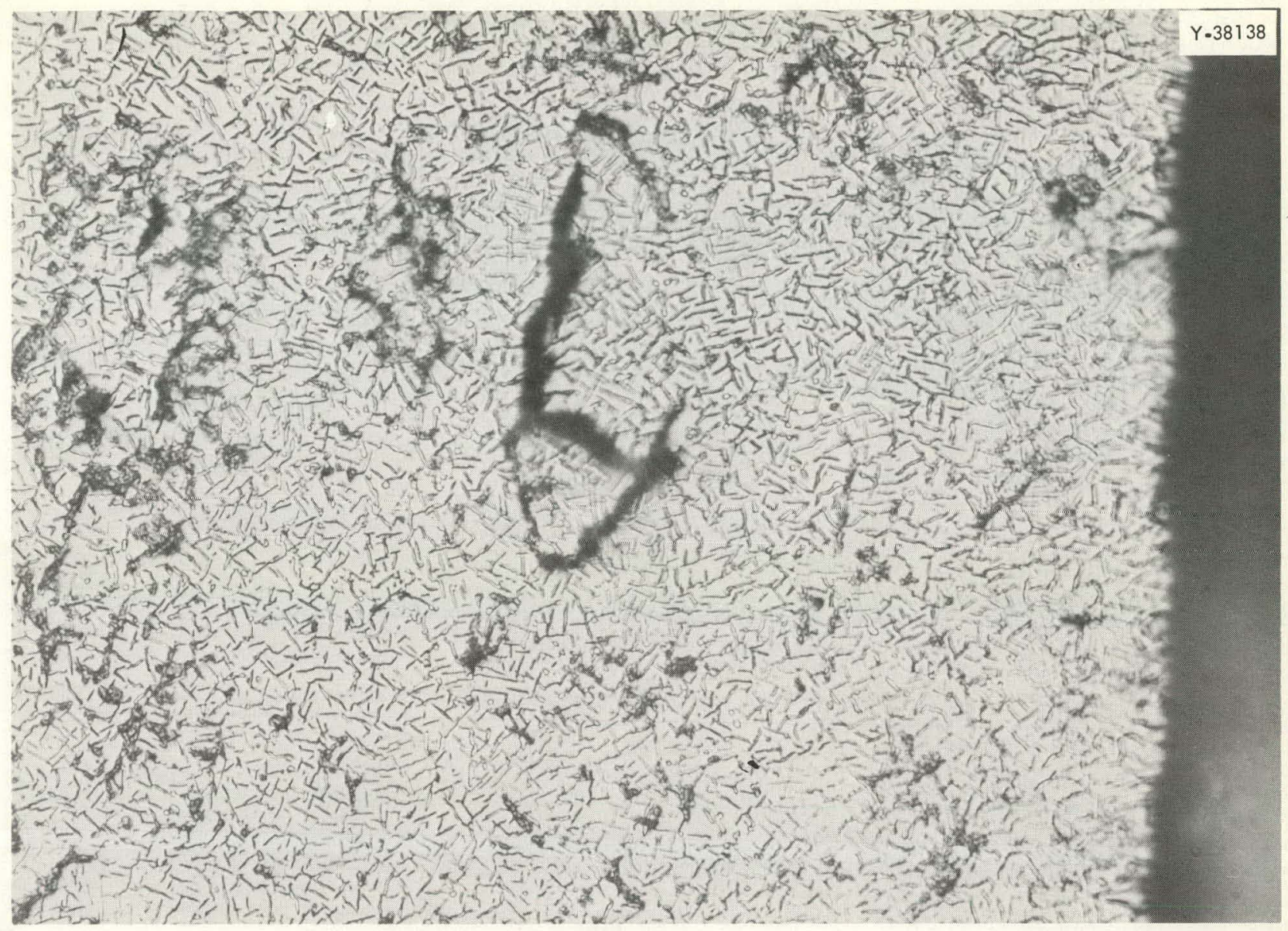

Fig. 40. Transverse Section at Inner Surface of Irradiated $\mathrm{UO}_{2}$ Pellet 40.9 from Capsule 01-1. This needle-like structure was dispersed throughout the inner half of the fuel pellet. An increase in size and frequency occurred as the inner surface was approached. Etched. 250x.

The group 2 fuel had a low nitrogen impurity content, typically $10 \mathrm{ppm}$, and the metallographic examination of the irradiated fuel showed no $\mathrm{U}_{2} \mathrm{~N}_{3}$ to be present, even though it appears that air was sealed in some of the elements prior to irradiation (see Table 1). No $\mathrm{U}_{4} \mathrm{O}_{9}$ was seen in either the controls or irradiated fuel of either group.

Only pellets from element 05-2 showed appreciable grain growth. Element 05-1, which had about the same central temperature as $05-2$, showed no appreciable increase in grain size. In most experiments, there was a slight variation in grain size across the pellets, the grains slightly increasing in size as the inside surface was approached.

Metallography appeared to indicate an increase in porosity in the irradiated pellets. However, it is believed that most of this was due to unavoidable "pullouts" during the polishing operation because of intergranular fractures that were present after irradiation. 
Metallographic examination of the fuel in the $\mathrm{O} / \mathrm{U}<2.02$ LITR experiments (which were all nominally $95 \%$ bulk density) indicated that generally

(1) There was little difference between the pre- and postirradiation grain size.

(2) Little or no variation in grain size and porosity across the pellet radius was apparent.

(3) Irradiation increased void size rather than number of voids.

(4) The irradiated pellets were exceedingly friable due to micro cracks.

(5) No micro structure features in the fuel could be consistently correlated with the fission-gas release. Metallographic examination of the fuel in the $\mathrm{O} / \mathrm{U}>2.02$ LITR experiments indicated that

(1) In the 75 and $85 \%$ bulk density pellets, the grain size increased from outside to inside and, in some cases, became quite large at the inside. In the $95 \%$ bulk density pellets, the grains were generally small and uniformly distributed.

(2) Usually the porosity was distributed uniformly across the pellet irrespective of the bulk density.

(3) The postirradiation inside diameter and outside diameter of the $75 \%$ pellets were appreciably smaller than the prei rradiation.

(4) The irradiated pellets were exceedingly friable due to micro cracks.

(5) No correlation between microstructure features and fission-gas release was found.

\subsection{Cladding Damage}

\subsubsection{Dimensional Changes of the Stainless Steel Cladding}

Generally the dimensional changes of the stainless steel cladding of the protutype elements were small as indicated in Tables 26 and 27 . The average diameter decreased less than $1 \%$ when surface temperatures were above $1300^{\circ} \mathrm{F}$, and had no change when temperatures were $1300^{\circ} \mathrm{F}$ or lower. There appeared to be no significant correlation of diameter change with pellet geometry or initial cold radial clearance. The collapse was no more than twice the minimum initial cold radial clearance (exccpt possibly in element 06-2).

At the higher surface temperatures, the cladding collapsed around the $\mathrm{UO}_{2}$ pellets without any longitudinal wrinkles. However, circumferential ridges were formed at the pellet interfaces. These ridges extend as much as $0.005 \mathrm{in}$. above the normal cladding surface. Their characteristics will be discussed more fully under cladding metallographic examination. Figure 41 presents representative outside diameter measurements for elements containing the three types of pellets, with the magnitude of the circum ferential ridges indicated.

Profilometer measurements in dicate the maximum bowing of an irradiated element to be less than 0.025 in. from the center line. Generally, the deviation from straightness was smallest for elements containing hollow, uncored pellets, with the deviation increasing with surface temperature for all three types of pellets. Tables 28 and 29 list the profile measurements for each group of elements. 
Table 26. Cladding Diameter Changes of EGCR Prototype Fuel Elements After Irradiation

\begin{tabular}{|c|c|c|c|c|c|}
\hline \multirow[t]{2}{*}{$\begin{array}{c}\text { Element } \\
\text { No. }\end{array}$} & \multirow[t]{2}{*}{$\begin{array}{c}\text { Pellet } \\
\text { Geometry }^{a}\end{array}$} & \multicolumn{2}{|c|}{$\begin{array}{c}\text { Pellet-to-Cladding } \\
\text { Cold Radial } \\
\text { Clearance (in.) }\end{array}$} & \multirow{2}{*}{$\begin{array}{c}\text { Av Cladding } \\
\text { Surface Temperature } \\
\text { During Operation } \\
(\mathrm{F})\end{array}$} & \multirow{2}{*}{$\begin{array}{c}\text { Av Cladd ing Diameter } \\
\text { Change After } \\
\text { Irradiation }{ }^{b} \\
\text { (in.) }\end{array}$} \\
\hline & & Maximum & Minimum & & \\
\hline $07-1$ & $\mathrm{~s}$ & 0.0031 & 0.0021 & 1250 & 0 \\
\hline $07-2$ & $s$ & 0.0028 & 0.0024 & 1290 & -0.002 \\
\hline O3-1 & $\mathrm{H}$ & 0.0029 & 0.0018 & 1300 & 0 \\
\hline 01.2 & $\mathrm{H}$ & 0.0033 & 0.0024 & 1310 & 0 \\
\hline $03-2$ & $\mathrm{H}$ & 0.0031 & 0.0024 & 1315 & -0.003 \\
\hline O4 2 & $\mathrm{H} \cdot \mathrm{B}$ & 0.0031 & 0.0024 & 1320 & -0.002 \\
\hline $01-1$ & $\mathrm{H}$ & 0.0029 & 0.0016 & 1325 & 0 \\
\hline O4-1 & $\mathrm{H}-\mathrm{B}$ & 0.0027 & 0.0019 & 1325 & 0 \\
\hline $05-1$ & $\mathrm{H}$ & 0.0031 & 0.0020 & 1450 & -0.002 \\
\hline $02-2$ & $\mathrm{H}$ & 0.0029 & 0.0024 & 1460 & -0.002 \\
\hline O6-1 & $\mathrm{H}-\mathrm{B}$ & 0,0031 & 0.0016 & 1475 & -0.002 \\
\hline $05-2$ & $\mathrm{H}$ & 0.0031 & 0.0022 & 1475 & -0.004 \\
\hline $08-2$ & $\mathrm{~s}$ & 0.0029 & 0.0024 & 1485 & -0.004 \\
\hline O6-2 & $\mathrm{H}-\mathrm{B}$ & 0.0027 & 0.0020 & 1490 & -0.005 \\
\hline $08-1$ & $\mathrm{~s}$ & 0.0031 & 0.0020 & 1500 & 0 \\
\hline O2-1 & $\mathrm{H}$ & 0.0030 & 0.0020 & 1515 & -0.004 \\
\hline
\end{tabular}

${ }^{a} \mathrm{H}=$ hollow pellet; $\mathrm{H}-\mathrm{B}=$ hollow pellet with $\mathrm{BeO}$ rod in void; $\mathrm{S}=$ solid pellet.

${ }^{b} \pm 0.0005$.

Figure 42 illustrates plots of the profile measurements of the least severely and most severely bowed group 2 elements. In Fig. 43 are plotted the profile measurements of representative elements loaded with the different types of pellets. Figure 44 indicates the relationship between a gamma scan and the dimensional measurements of element: 01-1 - this is typical. Other gamma scans are given in A ppendix $\mathrm{C}$.

\subsubsection{Cladding ond Fuel Reactions}

The cladding of all the prototype elements had dark markings on the inside surfaces opposite large cracks in the pellets and at pellet-pellet interfaces, as illustrated in Fig. 45. No other evidences of reactions were found in the group 2 elements.

Several types of deposits were found in the group 1 elements. Iron oxide was found on the top four pellets and inside cladding surface of 01-1 and 03-1, and on most of the fuel in 05-1. The cladding of n5-1 npposite the top MgO spacer was also heavily coated with iron oxide. Pale green deposits on the 
Table 27. Cladding Diameter Measurements of ORR Irradiated Group 2 Elements

\begin{tabular}{|c|c|c|c|c|}
\hline $\begin{array}{c}\text { Capsule } \\
\text { No. }\end{array}$ & $\begin{array}{c}\text { Cladding } \\
\text { Temperature } \\
\text { During Irradiation } \\
\left({ }^{\circ} \mathrm{F}\right)\end{array}$ & $\begin{array}{c}\text { Measurement } \\
\text { Position Along } \\
\text { Length } \\
\text { (in. from bottom) }\end{array}$ & $\begin{array}{c}\text { Change in } \\
\text { Cladding } \\
\text { Diameter } \\
\text { After Irradiation } \\
\text { (in.) }\end{array}$ & $\begin{array}{c}\text { Av Change in } \\
\text { Cladding } \\
\text { Diameter } \\
\text { After Irradiation } \\
\text { (in.) }\end{array}$ \\
\hline \multirow[t]{6}{*}{$01-2$} & 1310 & 1 & 0 & \\
\hline & & 2 & 0 & \\
\hline & & 3 & -0.001 & 0.000 \\
\hline & & 4 & 0 & \\
\hline & & 5 & 0 & \\
\hline & & 6 & 0 & . \\
\hline \multirow[t]{6}{*}{$02-2$} & 1460 & 1 & -0.002 & \\
\hline & & 2 & -0.001 & \\
\hline & & 3 & -0.003 & -0.002 \\
\hline & & 4 & +0.002 & \\
\hline & & 5 & -0.003 & \\
\hline & . & 6 & -0.003 & \\
\hline \multirow[t]{6}{*}{$03-2$} & 1315 & 1 & -0.002 & \\
\hline & & 2 & -0.004 & \\
\hline & & 3 & -0.004 & -0.003 \\
\hline & & 4 & -0.005 & \\
\hline & & 5 & -0.005 & \\
\hline & & 6 & 0 & \\
\hline \multirow[t]{6}{*}{$04-2$} & 1320 & 1 & -0.003 & \\
\hline & & 2 & -0.002 & \\
\hline & & 3 & -0.002 & -0.002 \\
\hline & & 4 & -0.005 & . \\
\hline & & 5 & -0.001 & \\
\hline & & 6 & o & \\
\hline \multirow[t]{6}{*}{$05-2$} & 1475 & 1 & -0.003 & \\
\hline & & 2 & -0.005 & \\
\hline & & 3 & -0.006 & -0.004 \\
\hline & & 4 & -0.005 & \\
\hline & . & 5 & -0.003 & \\
\hline & & 6 & -0.002 & \\
\hline \multirow[t]{6}{*}{$06-2$} & 1490 & 1 & -0.005 & \\
\hline & . & 2 & -0.006 & \\
\hline & & 3 & -0.008 & -0.005 \\
\hline & & 4 & -0.004 & \\
\hline & & 5 & -0.005 & \\
\hline & & 6 & $-0,003$ & \\
\hline \multirow[t]{6}{*}{$07-2$} & 1290 & 1 & -0.003 & \\
\hline & & 2 & -0.002 & \\
\hline & & 3 & -0.004 & -0.002 \\
\hline & & 4 & -0.003 & \\
\hline & & 5 & -0.003 & \\
\hline & & 6 & +0.001 & \\
\hline \multirow[t]{6}{*}{$08-2$} & 1485 & 1 & -0.004 & \\
\hline & & 2 & -0.005 & \\
\hline & & 3 & -0.004 & -0.004 \\
\hline & & 4 & -0.004 & \\
\hline & & 5 & -0.004 & \\
\hline & & 6 & -0.002 & \\
\hline
\end{tabular}



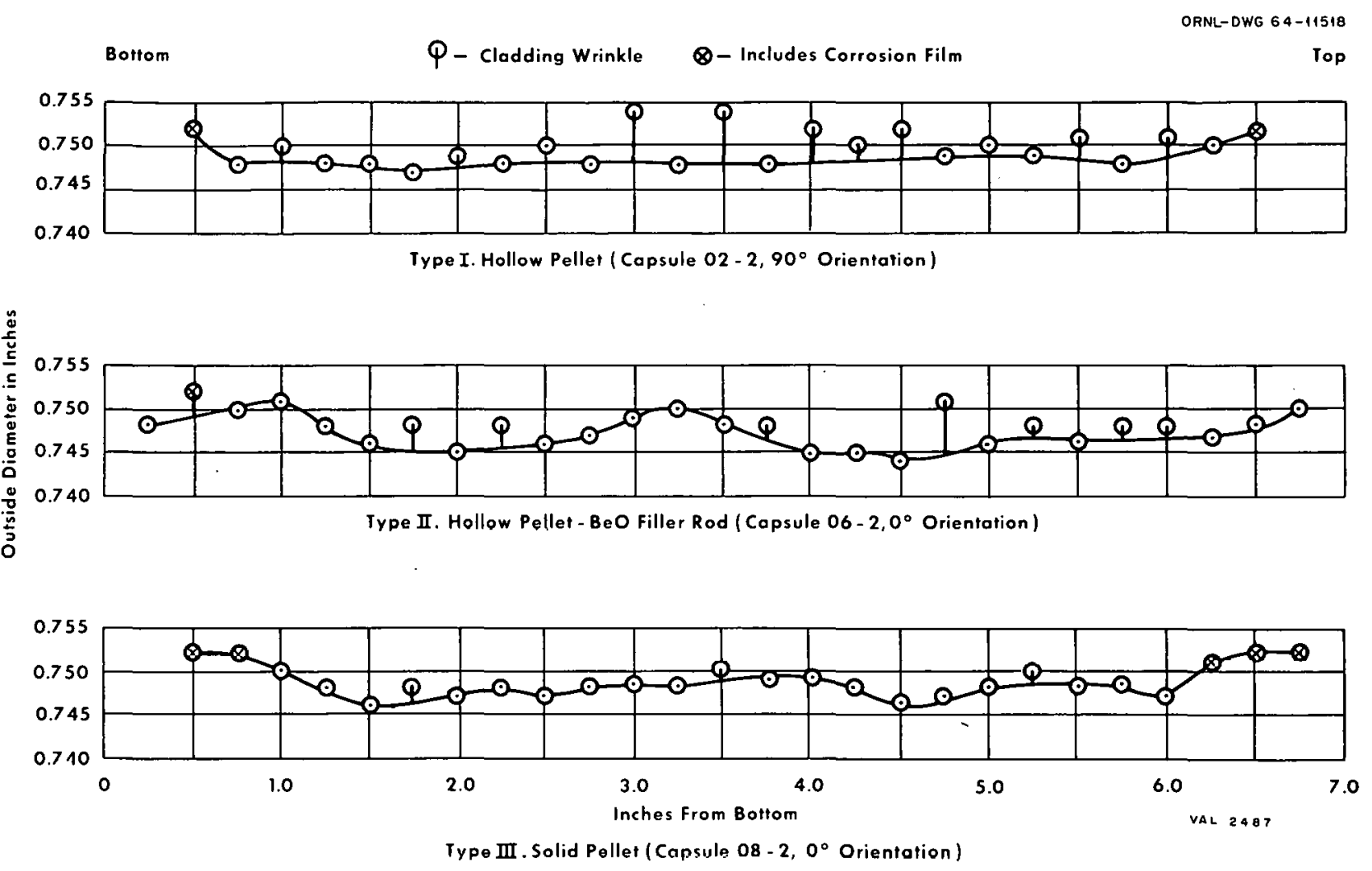

Fig. 41. Representative OD Measurements of Cladding of Irradiated Prototype Capsules.

outer surfaces of pellets were found in 03-1 and 05-1, with somewhat lesser amounts on the cracked surfaces and inside surface of pellets in 05-1. In addition, two blue spots were found on pellet 7 of element 03-1, and in element 05-1 a white deposit was present in the same areas as the green deposit but to a lesser degree.

Generally both MgO spacers had dark rings corresponding to the pellet ID on the side toward the fuel. In addition, the bottom spacer of element 01-1 contained a deposit of gray material in the area adjacent to the central void in the fuel. The top spacer of 05-1 had a small white deposit, and the spacers of 02-1 and 03-1 were somewhat discnlnred, particularly on the sides toward the fuel. Autoradiographs of the spacers showed that most of the radioactivity was confined to the surfaces of the spacers.

The NaK appeared to cause a slight amount of decarburization at the outer surface of the cladding, usually affecting about one to three grains $(\sim 0.003$ in.). However, decarburization was present for about one-third of the cladding thickness in element 04-2. 
Table 28. Summary of Profilometer Measurements for EGCR Prototype Group 1 Elements

\begin{tabular}{|c|c|c|c|c|c|c|c|c|c|c|c|c|c|c|c|c|}
\hline \multirow{2}{*}{$\begin{array}{c}\text { Element } \\
\text { No. }\end{array}$} & \multirow{2}{*}{$\begin{array}{l}\text { Angular } \\
\text { Position }\end{array}$} & \multicolumn{15}{|c|}{ Average Displacement in 0.001 in. at Position No. } \\
\hline & & 1 & 2 & 3 & 4 & 5 & 6 & 7 & 8 & 9 & 10 & 11 & 12 & 13 & 14 & 15 \\
\hline \multirow[t]{2}{*}{$01-1$} & $0-180^{\circ}$ & 0.0 & +0.55 & +1.35 & +2.2 & +2.9 & +3.1 & +3.1 & +3.85 & +3.2 & +2.85 & +2.9 & +2.55 & +1.1 & +0.2 & -0.6 \\
\hline & $90-270^{\circ}$ & -0.6 & 0.0 & +0.3 & +1.1 & +1.15 & +1.25 & +1.6 & +1.3 & +1.35 & +1.1 & +1.35 & +1.0 & +0.6 & +0.0 & -0.6 \\
\hline \multirow[t]{2}{*}{$02-1$} & $0-180^{\circ}$ & -0.5 & +0.6 & +1.35 & -3.05 & -2.7 & -2.2 & -1.95 & -1.75 & -1.8 & -3.4 & -4.85 & -8.2 & -6.3 & -0.25 & +0.45 \\
\hline & $90-270^{\circ}$ & -0.9 & +0.15 & $\div 2.1$ & +2.55 & +2.25 & +1.5 & +2.05 & +2.85 & +3.35 & +3.2 & +4.0 & +3.8 & +2.9 & -0.25 & -0.95 \\
\hline \multirow[t]{2}{*}{ O3-1 } & $0-180^{\circ}$ & 0.0 & +0.4 & $\div 0.8$ & +1.8 & +1.5 & +1.25 & +1.0 & +0.3 & -0.05 & +0.15 & +0.1 & +0.4 & +0.25 & +0.15 & 0.0 \\
\hline & $90-270^{\circ}$ & -0.7 & -0.15 & -0.05 & +0.25 & +0.15 & +0.35 & +0.45 & +0.45 & +0.8 & +0.8 & +1.2 & +0.45 & +0.1 & -0.2 & -0.35 \\
\hline \multirow[t]{2}{*}{ 04-1 } & $0-180^{\circ}$ & +0.25 & -0.35 & -1.5 & -2.5 & -3.25 & -4.4 & -5.9 & -6.45 & -6.6 & -7.95 & -5.05 & -4.55 & -1.95 & +0.2 & +1.45 \\
\hline & $90-270^{\circ}$ & +1.4 & -0.7 & -3.7 & -6.05 & -12.0 & -11.95 & -7.65 & -8.65 & -9.7 & -9.75 & -7.9 & -4.15 & -1.05 & +0.9 & +2.1 \\
\hline \multirow[t]{2}{*}{$05-1$} & $0-180^{\circ}$ & +1.45 & -0.1 & -1.6 & -3.8 & -4.65 & -6.15 & -8.05 & -9.2 & -9.75 & -9.35 & -10.55 & -8.6 & -4.45 & +0.15 & +1.65 \\
\hline & $90-270^{\circ}$ & +0.25 & +0.9 & +1.4 & +2.2 & +0.25 & +1.3 & +3.53 & +3.4 & +3.5 & +4.8 & +4.35 & +4.6 & +3.15 & -0.4 & -1.35 \\
\hline \multirow[t]{2}{*}{$06-1$} & $0-180^{\circ}$ & +0.55 & +0.25 & +0.55 & -0.4 & +0.05 & +0.25 & +0.3 & +0.3 & -0.2 & -3.0 & -4.95 & -3.65 & -3.3 & +0.5 & +1.35 \\
\hline & $90-270^{\circ}$ & +0.65 & +0.55 & +0.15 & -0.5 & +0.45 & +2.45 & +3.1 & +5.05 & +6.8 & $+11: 25$ & +15.1 & +14.1 & +8.2 & -0.45 & -2.45 \\
\hline \multirow[t]{2}{*}{$07-1$} & $0-180^{\circ}$ & -0.05 & -0.3 & -0.95 & -1.15 & -1.15 & -1.95 & -3.75 & -2.6 & -2.6 & -2.0 & -0.9 & -0.45 & -0.45 & -0.05 & -0.35 \\
\hline & $90-270^{\circ}$ & +0.15 & -0.15 & -0.3 & -1.0 & -1.0 & -2.55 & -3.1 & -3.9 & -2.45 & -2.4 & -0.7 & -0.25 & +0.25 & +0.04 & +0.3 \\
\hline \multirow[t]{2}{*}{$08-1$} & $0-180^{\circ}$ & +0.5 & -0.35 & -1.65 & -2.75 & -3.8 & -5.2 & -8.85 & -8.45 & -7.75 & -4.9 & -4.5 & -2.55 & -1.55 & -0.2 & +0.65 \\
\hline & $90-270^{\circ}$ & +0.75 & +0.4 & -0.4 & -0.8 & -1.75 & -1.05 & -2.45 & -2.35 & -3.35 & -3.3 & -2.2 & -1.05 & -0.6 & -0.25 & -0.05 \\
\hline
\end{tabular}


Table 29. Profile Measurements for EGCR Prototype Group 2 Elements (in mils)

\begin{tabular}{|c|c|c|c|c|c|c|c|c|c|c|c|c|c|c|c|c|c|c|c|c|c|c|c|c|c|c|c|c|c|c|c|c|}
\hline \multirow{2}{*}{ Positior. } & \multicolumn{4}{|c|}{$01-2$} & \multicolumn{4}{|c|}{$02 \cdot 2$} & \multicolumn{4}{|c|}{ O3-2 } & \multicolumn{4}{|c|}{$04 \cdot 2$} & \multicolumn{4}{|c|}{$05-2$} & \multicolumn{4}{|c|}{06.2} & \multicolumn{4}{|c|}{$07-2$} & \multicolumn{4}{|c|}{$08-2$} \\
\hline & $0^{\circ}$ & $90^{\circ}$ & $180^{\circ}$ & $270^{\circ}$ & $0^{\circ}$ & $90^{\circ}$ & $180^{\circ}$ & $270^{\circ}$ & $0^{\circ}$ & $60^{\circ}$ & $180^{\circ}$ & $270^{\circ}$ & $0^{\circ}$ & $90^{\circ}$ & $180^{\circ}$ & $270^{\circ}$ & $0^{\circ}$ & $90^{\circ}$ & $130^{\circ}$ & $270^{\circ}$ & $0^{\circ}$ & $90^{\circ}$ & $180^{\circ}$ & $270^{\circ}$ & $0^{\circ}$ & $90^{\circ}$ & $180^{\circ}$ & $270^{\circ}$ & $0^{\circ}$ & $90^{\circ}$ & $180^{\circ}$ & $270^{\circ}$ \\
\hline 0.5 & +4 & +2 & +1 & +3 & +12 & -8 & +11 & +7 & +9 & -3 & +2 & +6 & +8 & +7 & +6 & +3 & +11 & +14 & +7 & +2 & +24 & +9 & +24 & +7 & +33 & 0 & +2 & +24 & +2 & +2 & +18 & +12 \\
\hline 1.0 & +3 & +2 & +1 & +3 & +4 & -10 & +17 & 0 & +7 & -3 & +2 & +6 & +7 & +7 & +5 & +2 & +4 & +3 & +16 & +5 & +3 & +1 & +38 & +16 & +21 & 0 & +12 & +16 & +11 & +7 & +11 & 0 \\
\hline 1.5 & +2 & +2 & +2 & $t=$ & +2 & $\div 6$ & +15 & 0 & +6 & +2 & +3 & +5 & +6 & +6 & +4 & +3 & +3 & +2 & +16 & +8 & +5 & 0 & +38 & +14 & +9 & +4 & +21 & +6 & +16 & +6 & +6 & +1 \\
\hline 2.0 & +1 & +1 & +2 & $+\varepsilon$ & 0 & +7 & +15 & +1 & +4 & -2 & +3 & +3 & +4 & +3 & +4 & +3 & +2 & +1 & +13 & +7 & 0 & +2 & +35 & +12 & +1 & +6 & +28 & 0 & +17 & +3 & 0 & +8 \\
\hline 2.5 & c: & +1 & +2 & $+i$ & 0 & +5 & +13 & +2 & +3 & -3 & +4 & 0 & +1 & +1 & +5 & +4 & +3 & +1 & +11 & +6 & +1 & +2 & +34 & +11 & 0 & +5 & +28 & 0 & +16 & +2 & +1 & +7 \\
\hline 3.0 & C & +2 & +3 & +1 & +2 & +3 & +11 & +1 & +1 & $\div 4$ & +5 & 0 & 0 & +1 & +5 & +6 & +2 & +1 & +11 & +6 & +3 & +4 & +30 & +6 & +1 & +5 & +24 & 0 & +11 & 0 & +2 & +5 \\
\hline 3.5 & c & +1 & +3 & 0 & +3 & +3 & +9 & +2 & 0 & +3 & +6 & 0 & +1 & 0 & +4 & +5 & 0 & to & +9 & +8 & +5 & +6 & +26 & +2 & +3 & +4 & +20 & +3 & +9 & 0 & +4 & +8 \\
\hline 4.0 & $+\bar{z}$ & +1 & +2 & 0 & +4 & +4 & +7 & +2 & 0 & +3 & +4 & +1 & +2 & 0 & +2 & +3 & 0 & +o & +7 & +8 & +7 & +11 & +31 & +2 & +4 & +3 & +19 & +3 & +7 & +1 & +6 & +7 \\
\hline 4.5 & +6 & 0 & +1 & $+i$ & +5 & +2 & +5 & 0 & +3 & +1 & +3 & +1 & +4 & 0 & +2 & +3 & +1 & +1 & +6 & +6 & $\div 9$ & +7 & +16 & +1 & +8 & +3 & +13 & +6 & +6 & +3 & +8 & +5 \\
\hline 5.0 & +6 & 0 & +1 & +2 & +7 & 0 & +4 & +1 & +6 & +1 & +2 & +2 & +8 & 0 & +1 & +2 & 0 & +2 & +5 & +4 & $\div 11$ & +5 & +12 & 0 & +13 & +2 & +9 & +8 & +4 & +2 & +10 & +5 \\
\hline 5.5 & +5 & 0 & 0 & +3 & +7 & +1 & +1 & +2 & +8 & +1 & +1 & +4 & +8 & +1 & +1 & +1 & +2 & +4 & +3 & +2 & $\div 13$ & +3 & +7 & 0 & +17 & +2 & +5 & +13 & +3 & +3 & +11 & +3 \\
\hline$E .0$ & +4 & 0 & 0 & +3 & +7 & 0 & +1 & +4 & +8 & +1 & 0 & +5 & +8 & +2 & 0 . & +1 & +3 & +5 & 0 & 0 & $\div 16$ & +3 & +3 & 0 & +18 & +2 & +2 & +14 & 0 & +1 & +11 & +8 \\
\hline E.5 & +4 & +1 & 0 & +3 & +11 & +1 & 0 & +4 & +8 & +0 & 0 & +3 & +8 & +4 & 0 & 0 & +6 & +8 & 0 & 0 & +23 & +1 & 0 & +2 & +19 & +1 & 0 & +16 & +2 & 0 & +11 & +8 \\
\hline $\begin{array}{l}\text { Maximum } \\
\text { change in } \\
\text { profile }\end{array}$ & $\epsilon$ & 2 & 3 & 3 & 12 & 10 & 17 & 7 & 9 & 4 & 6 & 6 & 8 & 7 & 6 & 6 & 11 & 14 & 16 & 8 & 24 & 11 & $3 B$ & 16 & 33 & 6 & 28 & 24 & 17 & 7 & 18 & 12 \\
\hline
\end{tabular}


ORNL-LR-DWG 55105

CAPSULE O6-2 PROFILE

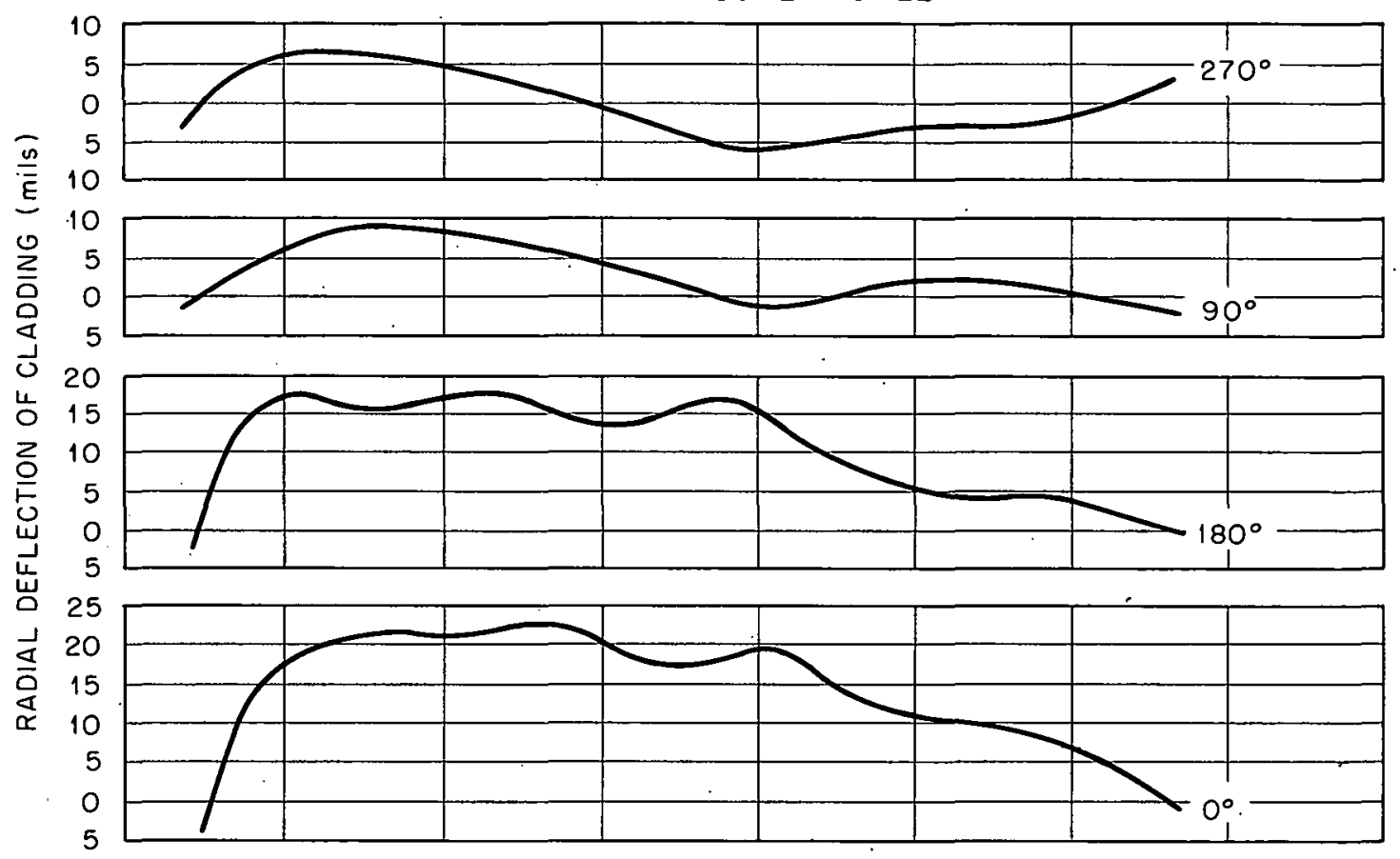

CAPSULE 01-2 PROFILE
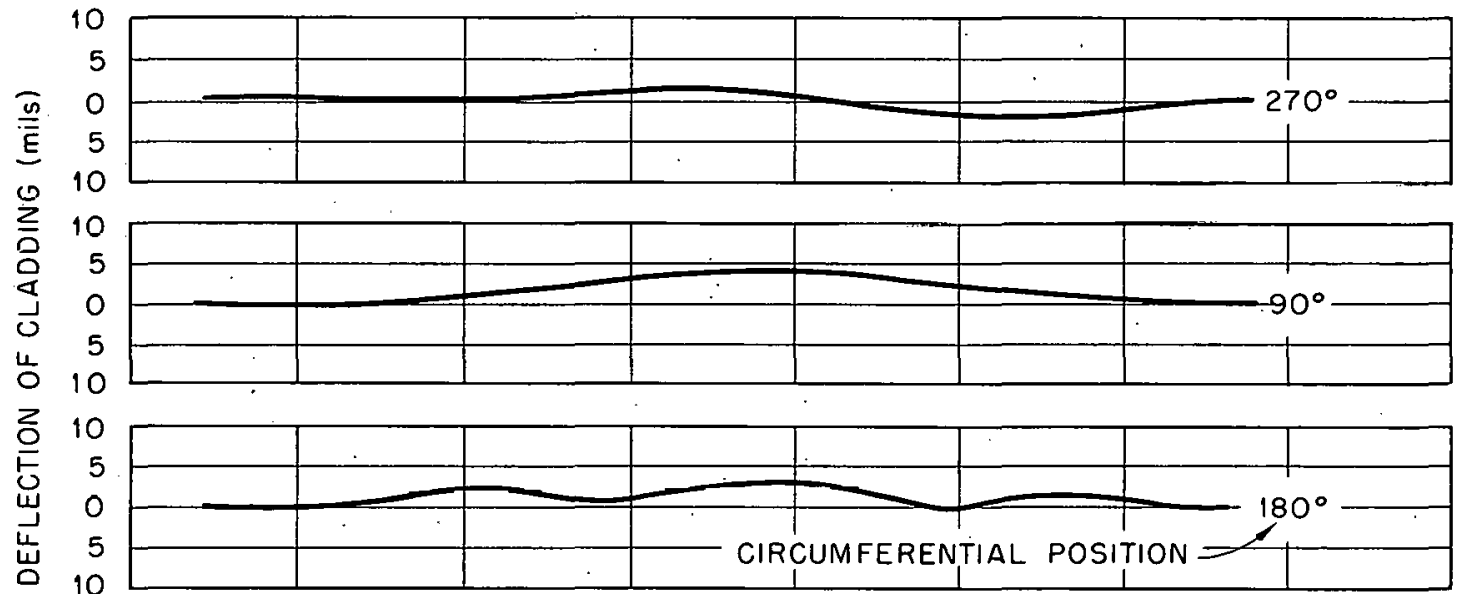

$\frac{1}{0}$

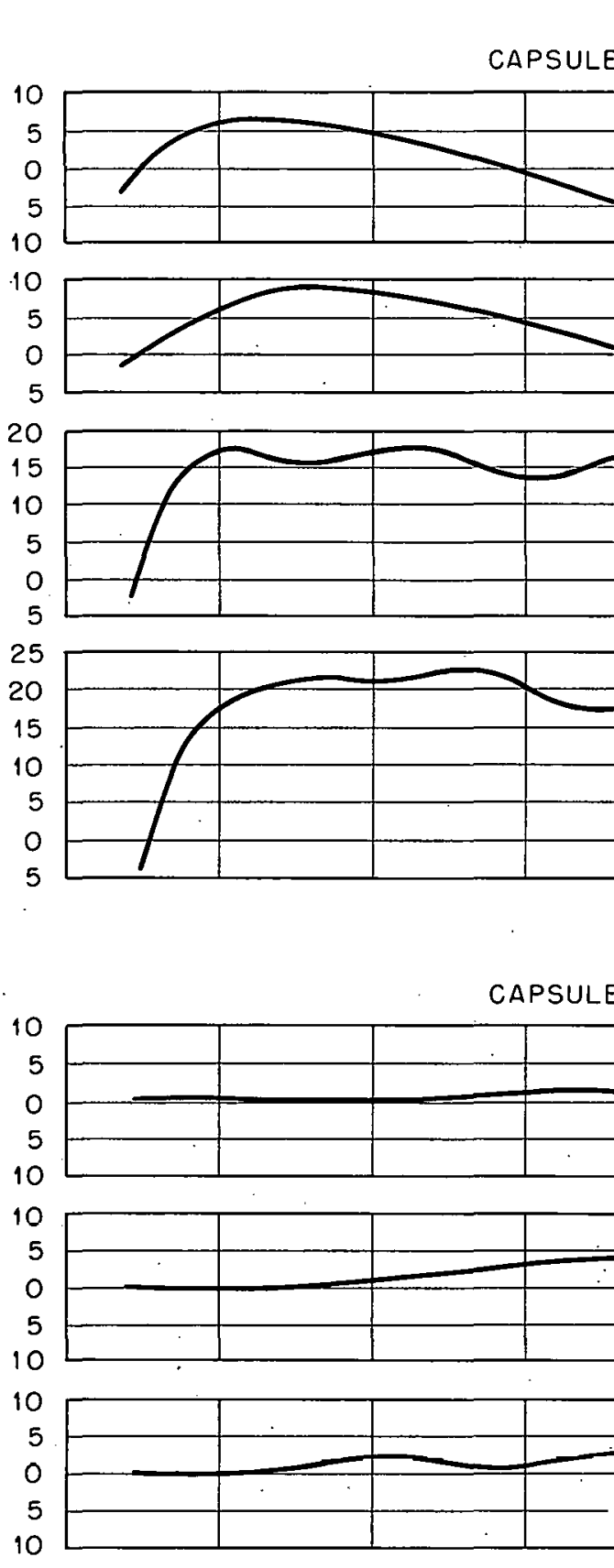




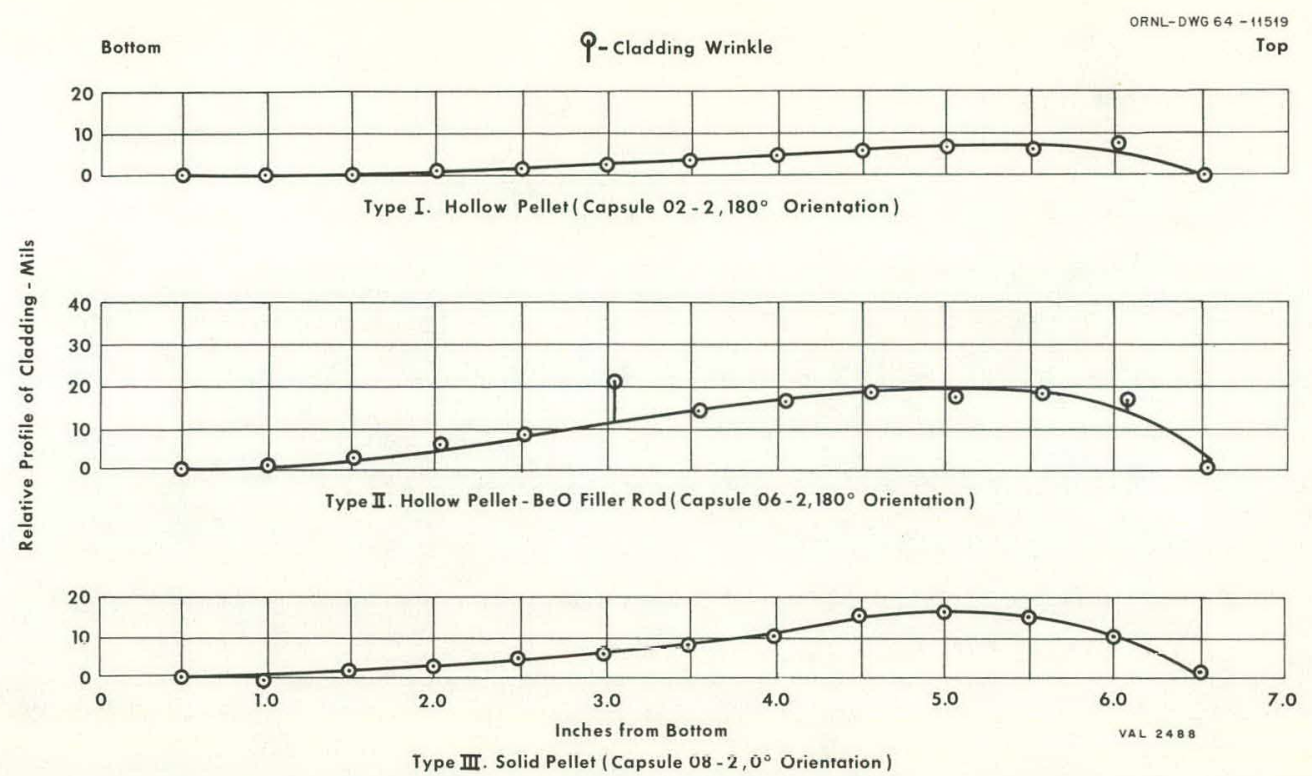

Fig. 43. Representative Profile of Cladding for Irradiated Group 2 ORR Capsules.

Fig. 44. Dimensional Measurements and Gamma Activity Scan of ORR Capsule 01-1.

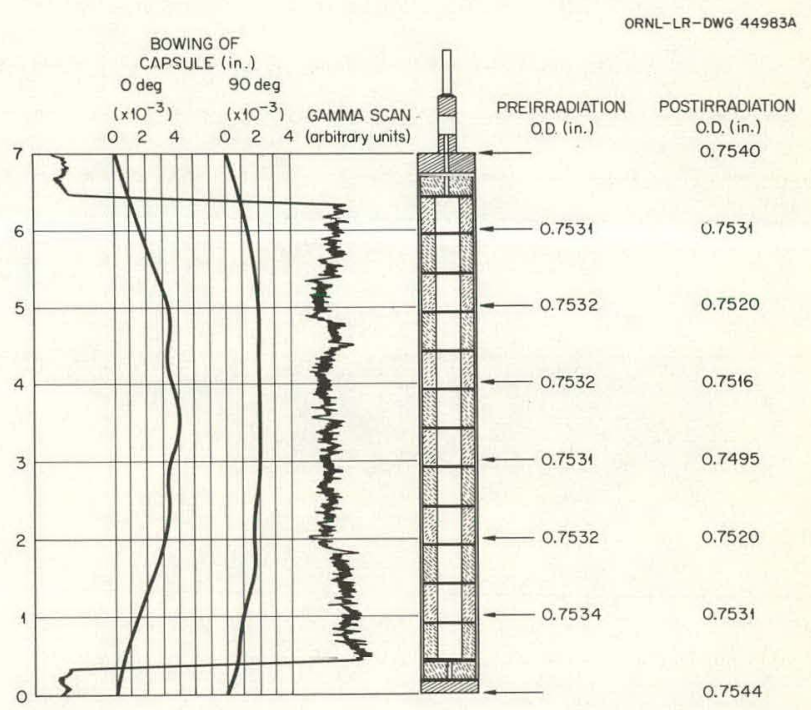

PHOTO 67817
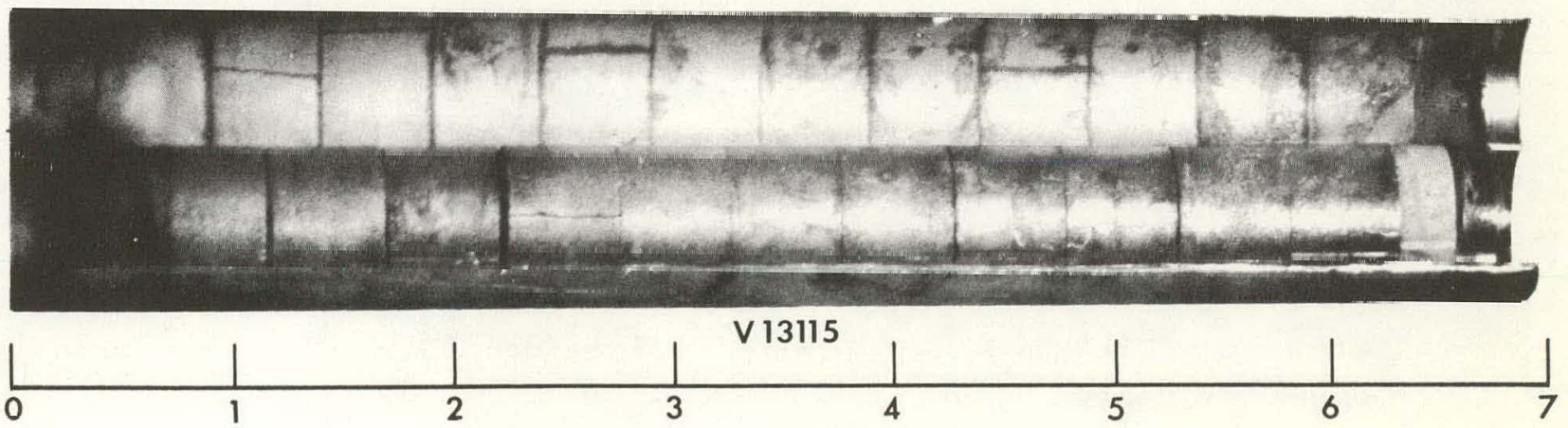

Dark lines in the cladding outline cracks in the fuel pellets. 


\subsubsection{Metallographical Results of Cladding Examinations}

Metallographic examination of sections of the cladding generally show ed no significant change due to irradiation except in the wrinkled areas. The wrinkles extended about 0.005 in. above the normal cladding surface and were located at pellet-pellet interfaces of those elements which had surface temperatures about $1500^{\circ} \mathrm{F}$ or above.

Sections through the wrinkles showed relatively large numbers of intergranular voids which decreased in frequency with distance from the pellet-pellet interface (see Fig. 46). In addition, an appreciable quantity of sigma phase was found at the wrinkles. Some sigma phase was located throughout the cladding in grain boundaries, preferentially at the intersection of grains (see Fig. 47). The presence of the sigma phase was confirmed by x-ray diffraction.

Several large grains were also found at the outside surface of the cladding in the neighborhood of a wrinkle (Fig. 46). It is believed that the presence of the large grains, the sigma phase, and concentration of the voids at the wrinkles are all indicative of high repetitive strain of the clad due to thermal cycling.

A precipitate found concen trated near the inner surface of the cladding of the group 1 elements has been tentatively identified as nitrides and is believed to be a result of the presence of nitrogen-uranium compounds in the as-fabricated fuel pellets. The nitrogen impurity level in the $\mathrm{UO}_{2}$ used in loading the group 1 elements was as high as $1900 \mathrm{ppm}$. There was no evidence of this type of precipitate in any of the cladding from the group 2 elements, which were loaded with $\mathrm{UO}_{2}$ that had a low nitrogen impurity level.

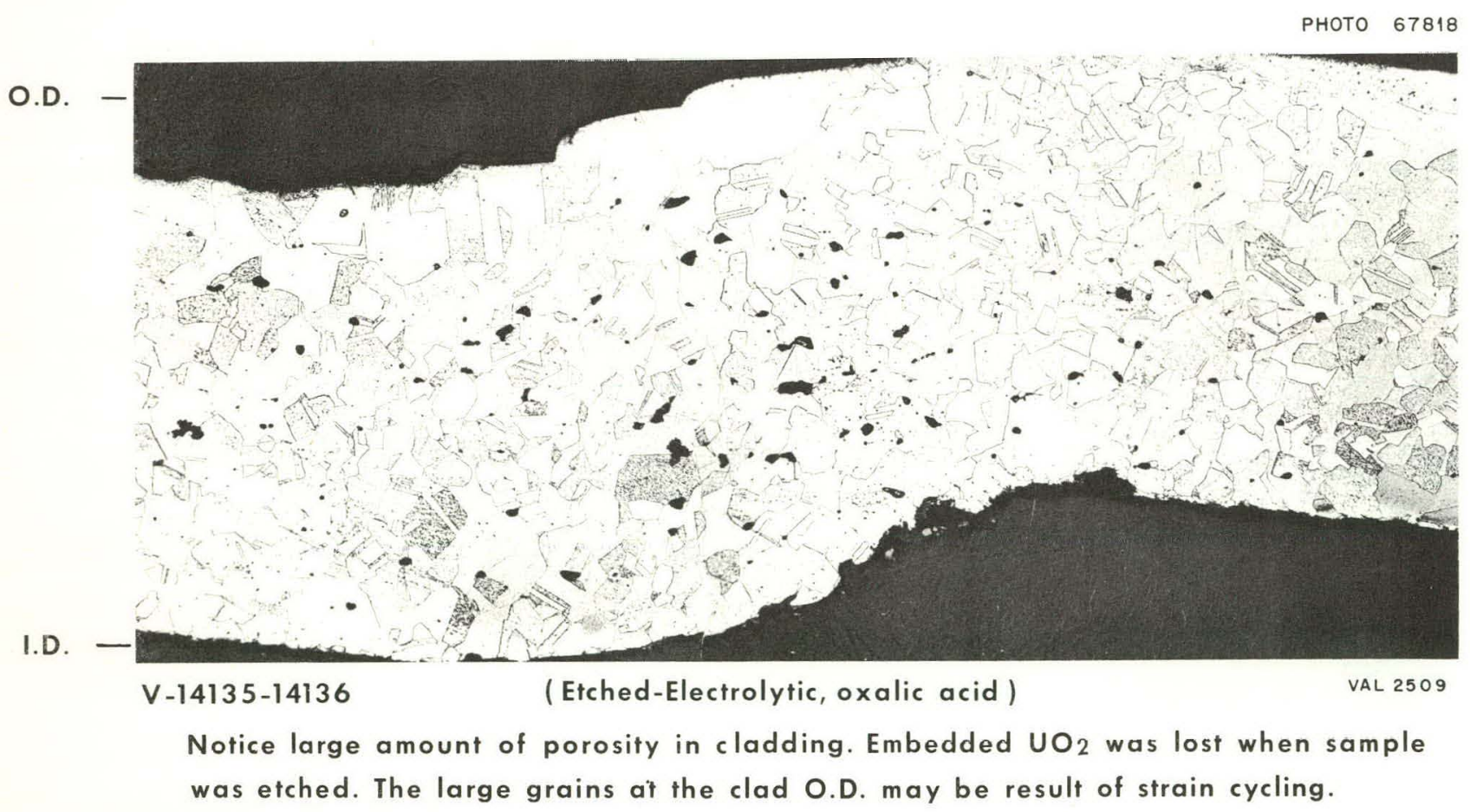

Fig. 46. Longitudinal Section Through Cladding Wrinkle at Interface Between Pellets 10 and 11 - Capsule 05-2. $100 \times$. Reduced $17 \%$. 
Fig. 47. Sigma Phase in Cladding. Reduced $40 \%$.

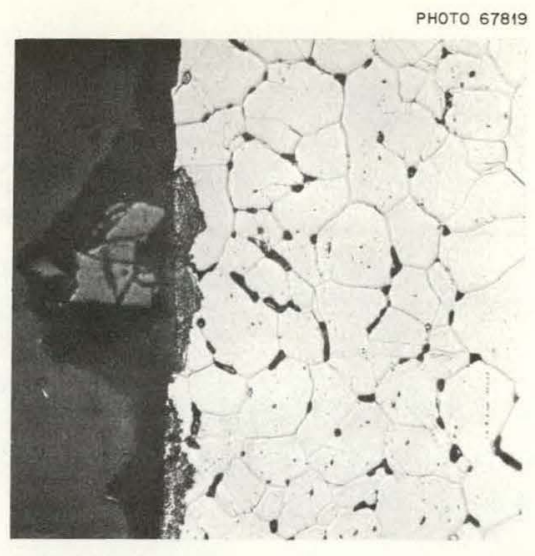

$02-2$

$250 x$

(Etched-Electrolytic, oxalic acid)

Voids left by removal of sigma phase.

Notice slight reaction at $\mathrm{UO}_{2}$ S.S. interface.

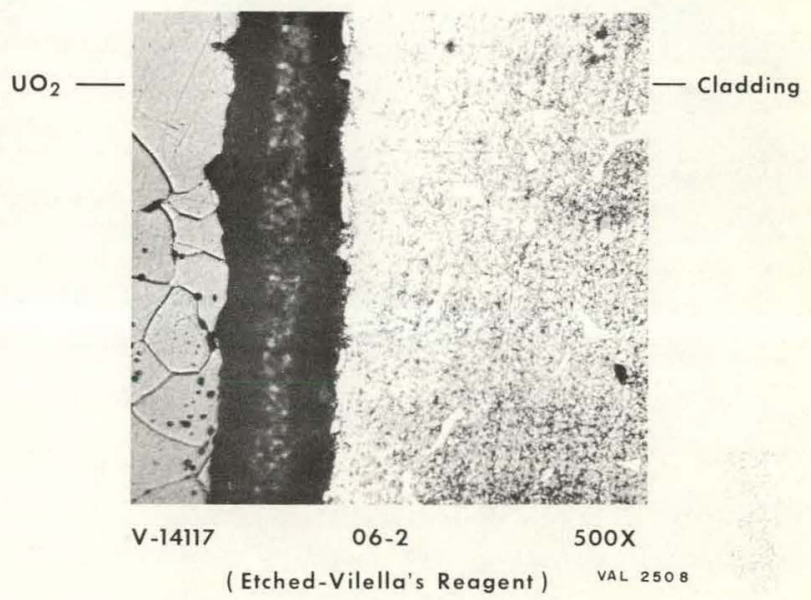

Austenite matrix has been heavily attacked leaving the sigma phase in relief - white phase.

The presence of nitrogen compounds in the $\mathrm{UO}_{2}$ is undesirable from the standpoint of nitriding of the cladding during irradiation. A marked decrease in ductility is generally associated with nitriding of steel.

Metallographic examination also showed a slight local reaction between the $\mathrm{UO}_{2}$ and the cladding in elements 01-2 and 02-2 (Fig. 48). The reaction was usually less than one grain in depth (about 0.001 in.).

The top end cap weld of element $\mathrm{O} 2-2$ was examined (see Fig. 49), and no significant effects due to irradiation were found.

The only cladding failure found by metallographic examination was that of element 04-1, shown in Fig. 50. This was one of the elements used in postirradiation pressure vs temperature measurements, and indications are that the r.1adding failure occurred during those measurements. 


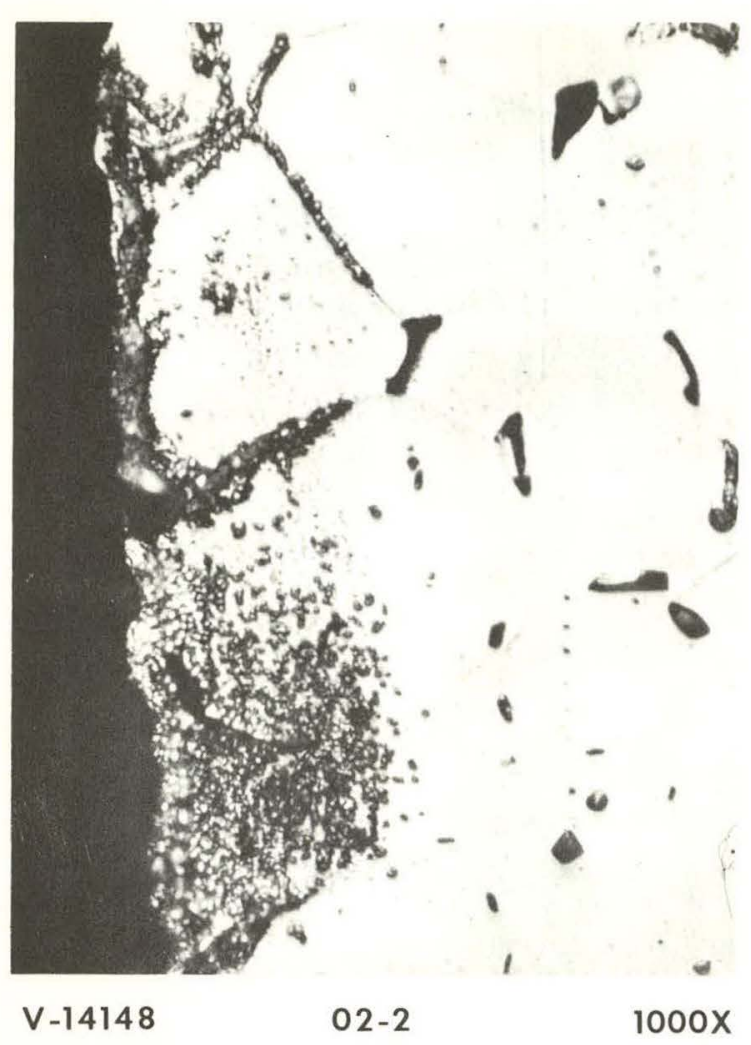

(Electrolytic oxalic acid etch)

Voids left by removal a of sigma phase.

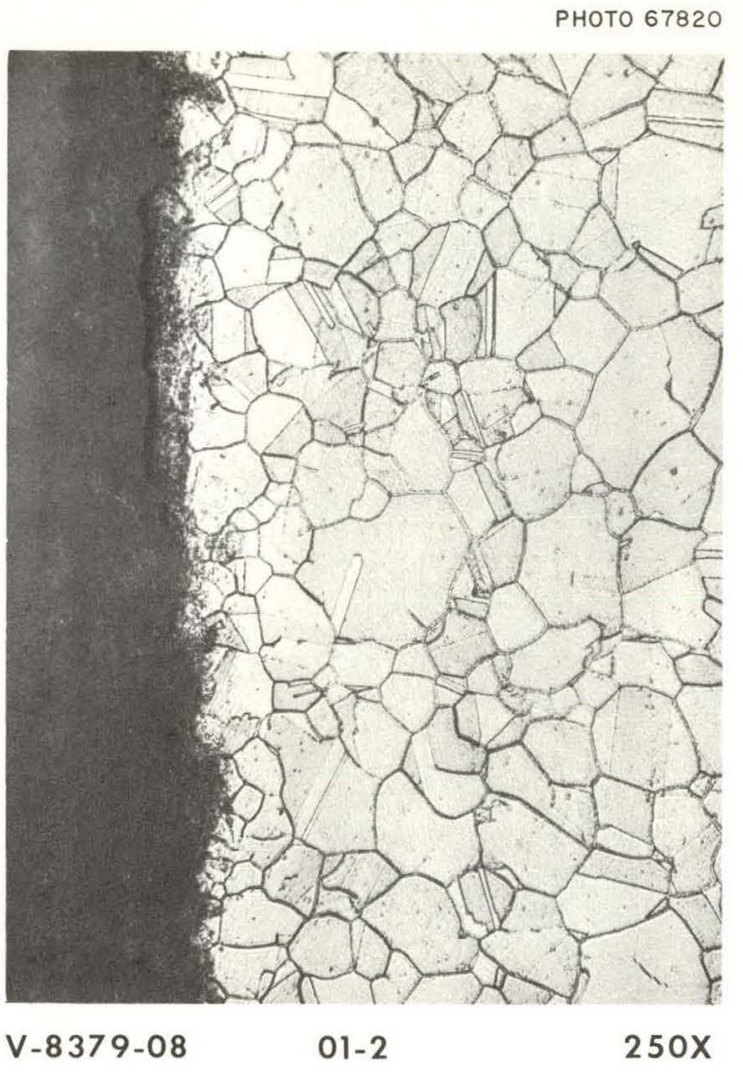

(Etched-modified Marble's reagent) Notice wide grain boundaries.

VAL 2512

Fig. 48. Reaction Between $\mathrm{UO}_{2}$ and Stainless Stepl Clndding of rapeules 012 and 02.2. Reduced $15 \%$.

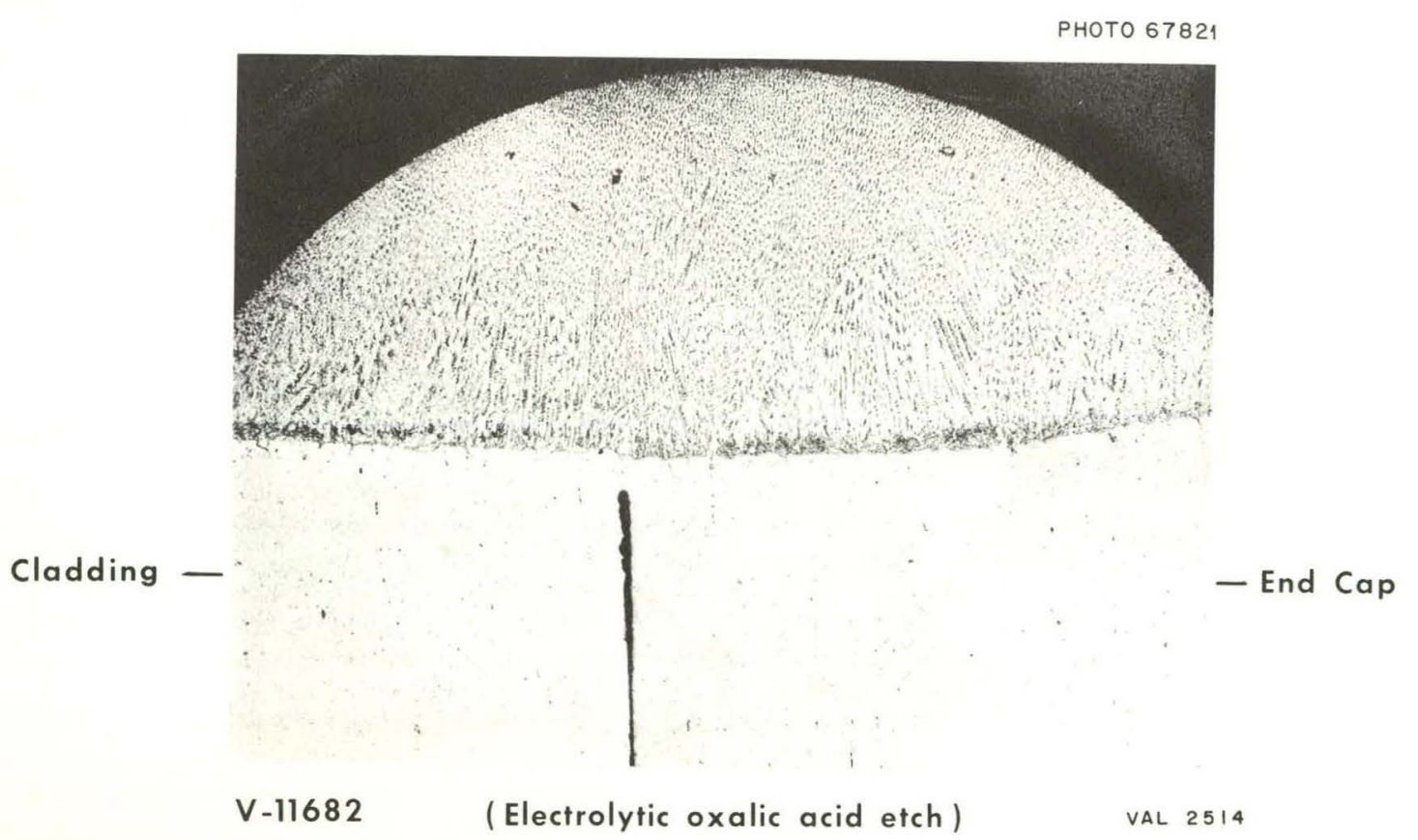

Fig. 49. Top End Cap Weld from Capsule 02-2 (Heliarc Weld). 100x. Reduced 15\%. 

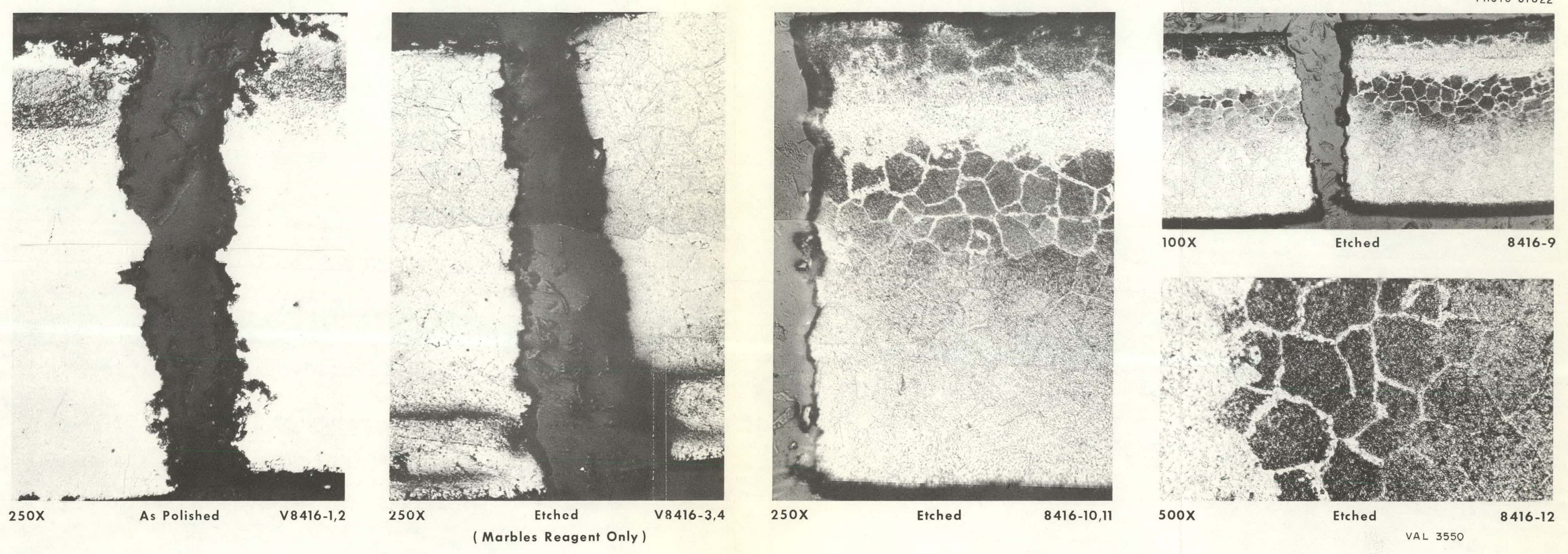

Fig. 50. Photomicrographs of Cladding Failure of Capsule 04-1, Reduced 15.5\%. 


\subsection{MgO Spacer Damage}

The $\mathrm{MgO}$ spacers did not appear to suffer appreciable damage from irradiation. They were recovered intact. While individual preirradiation spacer dimensions for the group 1 experiments were not available, the postirradiation dimensions do not appear to vary significantly from nominal preirradiated dimensions. The preirradiated thickness of the spacers varied somewhat more than the diameters. The postirradiation measurements are listed in Table 30.

Table 30. Postirradiation MgO Spacer Dimensions of EGCR Prototype Fuel Elements

\begin{tabular}{|c|c|c|c|c|c|}
\hline \multirow{2}{*}{$\begin{array}{l}\text { Element } \\
\text { No. }\end{array}$} & \multirow{2}{*}{$\begin{array}{l}\text { Component } \\
\text { (Spacer) }\end{array}$} & \multicolumn{2}{|c|}{ Outside Diameter (in.) } & \multicolumn{2}{|c|}{ Length (in.) } \\
\hline & & $\begin{array}{c}\text { Nominal } \\
\text { Preirradiation }\end{array}$ & Postirradiation & $\begin{array}{c}\text { Nominal } \\
\text { Preirradiation }\end{array}$ & Postirradiation \\
\hline O1-1 & Top & 0.696 & 0.696 & 0.250 & 0.258 \\
\hline O1-1 & Bottom & 0.696 & 0.696 & 0.250 & 0.248 \\
\hline $\mathrm{O} 2-1$ & Top & 0.696 & 0.696 & 0.250 & 0.258 \\
\hline $\mathrm{O} 2-1$ & Bottom & 0.696 & 0.696 & 0.250 & 0.252 \\
\hline O5-1 & Top & 0.696 & 0.6980 & 0.250 & 0.2552 \\
\hline $05-1$ & Bottom & 0.696 & 0.6975 & 0.250 & 0.258 \\
\hline-2 & Top and bottom & 0.696 & Slight decrease & 0.250 & $\begin{array}{l}\text { Slight swelling } \\
\text { at center }\end{array}$ \\
\hline
\end{tabular}

\subsection{Beryllium Oxide Bushing Damage}

In general the $\mathrm{BeO}$ bushings suffered little damage. The two group 1 bushings decreased approximately $1 \%$ in outside diameter while the group 2 bushings decreased less than $\frac{1}{3} \%$ in outside diameter. The bulk density of the group 1 bushings decreased approximately 1\%. The postirradiation carbon tetrachloride immersion density was $3.00 \mathrm{~g} / \mathrm{cc}$ for both groups - practically $100 \%$ theoretical. This indicates very little closed porosity.

In experiment 06-1 there was evidence of small amounts of $\mathrm{BeO}$ mass transfer from the rod (which was in the hottest portion of the element) to the cooler element wall and the ends of the pellet near the OD. It is possible that this occurred by hydrolysis and decomposition, that is,

$$
\mathrm{BeO}+\mathrm{H}_{2} \mathrm{O} \rightleftharpoons \mathrm{Be}(\mathrm{OH})_{2} .
$$

It is believed that small concentrations of water vapor $(\sim 1 \mathrm{ppm})$ would be sufficient to support this reaction under the conditions existing within the elements. Figure 51 shows points of attack on the $\mathrm{BeO}$ rod, while Figs. 52-54 show the deposited film on the pellet and cladding. Since this element was used in postirradiation internal gas pressure vs temperature experiments prior to sectioning, it is possible that this reaction did not take place during irradiation. 
PHOTO 67823

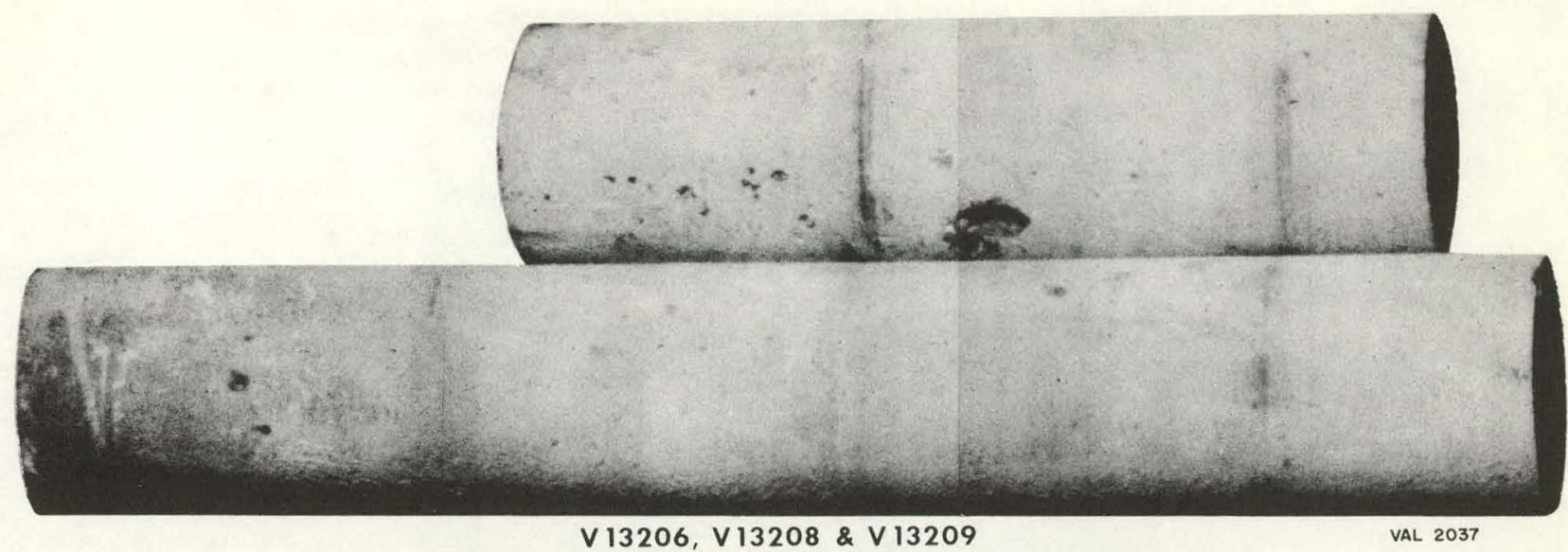

Fig. 51. Bottom Half of the Beryllium Oxide Inserts of Irradiated Capsule 06-1.

PHOTO 67824

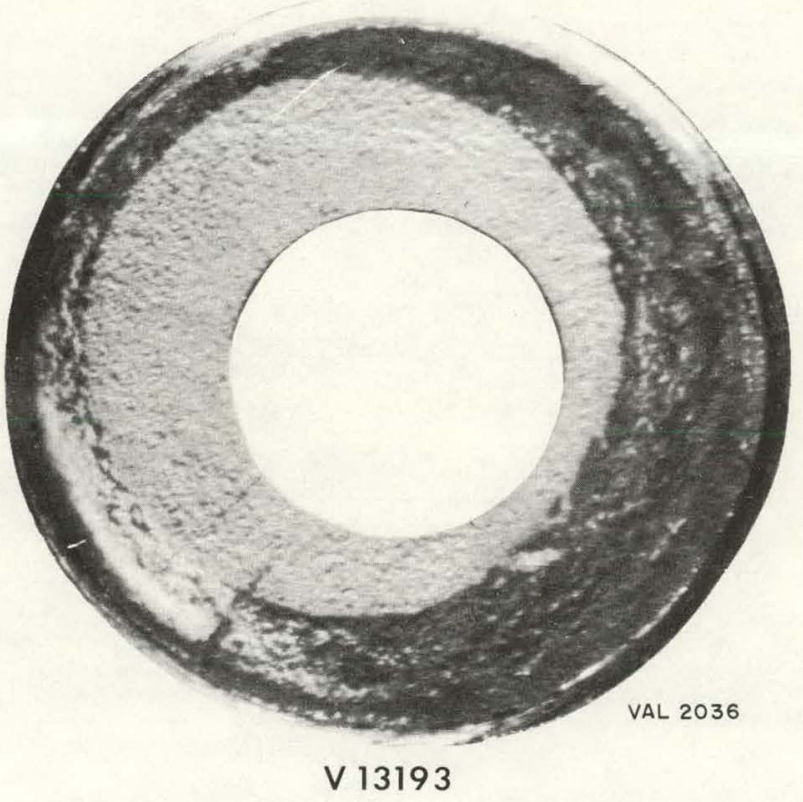

Fig. 52. Dark Colored Deposit on Fuel Pellet No. 6 of Irradiated Capsule 06-1. 
РНОTO 67825

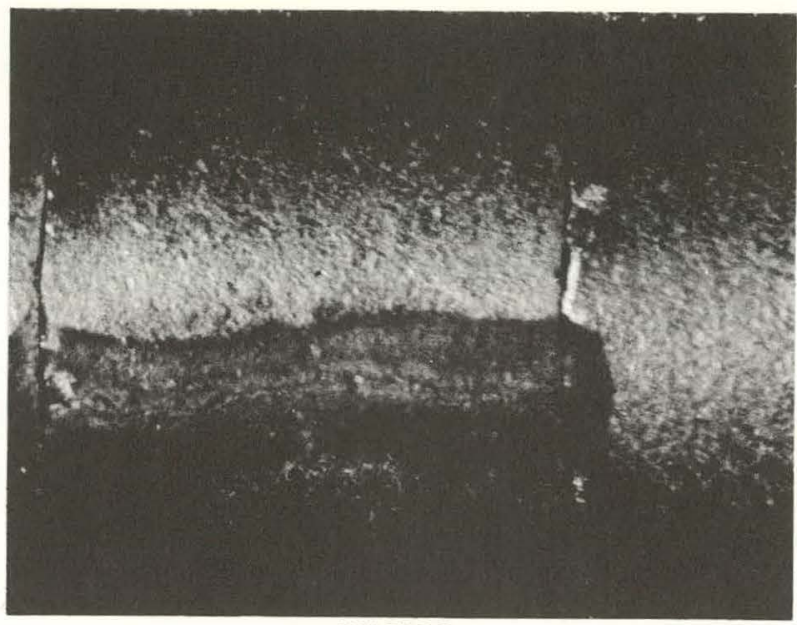

V 13193

Fig. 53. Dark Colored Deposit at a Radial Crack in Fuel Pellet No. 5 of Irradiated Capsule O6-1.

PHOTO 67826

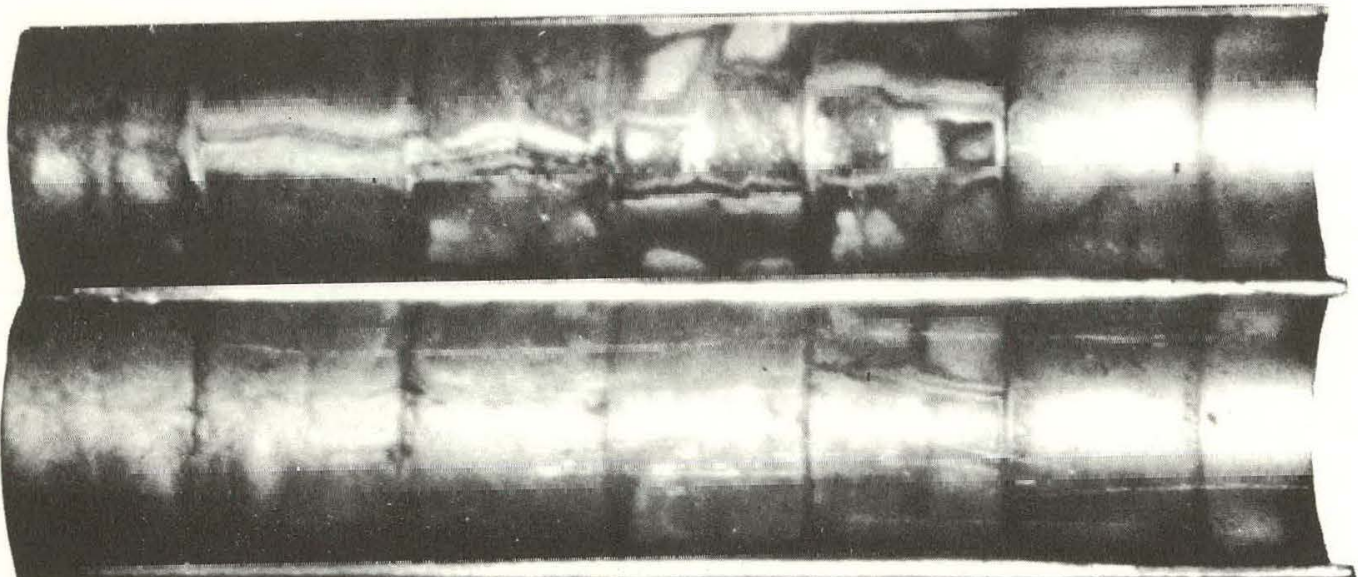

V 13211

Fig. 54. Discoloration of the Inside Surface of the Cladding of Irradiated Capsule 06-1. 


\subsection{Thermocouple Development}

A tantalum sheath was used to prevent direct contact of the thermocouple junction with $\mathrm{UO}_{2}$ or fission products. Many of these units were found to be in good mechanical condition even after prolonged service. In some instances, however, postirradiation examination revealed damage and even extensive disintegration of the thermocouple assembly. Some of the failures could be attributed to air exposure through leaks, but others are as yet unexplained. Transmutation effects for these thermocouple materials, evidenced by an indicated decrease in the fuel center temperature with exposure, are being investigated. Transmutation will not account for decreases in output observed for the $\mathrm{Pt}$ vs $\mathrm{Pt}-10 \% \mathrm{Rh}$ thermocouples.

\subsection{Gamma Scans}

The gamma scans of the individual prototype elements are shown in Figs. C.34-C. 41 and C. $47-$ C.54 in Appendix C. It should be remembered that the gamma scans were not made in situ in the reactor at operating temperature, but in a hot cell at room temperature after the elements had been removed from the operating rig. Thus, the sharp drops in activity which are associated with gaps between adjacent pellets (as shown in photographs of the opened fuel element) are not necessarily indicative of operating conditions in the reactor.

The majority of the gaps between pellets nccur in the upper portion of the element. Thus, this might be the result of differential contraction of the fuel pcllets and cladding upon cooling, rather than due to chips of fuel lodging between pellets (which one would expect to be more prevalent the nearer the bottom of the element). At any rate, one would expect that dished pellets would minimize this.

Pellets which differ in ${ }^{235} \mathrm{U}$ content from the other pellets in the element are noticeable in the gamma scans of elements 08-1, 04-2, 07-2, and 08-2.

The ambient neutron flux for the group 2 elements appears to be quite constant (as evidenced by the rather constant gamma activity over the entire length of the element), whereas the flux seems to drop off in the upper half of elements $03,04,05$, and 06 of group 1.

One would expect gamma peaking at both ends of a fuel clement due to the higher than average burnup in the end pellets. This is due to the greater surface area to volume ratio exposed by the end pellets to the somewhat less depressed flux at the ends of the element (i.e., self-absorption effect).

The gamma scans indicate activity peaking at the bottom of all the elements, while generally only the group 2 elements have peaking at the top. A small amount of the peaking at the bottom may be due to the accumulation of $\mathrm{UO}_{2}$ fines at the lower end of the element. However, the peaking is not great, and certainly there is not much, if any, fuel migration (i.e., portions of pellets falling to the bottom of the element). The cause of peaking at the top end of some, but not all, elements is not clear. This might be explained by the cadmium shutters not being completely raised above the elements during irradiation, so that the flux near the top end of the element was somewhat depressed.

The upper portion of element 03-2 was potted prior to longitudinal sectioning. Measurements of the top exparision gap indicate it to he approximately 32 mils. The element was assembled so that this gap 
would be 40 mils prior to irradiation. The reduction in top gap is a further indication that the pellet-topellet gap is real. Figure 44 is a summary drawing indicating the relationship between bowing, outside diame ter measurements, and gamma scan of element 01-1.

There appeared to be considerable residual compressive stresses in the cladding of elements 01-2 through 05-2. The cladding tended to close when slit through. The MgO spacers, which were loose prior to slitting of the cladding, became wedged after slitting.

\section{CONCLUSIONS}

\subsection{Prototype Tests}

The prototype tests differed from the proposed EGCR elements in that:

1. The pellet ends were flat instead of dished.

2. The length of the test element was two-ninths that of the proposed element.

3. The ambient fluid differed materially (stagnant $\mathrm{NaK}$ instead of circulating helium).

4. The maximum burnup attained was about $2400 \mathrm{Mwd}$ per metric ton of $\mathrm{UO}_{2}$ - about one-quarter that of the proposed element.

With the foregoing in mind, it was found that:

1. No significant amount of fuel migration or shifting occurred in the cored pellet test elements, even though the pellets were quite friable after irradiation.

2. There was some indication that ratchetting had occurred to a slight degree.

3. The single cladding failure was believed to have occurred during a postirradiation experiment.

4. "Wrinkles" formed on the cladding opposite pellet interfaces when the cladding was at $1500^{\circ} \mathrm{F}$ or above. Sigma phase and small voids were found in the neighborhood of the wrinkles.

5. No significant $\mathrm{UO}_{2}$-cladding interactions were found except for a small amount of cladding nitriding when the fuel contained a large amount of nitrides.

6. The quantitative effect of temperature on fission-gas release could not be evaluated.

7. The fuel-cladding radial gap did not vary enough to significantly affect the fission-gas release.

8. The BeO rod and $\mathrm{MgO}$ spacer components were not severely damaged.

\subsection{LITR Tests}

The LITR type experiments showed that fission-gas release:

1. appeared to increase materially for burnups above about $15,000 \mathrm{Mwd}$ per metric ton of $\mathrm{UO}_{2}$;

2. was quite sensitive to fuel structure, that is, the smaller the ratio of closed voids to total voids, the better the retention;

3. dependence on $\mathrm{O} / \mathrm{U}$ ratio was confused by density effects;

4. diffusion constants for xenon and krypton were about the same. 


\section{APPENDIX A}

In the development of the fuel for the LITR and ORR experiments, several duplicate analyses characterizing the fuel were made. The reasons for this are discussed in ref. 19. These analyses characterizing the LITR and the ORR fuel are presented in Tables A.1 and A.2 respectively. Evans ${ }^{19}$ has suggested "best values" to use in correlation studies; these values are listed in Table A.3 for the LITR and in Table A.4 for the ORR fuels.

Table A.1. Fuel Characterization for LITR Experiments as Listed in ORNL-CF-59-12-1

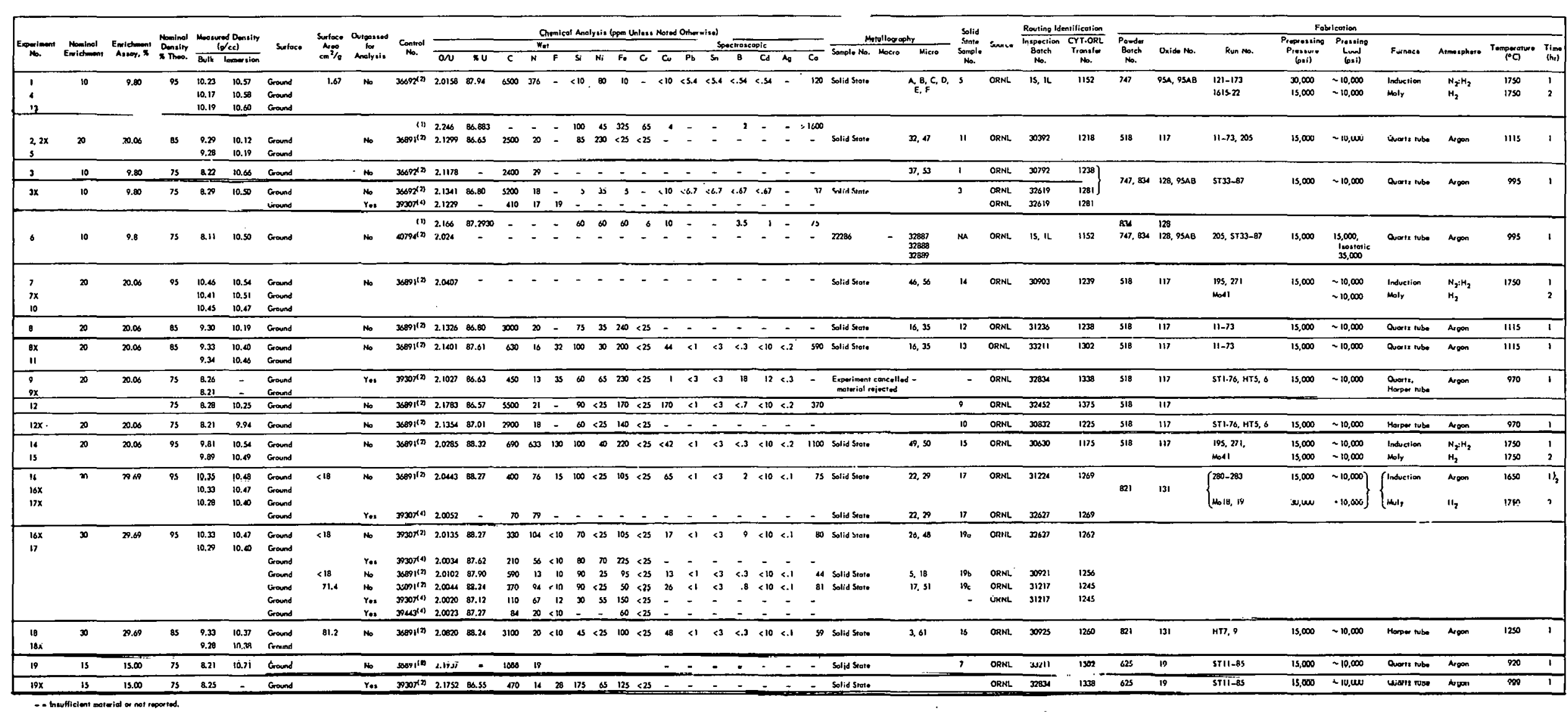


Table A.1 (continued)

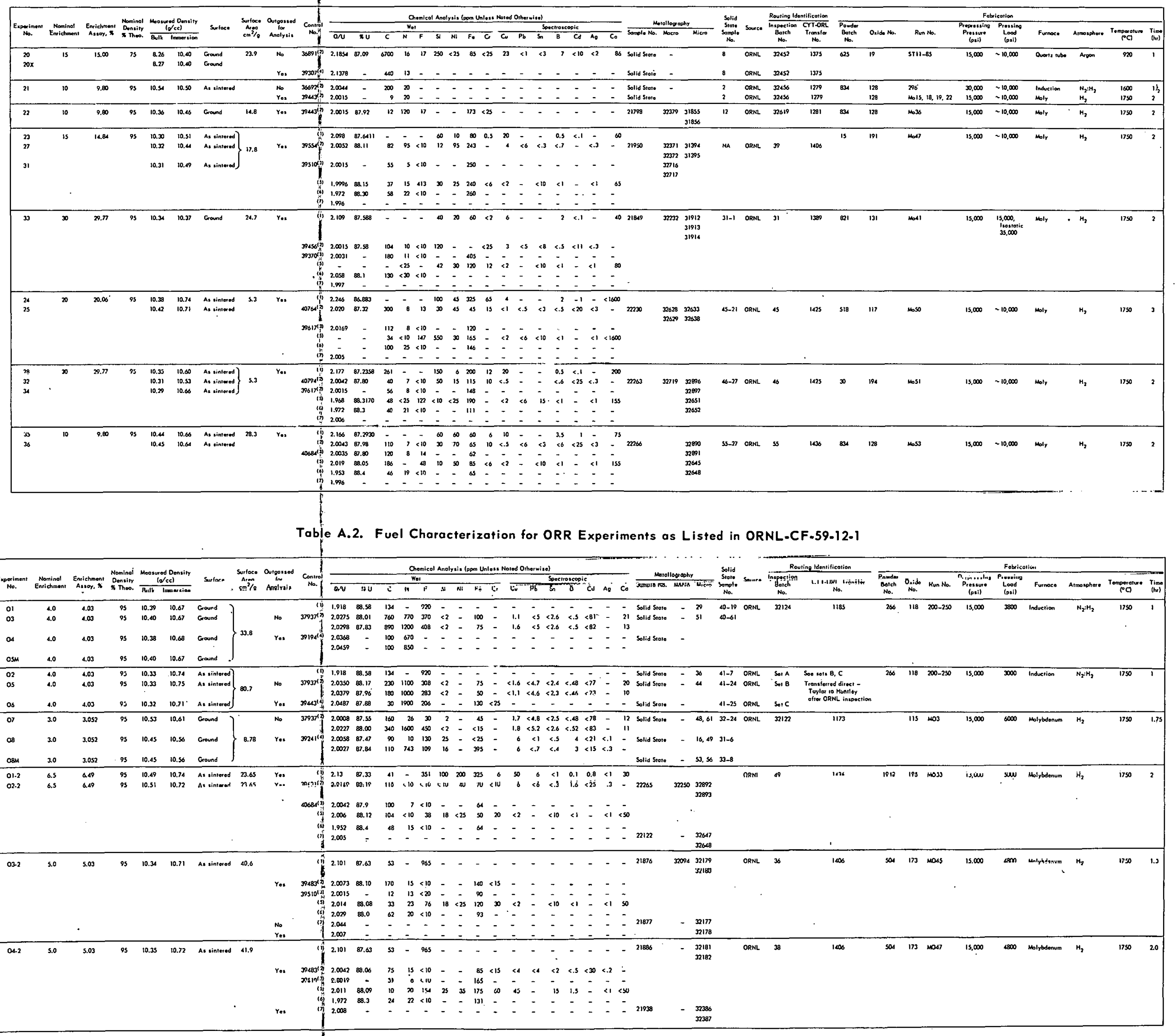


Toble A. 2 (continued)

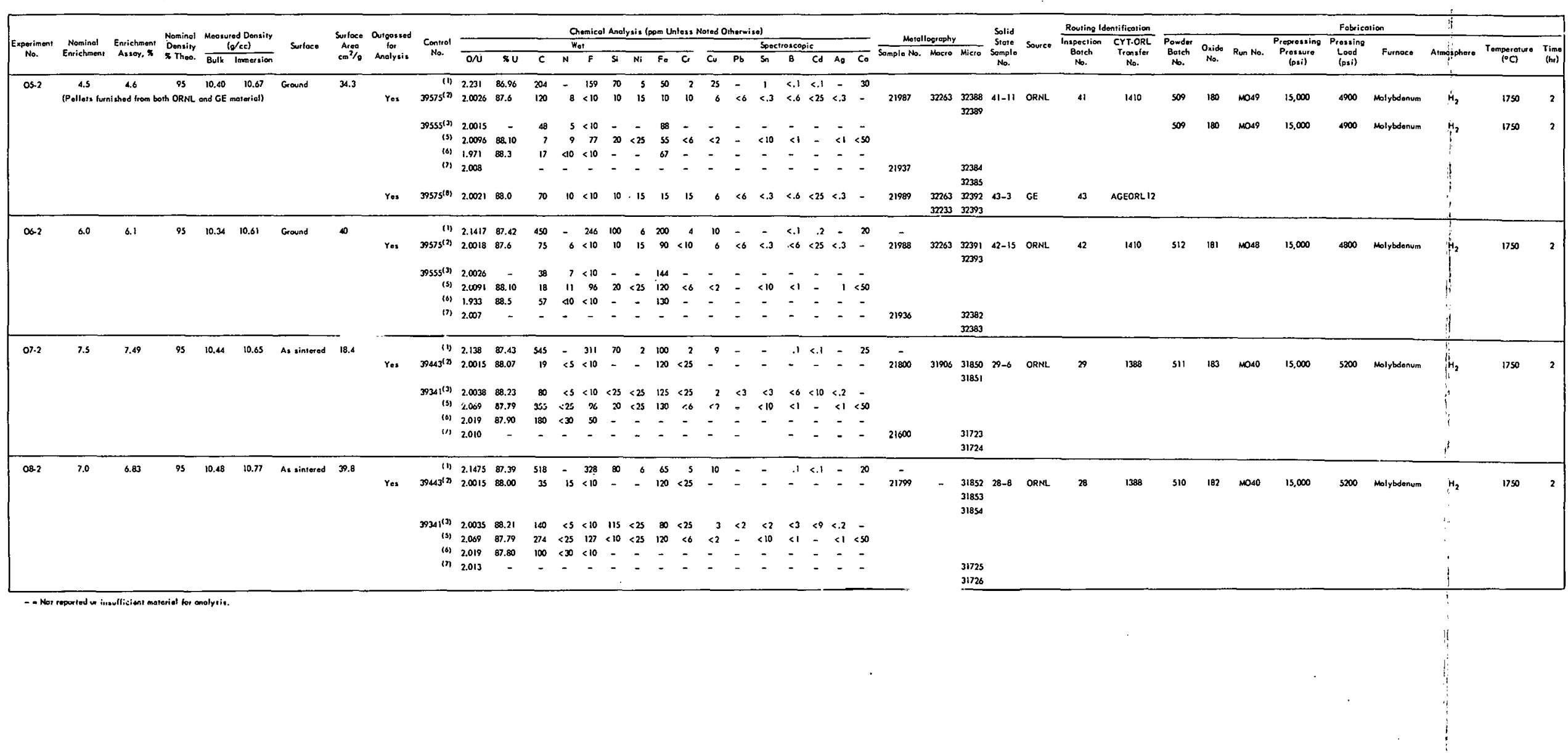


Table A.3. "Best Values" for Fuel Characterization of LITR Experiments 19

\begin{tabular}{|c|c|c|c|c|c|c|c|c|c|c|c|c|c|c|c|c|c|c|c|c|c|}
\hline \multirow{3}{*}{ Experiment No. } & \multirow{3}{*}{$\begin{array}{l}\text { Surface } \\
\text { Finish }\end{array}$} & \multirow{3}{*}{$\begin{array}{c}\text { Surface } \\
\text { Area } \\
\left(\mathrm{cm}^{2} / \mathrm{g}\right)\end{array}$} & \multirow{3}{*}{$\begin{array}{l}\text { Outgassed } \\
\text { for } \\
\text { Analysis }\end{array}$} & \multicolumn{16}{|c|}{ Chemical Analysis (ppm unless noted otherwise) } & \multicolumn{2}{|c|}{ Fabrication Identification ${ }^{a}$} \\
\hline & & & & \multicolumn{9}{|c|}{ Wet } & \multicolumn{7}{|c|}{ Spectroscopic } & \multirow{2}{*}{$\begin{array}{c}\text { Powder } \\
\text { Bateh } \\
\text { No. }\end{array}$} & \multirow[b]{2}{*}{ Run No. } \\
\hline & & & & $0 \%$ & $U(\%)$ & c & $N$ & $\mathbf{F}$ & $\mathrm{Si}$ & $\mathrm{Ni}$ & $\mathrm{Fe}$ & $\mathrm{C}_{\mathbf{r}}$ & Cu & $\mathrm{Pb}$ & Sn & $B$ & $\mathrm{Cd}$ & $\mathrm{Ag}$ & $\mathrm{Ca}$ & & \\
\hline$L 1, L 4, L 13$ & Ground & 1.67 & No & 2.016 & 87.94 & 6500 & 376 & & $<10$ & 80 & 10 & & $<10$ & $<5.4$ & $<5.4$ & $<5.4$ & $<5.4$ & & 120 & 747 & $121-173,1615.22$ \\
\hline L2 & Ground & & No & 2. 130 & 86.65 & 2500 & 20 & & 85 & $<25$ & 230 & $<25$ & & & & & & & & 518 & $11.73,205$ \\
\hline L3 & Ground & & No & 2.118 & & 2400 & 29 & & & & & & & & & & & & & 747,834 & ST $33-87$. \\
\hline L6 & Ground & & No & 2.024 & & & & & & & & & & & & & & & & 747,834 & ST 33.87 \\
\hline L7, L7X, L 10 & Ground & & No & 2.041 & & & & & & & & & & & & & & & & 518 & 195,271, MO-41 \\
\hline L8 & Ground & & No & 2. 133 & 86.80 & 3000 & 20 & & 75 & 35 & 240 & $<25$ & & & & & & & & 518 & $11-73$ \\
\hline LII & Ground & & No & 2. 40 & 87.61 & 630 & 16 & 32 & 100 & 30 & 200 & $<25$ & 44 & $<1$ & $<3$ & $<.3$ & $<10$ & $<.2$ & 590 & 518 & 11.73 \\
\hline L 14, L 15 & Ground & & No & 2.0 .28 & 88.32 & 690 & 633 & 130 & 100 & 40 & 220 & $<25$ & $<42$ & $<1$ & $<3$ & $<.3$ & $<10$ & $<.2$ & 1100 & 518 & $195,271, \mathrm{MO}-41$ \\
\hline L 16, L 16X, L 17X & Ground & $<18$ & No & 2.044 & 88.27 & 400 & .76 & 15 & 100 & $<25$ & 105 & $<25$ & 65 & $<1$ & $<3$ & .2 & $<10$ & $<.1$ & 75 & 821 & $280-283, \mathrm{MO} \cdot 18,19$ \\
\hline $\operatorname{L} 16 x_{0}^{c}\left\llcorner 17^{d}\right.$ & Ground & $<18$ & Yes & 2.005 & 87.62 & 140 & 68 & $<10$ & 80 & 70 & 225 & $<25$ & 17 & $<1$ & $<3$ & 9 & $<10$ & $<.1$ & 80 & 821 & 280-283, MO-18, 19 \\
\hline $\mathrm{L}_{17}{ }^{e}$ & Ground & $<18$ & No & 2.010 & 87.90 & 590 & 13 & 10 & 90 & 25 & 95 & $<25$ & 13 & $<1$ & $<3$ & $<.3$ & $<10$ & $<.1$ & 44 & 821 & 280-283, MO-18, 19 \\
\hline $\mathrm{L}_{17}{ }^{f}$ & Ground & 71.4 & Yes & 2.002 & 87.20 & 97 & 43 & 10 & 30 & 55 & 105 & $<25$ & 26 & $<1$ & $<3$ & .8 & $<10$ & $<.1$ & 81 & 821 & $280-283$, MO-18, 19 \\
\hline L 18, L 18X & Ground & 81.2 & No & 2.082 & 88.24 & 3100 & 20 & $<10$ & 45 & $<25$ & 100 & $<25$ & 48 & $<1$ & $<3$ & $<.3$ & $<10$ & $<.1$ & 59 & 821 & HT 7,9 \\
\hline L 21 & As sintered & & Yes & 2.002 & & 9 & 20 & & & & & & & & & & & & & 834 & $296, \mathrm{MO}-15,18,19,22$ \\
\hline L 22 & Ground & 14.8 & Yes & 2.002 & 87.92 & 12 & 120 & 17 & & & 173 & $<25$ & & & & & & & & 834 & $M O-36$ \\
\hline L 23, L 27 & As sintered & 17.8 & Yes & 2.002 & 88.11 & 68 & 50 & $<10$ & 12 & 95 & 247 & & 4 & $<6$ & $<.3$ & $<.7$ & & $<.3$ & & 15 & $M O .47$ \\
\hline L 24, L 25 & As sintered & 5.3 & Yes & 2.018 & 87.32 & 206 & 8 & 10 & 30 & 45 & 83 & 15 & $<1$ & $<.5$ & $<3$ & $<.5$ & $<20$ & $<3$ & & 518 & $M O .50$ \\
\hline$\llcorner 28,\llcorner 32$ & As siniered & 5.3 & Yes & $2.0,02$ & 87.80 & 48 & 8 & $<10$ & 50 & 15 & 133 & 10 & $<$. & 5 & & $<.6$ & $<25$ & $<.3$ & & 30 & $M O .51$ \\
\hline
\end{tabular}

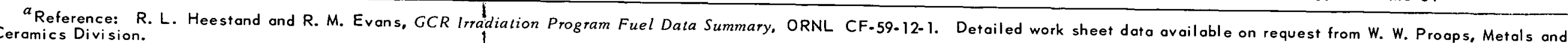
Ceramics Division.
$\quad b L 16 X$ - compartment b fuel plus lower pellet in comporthen in comportment a.

$d_{L}$ L 7 - top two pellets of comport

$e_{L} 17$ - lower two pellets of both compartments $a$ and $b$.

$f_{L} 17$ - top two pellets of comportment b.

Th 17 top two pellets of compartment b.

\begin{tabular}{|c|c|c|c|c|c|c|c|c|c|c|c|c|c|c|c|c|c|c|c|c|c|}
\hline \multirow{3}{*}{ Experiment No. } & \multirow{3}{*}{$\begin{array}{l}\text { Surfoce } \\
\text { Finish }\end{array}$} & \multirow{3}{*}{$\begin{array}{c}\text { Surface } \\
\text { Area } \\
\left(\mathrm{cm}^{2} / \mathrm{g}\right)\end{array}$} & \multirow{3}{*}{$\begin{array}{c}\text { Outgassed } \\
\text { for } \\
\text { Analysis }\end{array}$} & \multicolumn{16}{|c|}{ Chemical Analysis (ppm unless noted otherwise) } & \multicolumn{2}{|c|}{ Fabrication Identification } \\
\hline & & & & \multicolumn{9}{|c|}{ Wet } & \multicolumn{7}{|c|}{ Spectroscopic } & \multirow{2}{*}{$\begin{array}{l}\text { Powder } \\
\text { Botch No. }\end{array}$} & \multirow{2}{*}{ Run No. } \\
\hline & & & & $\mathrm{p} / \mathrm{u}$ & $U(\%)$ & $C$ & N & F & $\mathrm{Si}$ & $\mathrm{Ni}$ & $\mathrm{Fe}$ & $\mathrm{Cr}_{\mathrm{r}}$ & $\mathrm{Cu}$ & $\mathrm{Pb}$ & Sn & B & Cd & Ag & $\mathrm{Ca}$ & & \\
\hline $\mathrm{O} 1,03,04,05 \mathrm{M}$ & Ground & 33.8 & Yes & 2.041 & 87.92 & 100 & 760 & 390 & $<2$ & & 87 & & 1.3 & $<5$ & $<2.6$ & $<0.5$ & $<81$ & & 21 & 266 & $200 \cdot 250$ \\
\hline $02,05,06$ & As sintered & 80.7 & Yes & 2.049 & 87.88 & 30 & 1900 & 206 & $<2$ & & 130 & $<.25$ & $<1.3$ & $<4.7$ & $<2.3$ & $<4.6$ & $<73$ & & 15 & 266 & $200 \cdot 250$ \\
\hline $07,08,08 \mathrm{M}$ & Ground & 8.78 & Yes & 2.004 & 87.65 & 100 & 743 & 109 & 16 & & 395 & & 6 & $<1$ & $<0.5$ & 3.5 & $<18$ & $<0.2$ & & NA & MO.3 \\
\hline $01-2,02-2$ & As sintered & 23.65 & Yes & 2.011 & 88.05 & 105 & 7 & $<10$ & $<10$ & 40 & 70 & $<10$ & 6 & $<6$ & $<0.3$ & 1.6 & $<25$ & 0.3 & & 1043 & $M O-53$ \\
\hline $03-2$ & As sintered & 40.6 & Yes & 2.004 & 88.10 & 91 & 14 & $<15$ & 18 & $<25$ & 115 & 20 & $<2$ & & $<10$ & $<1$ & & $<1$ & 50 & 504 & $M O .45$ \\
\hline $04-2$ & As sintered & 41.9 & Yes & 2.003 & 88.06 & 57 & 10 & $<10$ & 25 & 35 & 125 & $<15$ & $<4$ & $<4$ & $<2$ & $<0.5$ & $<30$ & $<0.2$ & & 504 & $M O .47$ \\
\hline \multirow[t]{2}{*}{$05-2$} & Ground & 34.3 & Yes & 2.001 & 87.60 & 156 & 7 & $<10$ & 10 & 15 & 49 & 10 & 6 & $<6$ & $<0.3$ & $<0.6$ & $<25$ & $<0.3$ & & 509 & MO.49 \\
\hline & & & Yes & 2.002 & 88.00 & 70 & .10 & $<10$ & 10 & 15 & 15 & 15 & 6 & $<6$ & $<0.3$ & $<0.6$ & $<25$ & $<0.3$ & & \multicolumn{2}{|l|}{ AGE-ORL- $12^{b}$} \\
\hline 06.2 & Ground & 40.0 & Yes & 2.002 & 87.60 & 56 & 6 & $<10$ & 10 & 15 & 117 & $<10$ & 6 & $<6$ & $<0.3$ & $<0.6$ & $<25$ & $<0.3$ & & 5.12 & $M O .48$ \\
\hline 07.2 & As sintered & 18.4 & Yes & 2.002 & 88.15 & 49 & $<5$ & $<10$ & $<25$ & $<25$ & 122 & $<25$ & 2 & $<3$ & $<3$ & $<6$ & $<10$ & $<0.2$ & & 511 & $M O-40$ \\
\hline $08-2$ & As sintered & 39.8 & Yes & 2.003 & 88.10 & 87 & 10 & $<10$ & 115 & $<25$ & 100 & $<25$ & 3 & $<2$ & $<2$ & $<3$ & $<9$ & $<0.2$ & & 510 & $M O .40$ \\
\hline
\end{tabular}

a Reference: R. L. Heestand and R. M. Evans, GCR Irradiation Program Fuel Data Summary, ORNL CF-59-i2-1. Detailed work sheet data available on request from W. W. Proaps, Metals and Ceramics Division.
EExperiment $05-2$, pellest 11 and 12 fabricated by GE. 


\section{APPENDIX B}

\section{Irradiation History for Each LITR Capsule Experiment}

All of the LITR capsule irradiation experiments conducted in the test series are listed in Table B.1. Burnup, total power, and heat flux were calculated from flux measurement, fuel enrichment, and reactor operational experience, that is, megawatt days of operation. Except as noted in Table B.1, the capsules were filled with argon gas. This provided higher fuel temperatures than would have been obtained with helium and reduced changes in thermal conductivity resulting from dilution with fission gases. Measured central fuel temperatures listed in Table B.1 are initial values. Indicated temperatures drifted downward during irradiation, sometimes as much as 100 to $400^{\circ} \mathrm{F}$, but this may have resulted from drifting of thermocouples which was discussed earlier. The test temperature was controlled at $1300^{\circ} \mathrm{F}$ from a thermocouple on the bottom capsule. The upper (a) capsule always was irradiated at a lower temperature, since the cooling air passed from top to bottom.

Table B.1. Conditions of Irradiation of LITR Capsules for Fission-Gas-Release Measurements

\begin{tabular}{|c|c|c|c|c|c|c|c|c|c|}
\hline \multirow{2}{*}{$\begin{array}{l}\text { Experi- } \\
\text { mental } \\
\text { Assembly } \\
\text { No. }\end{array}$} & \multirow[b]{2}{*}{$\begin{array}{c}\text { Core } \\
\text { Facility } \\
\text { No. }\end{array}$} & \multirow{2}{*}{$\begin{array}{c}\text { Erfective } \\
\text { Thermal-Neutron } \\
\text { Flux } \\
\text { (neutrons } \\
\mathrm{cm}^{-2} \mathrm{sec}^{-1} \text { ) }\end{array}$} & \multicolumn{2}{|c|}{ Average Density } & \multirow[b]{2}{*}{$\begin{array}{c}\text { Enrich- } \\
\text { ment } \\
\left(\% \mathrm{U}^{235}\right)\end{array}$} & \multirow{2}{*}{$\begin{array}{c}\text { Oxygen- } \\
\text { to- } \\
\text { Uranium } \\
\text { Ratio }\end{array}$} & \multirow{2}{*}{$\begin{array}{l}\mathrm{UO}_{2 \text {-to- }} \\
\text { Cladding } \\
\text { Radial } \\
\text { Clearance, } \\
\text { Cold (in.) }\end{array}$} & \multirow{2}{*}{$\begin{array}{l}\text { Total } \\
\text { Power } \\
\left(\mathrm{Btuhr^{-1 }}\right. \\
\left.\mathrm{ft}^{-1}\right)\end{array}$} & \multirow{2}{*}{$\begin{array}{c}\text { Total Heat } \\
\text { Flux } \\
(\text { Btu hr } \\
\left.\mathrm{ft}^{-2}\right)\end{array}$} \\
\hline & & & $\begin{array}{l}\text { Bulk (\% of } \\
\text { theoretical) }\end{array}$ & $\begin{array}{l}\text { Immersion } \\
\left(\mathrm{g} / \mathrm{cm}^{3}\right)\end{array}$ & & & & & \\
\hline & & $\times 10^{13}$ & & & & . & & & \\
\hline L-1a & $C-47$ & 2.1 & 92.66 & 10.57 & 9.80 & 2.016 & 0.0011 & 7,400 & 182,000 \\
\hline$L=1 b$ & $C-47$ & 2.1 & 93.92 & 10.57 & 9.80 & 2.016 & 0.0009 & 7,400 & 182,000 \\
\hline $\mathrm{L}-2 \mathrm{a}^{a}$ & $\mathrm{C}-47$ & 1.4 & 84.87 & 10.16 & 20.06 & 2.130 & 0.001 & 10,500 & 260,000 \\
\hline$L-2 b$ & $C-47$ & 1.4 & 84.41 & 10.06 & 20.06 & 2.130 & 0.001 & 10,500 & 260,000 \\
\hline L-3a & $C-28$ & 1.6 & 75.01 & 10.66 & 9.80 & 2.118 & 0.0033 & 5,600 & 138,000 \\
\hline$L-3 b$ & $\mathrm{C}-28$ & 1.6 & 74.87 & 10.66 & 9.80 & 2.118 & 0.0027 & 5,600 & 138,000 \\
\hline$L-4 a$ & C-46, & 1.9 & 92.07 & 10.62 & 9.80 & 2.01 .6 & 0.001 & 7,000 & 173,000 \\
\hline L-4b & $\begin{array}{l}C-16 \\
C-42\end{array}$ & 1.9 & 93.35 & 10.56 & 9.80 & 2.016 & 0.001 & 7,000 & 173,000 \\
\hline$I,-6 a$ & $\mathrm{C}-28$ & 1.8 & 73.63 & 10.48 & 9.80 & 2.024 & 0.001 & 6,600 & 163,000 \\
\hline$L-6 b$ & C- 28 & 1.8 & 74.18 & 10.52 & 9.80 & 2.024 & 0.001 & 6,600 & 163,000 \\
\hline$L-7 a$ & C-57 & 1.0 & 95.47 & 10.55 & 20.06 & 2.041 & 0.0016 & 7,500 & 185,000 \\
\hline$L-7 b$ & C-57 & 1.0 & 05.15 & 10.54 & $? \cap \cap . \cap \kappa$ & 2.041 & 0.0016 & 7.500 & 185,000 \\
\hline L-7ax & $C-28$ & 1.5 & 94.99 & 10.51 & 20.06 & 2.041 & 0.0034 & 11,000 & 271,000 \\
\hline$L=-/ b x$ & $L-28$ & 1.3 & 94.85 & 10.50 & 20.06 & 3.011 & 0.0036 & 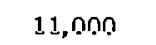 & $271, n \cap n$ \\
\hline L-8a & $C-47$ & 1.5 & 84.58 & 10.19 & 20.06 & 2.133 & 0.0028 & 11,300 & 278,000 \\
\hline L-8b & C- -47 & 1.5 & 85.01 & 10.18 & 20.06 & 2.133 & 0.0031 & 11,300 & 278,000 \\
\hline$L-10 a^{b}$ & C- -44 & 1.5 & 95.28 & 10.46 & 20.06 & 2.041 & 0.0033 & 11,400 & 280,000 \\
\hline L-10b & $C-44$ & 1.5 & 05.18 & 10.48 & 20.06 & 2.041 & 0.00 .3 .3 & 11.400 & 280,000 \\
\hline L-11a & $C-47$ & 1.3 & 85.05 & 10.47 & 20.06 & 2.140 & 0.0037 & 9,800 & 242,000 \\
\hline L-1 $1 b$ & $C-47$ & 1.3 & 85.23 & 10.46 & 20.06 & 2.140 & 0.0033 & 9,800 & 242,000 \\
\hline
\end{tabular}


Table B.1. (continued)

\begin{tabular}{|c|c|c|c|c|c|c|c|c|c|}
\hline \multirow{2}{*}{$\begin{array}{l}\text { Experi- } \\
\text { mental } \\
\text { Assembly } \\
\text { No. }\end{array}$} & \multirow[b]{2}{*}{$\begin{array}{c}\text { Core } \\
\text { Facility } \\
\text { No. }\end{array}$} & \multirow{2}{*}{$\begin{array}{c}\text { Effective } \\
\text { Thermal-Neutron } \\
\text { Flux } \\
\text { (neutrons }^{-2} \mathrm{sec}^{-1} \text { ) }\end{array}$} & \multicolumn{2}{|c|}{ Average Density } & \multirow[b]{2}{*}{$\begin{array}{c}\text { Enrich- } \\
\text { ment } \\
\left(\% U^{235}\right)\end{array}$} & \multirow{2}{*}{$\begin{array}{l}\text { Oxygen- } \\
\text { to- } \\
\text { Uranium } \\
\text { Ratio }\end{array}$} & \multirow{2}{*}{$\begin{array}{l}\mathrm{UO}_{2} \text {-to- } \\
\text { Cladding } \\
\text { Radial } \\
\text { Clearance, } \\
\text { Cold (in.) }\end{array}$} & \multirow{2}{*}{$\begin{array}{c}\text { Total } \\
\text { Power } \\
(\text { Btu ht } \\
\left.\mathrm{ft}^{-1}\right)\end{array}$} & \multirow{2}{*}{$\begin{array}{c}\text { Total Heat } \\
\text { Flux } \\
(\mathrm{Btu} \mathrm{hr}-1 \\
\left.\mathrm{ft}^{-2}\right)\end{array}$} \\
\hline & & & $\begin{array}{l}\text { Bulk (\% of } \\
\text { theoretical) }\end{array}$ & $\begin{array}{l}\text { Immersion } \\
\left(\mathrm{g} / \mathrm{cm}^{3}\right)\end{array}$ & & & & & \\
\hline L-13a & C-46 & 1.8 & 93.68 & 10.60 & 9.80 & 2.016 & 0.001 & 6,600 & 162,000 \\
\hline$L=13 b$ & C-46 & 1.8 & 92.07 & 10.60 & 9.80 & 2.016 & 0.001 & 6,600 & 162,000 \\
\hline L-14a & C-57 & 0.91 & 88.70 & 10.53 & 20.06 & 2.029 & 0.001 & 6,700 & 166,000 \\
\hline$L-14 b$ & $C-57$ & 0.91 & 90.26 & 10.55 & 20.06 & 2.029 & 0.001 & 6,700 & 166,000 \\
\hline$L-15 a$ & C. 58 . & 0.79 & 91.43 & 10.49 & 20.06 & 2.029 & 0.001 & 5,800 & $1.43,000$ \\
\hline L-15b & $C-58$ & 0.79 & 88.97 & 10.48 & 20.06 & 2.029 & 0.001 & 5,800 & 143,000 \\
\hline L-16a & C-57 & 0.71 & 94.35 & 10.48 & 29.69 & 2.005 & 0.0009 & 7,800 & 193,000 \\
\hline$L-16 b$ & $C-57$ & 0.71 & 94.38 & 10.47 & 29.69 & 2.005 & 0.0007 & 7,800 & 193,000 \\
\hline L-16ax & C-44 & 0.95 & 93.98 & 10.46 & 29.69 & 2.005 & 0.0026 & 10,400 & 257,000 \\
\hline L-16bx & C-44 & 0.95 & 94.35 & 10.48 & 29.69 & 2.005 & 0.0032 & 10,400 & 257,000 \\
\hline$L-17 a$ & C-58 & 0.78 & 93.69 & 10.42 & $29: 69$ & 2.002 & 0.0031 & 8,400 & 207,000 \\
\hline$L-17 b$ & C-58 & 0.78 & 93.80 & 10.38 & 29.69 & 2.002 & 0.0030 & 8,400 & 207,000 \\
\hline L-17ax & C-46 & 0.84 & 94.62 & 10.48 & 29.69 & 2.005 & $0.0038^{\circ}$ & 9,200 & 227,000 \\
\hline$L-17 b x$ & C-46 & 0.84 & 94.83 & 10.45 & 29.69 & 2.005 & 0.0038 & 9,200 & 227,000 \\
\hline$L-18 a$ & C-42 & 0.95 & 84.91 & 10.34 & 29.69 & 2.082 & 0.0021 & 10,400 & 257,000 \\
\hline$L-18 b$ & $C-42$ & 0.95 & 85.19 & 10.40 & 29.69 & 2.082 & 0.0021 & 10,400 & 257,000 \\
\hline L-18ax & C -42 & 0.79 & 84.69 & 10.39 & 29.69 & 2.082 & 0.0029 & 8,600 & 212,000 \\
\hline$L-18 b x$ & C-42 & 0.79 & 84.58 & 10.37 & 29.69 & 2.082 & 0.0026 & 8,600 & 212,000 \\
\hline L-21a & C-58 & 0.61 & 96.04 & 10.56 & 9.80 & 2.002 & 0.0029 & 2,200 & 54,000 \\
\hline$L-21 b^{c}$ & C- -58 & 0.61 & 96.15 & 10.55 & 9.80 & 2.002 & 0.0031 & 2,200 & 54,000 \\
\hline$L-22 a^{d}$ & $C-57$ & 0.95 & 94.47 & 10.47 & 9.80 & 2.002 & 0.0021 & 3,400 & 84,400 \\
\hline$L=22 b$ & C- 57 & 0.95 & 94.47 & 10.46 & 9.80 & $2.002^{\circ}$ & $0.0021^{\circ}$ & 3,400 & 81,100 \\
\hline$L-23 a^{e}$ & C 42 & 1.2 & 93.78 & 10.51 & 14.84 & 2.002 & 0 to & 6,600 & 162,000 \\
\hline L-23b & C- 42 & 1.2 & 94.03 & 10.51 & 14.84 & 2.002 & 0.0005 & 6,600 & 162,000 \\
\hline L-24a & C -44 & 1.6 & 94.80 & 10.78 & 20.06 & 2.017 & & 11,600 & 287.000 \\
\hline$L \cdot 24 b$ & C-44 & 16 & 94.53 & 10.69 & 20.06 & 2.017 & & 11,600 & 287,000 \\
\hline L-25a & C- 28 & 1.2 & 95.17 & 10.69 & 20.06 & 2.017 & through & 8.700 & 215,000 \\
\hline$L-25 b$ & C-28 & 1.2 & 94.90 & 10.73 & 20.06 & 2.017 & L-32 & 8,700 & 215,000 \\
\hline L-27a & C. -46 & 1.6 & 94.07 & 10.47 & 14.84 & 2.002 & & 8,800 & 216,000 \\
\hline L-27b & C-46 & 1.6 & 94.07 & 10.40 & 14.84 & 2.002 & & 8,800 & 216,000 \\
\hline$L-28 a$ & C-47 & 1.1 & 94.4 & 10.55 & 29.77 & 2.002 & & 11.500 & 284,000 \\
\hline$L-28 b$ & C- 47 & 1.1 & 94.8 & 10.64 & 29.77 & 2.002 & & 11,500 & 284,000 \\
\hline L-32a & C -42 & 0.94 & 94.26 & 10.42 & 29.77 & 2.002 & & 10,300 & 254,000 \\
\hline L-32b & C -42 & 0.94 & 93.71 & 10.63 & 29.77 & 2.002 & $\downarrow$ & 10,300 & 254,000 \\
\hline
\end{tabular}

${ }^{a}$ Capsule ruptured at pin closure braze.

${ }^{b}$ Experimental assembly was filled with helium.

${ }^{c}$ Capsule cladding failed in region of $b$ sample.

${ }^{d}$ Assembly was filled with helium.

${ }^{e}$ Assemblies L-23 through L- 32 contained helium-filled ceramic-insulated capsules. These were of the ceramicinsulated design, whereas assemblies L-1 through L-22 were of the gas-insulated design. 
Table B.1. (continued)

\begin{tabular}{|c|c|c|c|c|c|c|c|}
\hline \multirow{2}{*}{$\begin{array}{l}\text { Experi- } \\
\text { mental } \\
\text { Assembly } \\
\text { No. }\end{array}$} & \multicolumn{2}{|c|}{ Estimated Burnup } & \multirow{2}{*}{$\begin{array}{l}\text { Actual } \\
\text { Irradiation } \\
\text { Time } \\
\text { (days) }\end{array}$} & \multicolumn{2}{|c|}{ Temperatures $\left({ }^{\circ} \mathrm{F}\right)$} & \multirow{2}{*}{$\begin{array}{c}\text { Type of } \\
\text { Thermocouple } \\
\text { Used in } \\
\text { Fuel }^{8}\end{array}$} & \multirow[b]{2}{*}{$\begin{array}{l}\text { No. of Thermal } \\
\text { Cycles } \\
>500^{\circ} \mathrm{F} \Delta T\end{array}$} \\
\hline & $\begin{array}{c}\text { Total } \\
\text { (Mwd per metric } \\
\text { ton of } \mathrm{UO}_{2} \text { ) }\end{array}$ & $\begin{array}{c}\text { Rate } \\
(\mathrm{Mw} \text { per metric } \\
\left.\text { ton of } \mathrm{UO}_{2}\right)\end{array}$ & & $\begin{array}{l}\text { Cladding } \\
\text { Outer Surface }\end{array}$ & $\begin{array}{c}\text { Fuel } \\
\text { Inner Surface }^{f}\end{array}$ & & \\
\hline L-1a & 7,800 & 74 & 103 & 700 & 1800 & $P, A, 1$ & \\
\hline L-1b & 7,800 & 74 & 103 & 1300 & & None & \\
\hline$L-2 a$ & 3,200 & 106 & 30 & 900 & 2480 & $P, A, 2$ & \\
\hline$L-2 b$ & 3,200 & 106 & 30 & 1300 & & None & 22 \\
\hline L-3a & 4,100 & 56 & 76 & 1200 & 2200 & $w, C, 3$ & \\
\hline$L-3 b$ & 4,100 & 56 & 76 & 1300 & $2220^{h}$ & None & 22 \\
\hline$L-4 a$ & 12,000 & 71 & 175 & 1150 & 2350 & $\mathrm{P}, \mathrm{A}, 1$ & \\
\hline$L-4 b$ & 12,000 & 71 & 175 & 1300 & & None & 113 \\
\hline L-6a & 12,000 & 67 & 175 & 1000 & 2020 & P, A, 1 & \\
\hline L-6b & 12,000 & 67 & 175 & 1300 & & None & 111 \\
\hline$L-7 a$ & 5.400 & 75 & 73 & 700 & 2160 & $P, A, 2$ & \\
\hline$L-7 b$ & 5,400 & 75 & 73 & 1300 & & None & 47 \\
\hline$L-7 a x$ & 14,000 & 111 & 126 & 1050 & & $\mathrm{P}, \mathrm{C}, 4$ & $\cdot$ \\
\hline$L-7 b x$ & 14,000 & 111 & 126 & 1300 & 2780 & $w, c, 3$ & 66 \\
\hline L-8a & 6,300 & 114 & 55 & 1200 & 2660 & w, c, 3 & \\
\hline$L-8 b$ & 6,300 & 114 & 55 & 1300 & & None & 21 \\
\hline$L-10 a$ & $3,500^{i}$ & 114 & 30 & 1200 & 2280 & $P, C, 4$ & \\
\hline$L-10 b$ & $3,500^{i}$ & 114 & 30 & 1300 & 2745 & $w, C, 4$ & 14 \\
\hline$L-11 a$ & 19,000 & 99 & 195 & 1200 & 2580 & P, C, 2 & \\
\hline$L-11 b$ & 19,000 & 99 & 195 & 1300 & 2700 & $w, C, 3$ & 87 \\
\hline$L-13 a$ & $11,800^{i}$ & 66 & 179 & 1050 & 2220 & P, A, 2 & \\
\hline$L-13 b$ & $11,800^{i}$ & 66 & 179 & 1300 & & None & 106 \\
\hline$L-14 a$ & 4,500 & 68 & 69 & 1100 & 2080 & P, A, 2 & \\
\hline$L-14 b$ & 4,500 & 68 & 69 & 1300 & & None & 33 \\
\hline L-15a & 5,200 & 59 & 90 & $y^{2} / 3$ & 1620 & $\mathrm{P}, \mathrm{A}, 2$ & \\
\hline$L-15 h$ & 5,200 & 59 & 90 & 1300 & & None & 43 \\
\hline$L-16 a$ & $6,900^{i}$ & 79 & 88 & 1025 & 1860 & P, C, 2 & \\
\hline$L=16 b$ & $6,900^{i}$ & 79 & 88 & 1300 & 1915 & $w, c, 3$ & 26 \\
\hline L-16ax & $3,300^{i}$ & 105 & 31 & 1025 & 2705 & $w, C, 4$ & \\
\hline$L-16 b x$ & $3,300^{i}$ & 105 & 31 & 1300 & 3065 & $w, c, 1$ & 23 \\
\hline$L \cdot 17 a$ & 9,300 & 85 & 112 & 1100 & 2410 & $P, B, 3$ & \\
\hline$L \cdot 17 b$ & 9,300 & 85 & 112 & 1300 & & None & 43 \\
\hline L-17ax & 2,700 & 92 & 30 & 1100 & & P, C, 4 & \\
\hline$L-17 b x$ & 2,700 & 92 & 30 & 1300 & 3130 & $w, C, 4$ & 14 \\
\hline$L-18 a$ & $5,800^{i}$ & 105 & 55 & 1075 & $2520^{h}$ & $w, C, 2$ & \\
\hline$L \cdot 18 b$ & $5,800^{i}$ & 105 & 55 & 1300 & $2575^{h}$ & None & 21 \\
\hline L-18ax & 7,600 & 87 & 88 & 1175 & 2860 & P, C, 2 & \\
\hline$L \cdot 18 b x$ & 7,600 & 87 & 88 & 1300 & 3035 & $w, c, 3$ & 31 \\
\hline L-21a & 1,100 & 22 & 50 & 850 & 1500 & $P, C, 2$ & \\
\hline$L-21 b$ & $1, i \cup 0$ & 22 & 50 & 1000 & 1535 & $w, r ; 3$ & 22 \\
\hline
\end{tabular}


Table B.1. (continued)

\begin{tabular}{|c|c|c|c|c|c|c|c|}
\hline \multirow{2}{*}{$\begin{array}{l}\text { Experi- } \\
\text { mental } \\
\text { Assembly } \\
\text { No. }\end{array}$} & \multicolumn{2}{|c|}{ Estimated Burnup } & \multirow{2}{*}{$\begin{array}{l}\text { Actual } \\
\text { Irradiation } \\
\text { Time } \\
\text { (days) }\end{array}$} & \multicolumn{2}{|c|}{ Temperatures $\left({ }^{\circ} \mathrm{F}\right)$} & \multirow{2}{*}{$\begin{array}{c}\text { Type of } \\
\text { Thermocouple } \\
\text { Used in } \\
\text { Fuel }^{\mathrm{g}}\end{array}$} & \multirow[b]{2}{*}{$\begin{array}{l}\text { No. of Thermal } \\
\text { Cycles } \\
>500^{\circ} \mathrm{F} \Delta T\end{array}$} \\
\hline & $\begin{array}{c}\text { Total } \\
\text { (Mwd per metric } \\
\text { ton of } \mathrm{UO}_{2} \text { ) }\end{array}$ & $\begin{array}{c}\text { Rate } \\
\text { (Mw per metric } \\
\text { ton of } \mathrm{UO}_{2} \text { ) }\end{array}$ & & $\begin{array}{c}\text { Cladding } \\
\text { Outer Surface }\end{array}$ & $\begin{array}{c}\text { Fuel } \\
\text { Inner Surface }^{f}\end{array}$ & & \\
\hline$L-22 a$ & 10,500 & 34 & 305 & 1075 & 1350 & P, C, 2 & \multirow[b]{2}{*}{121} \\
\hline$L-22 b$ & 10,500 & 34 & 305 & 1300 & 1475 & W, C, 4 & \\
\hline$L=23 a$ & 12,200 & 66 & 184 & 1150 & 2805 & $w, C, 4$ & \multirow[b]{2}{*}{73} \\
\hline$L-23 b$ & 12,200 & 66 & 184 & 1300 & 2600 & $w, C, 4$ & \\
\hline$L=24 a$ & 26,000 & 117 & 228 & 1000 & 2565 & $w, C, 4$ & \multirow[b]{2}{*}{81} \\
\hline$L \cdot 24 b$ & 26,000 & 117 & 228 & 1300 & 2925 & $w, C, 4$ & \\
\hline$L-25 a$ & 4,500 & 88 & 51 & 1050 & 2080 & $w, C, 4$ & \multirow[b]{2}{*}{40} \\
\hline$L-25 b$ & 4,500 & 88 & 51 & 1300 & 2330 & $w, c, 4$ & \\
\hline L-27a & 12,800 & 88 & 145 & 1050 & 2015 & $w, C, 4$ & \multirow[b]{2}{*}{47} \\
\hline$L-27 b$ & 12,800 & 88 & 145 & 1300 & 2375 & $w, C, 4$ & \\
\hline$L-28 a$ & 17,200 & 116 & 148 & 1000 & 2180 & $w, C, 4$ & \multirow[b]{2}{*}{57} \\
\hline$L-28 b$ & 17,200 & 116 & 148 & 1300 & 3450 & $w, C, 4$ & \\
\hline L-32a & 7,500 & 104 & 73 & 900 & & $w, C, 4$ & \multirow{2}{*}{32} \\
\hline$L=32 b$ & 7.500 & 104 & 73 & 1300 & 3060 & $W, C, 4$ & \\
\hline
\end{tabular}

\footnotetext{
${ }^{f}$ Some measured temperatures are lower than previously reported in ORNL progress reports because of an earlier. error in lead wire compensation. Values quoted are for the initial period of test.

$$
\begin{array}{ll}
\frac{\text { Wire Material }}{\mathrm{P}=\mathrm{Pt}-\mathrm{Pt}-10 \% \mathrm{Rh}} & \frac{\text { Insulator Material }}{\mathrm{A}=\mathrm{Al}_{2} \mathrm{O}_{3}} \\
\mathrm{~W}=\mathrm{W}-\mathrm{Re} & \begin{array}{l}
\mathrm{B}=\mathrm{MgO} \\
\mathrm{C}=\mathrm{BeO}
\end{array}
\end{array}
$$$$
\begin{aligned}
& \text { Type of Thermocouple } \\
& 1=\text { exposed bead } \\
& 2=\text { hiddcn bead } \\
& 3=\text { fused junction with } \mathrm{Ta} \text { sheath } \\
& 4=\text { insulated junction with } \mathrm{Ta}
\end{aligned}
$$$$
\text { sheath }
$$

${ }^{h}$ Calculated; all other temperatures measured.

${ }^{\prime}$ Calculated from thermal-neutron flux history for the core facility used.

Example: $W, C, 3$ means a tungstenrhenium thermocouple with a tantalum. sheathed fused junction and a $\mathrm{BeO}$ in sulator.
}

\section{Irradiation History for Each Prototype Capsule Experiment}

All of the prototype capsule irradiation experiments conducted in the ORR test series are listed in Table B.2. Burnup, total power, and heat flux were, in all cases, calculated from flux measurement, fuel enrichment, and reactor operational experience, that is, megawatt days of operation. Fuel central temperatures were computed using nominal dimensions for the gap between the $\mathrm{UO}_{2}$ pellets and the cladding, the thermal conductivity, of pure helium, and a $\mathrm{UO}_{2}$ thermal conductivity of $1.5 \mathrm{Btu} \mathrm{hr}^{-1} \mathrm{ft}^{-2}\left({ }^{\circ} \mathrm{F} / \mathrm{ft}\right)^{-1}$. The values were subject to variation during irradiation from possible changes in the conductivity of $\mathrm{UO}_{2}$ and the helium-gas annulus, respectively, by fracturing and radiation damage and by dilution with fission gases. The central fuel pellet temperatures measured in recent ORR-type capsules containing a thermocouple in hollow $\mathrm{UO}_{2}$ pellets of EGCR size were, however, in approximate agreement with the calculated values. 
Table B.2. Conditions of Irradiation in ORR of Full-Diameter Prototype EGCR Fuel Elements

\begin{tabular}{|c|c|c|c|c|c|c|c|}
\hline $\begin{array}{l}\text { Experi- } \\
\text { mental } \\
\text { Assembly } \\
\text { No. }^{a}\end{array}$ & $\begin{array}{c}\text { Effective } \\
\text { Thermal-Neutron } \\
\text { Flux } \\
\text { (neutrons } \\
\mathrm{cm}^{-2} \sec ^{-1} \text { ) }\end{array}$ & $\begin{array}{c}\text { Average } \\
\text { Immersion } \\
\text { Density } \\
\left(\mathrm{g} / \mathrm{cm}^{3}\right)\end{array}$ & $\begin{array}{c}\text { Enrich- } \\
\text { ment } \\
\left(\% U^{235}\right)\end{array}$ & $\begin{array}{c}\text { Oxygen- } \\
\text { to- } \\
\text { Uranium } \\
\text { Ratio }\end{array}$ & $\begin{array}{l}\mathrm{UO}_{2} \text {-to- } \\
\text { Cladding } \\
\text { Radial } \\
\text { Clearance, } \\
\text { Cold (in.) }\end{array}$ & $\begin{array}{l}\text { Estimated } \\
\text { Total } \\
\text { Power }^{c} \\
(\text { Btu hr } \\
\left.\text { lin } \mathrm{ft}^{-1}\right)\end{array}$ & $\begin{array}{c}\text { Estimated } \\
\text { Total Heat } \\
\text { Flux } \\
(\text { Btu hr } \\
\left.\mathrm{ft}^{-2}\right)\end{array}$ \\
\hline & $\times 10^{12}$ & & & & & & \\
\hline $01-1$ & 4.1 & 10.68 & 4.03 & 2.007 & $\begin{array}{l}0.0029 \\
0.001 .6\end{array}$ & 14,000 & 71,000 \\
\hline $02-1$ & 4.4 & 10.74 & 4.03 & 2.017 & $\begin{array}{l}0.0030 \\
0.0020\end{array}$ & 15,000 & 76,000 \\
\hline O3-1 & 3.7 & 10.67 & 4.03 & 2.007 & $\begin{array}{l}0.0029 \\
0.0018\end{array}$ & 13,000 & 65,000 \\
\hline O $4-1^{d}$ & 5.8 & 10.68 & 4.03 & 2.007 & $\begin{array}{l}0.0027 \\
0.0019\end{array}$ & 19,000 & 99,000 \\
\hline $05-1$ & 7.5 & 10.75 & 4.03 & 2.017 & $\begin{array}{l}0.0031 \\
0.0020\end{array}$ & 26,000 & 130,000 \\
\hline $06-1^{d}$ & 4.6 & 10.77 & 4.03 & · 2.017 & $\begin{array}{l}0.0031 \\
0.0016\end{array}$ & 15,000 & 79,000 \\
\hline $07-1$ & 4.3 & 10.61 & 2.18 & 2.004 & $\begin{array}{l}0.0031 \\
0.0021\end{array}$ & 11,000 & 54,000 \\
\hline $08-1$ & 4.1 & 10.55 & 2.18 & 2.004 & $\begin{array}{l}0.0031 \\
0.0020\end{array}$ & 10,000 & 51,000 \\
\hline $01-2$ & 3.6 & 10.74 & 6.49 & 2.004 & $\begin{array}{l}0.0033 \\
0.0024\end{array}$ & 20,000 & 100,000 \\
\hline $02-2$ & 3.6 & 10.72 & 6.49 & 2.004 & $\begin{array}{l}0.0029 \\
0.0024\end{array}$ & 20,000 & 100,000 \\
\hline O3-2 & 3.6 & 10.71 & 6.20 & 2.001 & $\begin{array}{l}0.0031 \\
0.0024\end{array}$ & 19,000 & 97,000 \\
\hline $04-2^{d}$ & 4.5 & 10.72 & 6.20 & 2.002 & $\begin{array}{l}0.0031 \\
0.0024\end{array}$ & 23,000 & 117,000 \\
\hline $05-2$ & 7.9 & 10.67 & 4.60 & 2.001 & $\begin{array}{l}0.0031 \\
0.0022\end{array}$ & 30,000 & 152,000 \\
\hline $06-2^{r}$ & 4.1 & 10.77 & 6.10 & 2.003 & $\begin{array}{l}0.0027 \\
0.0020\end{array}$ & 21,000 & 105,000 \\
\hline $07-2$ & 2.3 & 10.65 & 7.49 & 2.004 & $\begin{array}{l}0.0028 \\
0.0024\end{array}$ & 18,000 & 94,000 \\
\hline$n R-2$ & 2.2 & 10.77 & 6.83 & 2.004 & $\begin{array}{l}0.0029 \\
0.0024\end{array}$ & 16,000 & 82,000 \\
\hline
\end{tabular}

${ }^{a}$ All fuel pellets were hollow cylinders nominally $0.705 \mathrm{in.}$ OD by $0.323 \mathrm{in}$. ID, except $07-1,08-1,07-2$, and $08-2$, which were solid; cladding was 0.750 in. OD with 0.020 in. wall.

${ }^{b}$ Numbers in this column represent, in sequence, maximum and minimum measured valnes.

${ }^{c}$ Power and heat flux calculations are based on a $176 \mathrm{Mev} /$ fission reaction energy plus $0.37 \mathrm{w} / \mathrm{g}$ gamma heating.

${ }^{d}$ Experimental assemblies 04-1, 06-1, 04-2, and 06-2 contained a porous BeO plug in the pellet core. 
Table B.2. (continued)

\begin{tabular}{|c|c|c|c|c|c|c|c|}
\hline \multirow{3}{*}{$\begin{array}{c}\text { Experi- } \\
\text { mental } \\
\text { Assembly } \\
\text { No. }\end{array}$} & \multicolumn{2}{|c|}{ Estimated Burnup } & \multicolumn{3}{|c|}{ Temperatures $\left({ }^{\circ} \mathrm{F}\right)$} & & \\
\hline & \multirow{2}{*}{$\begin{array}{c}\text { Total } \\
\text { (Mwd per metric } \\
\text { ton of } \mathrm{UO}_{2} \text { ) }\end{array}$} & \multirow{2}{*}{$\begin{array}{c}\text { Rate } \\
\text { (Mw per metric } \\
\text { ton of } \mathrm{UO}_{2} \text { ) }\end{array}$} & \multicolumn{2}{|c|}{ Cladding } & \multirow{2}{*}{$\begin{array}{c}\text { Fuel Center } \\
\text { (Design) }\end{array}$} & \multicolumn{2}{|c|}{ Thermal Cycles ${ }^{t}$} \\
\hline & & & Design & $\begin{array}{l}\text { Typical } \\
\text { Measured }\end{array}$ & & Shutter & Reactor \\
\hline $01-1$ & 1000 & 6.9 & $1300^{8}$ & 1320 & 1770 & 0 & 429 \\
\hline $02-1$ & 1100 & 7.4 & $1600^{h}$ & 1580 & 2100 & 77 & 493 \\
\hline 03-1 & 900 & 6.3 & 1300 & . 1300 & 1730 & 105 & 461 \\
\hline $04-1$ & 1400 & 9.8 & 1300 & 1320 & 1960 & 101 & 392 \\
\hline O5-1 & 1900 & 12.7 & 1600 & 1580 & 2450 & 182 & 563 \\
\hline O6-1 & 1100 & 7.8 & 1600 & 1560 & 2120 & 178 & 370 \\
\hline $07-1$ & 550 & 3.9 & 1300 & 1250 & 1890 & 240 & 318 \\
\hline O8-1 & 550 & 3.7 & 1600 & 1530 & 2160 & 178 & 299 \\
\hline $01-2$ & 1400 & 9.8 & 1300 & 1310 & 1960 & 0 & 173 \\
\hline $02 \cdot 2$ & 1400 & 9.8 & 1600 & 1600 & 2260 & 156 & 190 \\
\hline $03-2$ & 1400 & 9.6 & 1300 & 1320 & 1940 & 161 & 176 \\
\hline $04-2$ & 1700 & 11.7 & 1300 & 1320 & 2070 & 1.59 & 164 \\
\hline $05-2$ & 2200 & 15.2 & 1600 & 1600 & 2600 & 96 & 184 \\
\hline $06-2$ & 1500 & 10.5 & 1600 & 1580 & 2290 & 97 & 156 \\
\hline $07-2$ & 1000 & 7.2 & 1300 & 1290 & 2330 & 91 & 178 \\
\hline $08-2$ & 900 & 6.3 & 1600 & 1590 & 2500 & 86 & 161 \\
\hline
\end{tabular}

Burnup calculations are based on a $200 \mathrm{Mev} / \mathrm{fission}$ reaction energy; capsules were irradiated for approximately 145 days.

${ }^{t} \mathrm{~A}$ thermal cycle is defined as an increase or decrease in temperature by an amount greater than $50^{\circ} \mathrm{F}$ in $10 \mathrm{~min}$ or less time; a separate count was added for each direction of temperature change.

. Average design temperature is $1300 \pm 50^{\circ} \mathrm{F}$.

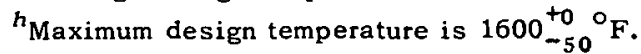




\section{APPENDIX C \\ POSTIRRADIATION EXAMINATION OF ORR PROTOTYPE ELEMENTS}

\section{Group 1}

Elements $01,02,03,05$, and 06 were sent to GEVAL for postirradiation examination after gamma scans and the fission gas release had been measured by ORNL. The gamma scans of all group 1 capsules are shown in Figs. C.34-C.41.

The following discussion of the postirradiation examination of these elements is essentially a verbatim copy of pertinent parts of GEAP-3774.

Elements 04, 06, 07, and 08 were used in high-temperature postirradiation experiments at ORNL. The postirradiation examination of these elements (except 06 ) will not be presented here.

Figure C.1 shows the elements upon arrival at GEVAL. The elements were slit open and the contents visually examined.

\section{Visual Examination - Fuel and Internal Hardware}

Capsule 01-1. - Each fuel pellet was fractured into four to ten pieces. The majority of the fractures were radial although several of the pellets also contained transverse cracks. Figure C.2 is a photograph of the fuel in place in the cladding immediately after the capsule was opened. A deposit of what appeared to be iron oxide was observed on the outer surface of the top four fuel pellets (Fig. C.3). A similar deposit was observed on the inside surface of the cladding. The MgO end spacers from both ends of the capsule were intact. Both spacers were discolored primarily on the side that was in contact with the fuel. The bottom spacer contained a deposit of gray material in the area adjacent to the central void in the fuel.

Copsule 02-1. - All of the fuel pellets remained in place in the cladding except for the bottom pellet which dropped from the capsule during the slitting operations. Small hairline cracks were observed in each of the fuel pellets. In addition, some larger radial fractures were present in several of the fuel pellets (Fig. C.4). The inside surface of the stainless steel cladding contained dark lines showing the location of interfares and large r.rarks in the fuel pellets. Both MgO end spacers were intact and showed only a slight amount of discoloration on the areas adjacent to the fuel. Dark circles were present in their centers corresponding to fuel pellet inner surfaces. Two of the fuel pellets (No. 6 and No. 12) were removed from the cladding in one piece and measured. The outer surfaces of the top two fuel pellets were darkened slightly as was the inside cladding surface in the region in which they were located. Both ends of fuel pellet No. 12 are shown in Fig. C.5 to illustrate the type of cracks which were present in the fuel pellets. Figure C. 6 shows the bottom spacer, end plug, and fuel pellet No. 1, which fell from the cladding during the slitting operations.

Capsule 03-1. - The top half of this capsule was potted with an epoxy resin, Hysol, to preserve the fuel pellets in their original state before disassembly. In order to accomplish this a circular cut was made through the cladding at the interface between fuel pellets No. 7 and No. 8 . The position of the interface was established by the dark lines showing on the outer surface of the cladding. The exposed surface of 
fuel pellet No. 7 contained two deep-blue-colored spots of undetermined origin. The bottom half of the capsule was opened in the usual manner. The fuel in the bottom section of the capsule was fractured into approximately ten pieces per pellet. Small deposits of extraneous material were observed on the outer surfaces of the fuel. The deposits included a pale-green crystalline material and a slight amount of what appeared to be iron oxide. The pale-green deposit is shown as a white material in Fig. C.7. The ruștcolored deposit does not show in the photographs, but was scattered over outer surfaces in any slight recessions in the surface of the fuel. Fuel pellets No. 1 and No. 2, which illustrate typical crack patterns in the fuel, are shown in Fig. C.8. As in previous capsules, the inside surface of the cladding contained dark lines at pellet interfaces and in cracks; however, the inside surface was generally darker than the two previous capsules. The surface of the bottom $\mathrm{MgO}$ spacer was discolored, and had small amounts of material adhering to it in the areas adjacent to the fuel (Fig. C.9). The fuel from the top half of the capsule, which had been potted, was lost during the sectioning operations and no examinations were possible.

Capsule 05-1. - The fuel pellets were fractured to a great extent as may be seen in Fig. C.10. The majority of the cracks were radial; however, 8 of the 12 fuel pellets also contained one or more transverse cracks. As in capsule 03-1, a pale-green deposit was present on the outer surfaces of the fuel pellets with lesser amounts on the cracked and inner surfaces. A white deposit was also present in the same areas, but in lesser quantity than the green deposit. The inside surface of the cladding was heavily coated with a deposit of iron oxide in the portion occupied by the top MgO spacer. A very thin filmy deposit of the iron oxide material was present on all of the fuel. The white deposit may be seen in Fig. C.11 which shows the top MgO spacer and fuel pellet No. 12 .

Capsule 06-1. - (This element had been heated to above $1700^{\circ} \mathrm{F}$ at ORNL in a postirradiation experiment prior to shipment to GEVAL.) This was the only capsule from group 1 which contained a BeO insert in the central void in the fuel. One half of the capsule was vacuum potted with Hysol mounting compound in order to preserve its integrity. The capsule was sectioned by making a circular cut at the interface between fuel pellets No. 6 and No. 7. The exposed surfaces of both of these pellets were partially covered by a.deposit slightly darker in color than the fuel pellets themselves (Fig. C.12). This deposit was concentrated near the outer edge of the surface. All of the fuel pellets contained several radial cracks while very few transverse cracks were observed. Some of the cracks contained a border of the same dark-gray deposit observed on fuel pellets No. 6 and No. 7 (Fig. C.13). In every case the deposit was heaviest near the outer surface of the fuel. These observations are consistent with the following mechanism. Water vapor within the capsule hydrolyzed the $\mathrm{BeO}$ at the temperature experienced in the center of the fuel. The resultant $\mathrm{Be}(\mathrm{OH})_{2}$ migrated to a cooler region where it dissociated into $\mathrm{BeO}$ and $\mathrm{H}_{2} \mathrm{O}$. The $\mathrm{BeO}$ remained as a deposit on the cooler surface and the water returned to repeat the cycle. ${ }^{25}$ An attempt to identify the deposit by $x$-ray diffraction analysis was unsuccessful. The deposit was too thin to allow a suitable sample from the fuel pellet surfaces to be obtained. Several large craters were observed in the surface of the BeO insert from the bottom of the capsule (Fig. C.14). These craters are

\footnotetext{
${ }^{25}$ W. A. Young, J. Phys. Chem. 64, 1003-6 (1960).
} 
possible locations at which the hydrolysis reaction may have taken place. The inside surface of the cladding contained the dark lines at pellet interfaces and cracks and was slightly discolored over the entire surface, apparently, by the same deposit observed on the fuel pellets (Fig. C.15).

The upper half of the capsule, which had been potted, was sectioned transversely through fuel pellet No. 7 and longitudinally through the remainder of the length. Several radial hairline cracks were observed in the transverse section. There appeared to be intimate contact between the cladding and fuel around the entire circumference (Fig. C.16). The longitudinal section showed intimate contact between the fuel and cladding over the length of five fuel pellets (Fig. C.17). The cladding had apparently collapsed over the fuel pellets due to external pressures on the cladding. These pressures were sufficient to induce longitudinal cracking of some of the fuel pellets. The MgO spacer had been forced upward against the end plug by the expansion of the $\mathrm{BeO}$ insert. A small portion of the $\mathrm{BeO}$ even extended into the center hole in the $\mathrm{MgO}$,

\section{Mctallographic Examination}

Capsule 01-1. - A transverse cross section of fuel pellet No. 8, from near the center of the capsule, was selected for metallographic examination. Considerable porosity was uniformly distributed over the entire cross section. Etching of the sample revealed a fairly uniform grain size from outer to inner edges. An acicular structure was present, dispersed throughout the inner half of the cross section. The sample is shown in the as-etched condition at $100 \times$ and $250 \times$ magnifications in Figs. C. 18 and C.19.

A considerable amount of a light-colored second-phase material was present in the control sample. for this fuel. This material was identified as $\mathrm{UN}_{2}$ by $\mathrm{x}$-ray diffraction techniques and was estimated to occupy $5-10 \%$ of the volume.

Capsule 02-1. - Two fuel pellets from this capsule were selected for metallographic examination: pellet No. 12 from the top of the capsule and pellet No. 6 from the center of the capsule.

Pellet No. 12. - This pellet was fractured to a great extent. Most of the observed cracking was intergranular. The grain size was fairly uniform over the examined cross section and there was no apparent porosity gradient. Some of the observed porosity may be the result of pullout introduced during the polishing operation. Photomicrographs of the sample are shown in Figs. C.20 and C.21.

Pellet No. 6. - A slight amount of a light-colored second-phase material was present in the sample. This material resembled the $\mathrm{UN}_{2}$ observed in the control material although it was not present in the same amounts. An acicular structure was present, concentrated mainly near the inner surface of the fuel pellet. The porosity of the sample was somewhat greater than in pellet No. 12 even though it was not fractured to as great an extent. As in pellet No. 12, the grain size distribution across the sample was nearly uniform. Photomicrographs of the sample in the as-etched condition taken at the inner surface, center, and outer surface are shown in Fig. C.22.

Capsule 03-1. - Pellet No. 6, from the center of the capsule, was selected for metallographic examination. A second phase resembling the $\mathrm{UN}_{2}$ observed in other samples was also present in this pellet. Most of the second-phase material was concentrated near the inner surface where it was not as well developed into the acicular structure as in pellet No. 6 from capsule 02-1. Microcracking was present, but 
of a generally shorter range than in some of the other samples. Porosity was about normal for a body of this density. Some of the larger voids appear to have been pullouts incurred during preparation. Figure $\mathrm{C}-23$ shows the entire cross section as polished and as etched at $100 \times$ magnification. Figure C. 24 shows the sample at $250 \times$ in the as-etched condition.

Capsule 05-1. - Two metallographic samples were selected from this capsule: pellet No. 12 from the top of the capsule and pellet No. 8 from near the center of the capsule.

Pellet No. 12. - The examined sample revealed numerous large voids as a result of the polishing operation. Numerous intergranular cracks were present which made the sample very susceptible to pullout. A needle-shaped second-phase material was present at the inner half of the cross section (Fig. C.25).

Pellet No. 8. - The outer circumference of this pellet was severely fractured. The grains along the fractured band appeared to be more dense than the remainder of the sample. The acicular structure was present, again concentrated within the inner portion of the cross section. No grain size variation was apparent. Photomicrographs of the sample are shown in Figs. C.26 and C.27.

Capsule 06-1. - Fuel pellet No. 7, from the center of the capsule, was selected for metallographic examination. The sample was polished for approximately $100 \mathrm{hr}$ on a Syntron polisher in order to bring out the second-phase materials. A considerable quantity of $\mathrm{UN}_{2}$ was present in approximately the same concentration and distribution as in the control material. The majority of this phase was intergranular; however, a slight amount of precipitation along crystallographic cleavage planes may be seen near the inner surface at $250 \times$. A third phase, tentatively identified as uranium carbide, was present in the sample. Identification was based on its staining by water and a tendency to preferentially etch. This capsule contained a beryllia insert which filled the central void in the fuel pellets. Although stains were observed in the fuel around radial cracks, pellet-to-pellet interfaces, and outer surfaces, there was no evidence of a reaction between the fuel and beryllia. Photomicrographs of the fuel are shown in Figs. C. 28 and C.29.

Cladding. - A transverse section through the center of one half of the opened cladding of element 01-1 was taken for metallographic examination. A precipitate thought to be either a nitride or a carbide was observed at the inner surface extending outward along the grain boundaries (Fig. C.30). The depth to which the precipitate penetrated and its concentration were quite uniform over the examined cross section. An unusual material, possibly a film left by the $\mathrm{NaK}$, was observed at the outer surface of the cladding.

MgO Spacers. - The bottom end spacers from capsules 02-1 and 05-1 were sectioned across their diameters for metallographic examination. Both $\mathrm{MgO}$ spacers were similar in appearance. A darkening, particularly in those areas that were in contact with the fuel, was observed. Selective darkening of grains throughout the samples was also noted. Etching of the samples revealed a grain boundary second phase. At $500 \times$ magnification in the as-polished condition, the second phase has a glassy character. Etching of the specimen removed all of the intergranular phase; however, some of the material remained intragranular. Photomicrographs of the area next to the fuel are shown in Fig. C.31.

BeO Insert. - The beryllium oxide core from capsule 06-1 exhibited darkening, particularly in the outer region next to the fuel. No gross structural changes were noted. Photomicrographs of the control material and irradiated sample are shown in Figs. C.32 and C.33. 


\section{Group 2}

The postirradiation examinations of all the group 2 capsules were made by GEVAL. The following discussion is essentially a verbatim copy of pertinent parts of GEAP-3813.

\section{Visual Examination}

Photographs of the elements upon arrival at GEVAL are shown in Figs. C.42-C.46. All capsules exhibited some degree of cladding surface staining which was later identified as decarburization. Ridges had formed in the cladding at pellet-to-pellet gap locations. These ridges were more prominent in capsules 02-2, 05-2, 06-2, and 08-2. The lighter areas were locations where thermocouples and flux monitor bands contacted the cladding. Two discolored areas were observed, one near the top end of capsule 02-2 cladding and another on the bottom end of capsule O5-2 (Fig. C.46).

Gamma scans were made by GEVAL. The elements were then slit open and visual observations of fuel, cladding, and components were made.

Capsule 01-2 (Fig. C.47). - By comparing the photograph of the as-opened capsule with the photograph of the gamma scan trace, a one-to-one correspondence between anomalies in the capsule and anomalies in the gamma scan can be observed. Large pellet-to-pellet gaps show as considerable drops in gamma activity level in the scan trace. Flux peaking is evident in both top and bottom fuel pellets. The dark markings on the cladding interior correspond to fuel cracks and gaps.

Capsule 02-2 (Fig. C.48). - Notice the $\mathrm{UO}_{2}$ embedded in the cladding opposite the top pellet. This $\mathrm{UO}_{2}$ is directly under the discolored spot in the cladding mentioned previously. A metallographic sample taken through this region is discussed in the section on metallography.

Capsule 03-2 (Fig. C.49). - The capsule was cut in half at the interface between pellets No. 6 and No. 7 and the top portion was potted in Hysol. After curing, the top half of the capsule was sectioned partially lengthwise with a 12 -in. abrasive wheel. Difficulties were encountered so the cut was completed with a 12 -in. diamond wheel. Wheel marks can be seen in the photograph of this section。

The top expansion space was "frozen" in by the Hysol. From the photograph, the expansion space was scaled to be approximately $32 \mathrm{mils}$. Since the preirradiation value was given as $40 \mathrm{mils}$, it would appear that some of the expansion space has been redistributed throughout the capsule length. This is also shown in the gamma scan where several large pellet-to-pellet gaps can be seen.

Capsule 04-2 (Fig. C.50). - Fracturing of the top fuel pellet shows clearly in the level changes in the gamma scan trace. The $\mathrm{UO}_{2}$ shifted before the as-opened capsule could be photographed but there had existed a large pcllct-to pcllet gap as indicated in the gamma sran.

The $\mathrm{BeO}$ slid easily from the hollow pellets, but two rods broke even though they were gently handled. Fracturing of the $\mathrm{BcO}$ rods made it impossible to measure an nverall $\mathrm{BeO}$ rod length. However, the rods did not appear to extend beyond the fuel length and they appeared to be stable dimensionally. Rod diameters were within 1 mil of the preirradiation diameter.

A discoloration was present on most fuel pellets at the pellet-to-pellet interface, especially on pellets No. 5 and Nn. 6. 
Capsule 05-2 (Fig. C.51). - The capsule was cut in half at the pellet interface between No. 6 and No. 7 and the bottom section was potted in Hysol. After curing, the bottom half of the capsule was sectioned longitudinally with a 12-in. diamond wheel. The section shown in Fig. C.51 was polished on No. 200 grit paper using $\mathrm{H}_{2} \mathrm{O}$ lubricant. Considerable fracturing of the bottom fuel pellet is shown in the gamma scan. Some of these cracks can be seen in the rough polished section.

Capsule 06-2 (Fig. C.52). - The bottom end cap was removed and an attempt was made to pot the entire capsule through the bottom. After the Hysol had cured, the entire capsule was cut open lengthwise on the slitter. Unfortunately, the $\mathrm{BeO}$ rods rotated in the $\mathrm{UO}_{2}$ and were mostly lost during the slitting operation. When the two halves of the slit sample were examined (Fig. C.52), it was discovered that only a small section of one BeO rod was left in the bottom portion of the capsule. Because of chattering of the slitter wheel, the $\mathrm{UO}_{2}$ fracture pattern is distorted and not representative. It does appear however that no growth occurred in the $\mathrm{BeO}$ rods since they rotated freely under the slitter wheel and the bottom $\mathrm{BeO}$ rod did not extend beyond the bottom $\mathrm{UO}_{2}$ pellet.

Capsule 07-2 (Fig. C.53). - The top MgO spacer, under the stainless steel spacer ring, was fractured into five piecés. Here again, upon opening the capsule the fractured peilets and the pellet gaps were observed to correlate well with the gamma scan anomalies. Most of the fuel pellets were intact.

Capsule 08-2 (Fig. C.54). - The top MgO spacer, under the stainless steel spacer ring, was fractured into four pieces. A pronounced anomaly can be seen in the gamma scan trace level at pellet No. 3. This pellet was chosen for postirradiation density measurement. No large change in density was observed. Therefore, it appears that this pellet has a higher enrichment than the other $\mathrm{UO}_{2}$ pellets.

\section{Metallographic Examination}

$\mathrm{UO}_{2}$ Fuel. - Second phases were observed in all fuel examined (one or more fuel pellets from each capsule). There were four types of second phases which can be described as follows:

1. Yellow phase (Fig. C.55a) - previously identified as $\mathrm{UN}_{2}$ by $\mathrm{x}$-ray diffraction.

2. Spherical phase (Fig. C. $55 b$ ) - appears to be a higher oxide of uranium such as $\mathrm{U}_{3} \mathrm{O}_{8}$ or $\mathrm{U}_{4} \mathrm{O}_{9}$.

3. Gray phase (Fig. C.55c) - one of the uranium nitrides.

4. Green phase (Fig. C.55d) - one of the uranium nitrides.

Fuel from capsules 01-2, 03-2, and 07-2 contained significant amounts of $\mathrm{UN}_{2}$. This phase was attacked by the $\mathrm{UO}_{2}$ etchant and partially converted to a structure which was observed in the as-polished fuel in capsule 01-2.

No grain growth was noticed but the variable grain size present in the unirradiated fuel would obscure any slight changes in grain size during irradiation (Fig. C.56). Cracking was transgranular in nature. Voids seen in the fuel were pullouts of $\mathrm{UO}_{2}$ grains and second phases such as $\mathrm{UN}_{2}$ particles.

Sigma Phase (Fig. C.57). - It is unusual to find this phase in 304 stainless steel. Although the identification procedures used were those specified in an ASTM publication, ${ }^{26}$ it was felt that a check by $\mathrm{x}$-ray diffraction was necessary to confirm metallographic results. 
A portion of cladding from capsule 08-2 was selected adjacent to where the metallographic sample had been taken. Subsequently, the presence of sigma phase was verified in this sample by finding the characteristic lines for sigma in the $\mathrm{x}$-ray diffraction pattern. One strong line, probably associated with the unknown precipitate, was also observed.

Sigma was located throughout the cladding in grain boundaries preferentially at the intersection of grains. The particles were relatively massive as shown in Fig. C.57.

Porosity at Locations Corresponding to Pellet-to-Pellet Interfaces (Fig. C.58). - In most cladding samples, there were relatively large amounts of porosity present at pellet-to-pellet interface locations. The cladding opposite the center portion of the fuel pellets showed very little porosity. The porosity appears similar to that produced by strain in specimens during tensile testing (strain-induced porosity).

Large Grains at Cladding Wrinkle. - In Fig. C.58 several large grains can be seen at the cladding outer surface in the "stepped" region of the wrinkle. It appears that strain cycling is producing these large grains.

Section Through Cladding Wrinkle (Fig. C.58). - This sample was re-sectioned in an effort to find the void shape in the radial direction. Continued grinding failed to reveal the region at the large outer surface grains so the void shape in the radial direction remains unknown. However, more large grains were observed at the "stepped" region of the wrinkle.

Unidentified Precipitate (Fig. C.59). - This is not an etching artifact. In some samples the precipitate shows in the as-polished condition. The concentration is highest at the inner and lowest at the outer surface. Possibly some constituent from the fuel is entering the cladding.

$\mathrm{UO}_{2}$ Embedded in Cladding Inner Surface (Fig. C.60). - In a number of local regions, $\mathrm{UO}_{2}$ was found embedded in the cladding inner surface. Fission fragment damage was not observed positively, so the time during irradiation when the cladding collapsed on the fuel could not be determined.

Slight Reaction Between $\mathrm{UO}_{2}$ and Stainless Cladding (Fig. C.61). - In capsules 01-2 and O2-2 a local reaction between the $\mathrm{UO}_{2}$ and the cladding was observed. The extent of the reaction was usually less than one grain in depth (about $0.001 \mathrm{in.}$ ).

"Hot" Spot in Cladding - Top of Capsule O2-2. - A metallographic section through the dark spot in capsule $02-2$ showed that there was a slight reaction between $\mathrm{UU}_{2}$ and cladding. A relatively large piece of $\mathrm{UO}_{2}$ had been mechanically embedded in the cladding (Fig. C.48). No decarburization was observed in this sample.

Decarburization of the Stainless Cladding (Fig. C.62). - Decarburization was usually limited to a small region at the cladding outer surface, about one to three grains ( $\sim 0.003$ in.). However, in capsule 04-2, decarburization was present for about one-third of the cladding thickness. In capsule 01-2 a feathery structure, present within grains near the $\mathrm{NaK}$-stainless steel interface, has the appearance of ferrite.

Weld. - The top end cap weld of capsule 02-2 was examined (Fig. C.63). There is essentially no heat-affected region between the melt zone and the parent metal. Small inclusions can be seen in the melt zone. A few carbide stringers were observed in the end cap.

26 "Symposium on the Nature, Occurrence and Effects of Sigma Phase," ASTM Symposium (1950). 
General Structure (Fig. C.64). - A representative cladding microstructure is shown in this figure.

$\mathrm{MgO}$ and BeO. - BeO (Fig. C.65). - An autoradiograph showed that the light-colored region at the rod periphery contained most of the fission products. Very little could be learned from a metallographic study of the $\mathrm{BeO}$ except that there was a second phase present within $\mathrm{BeO}$ grains.

$M g O$ (Fig. C.66). - The two dark-colored regions correspond to regions in the autoradiograph which show no appreciable fission product accumulation. Because this is a top MgO spacer, it had a hole through the center which would therefore have an accumulation of fission products. No microstructure could be developed by etching this sample. An increase in thickness is evident at the spacer center. Some plateout of material from the $\mathrm{UO}_{2}$ fuel has occurred.

\section{Autoradiographs}

Autoradiographs were made with the $\mathrm{BeO}$ (capsule 04-2) and the $\mathrm{MgO}$ (capsule O2-2) metallographic samples. Various kinds of films, exposure times, and absorbers between sample and film were tried. No prints were suitable for reproduction. However, in each case it was observed that essentially all of the activity resided in a surface layer of the ceramic. 
PHOTO 67880
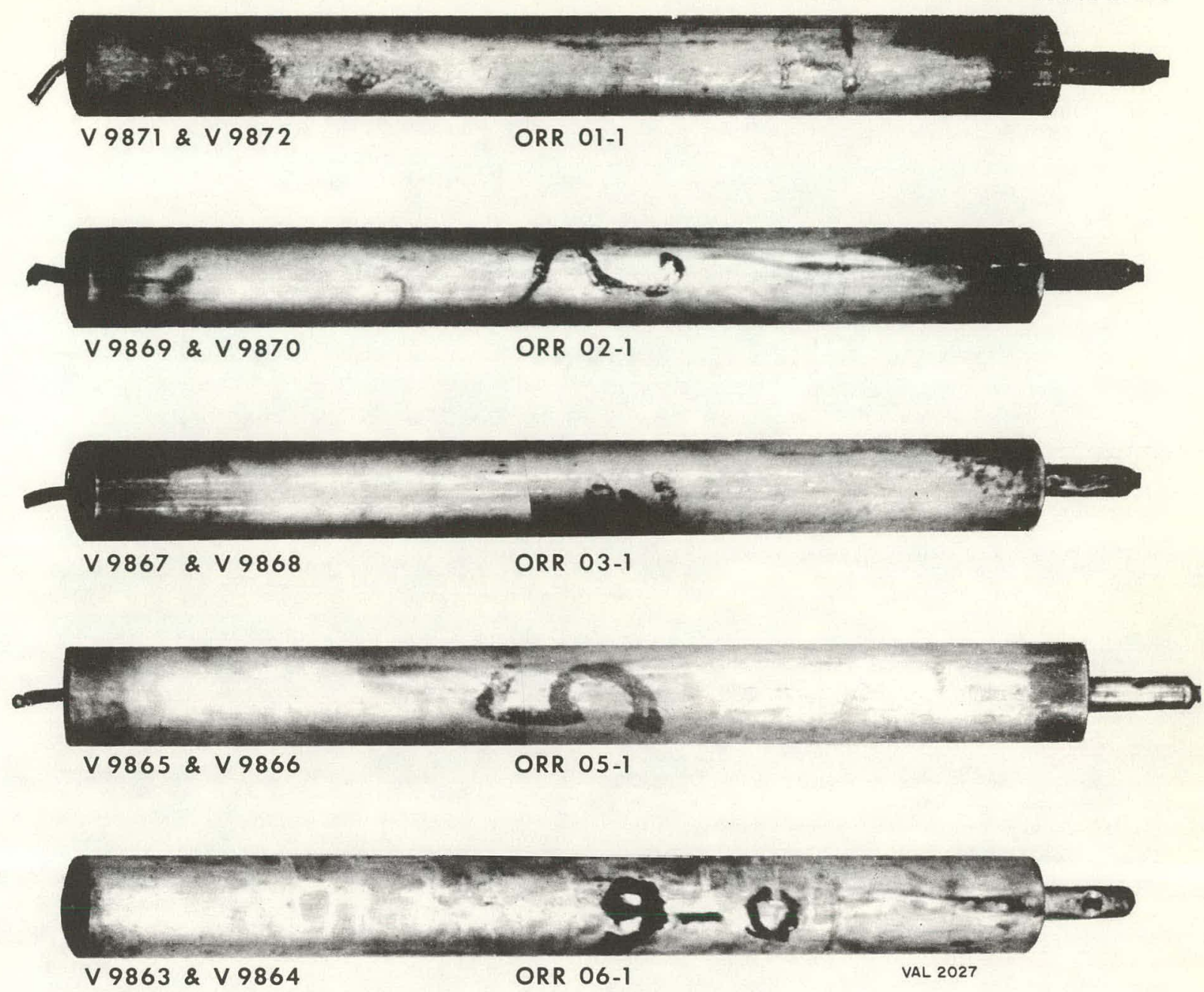

Fig. C.1. ORR Group 1 Capsules at GEVAL After Removal from the Shipping Tubes.

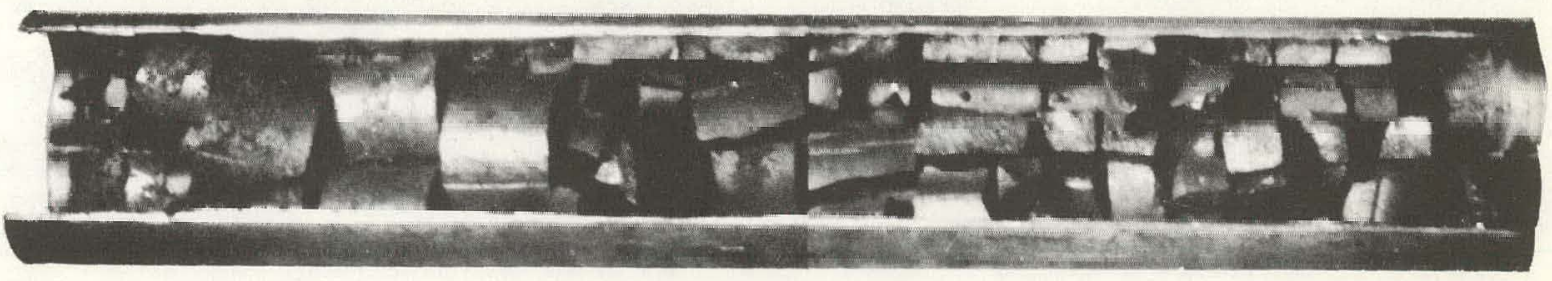

$V 13102 \& V 13103$

Fig. C.2. ORR 01-1 As Opened. 


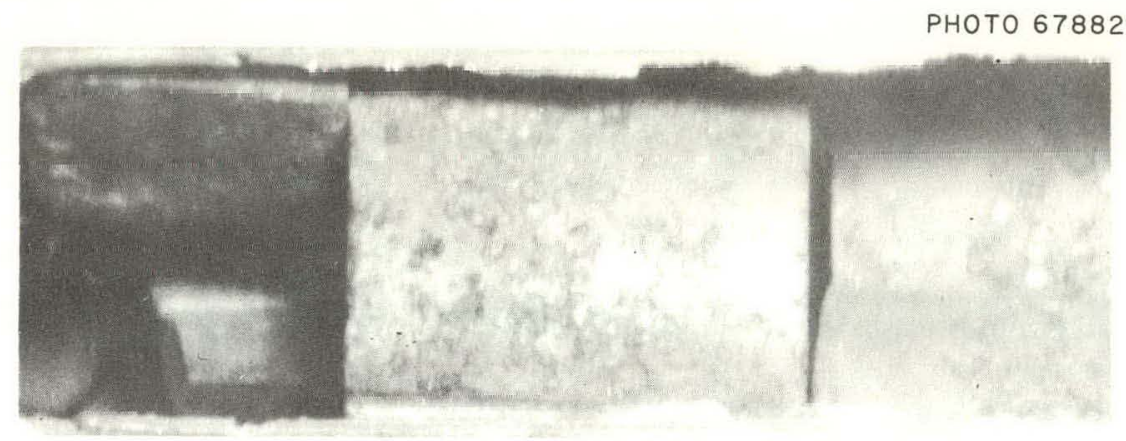

V 13100

VAL 2031

Fig. C.3. Rust-Colored Deposit Observed on Top Three Fuel Pellets of ORR 01-1.

PHOTO 67883
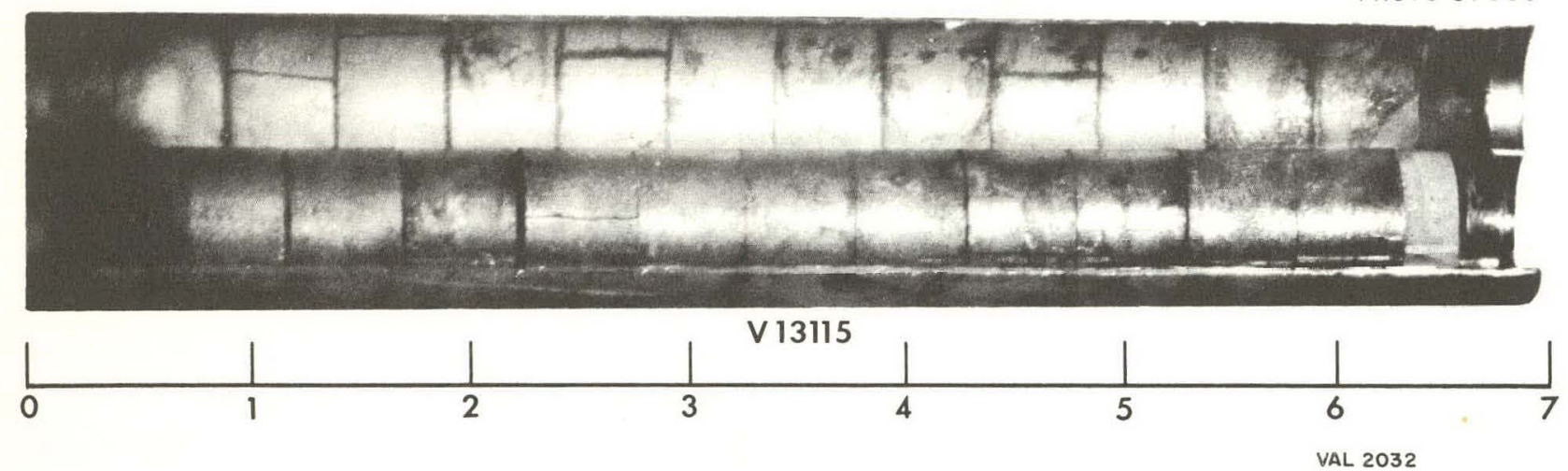

Dark lines in the cladding outline cracks in the fuel pellets.

Fig. C.4. ORR 02-1 As Opened.

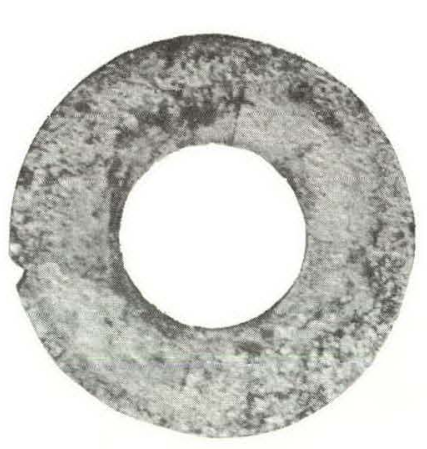

V 13132

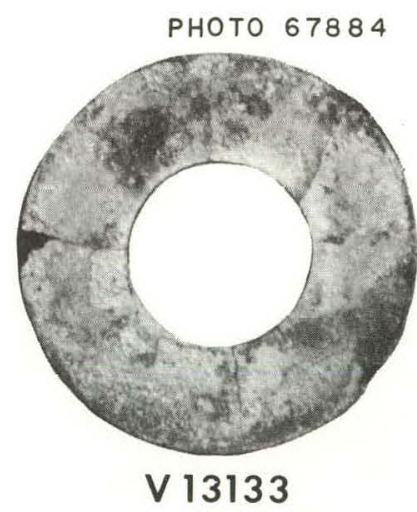

Two views of an intact fuel pellet showing the type of cracks which were present.

Fig. C.5. ORR 02-1, Fuel Pellet No. 12. 


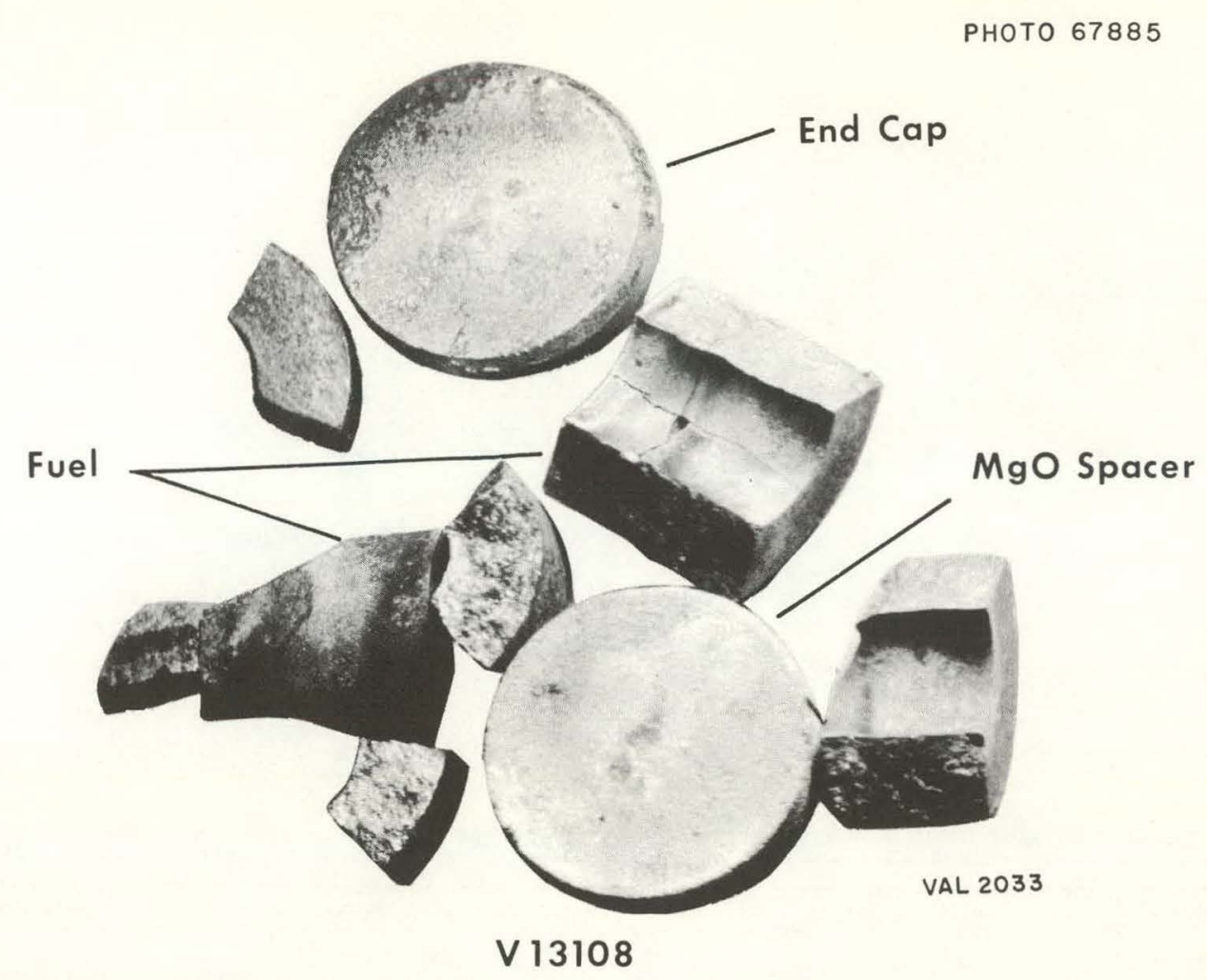

Fig. C.6. ORR 02-1, Bottom End Plug, Spacer, and Fuel Pellet No. 1.

PHOTO 67886

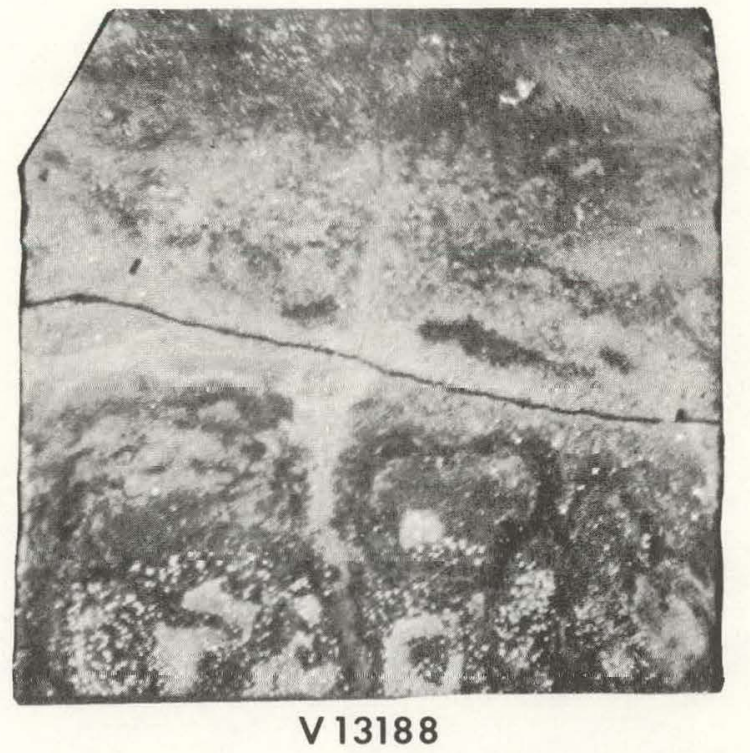

VAL 2034

Pale green deposit on O.D. surface. Traces of a very light rust colored deposit and deep blue marks were also present.

Fig. C.7. ORR 03-1, Fuel Pellet No. 4. 
PHOTO 67887

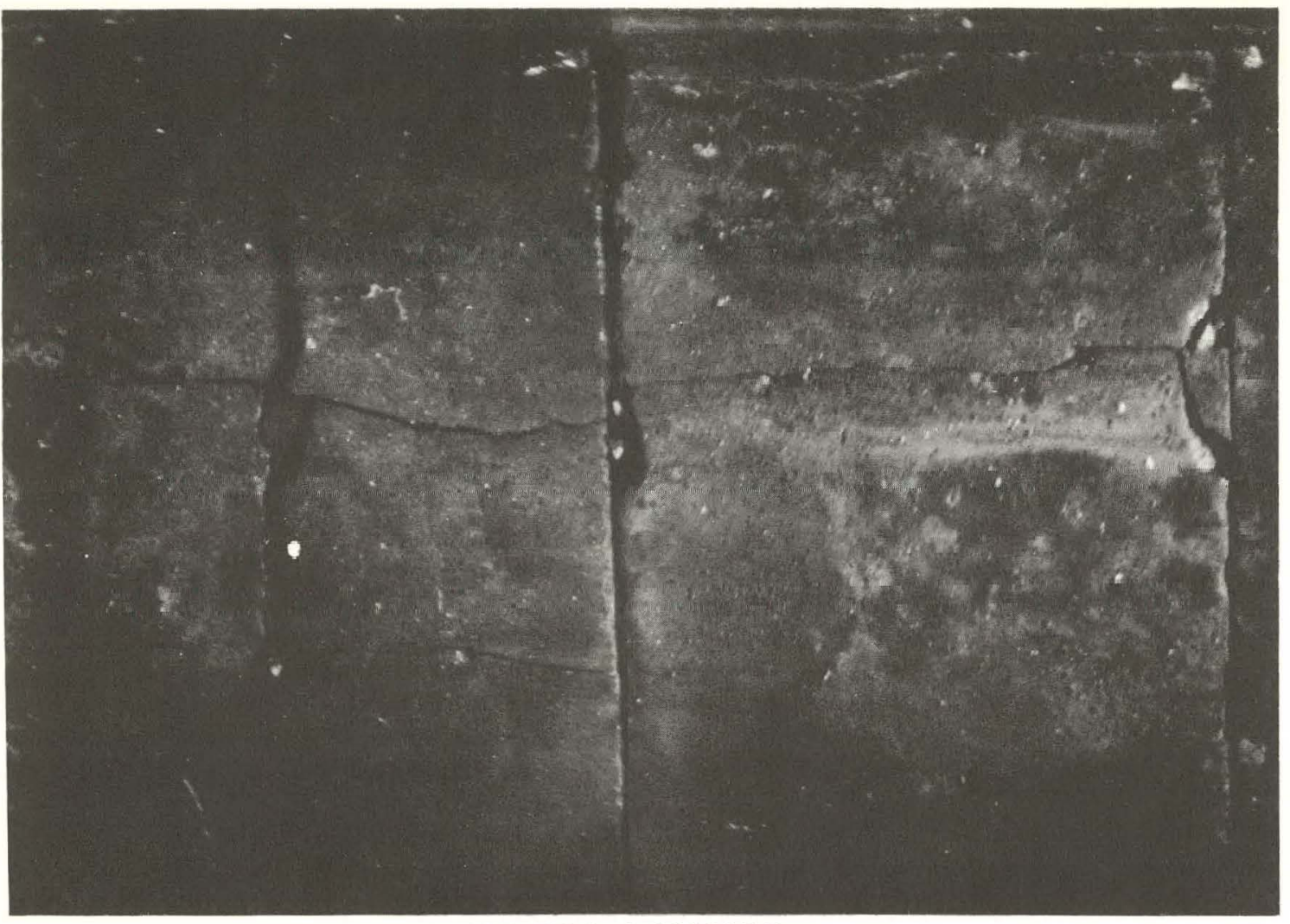

$V 13186 \& V 13185$

Typical cracking patterns in the fuel pellets from this capsule

Fig. C.8. ORR 03-1, Fuel Pellets No. 1 and No. 2.

PHOTO 67888

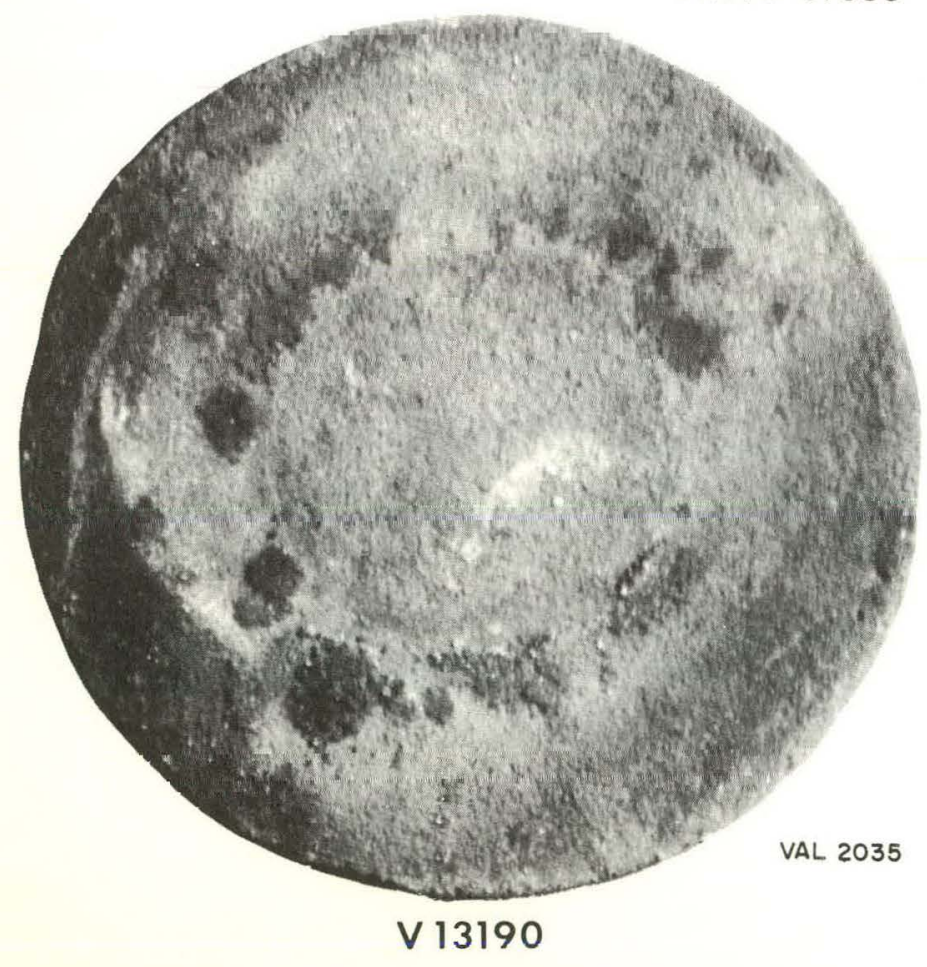

Fig. C.9. ORR 03.1, Bottom MgO Spacor. 
РНОTO 67889

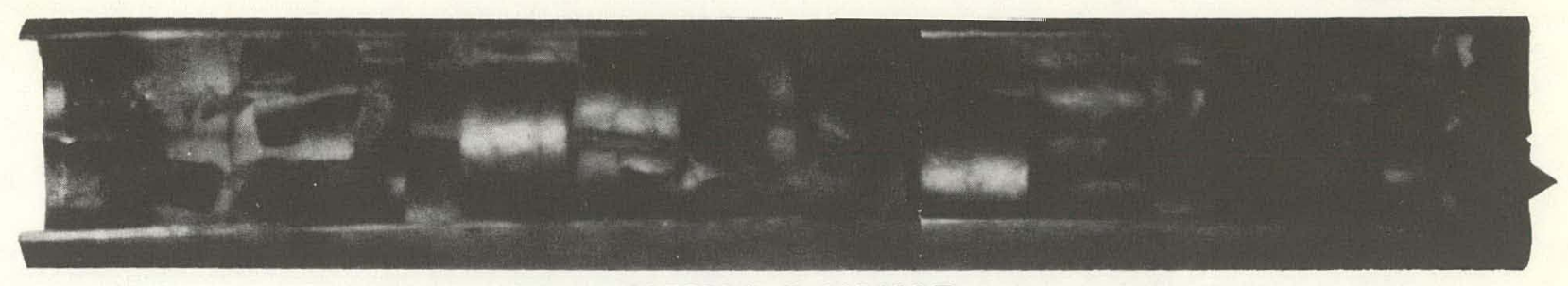

\section{$V 13136 \& V 13137$}

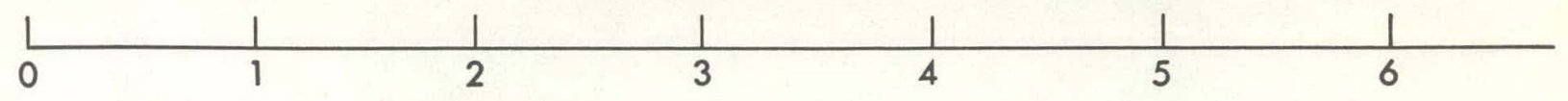

Fig. C.10. ORR 05-1, As Opened.

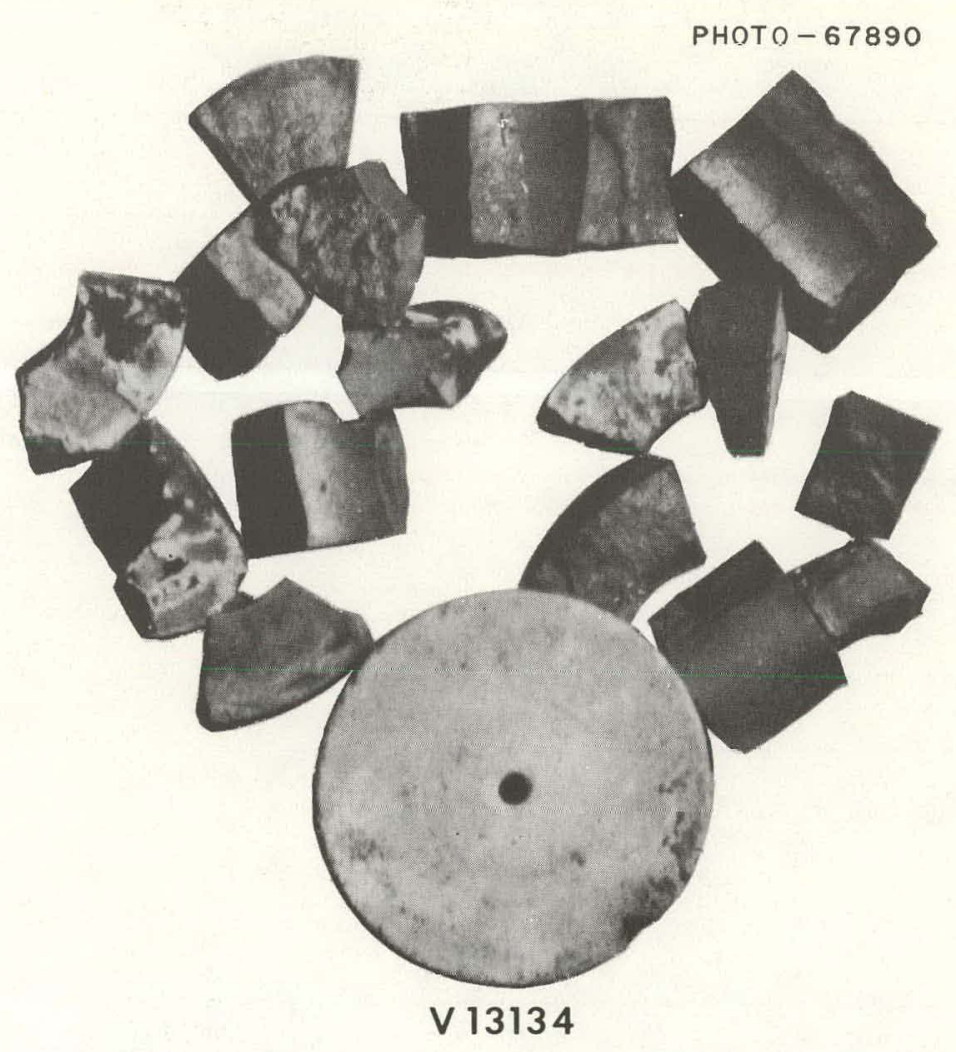

Fig. C.11. ORR 05-1, Top MgO Spacer and Fragments of Fuel Pellet Nu. 12. 


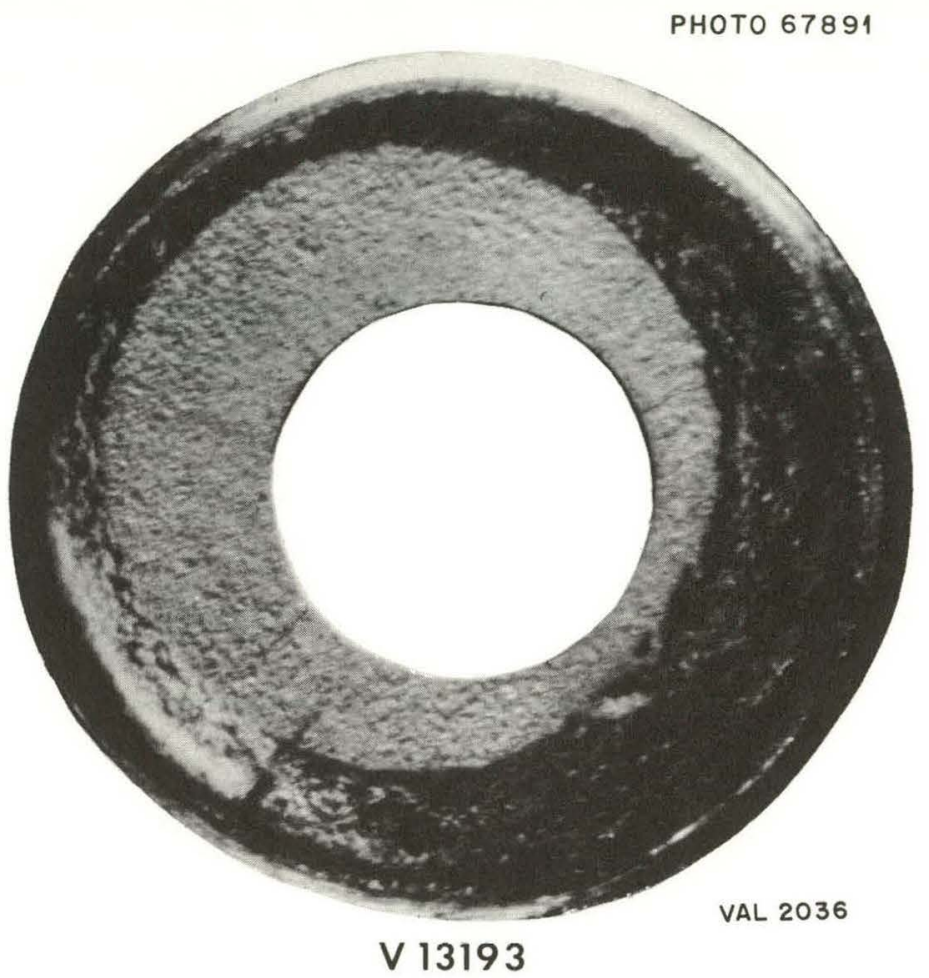

Fig. C.12. ORR 06-1, Dark-Colored Deposit on Fuel Pellet No. 6.

PHOTO 67892

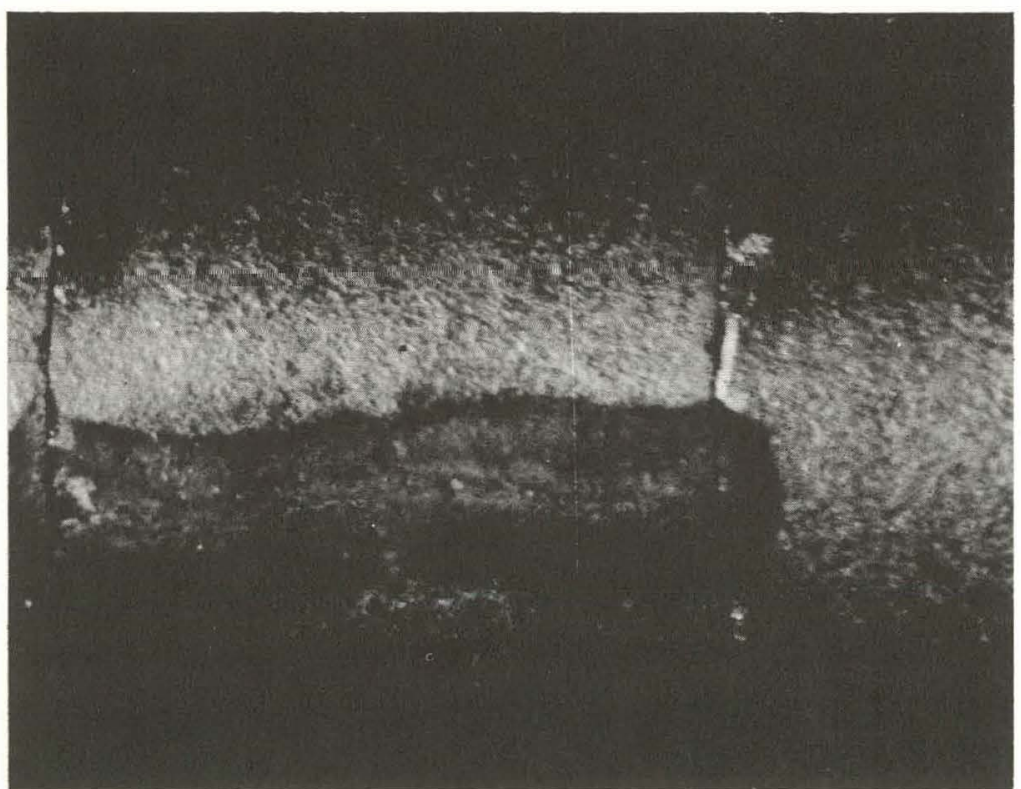

V 13193

Fig. C.13. ORR 06-1, Dark-Colored Deposit at a Radial Crack in Fuel Pellet No. 5. 


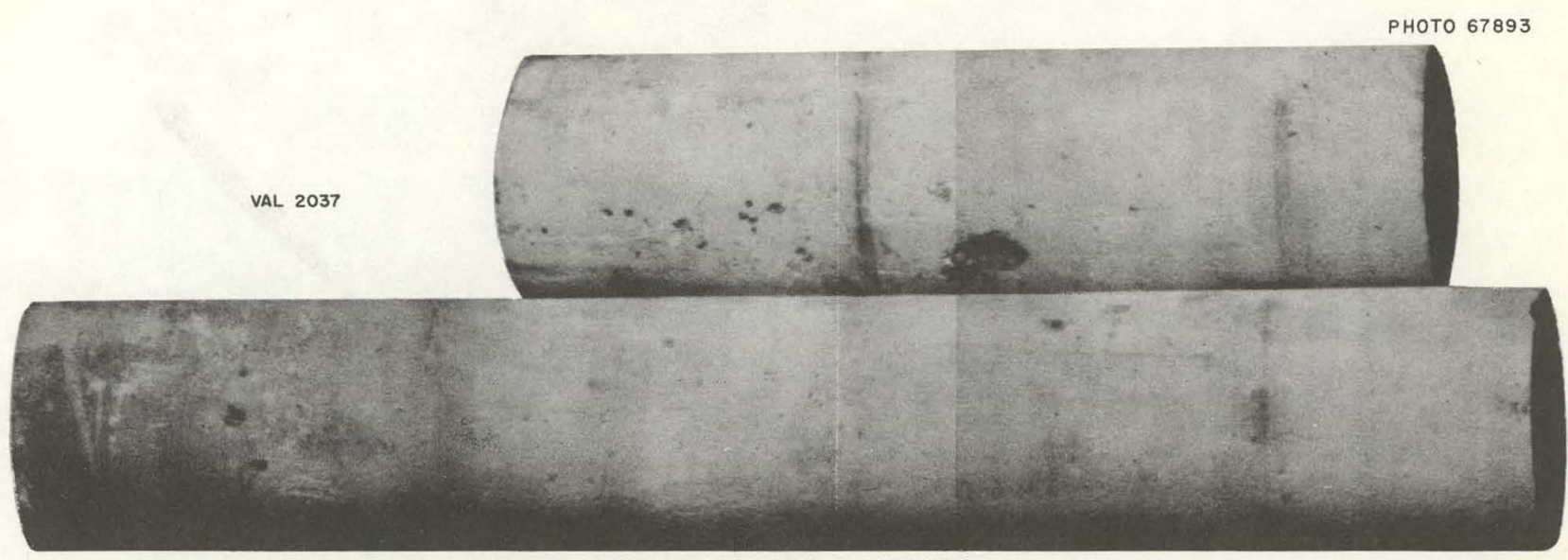

V 13206, V $13208 \&$ V 13209

Fig. C.14. ORR 06-1, Bottom Half of the BeO Inserts.

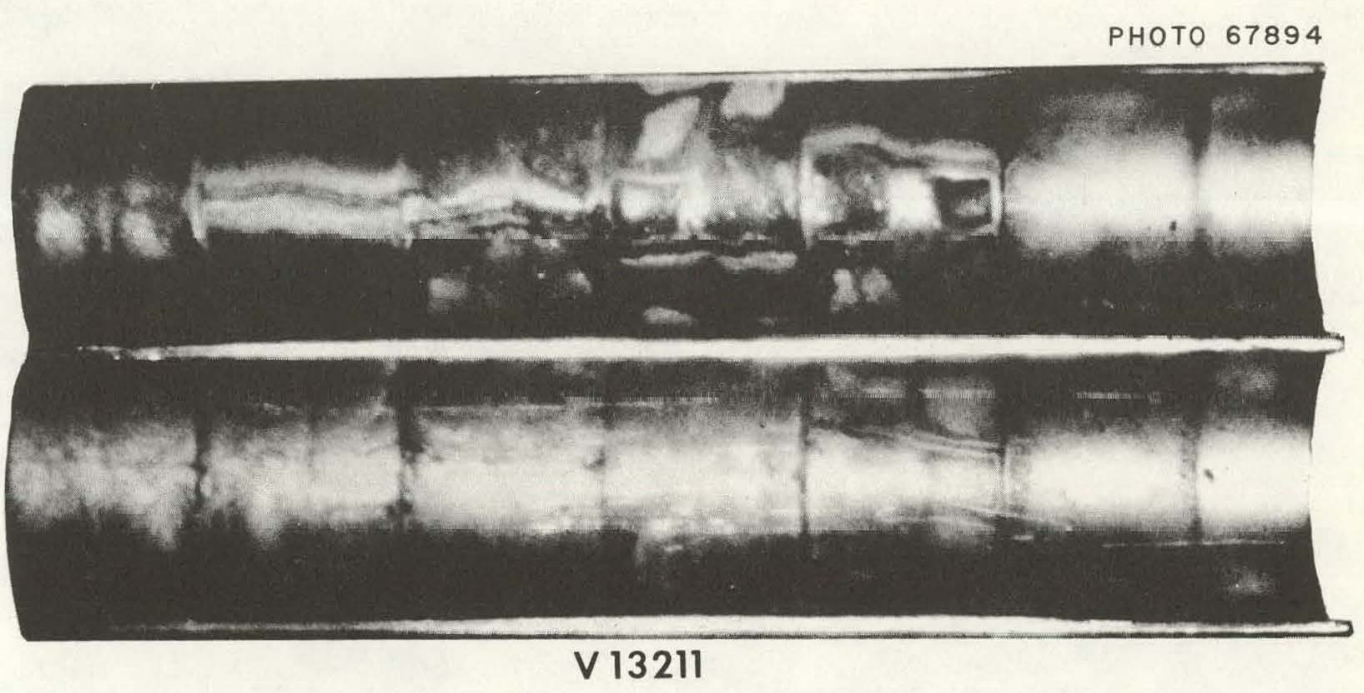

Fig. C.15. ORR 06-1, Discoloration of the Inside Surface of the Cladding. 


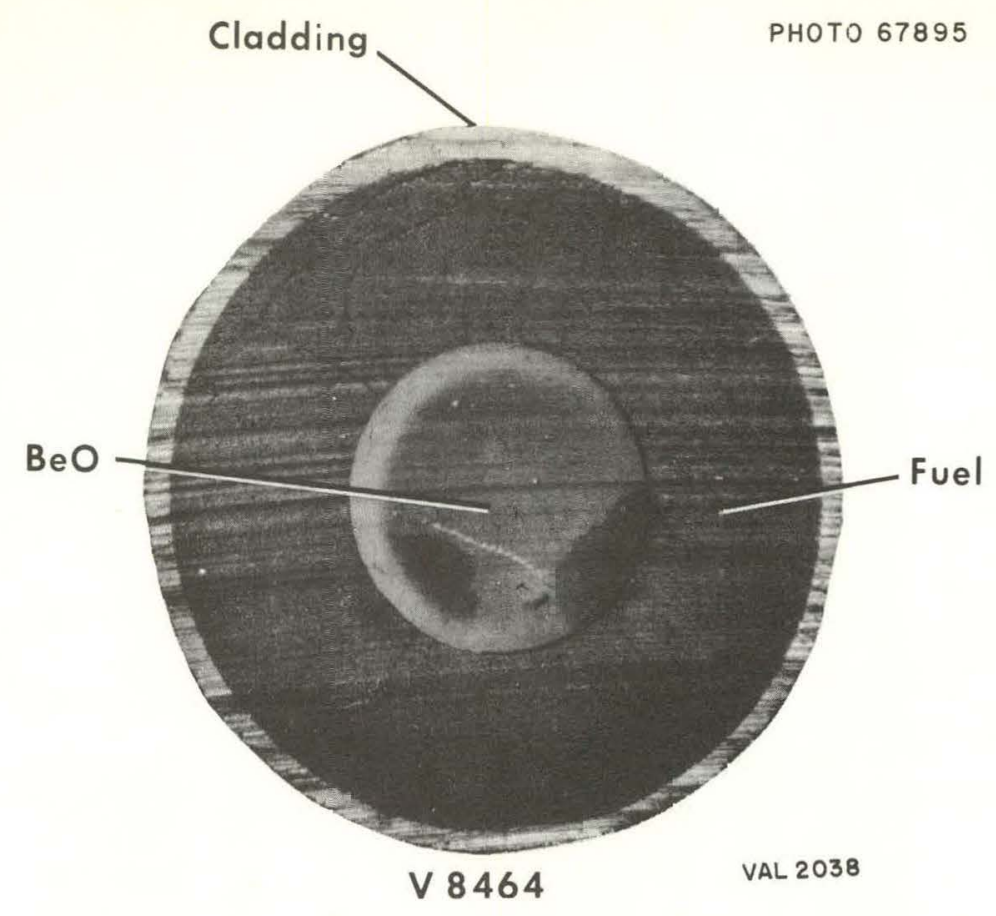

Fig. C.16. ORR 06-1, Transverse Section Through Fuel Pellet No. 7.

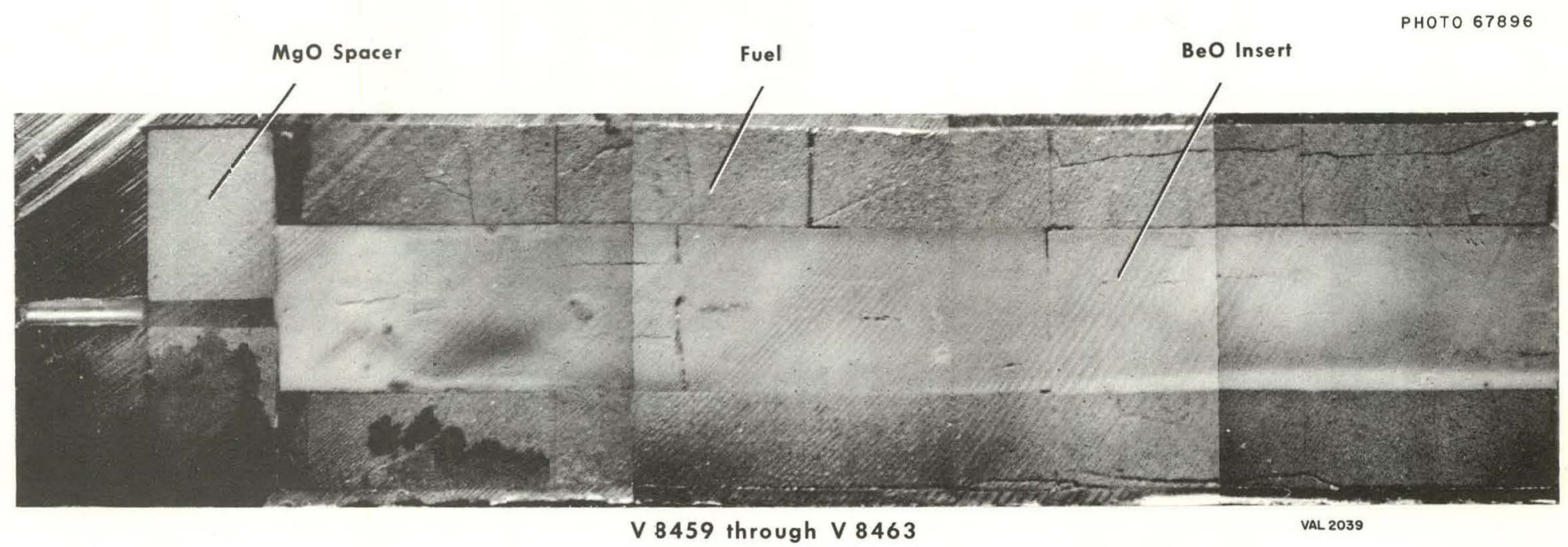

Fig. C.17. ORR 05-1, Longitudinal Section Through the Top Half of the Capsule. 


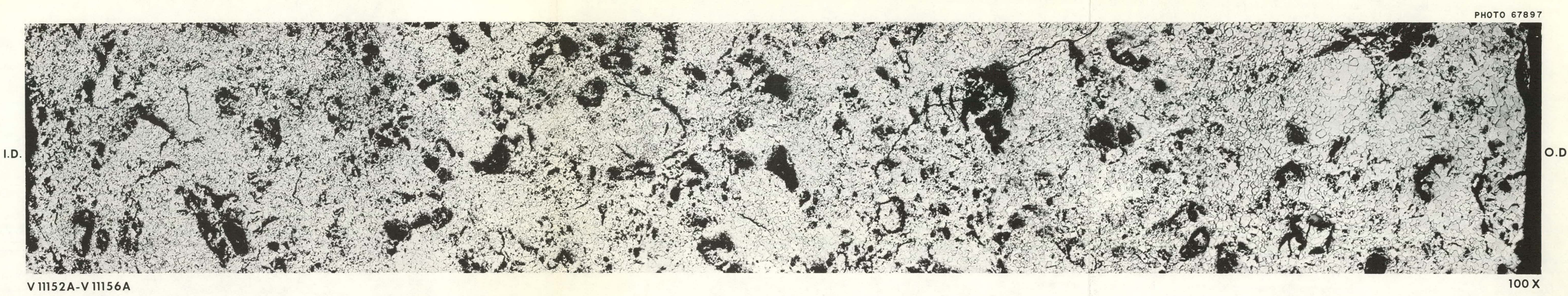
V III52A-V III56A
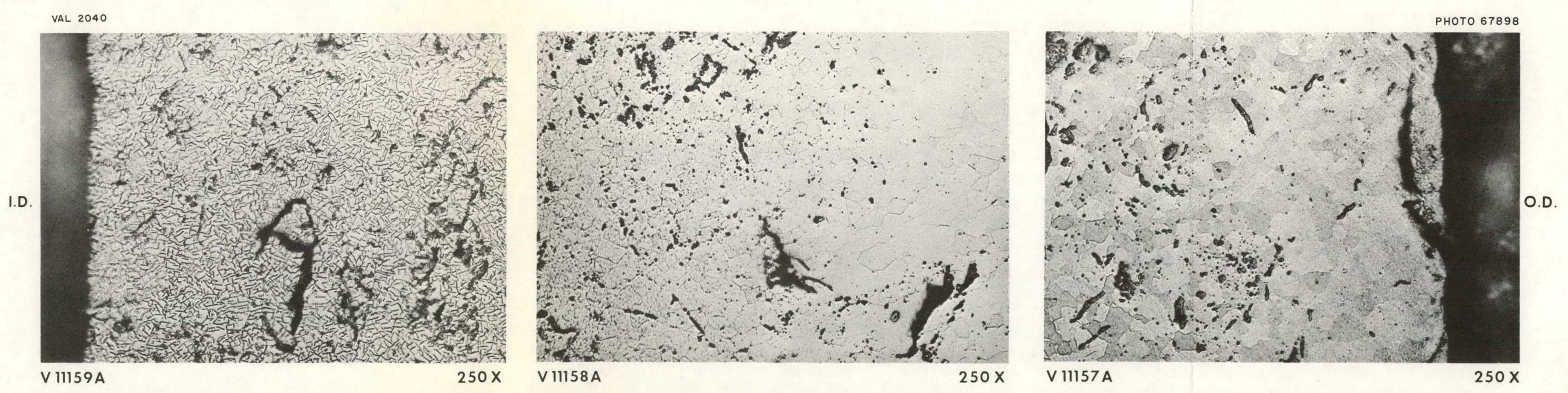

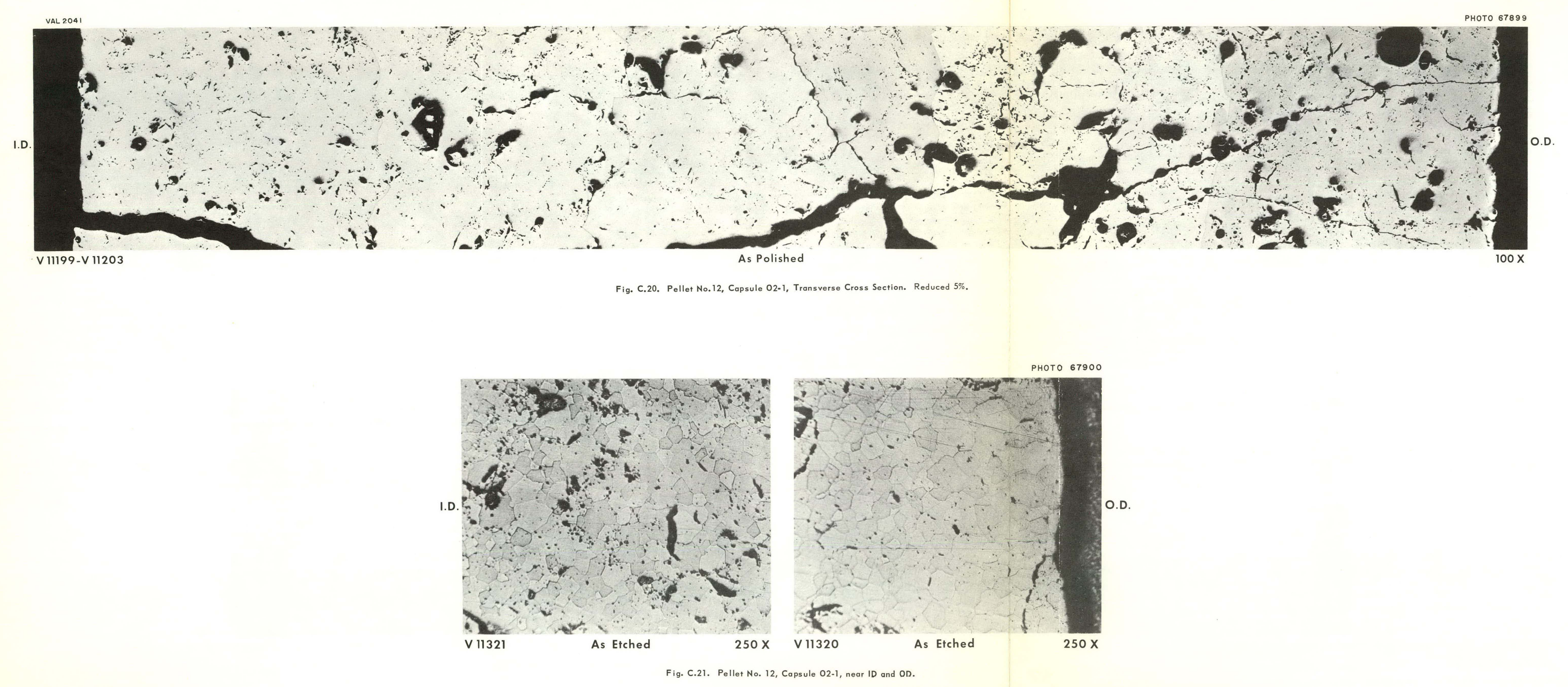

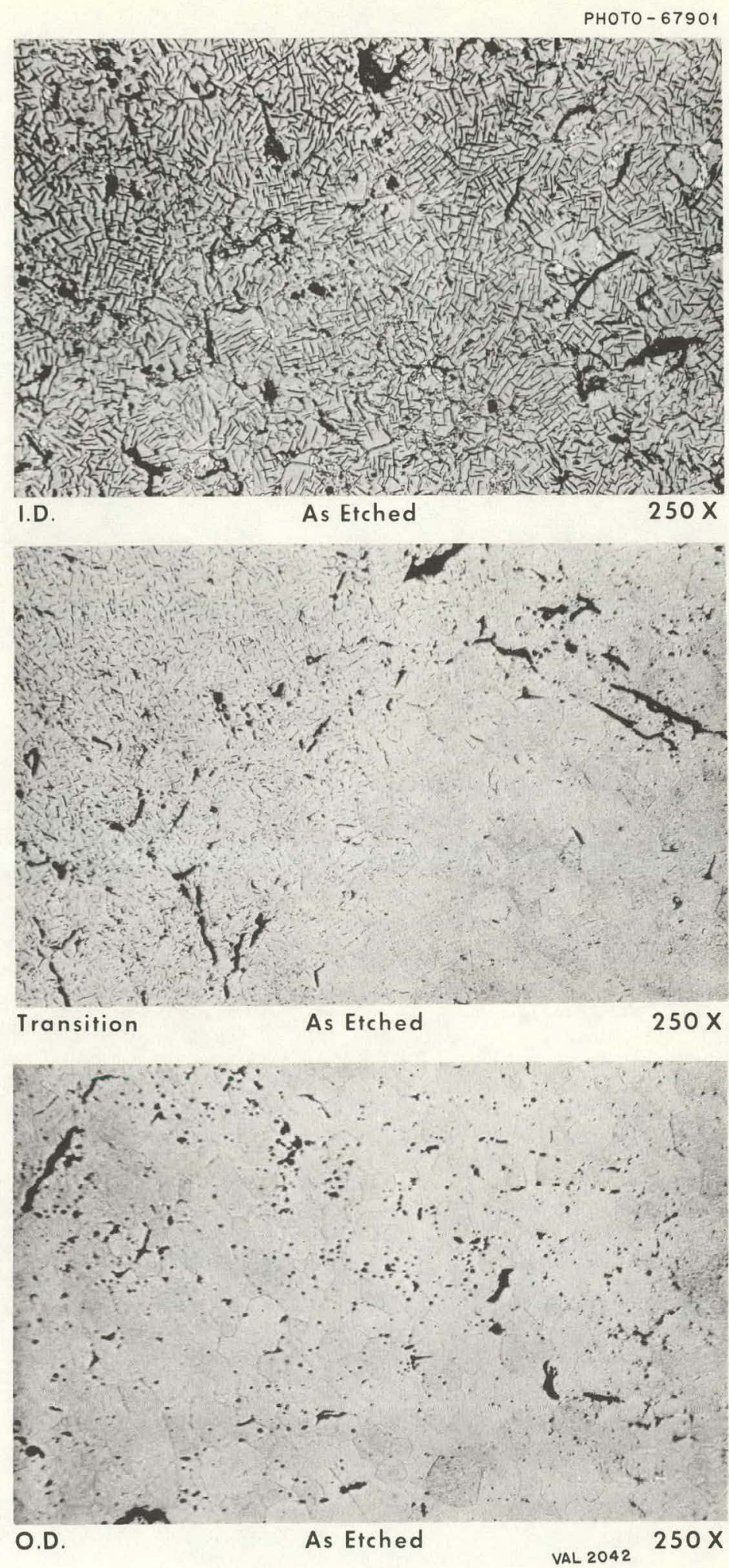

Fig. C.22. Pellet No. 6, Capsule 02-1. Reduced $18.5 \%$. 

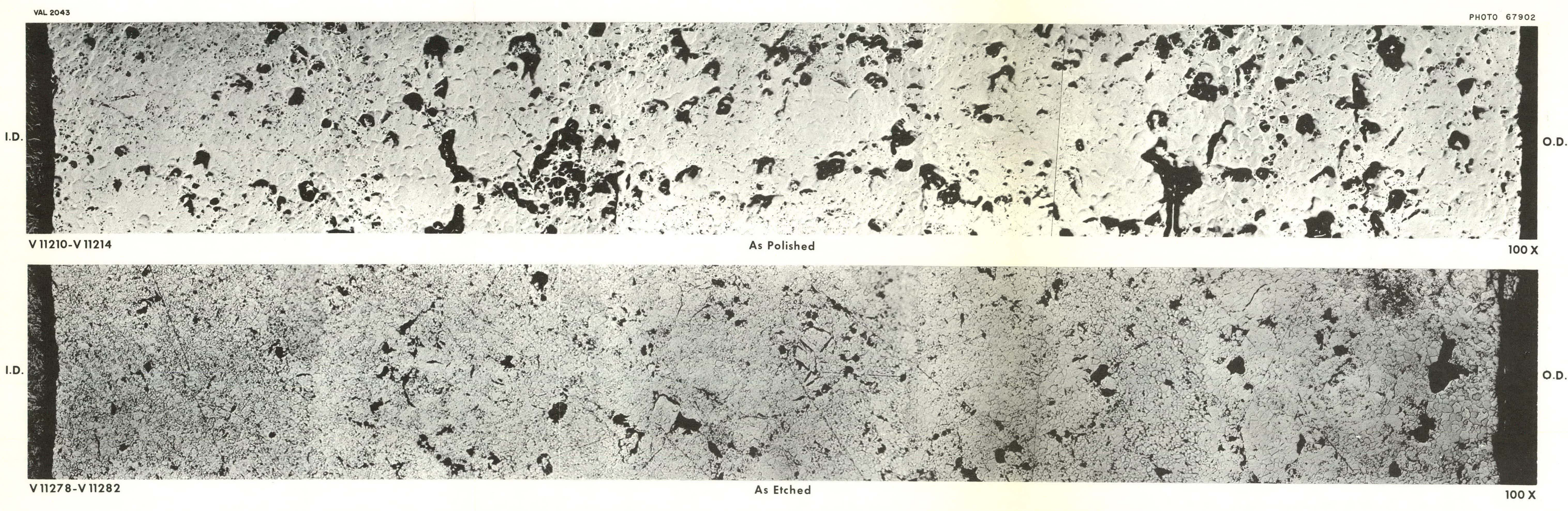
РнОто 67903
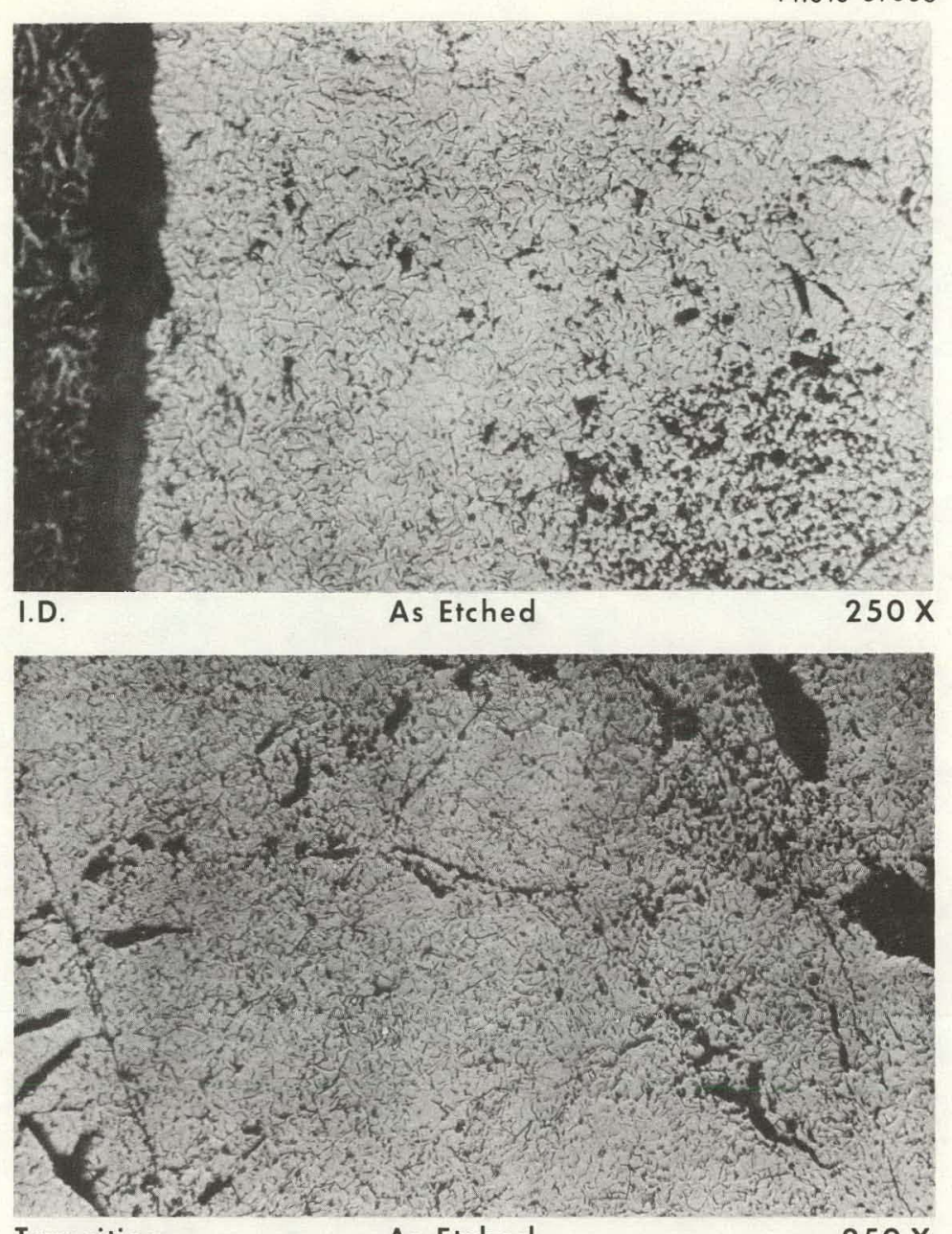

Transition

As Etched

$250 x$

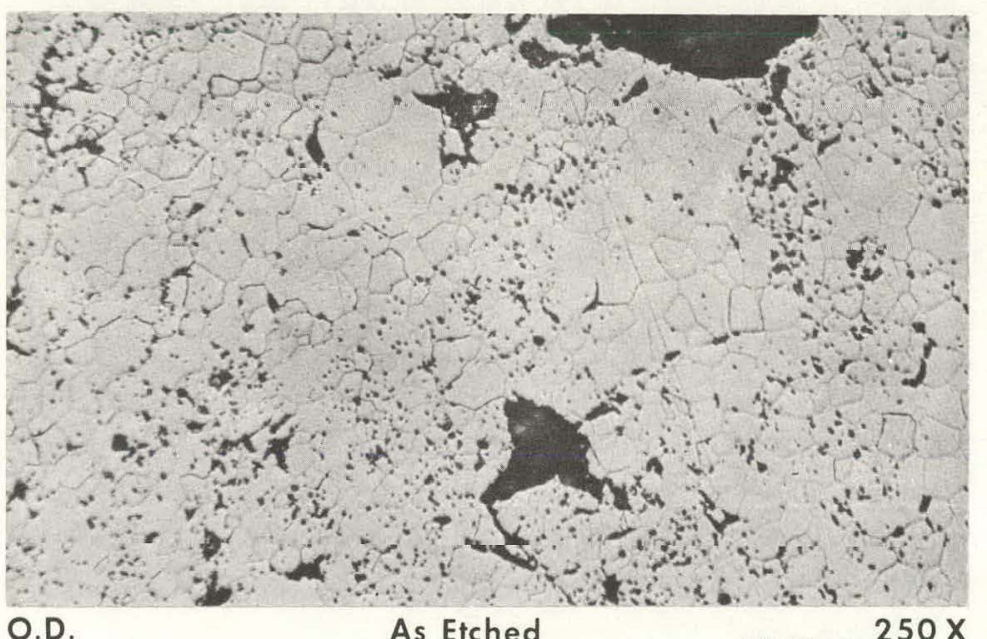

Fig. C.24. Pellet No. 6, Capsule 03-1. Reduced $16.5 \%$.
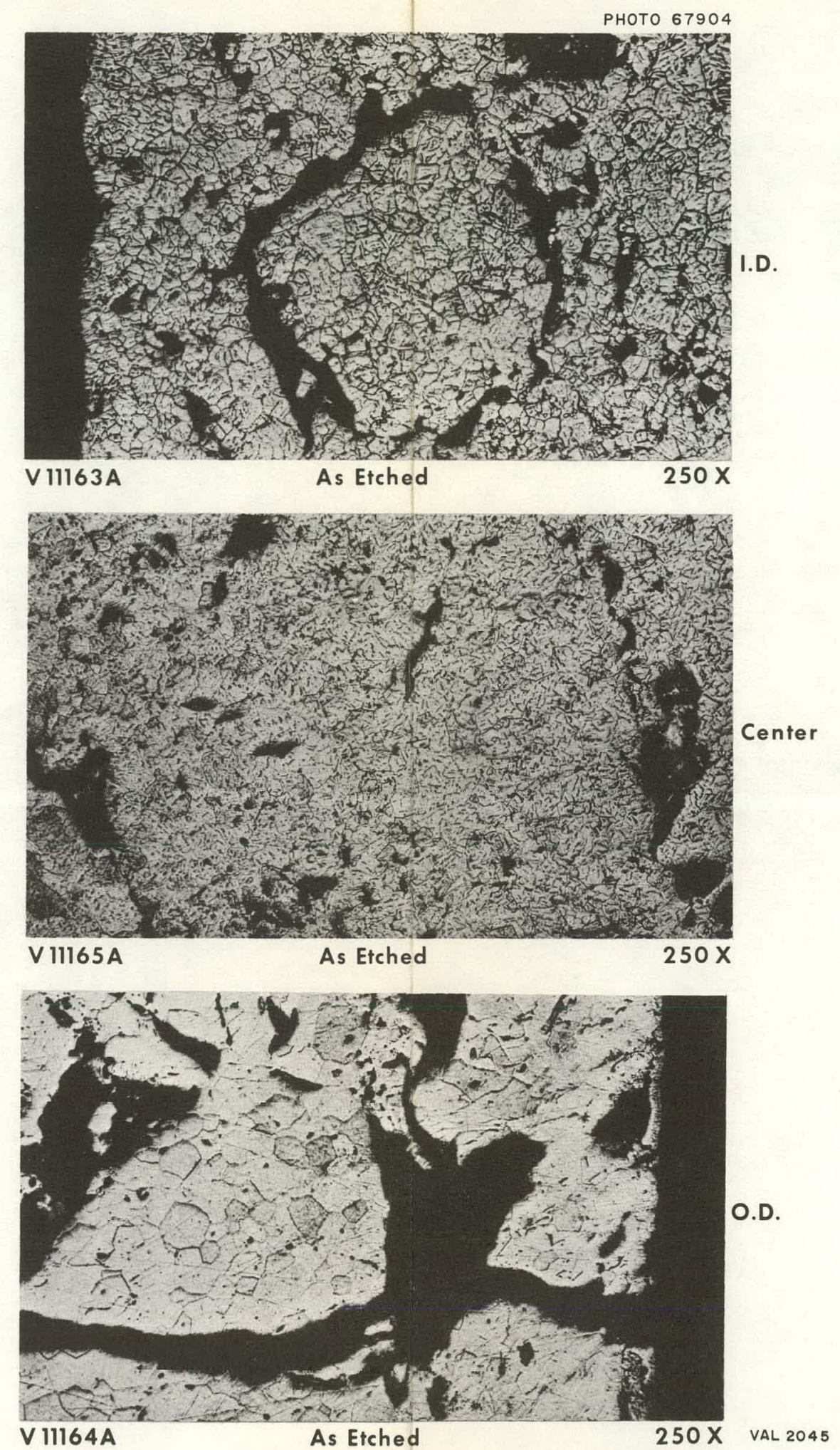

Fig. C.25. Pellet No. 12, Capsule 05-1. Reduced $16.5 \%$. 


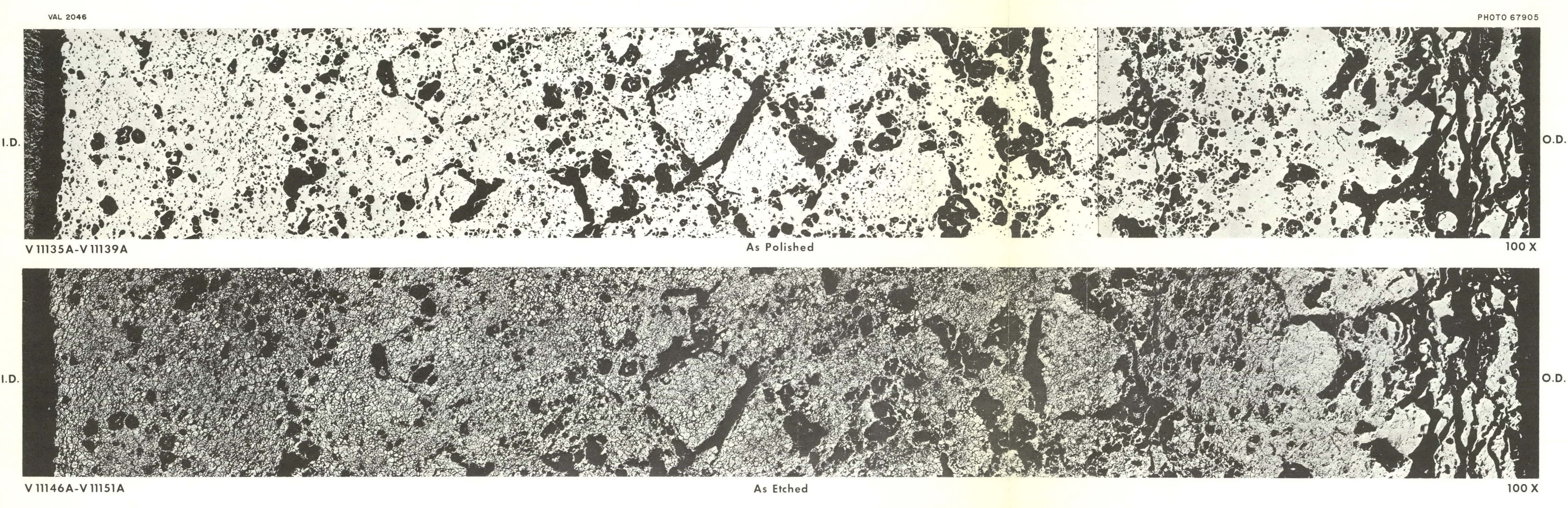


PHOTO -67906

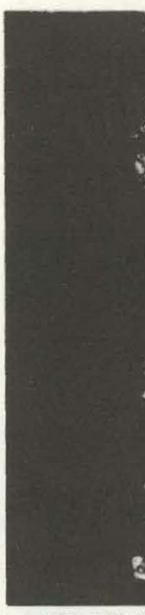

8.

Fes

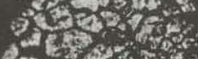

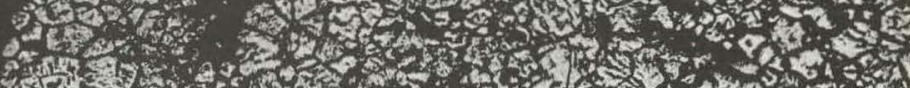

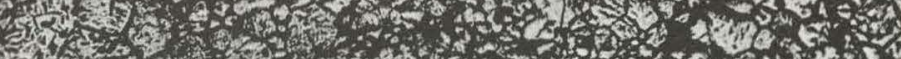

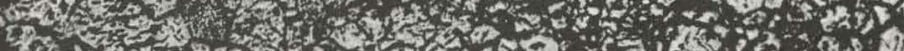

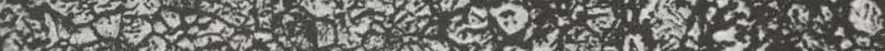

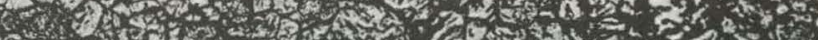

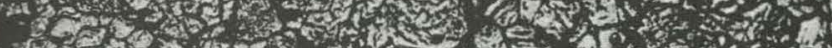

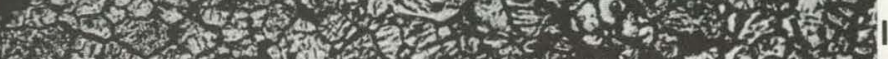

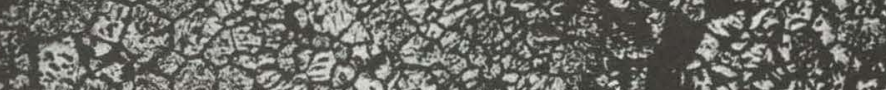

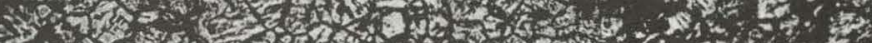

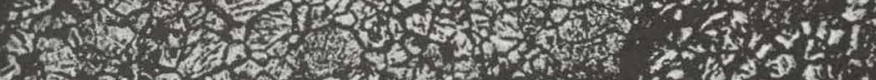

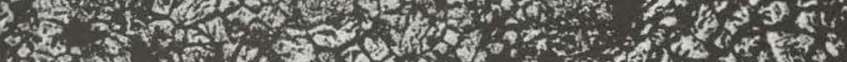

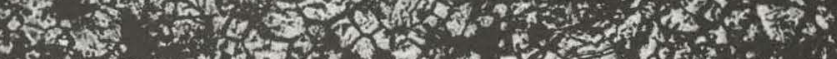
4 is

V $11162 \mathrm{~A}$

As Etched

$250 x$

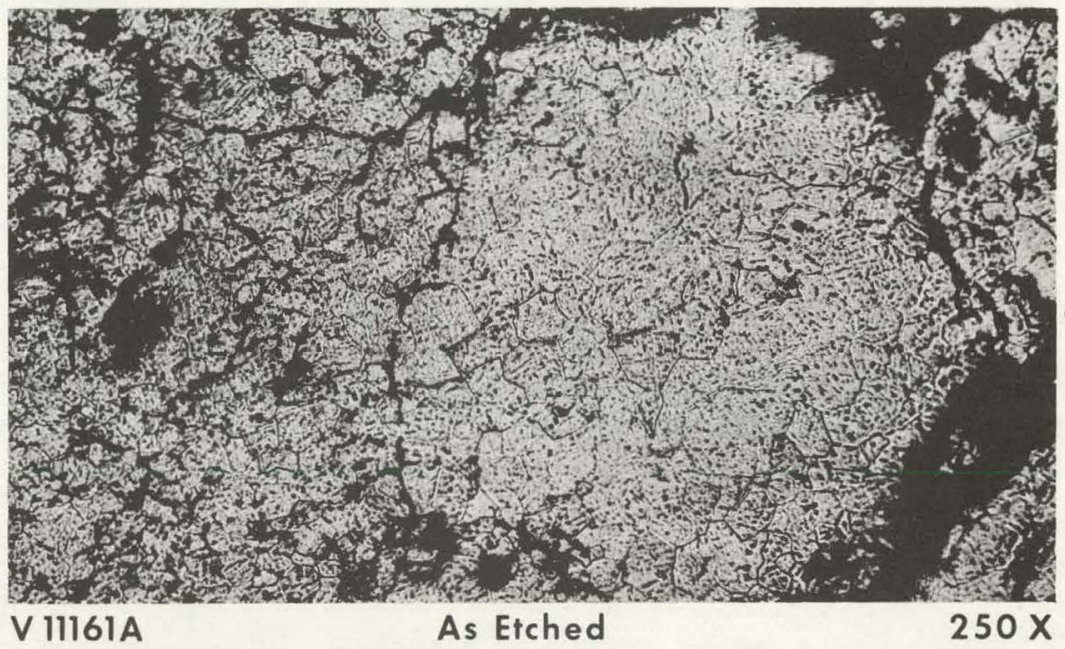

Center

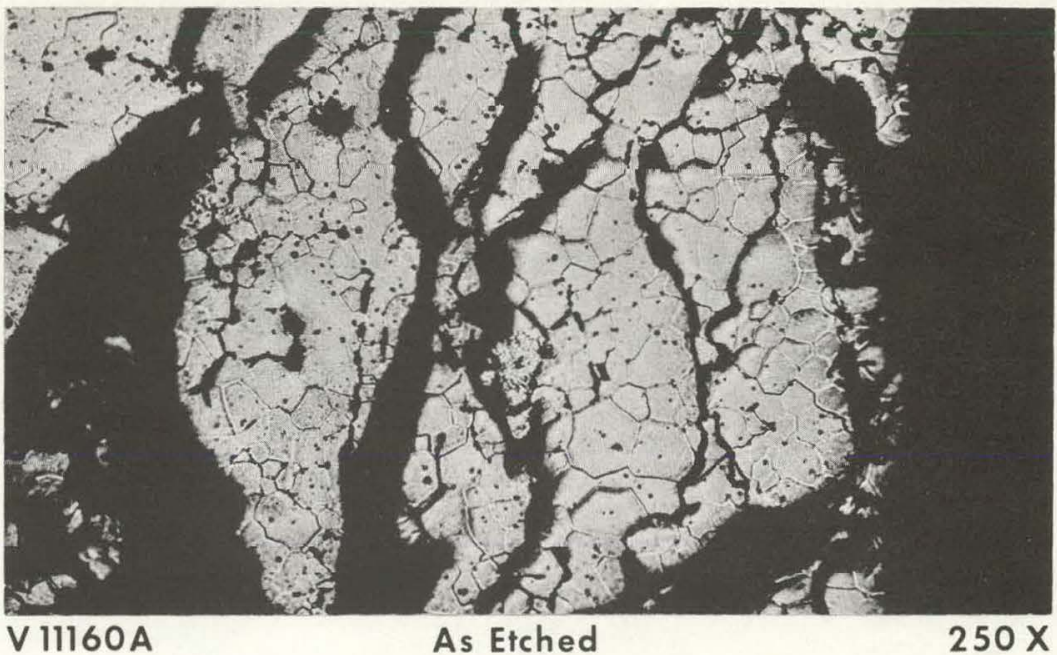

O.D.

Fig. C.27. Pellet No. 8, Capsule 05-1. Reduced 10\%. 

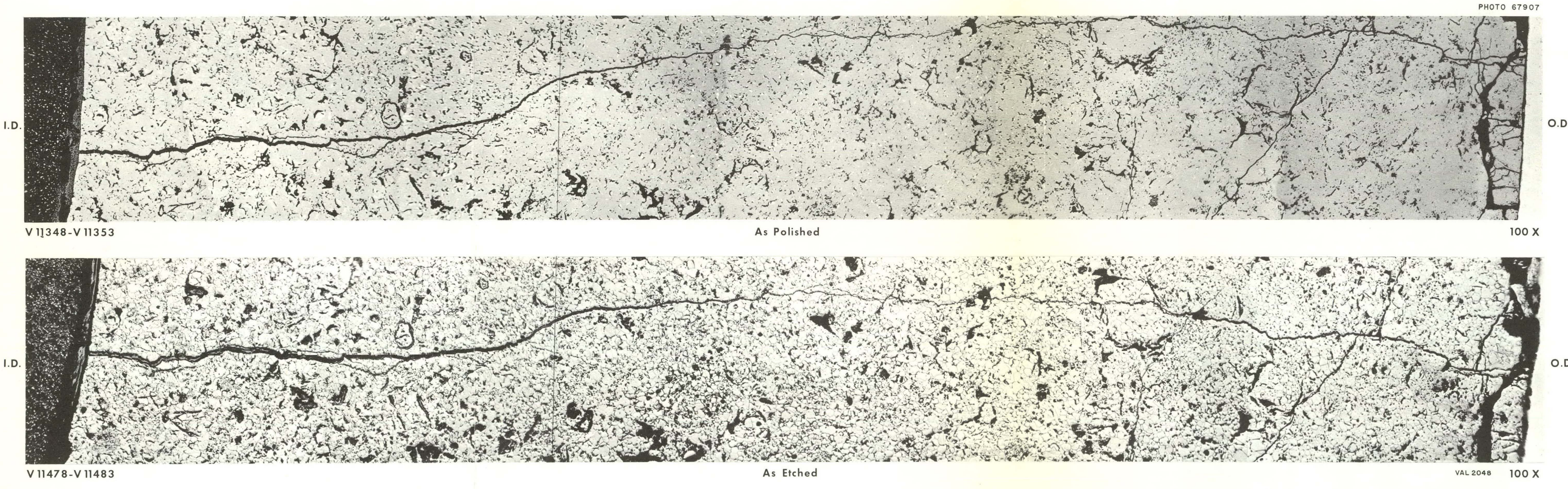

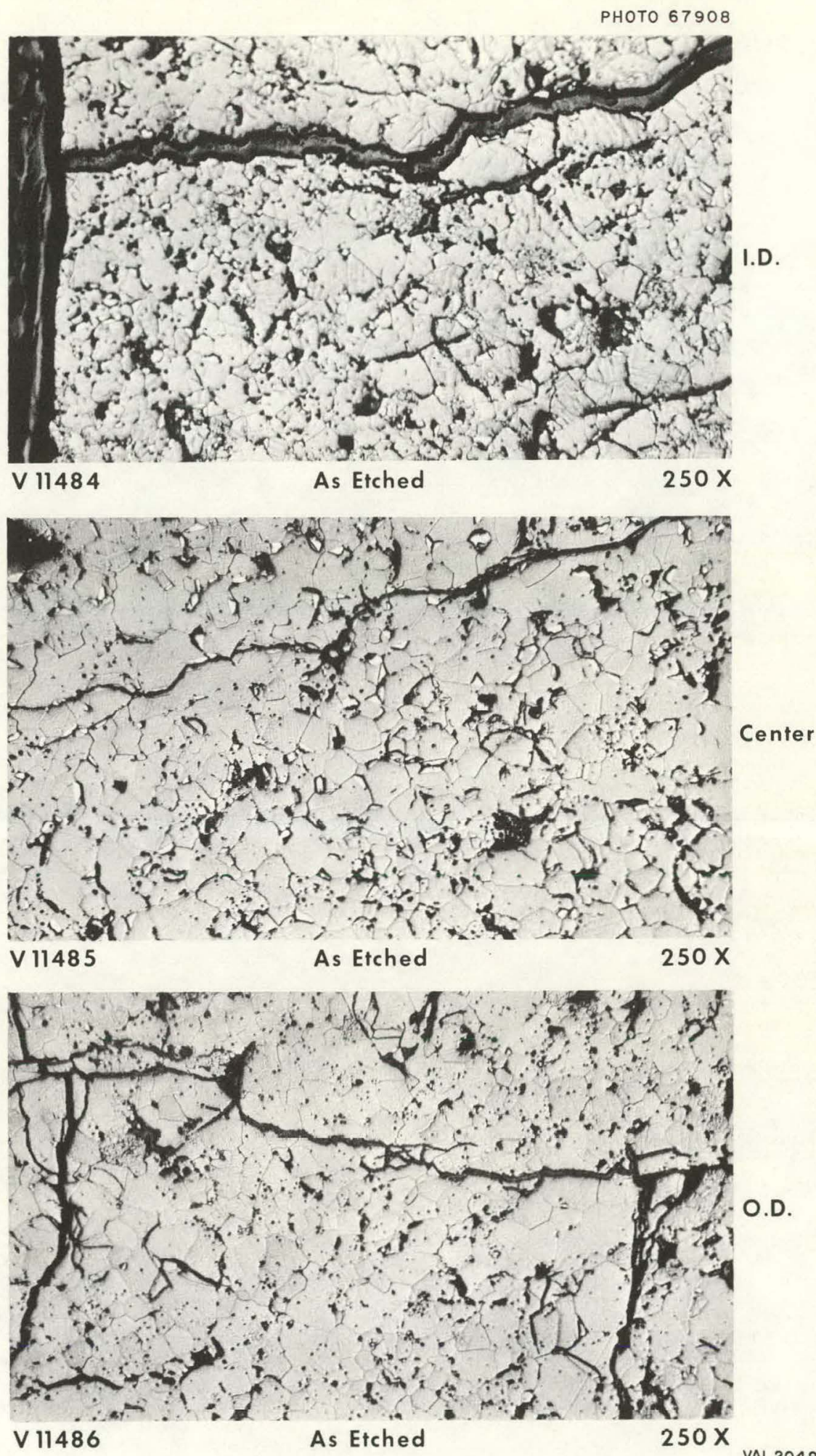

Fig. C.29. Pellet No. 7, Capsule 06-1. Reduced 16\%. 
PHOTO 67909
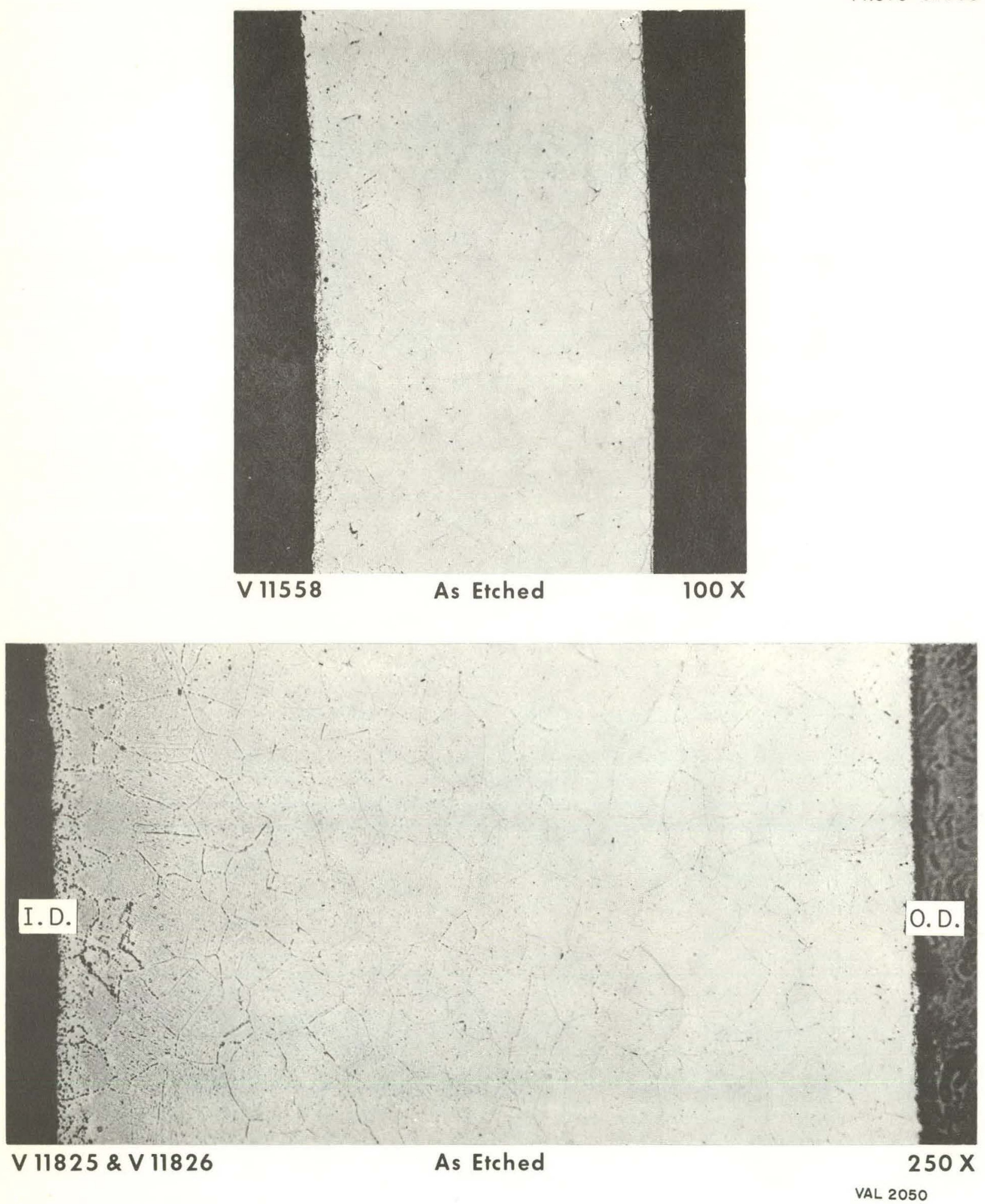

Fig. C.30. Stainless Cladding from Capsule 01-1. Reduced $2 \%$. 


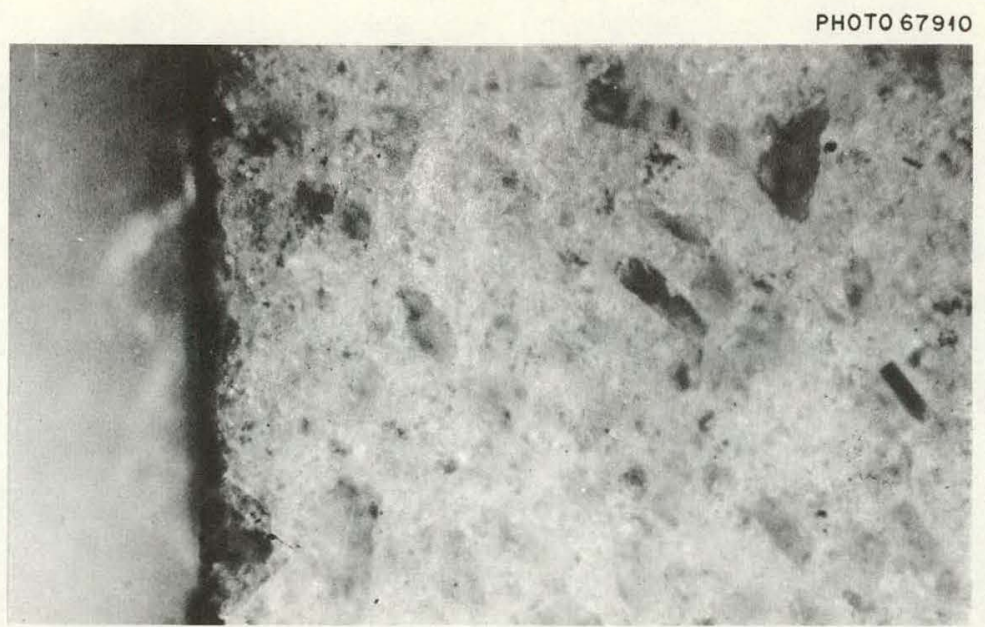

As Polished

$100 x$
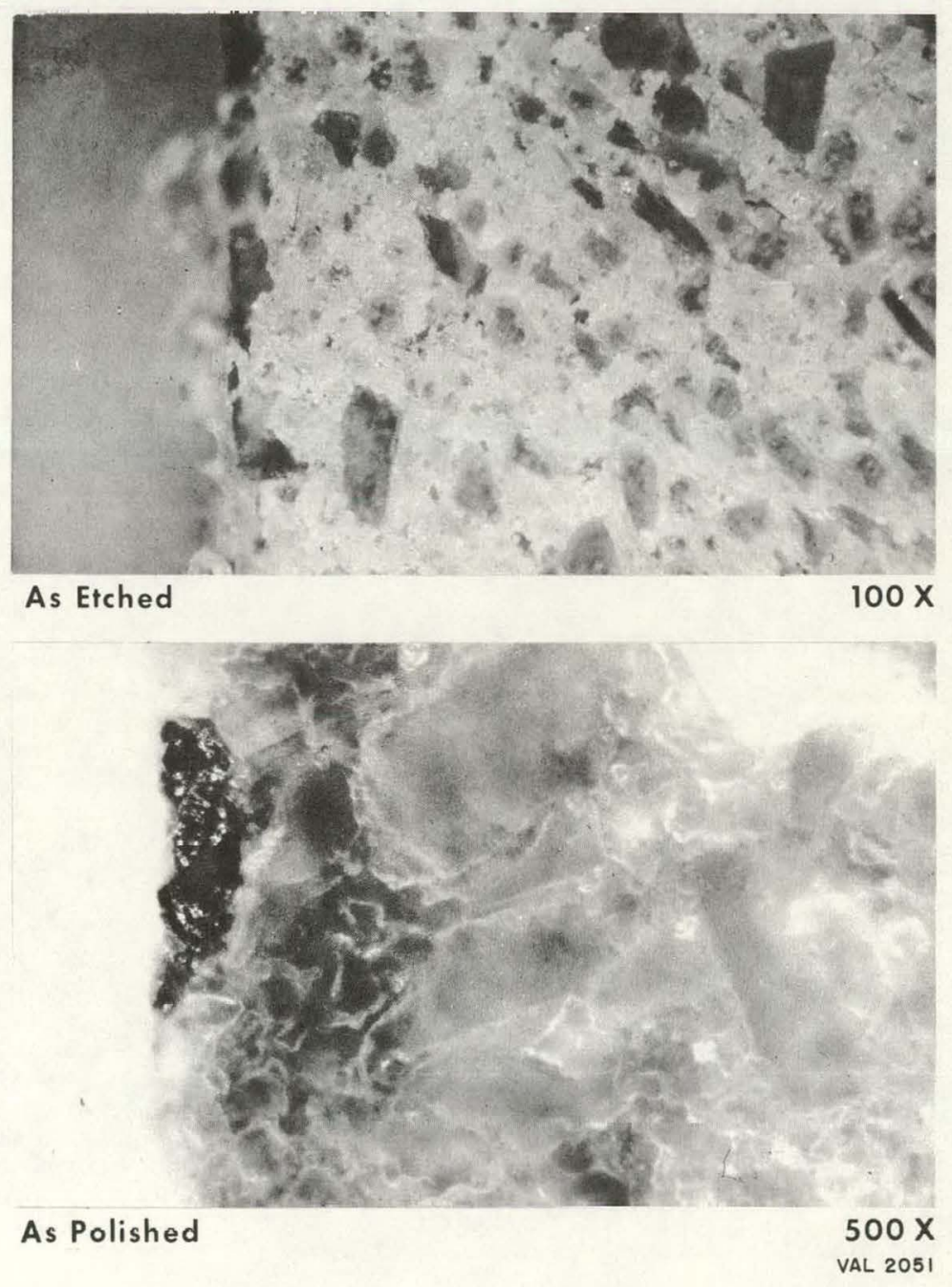

Fig. C.31. Bottom MgO End Spacer from Capsule 05-1. Reduced $17 \%$. 
РНОTO 67911
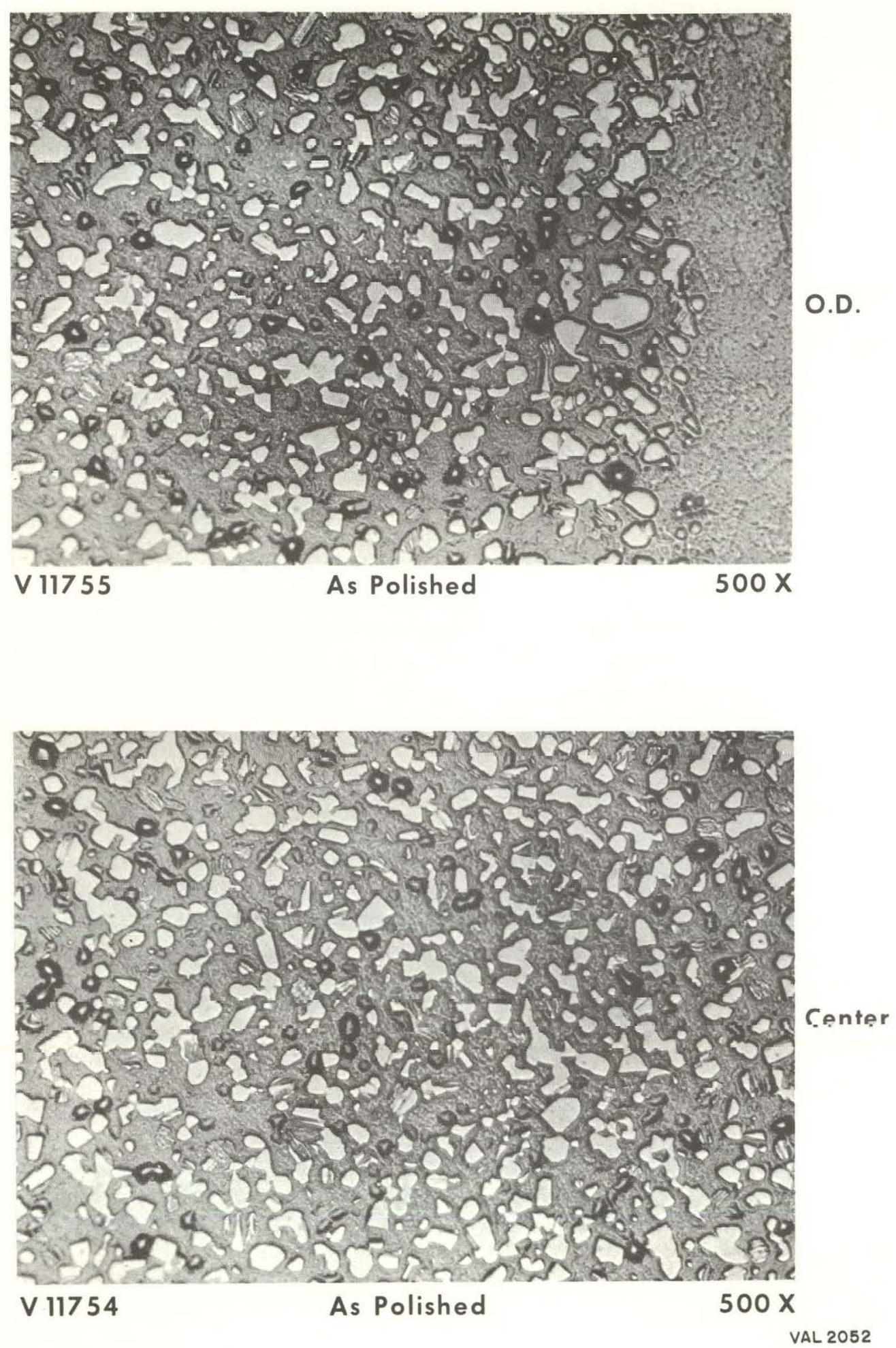

Fig. C.32. Control for BeO Insert in Capsule 06.1. 

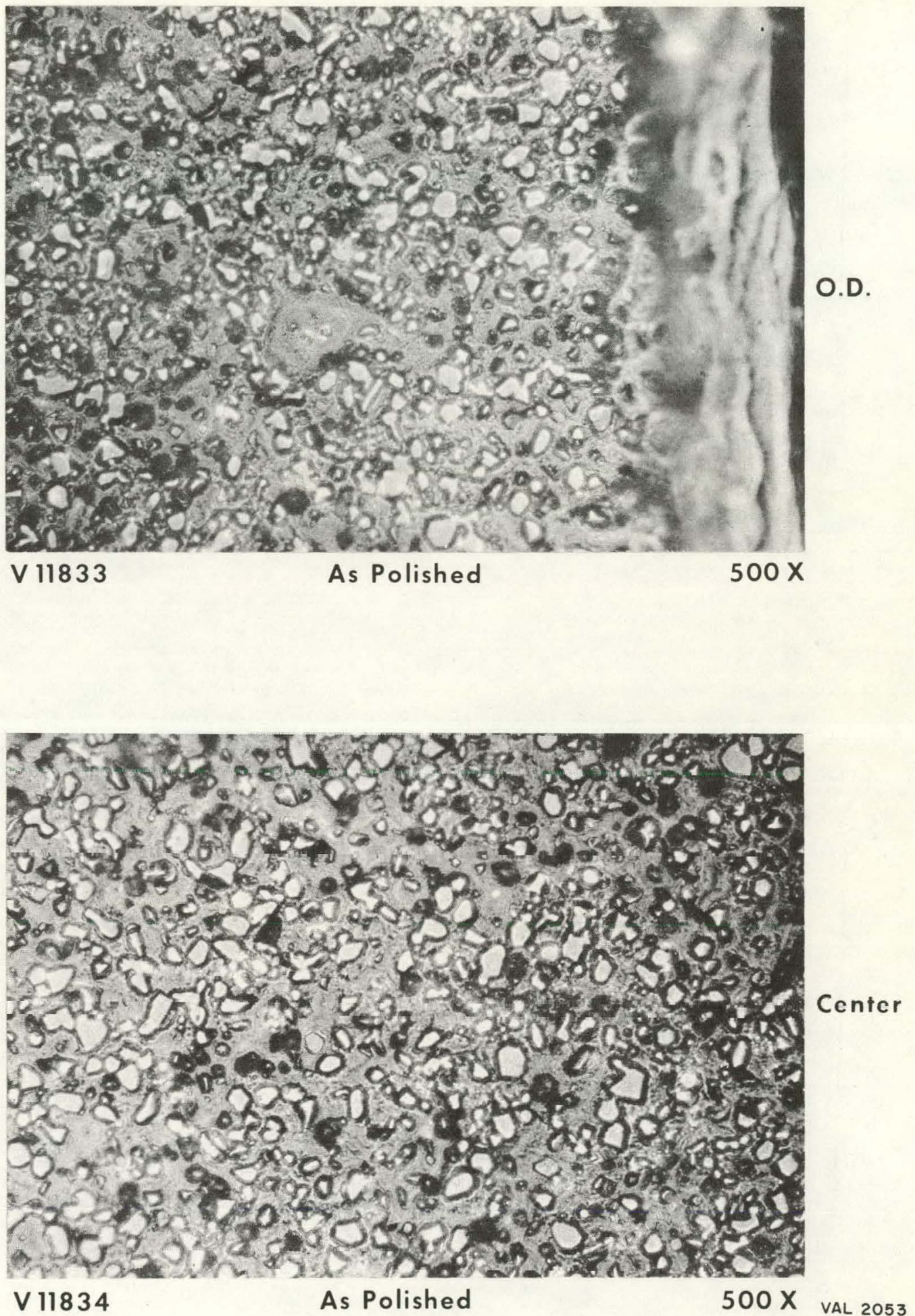

Fig. C.33. BeO Insert from Capsule 06-1. 

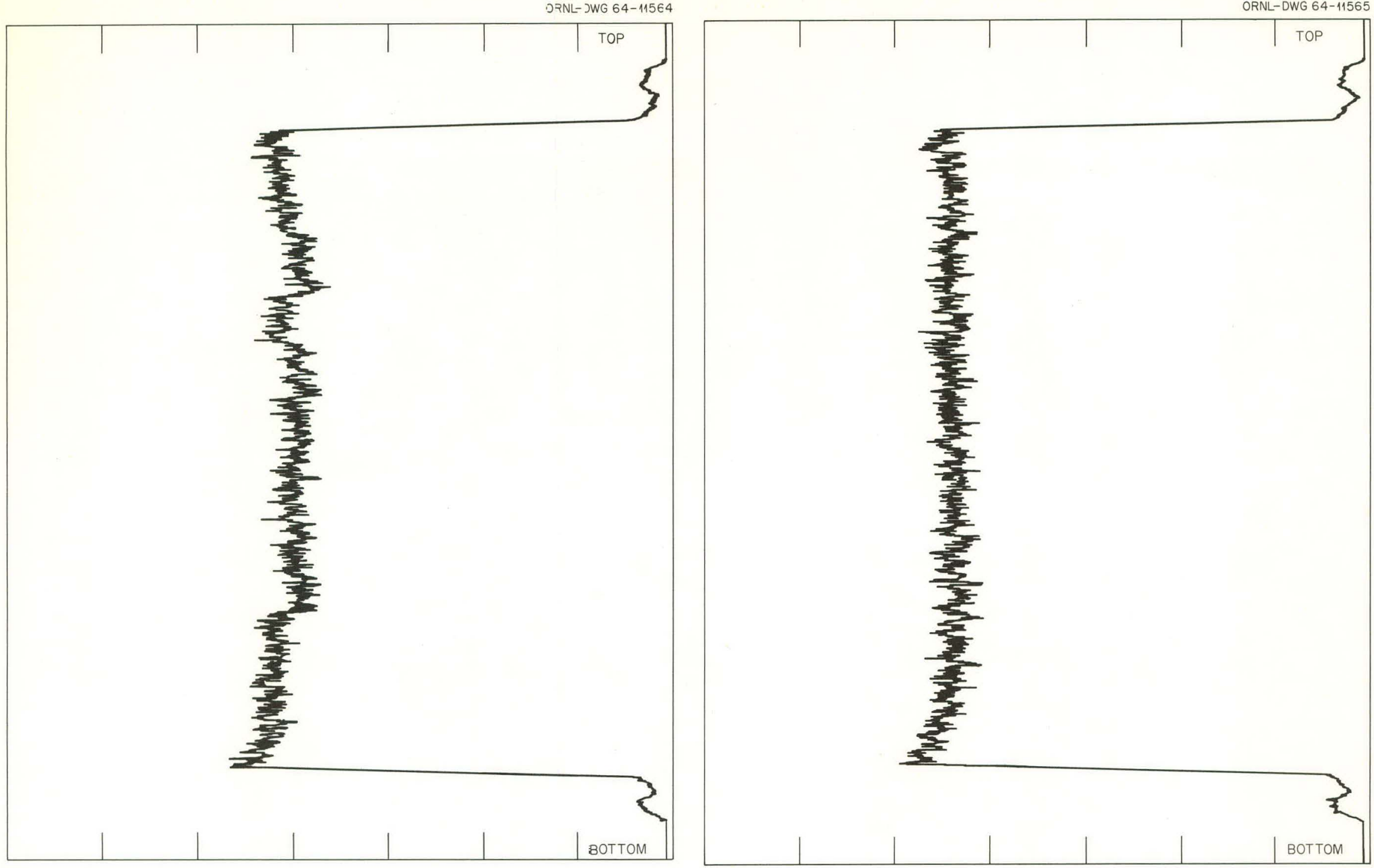

Fig. C.34. Gross Gamma Activity Scan of ORR 01-1.

Fig. C.35. Gross Gamma Activity Scan of ORR 02-1. 

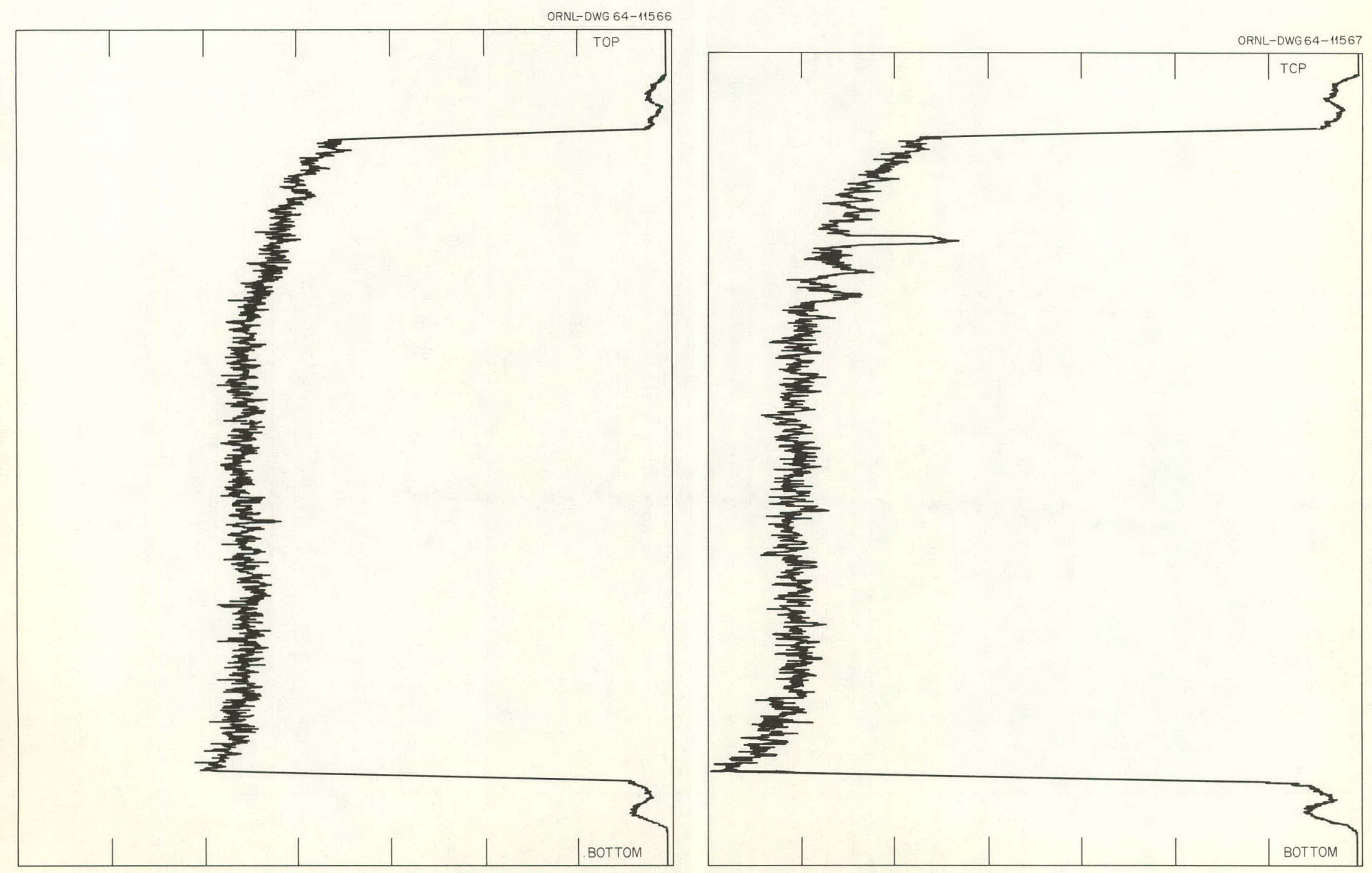

Fic. C.36. Gross Gamma Activity Scan of ORR 03-1.

Fig. C.37. Gross Gamma Activity Scan of ORR 04-1. 


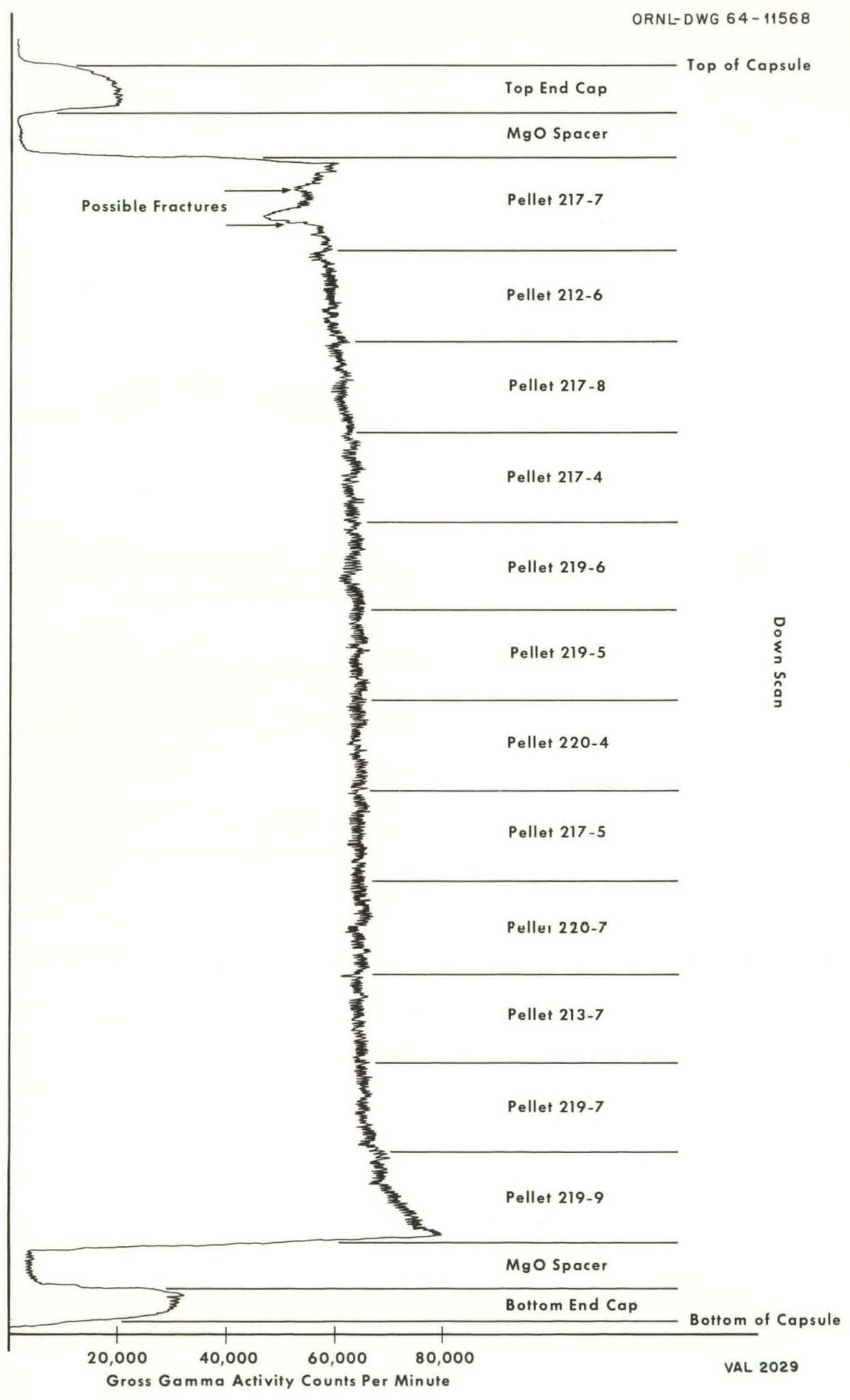

Fig. C.38. Gross Gamma Activity Scan of ORR 05-1. 


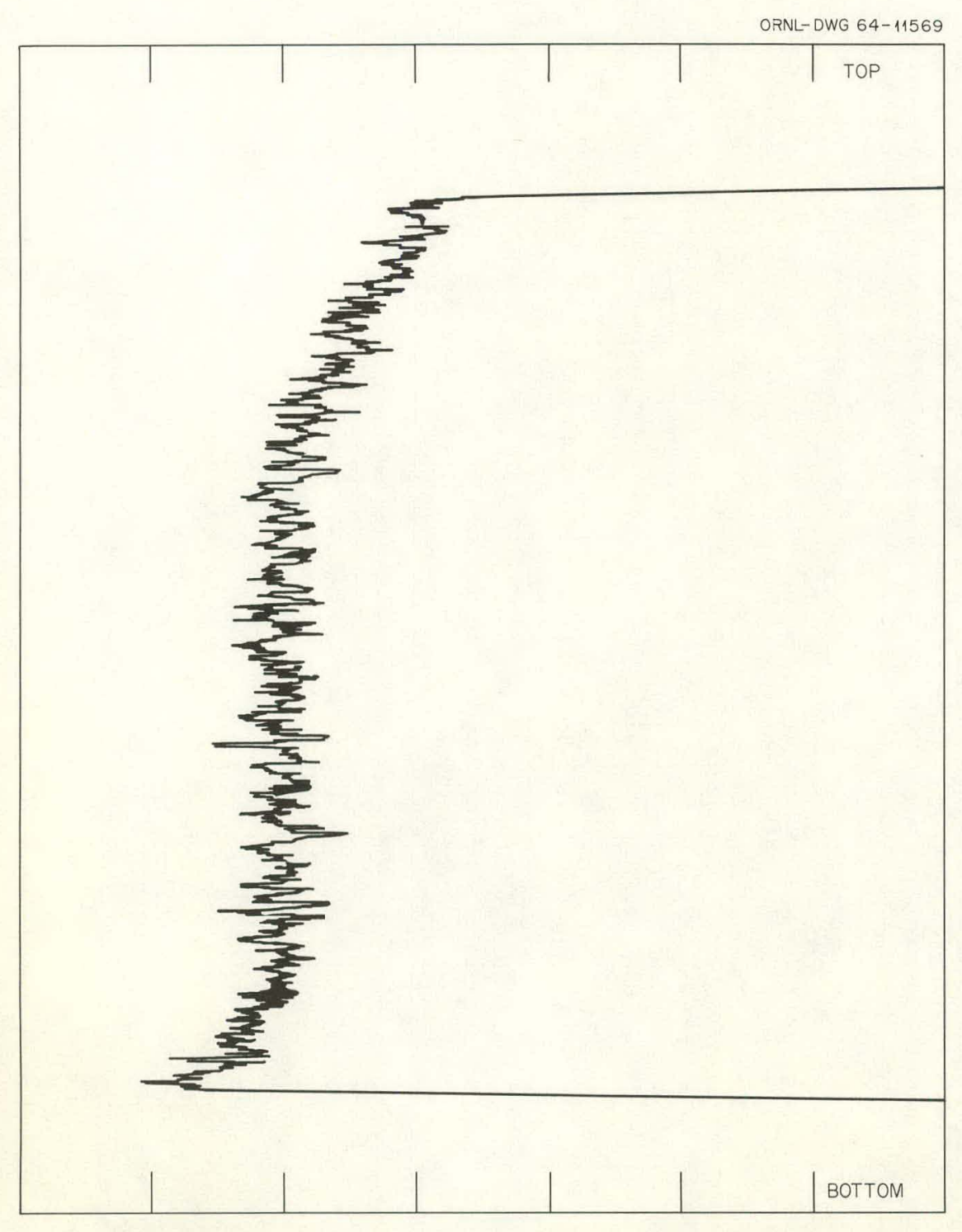

Fig. C.39. Gross Gamma Activity Scan of ORR 06.1.

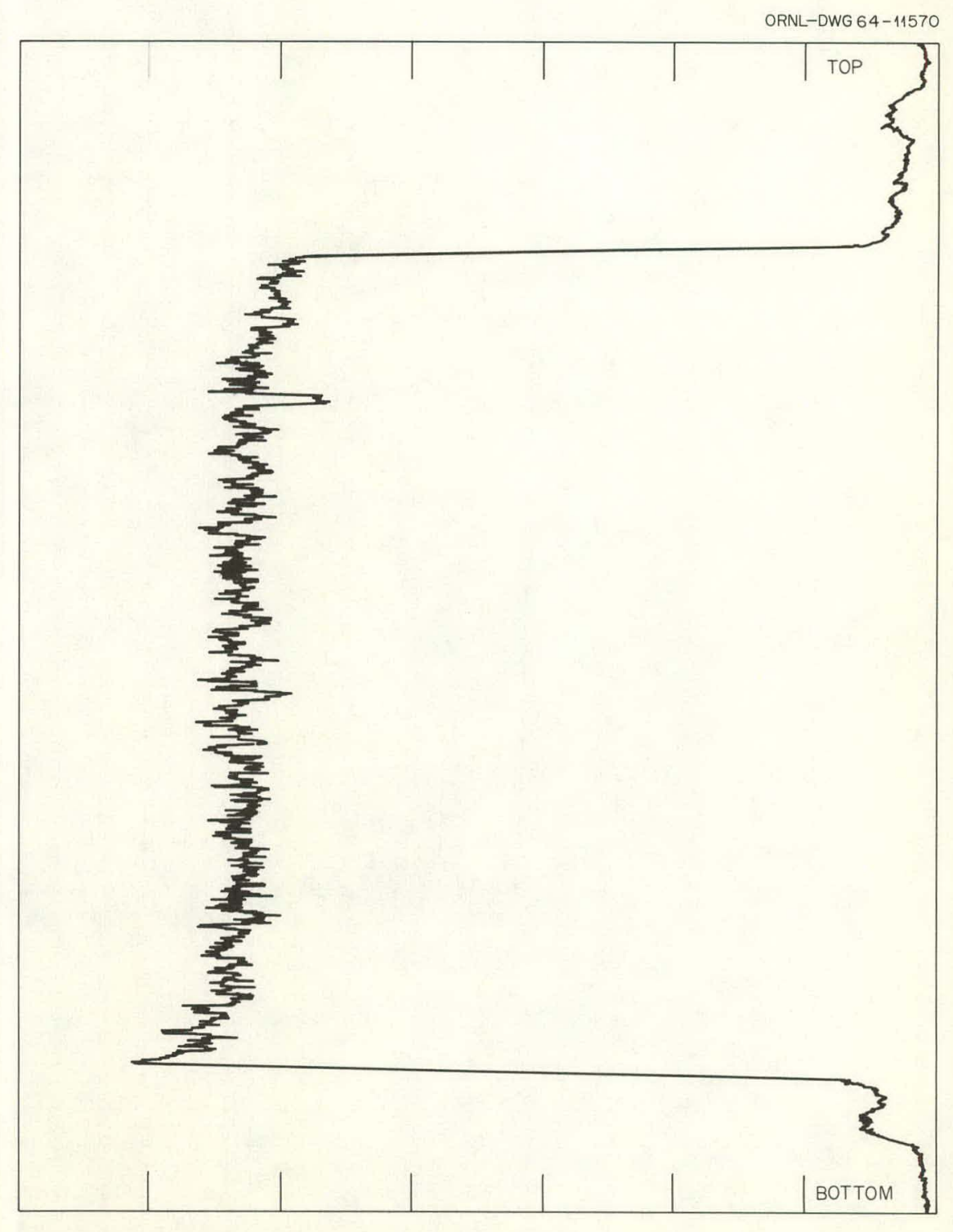

Fig. C.40. Gross Gamma Activity Scan of ORR 07.1. 
142

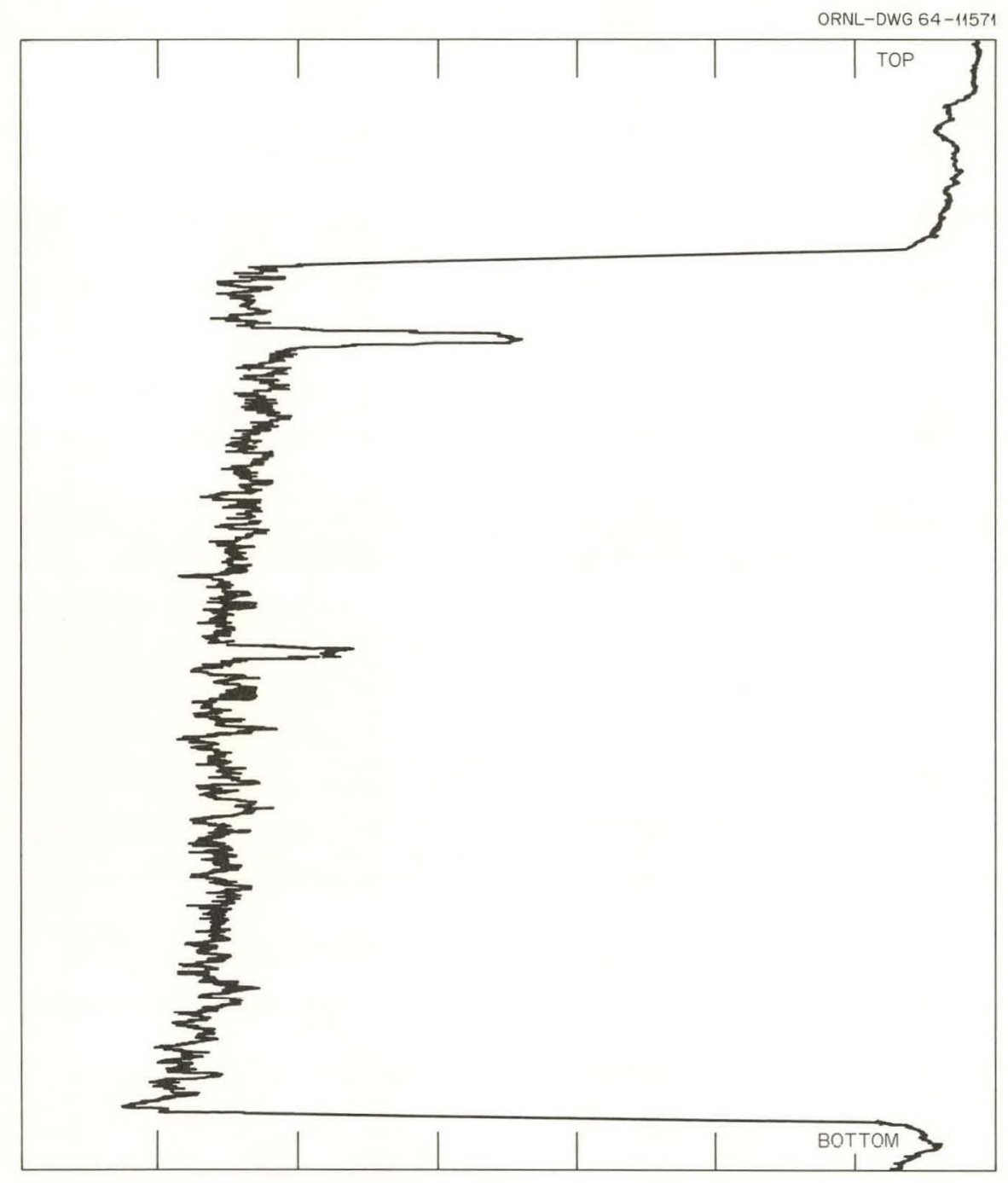

Fig. C.41. Gross Gamma Activity Scan of ORR 08-1. 


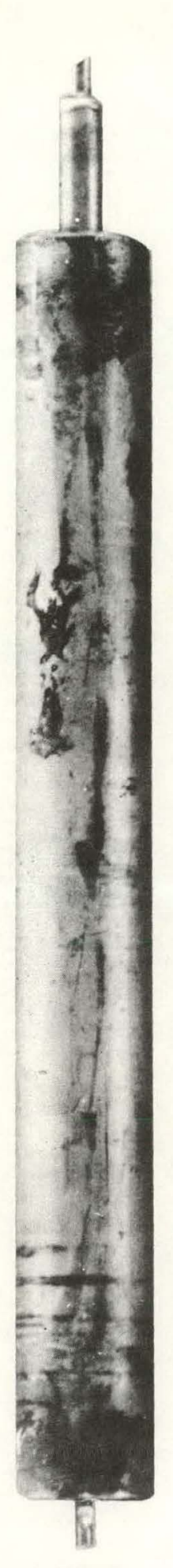

$01-2$
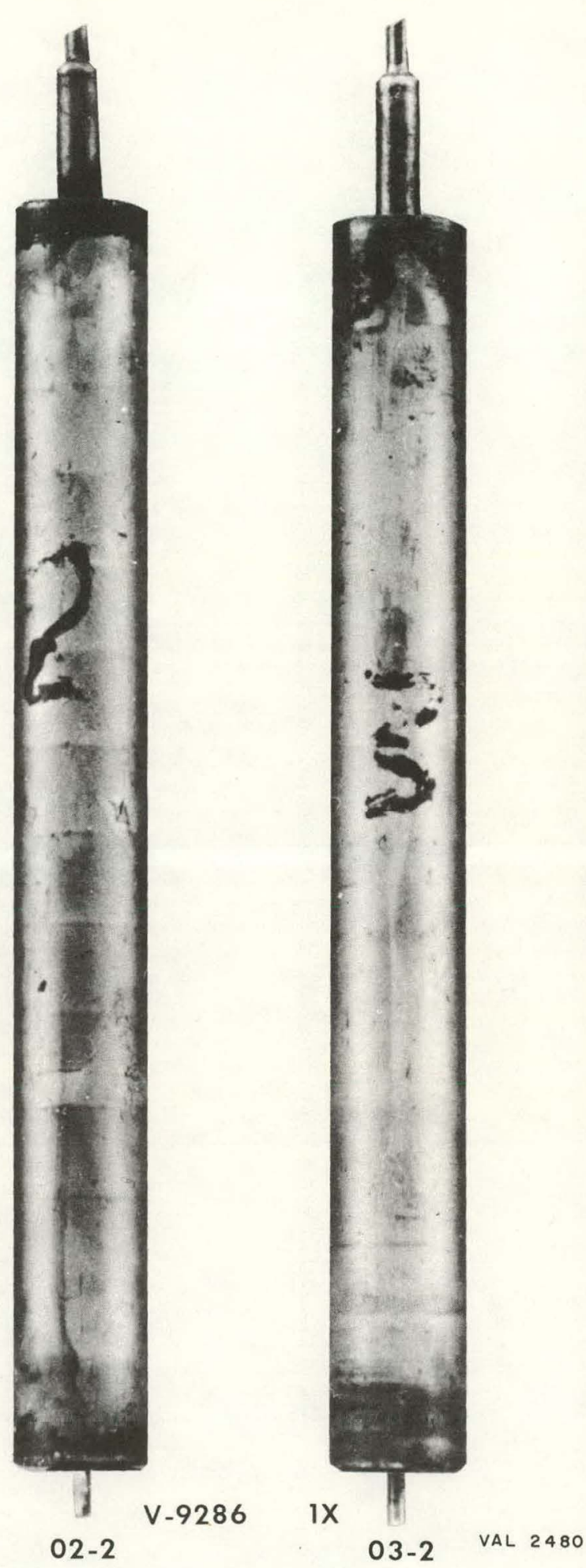

РНОTO 67913
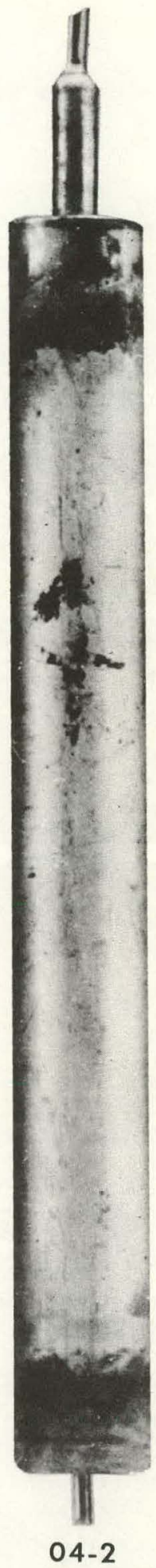

Fig. C.42, Front of Capsules 01-2, 02-2, 03-2, and 04-2 As Received at Vallecitos. Reduced $10 \%$. 


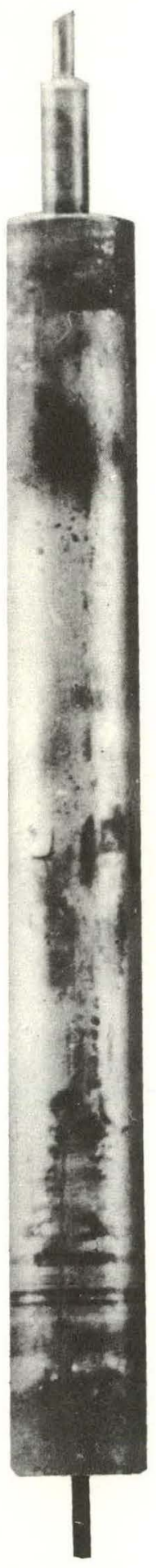

01-2
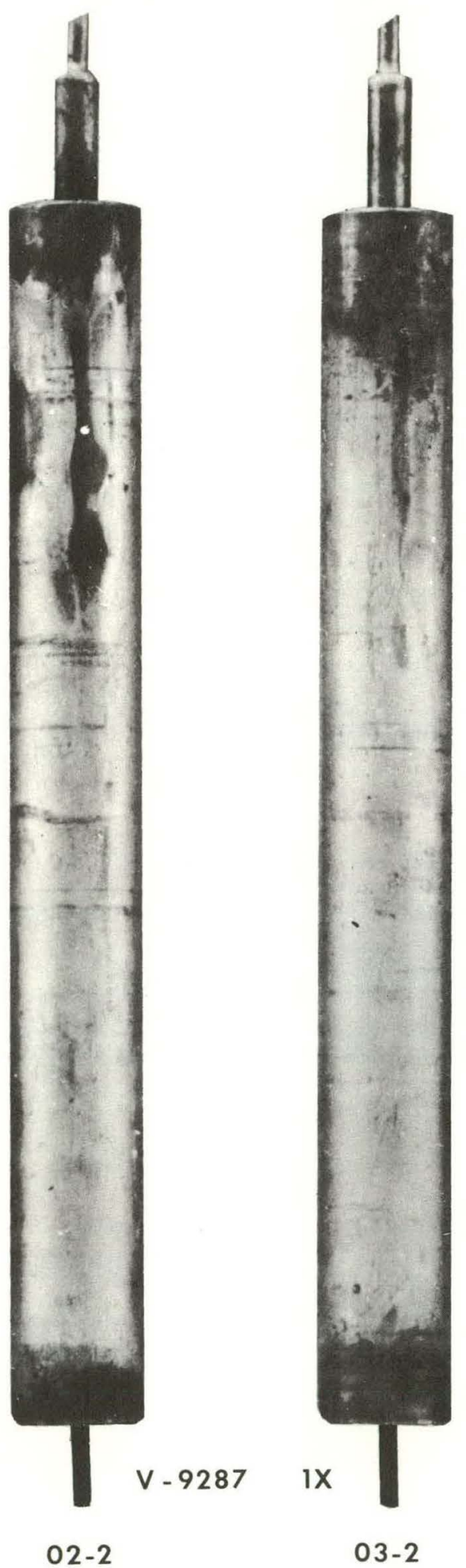

PHOTO 67944

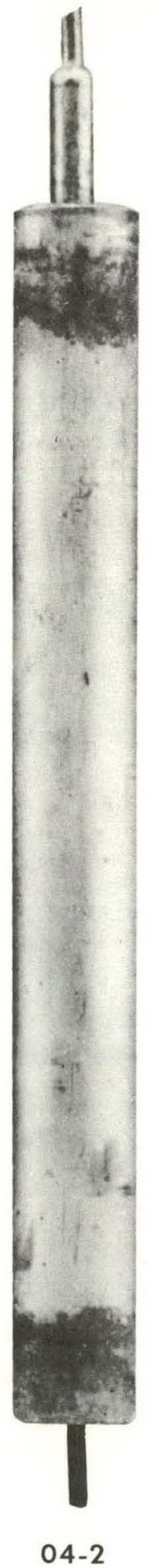

Fig. C.43. Back of Capsules 01-2, 02-2, 03-2, and 04-2 As Received at Vallecitos. Reduced $12 \%$. 


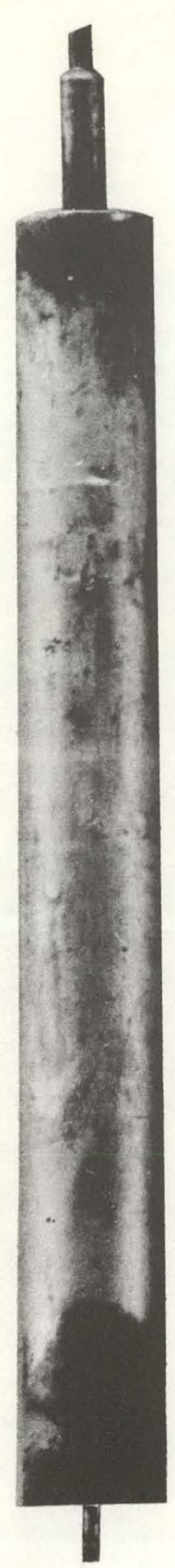

05-2

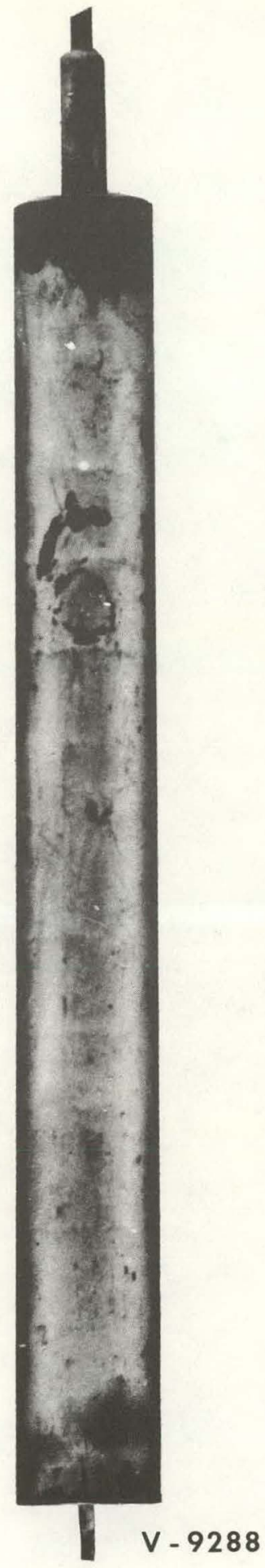

06-2

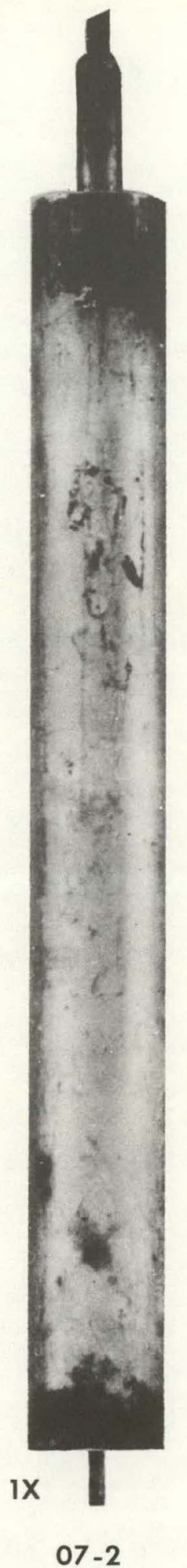

PHOTO 67915

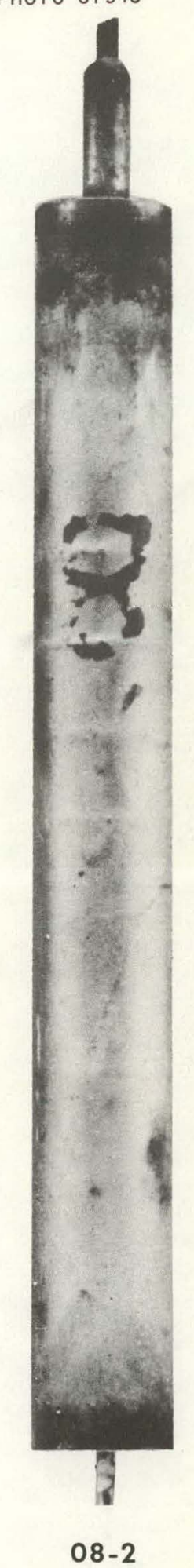

Fig. C.44. Front of Capsules 05-2, 06-2, 07-2, and 08-2 As Received at Vallecitos. Reduced 9.5\%. 

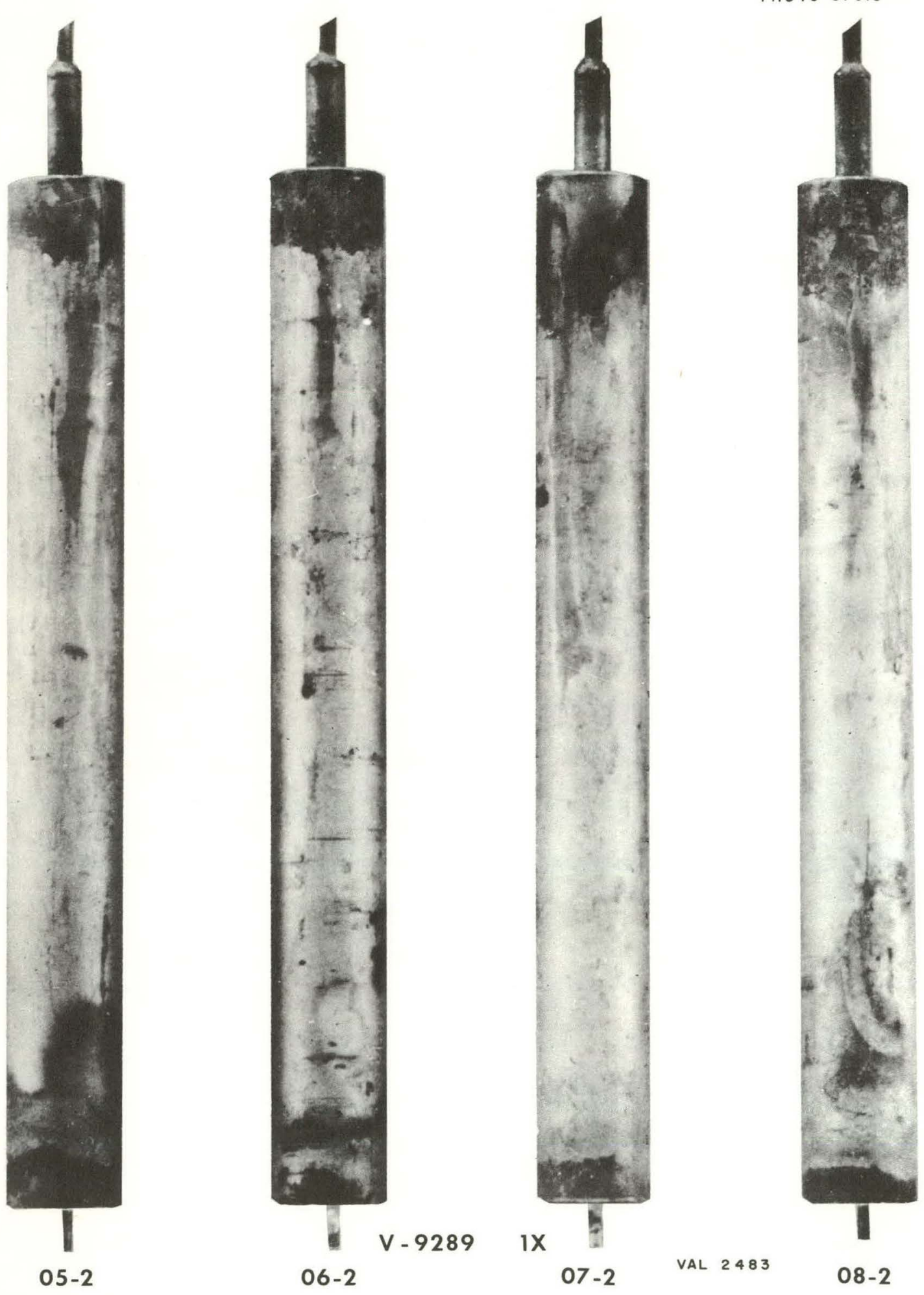

Fig. C.45. Back of Capsules 05-2, 06-2, 07-2, and 08-2 As Received at Vallecitos. Reduced 9.5\%. 


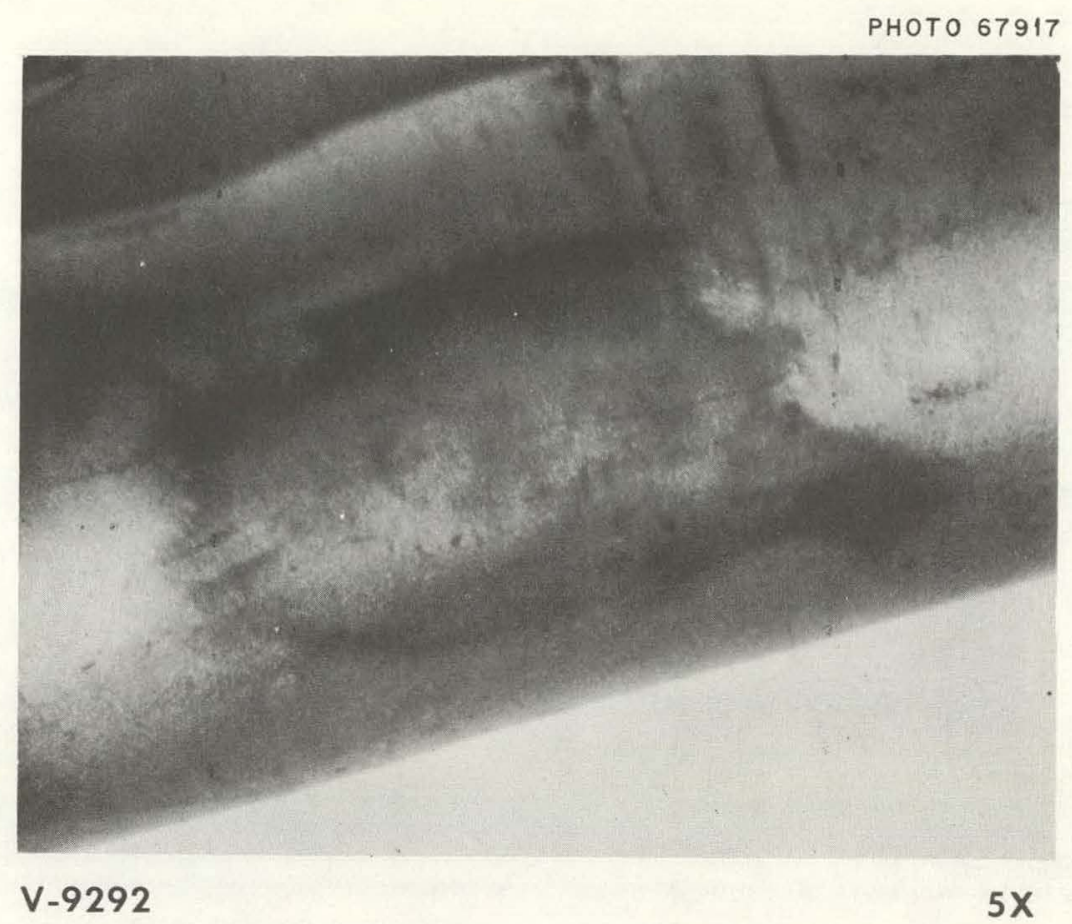

Discolored spot on cladding of capsule 02-2, top end.

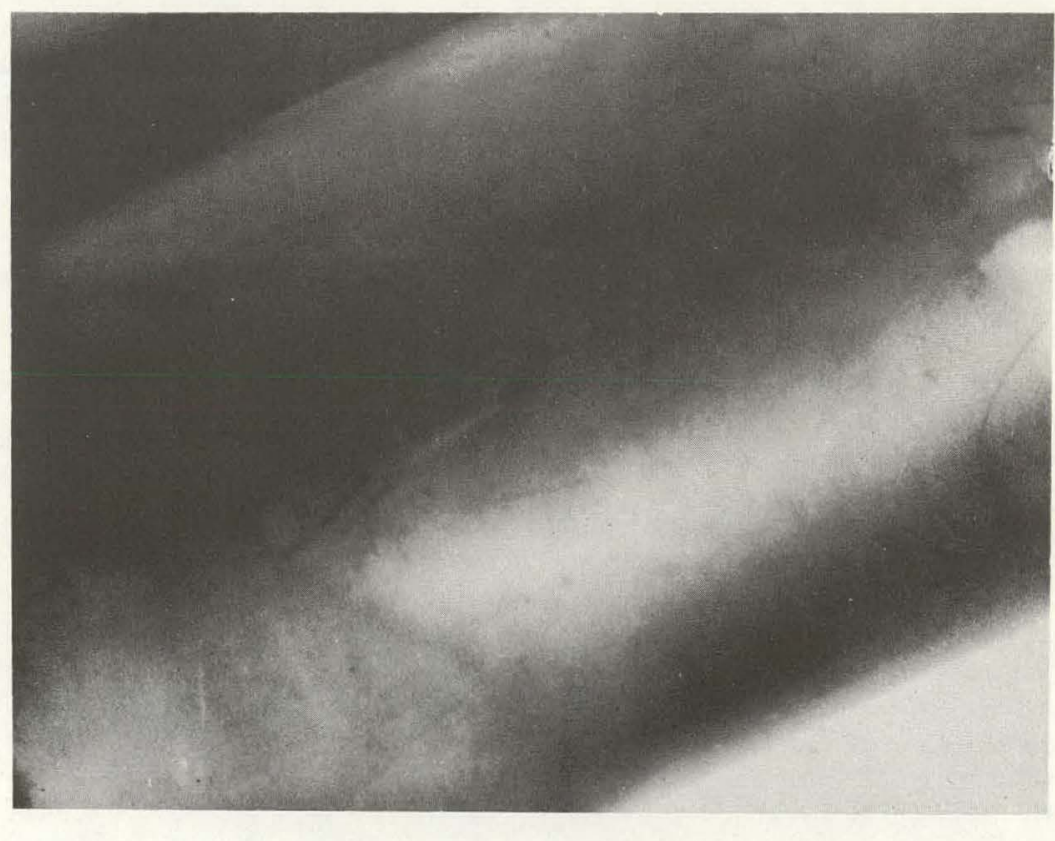

V-9295

$5 X$

Discolored spot on cladding of capsule 05-2, bottom end.

VAL 2484

Fig. C.46. Discolored Spots on Cladding. Reduced $8.5 \%$. 

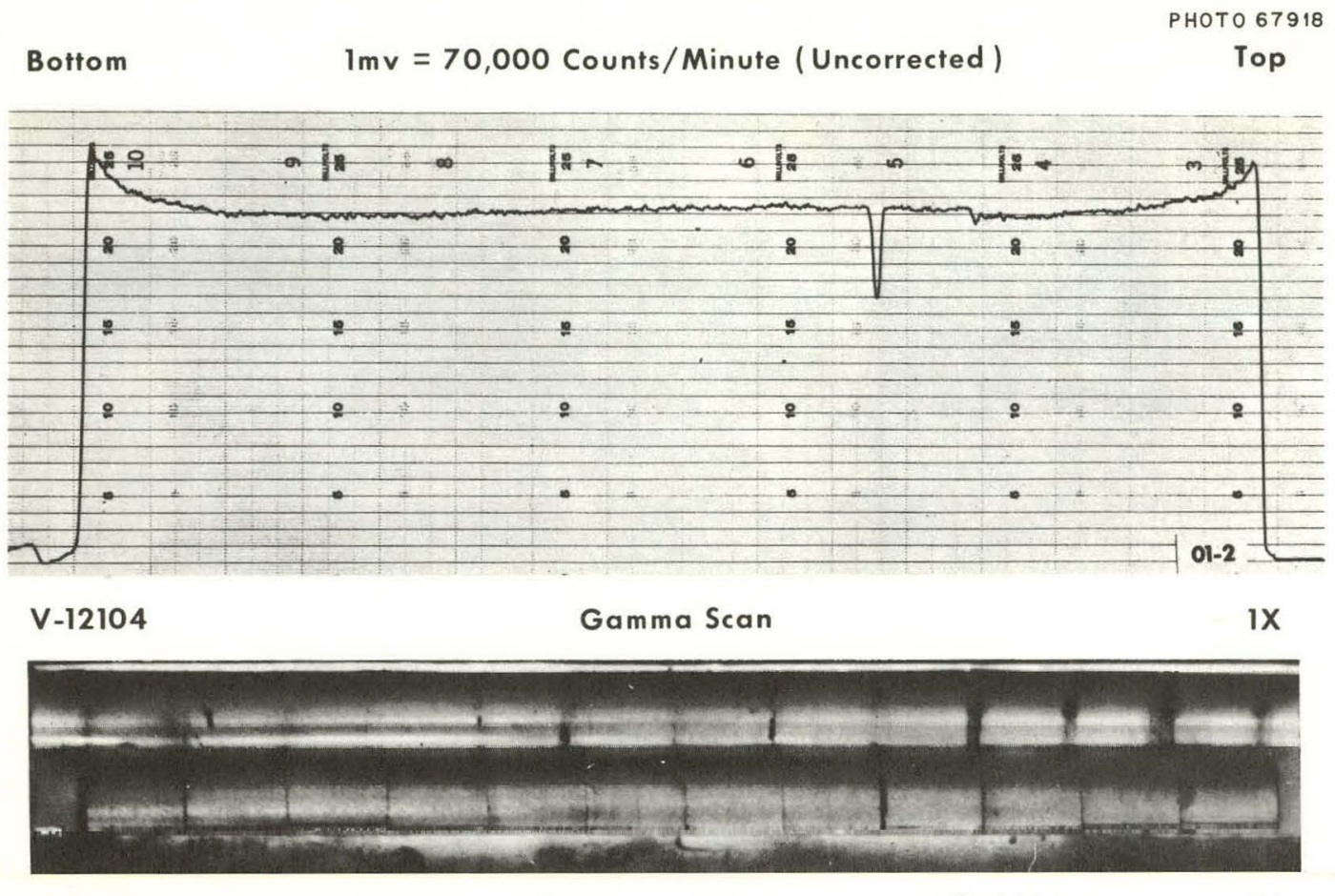

V-13236

As Opened Capsule

VAL 2494

$1 X$

Fig. C.47. Capsule 01-2 As Opened and Gamma Scan. Reduced $20 \%$.

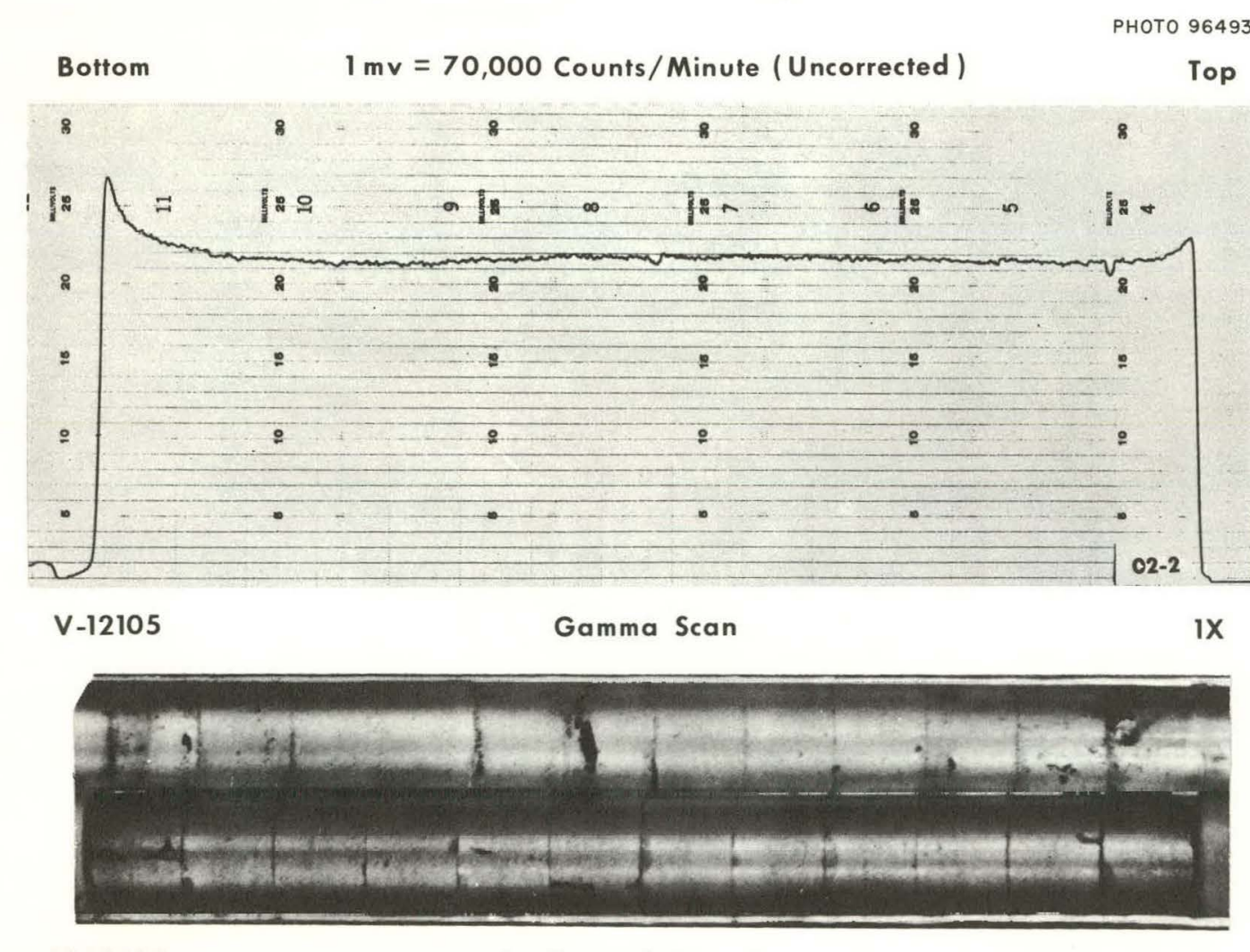

V-13288

As Opened Capsule

VAL $2495 \quad$ IX

Fig. C.48. Capsule 02-2 As Opened and Gamma Scan. Reduced $20 \%$. 

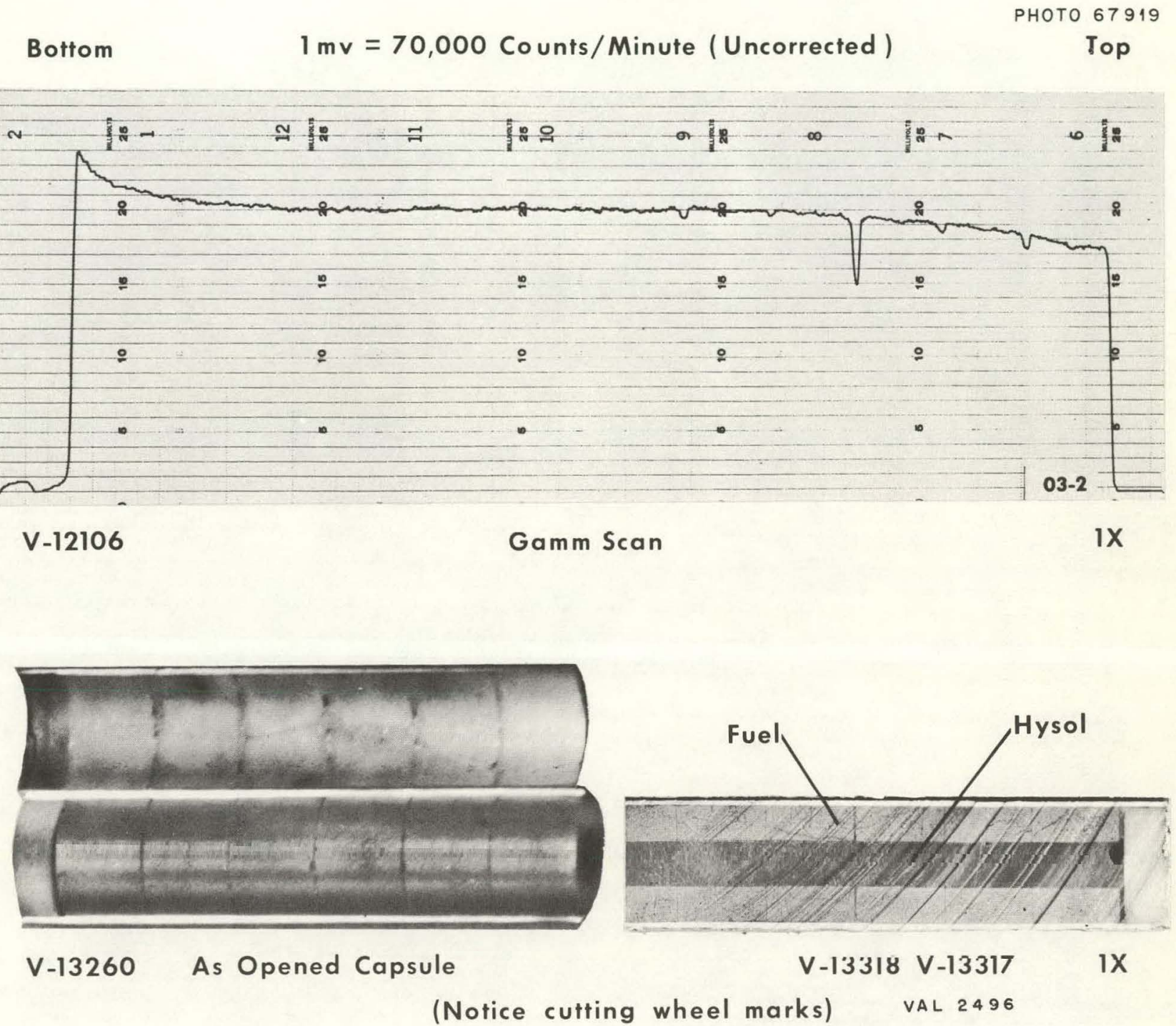

Fig. C.49. Capsule 03-2 As Opened and Gamma Scan. Reduced 4.5\%. 

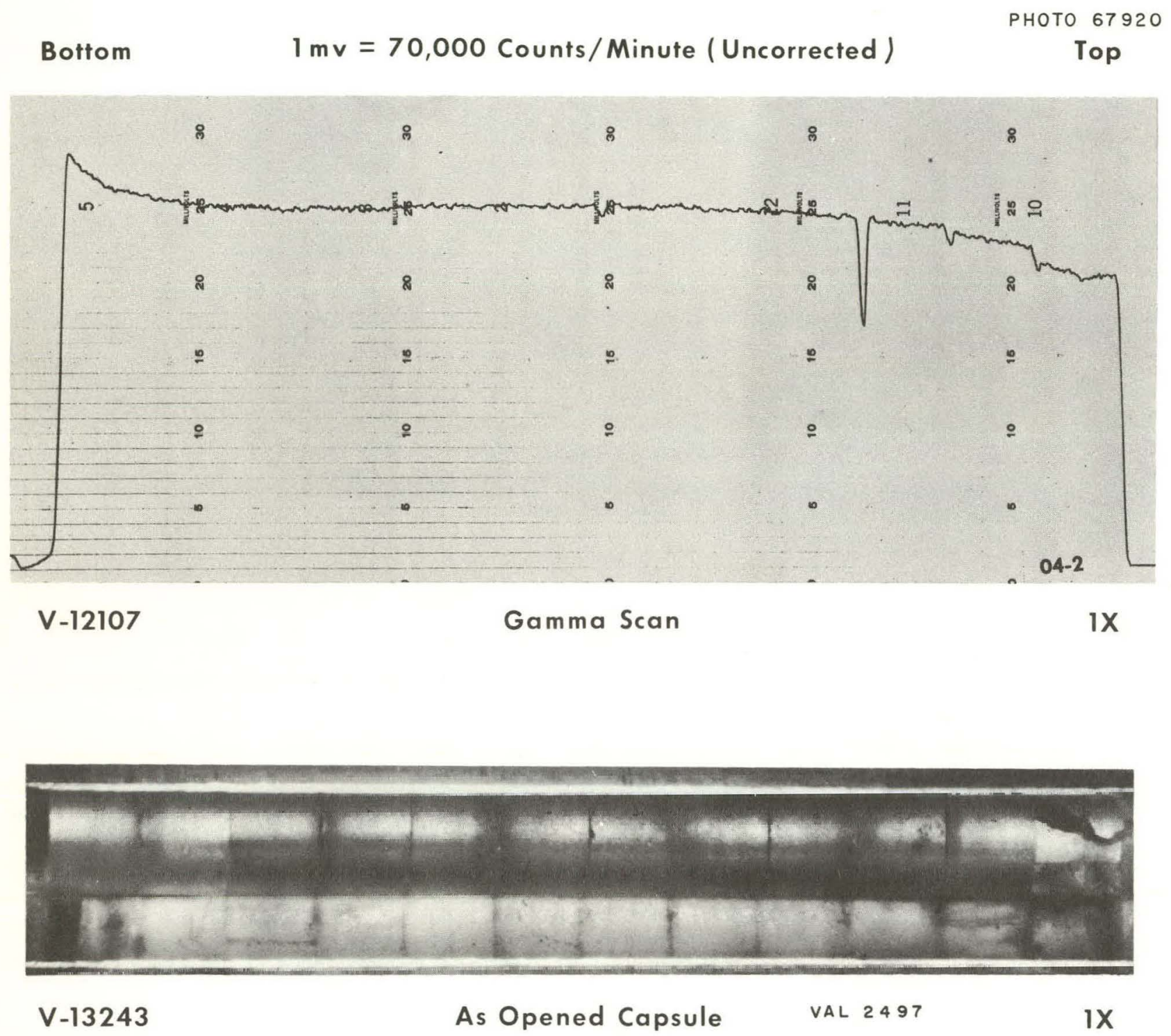

Fig. C.50. Capsule 04-2 As Opened and Gamma Scan. 

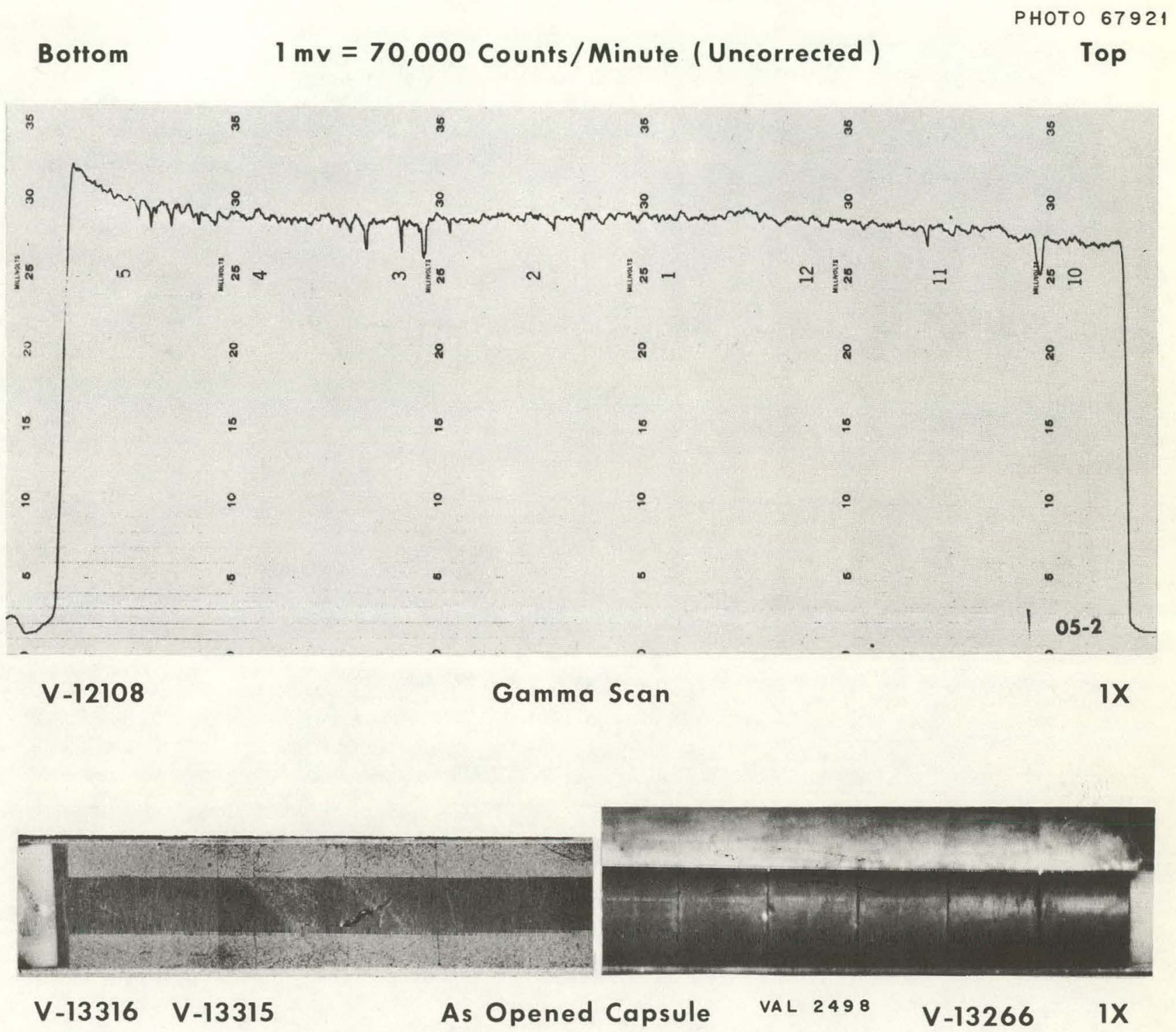

VAL 2498

V-13266

IX

Fig. C.51. Capsule 05-2 As Opened and Gamma Scan. 


\section{Bottom \\ $1 \mathrm{mv}=25,000$ Counts $/$ Minute (Uncorrected) \\ PHOTO 67922 \\ Top}

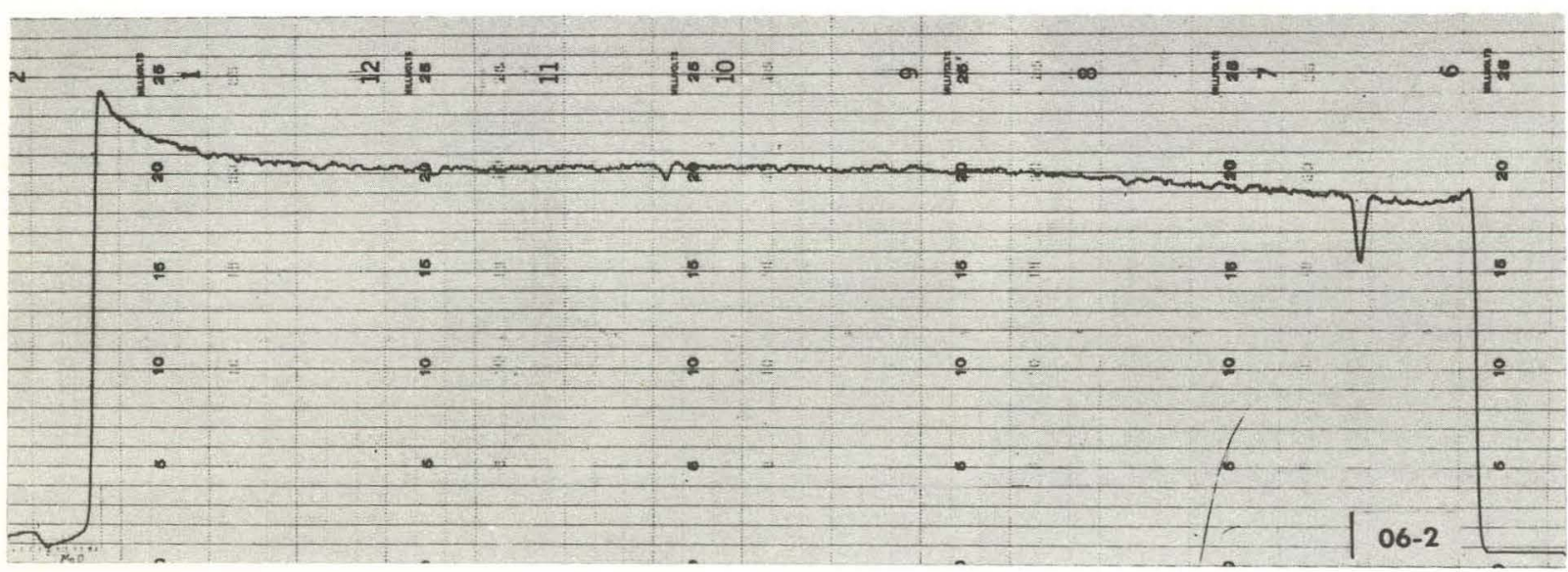

V-12189

Gamma Scan

$1 \mathrm{x}$

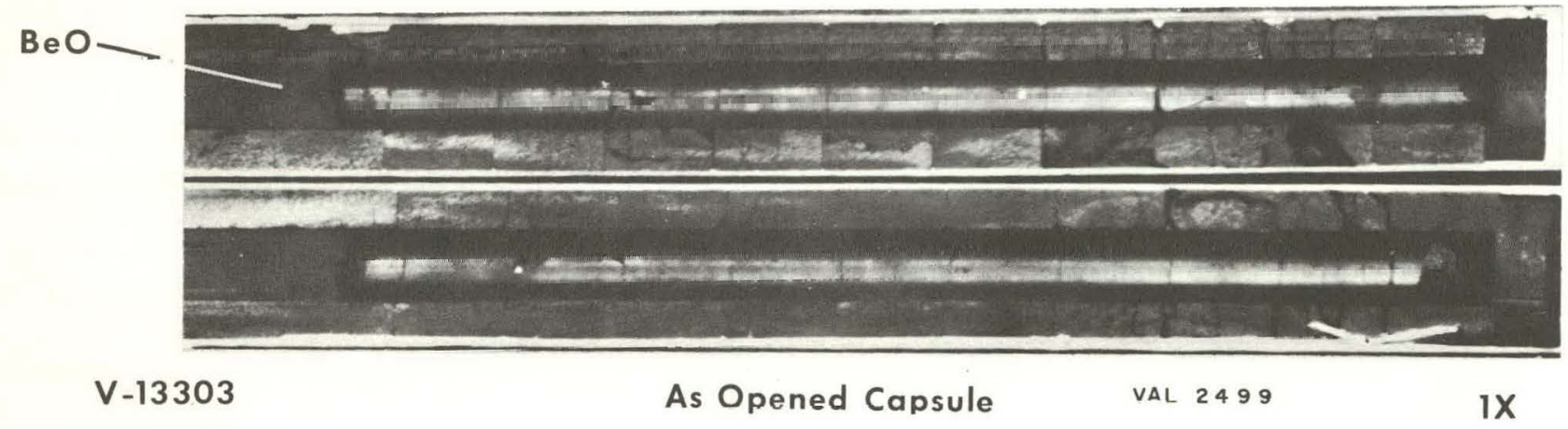

Fig. C.52. Capsule 06.2 As Opened and Gamma Scan. Reduced 7.5\%. 

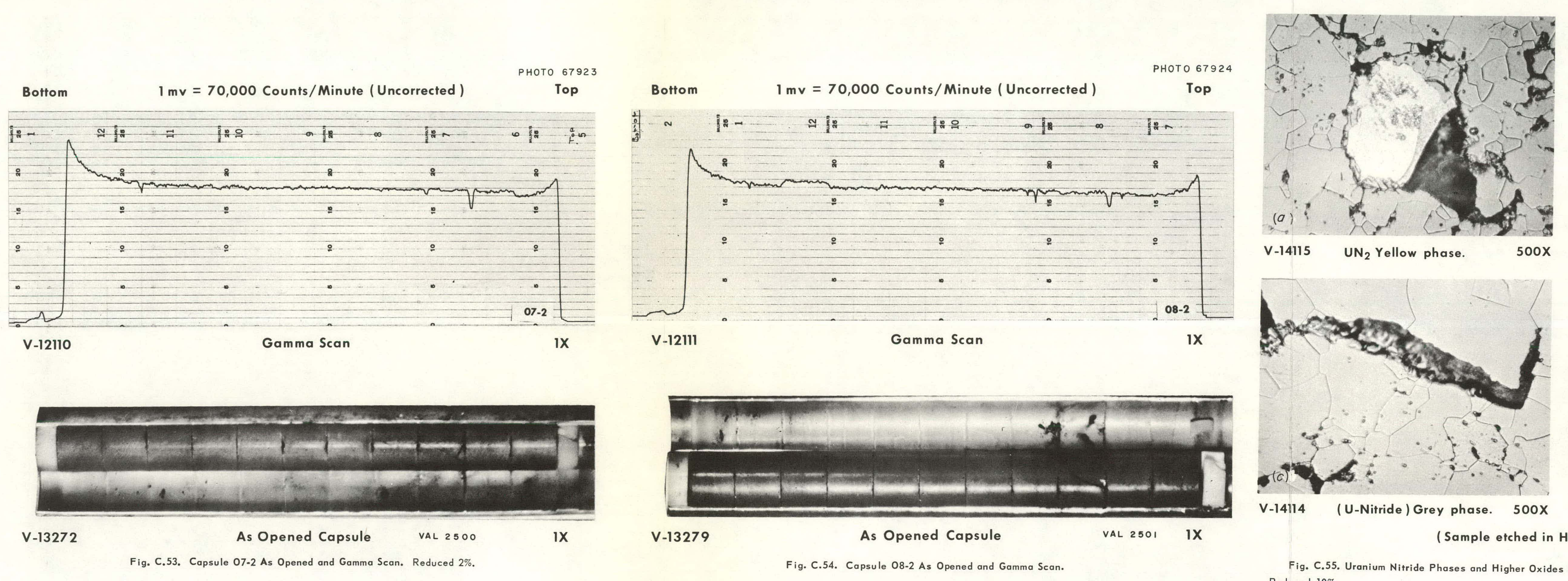

V-13272

As Opened Capsule

Fig. C.54. Capsule 08-2 As Opened and Gamma Scan.
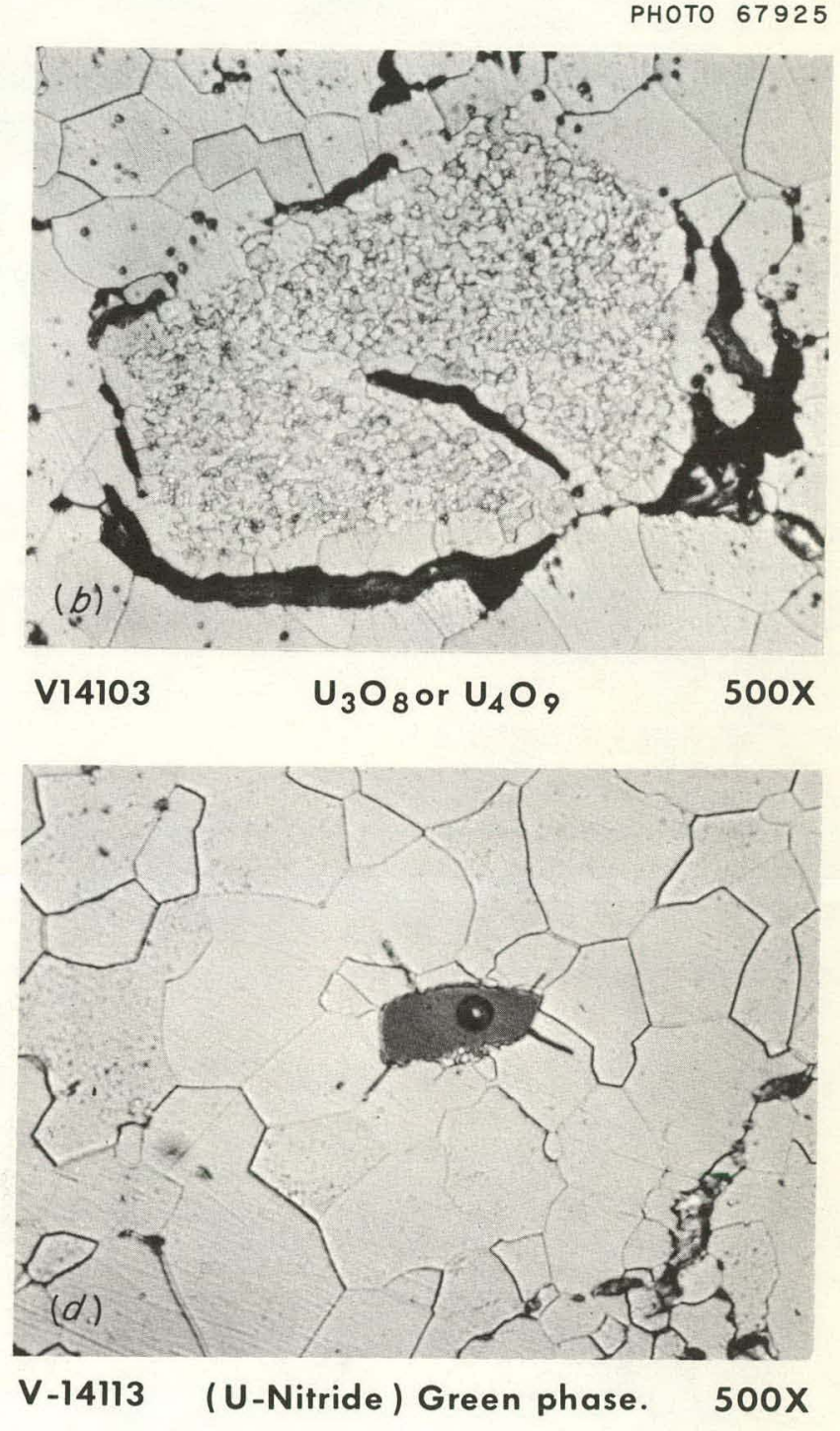

(c) $1+6$

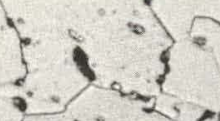

V-14114 (U-Nitride) Grey phase. 500X V-14113 (U-Nitride) Green phase. $500 \mathrm{X}$ Fig. C.53. Capsule 07-2 As Opened and Gamma Scan, Reduced 2\%

Fig. C.5.
Reduced $10 \%$. (Sample etched in $\mathrm{HNO}_{3}-\mathrm{H}_{2} \mathrm{O}_{2}-\mathrm{H}_{2} \mathrm{O}$ ) 

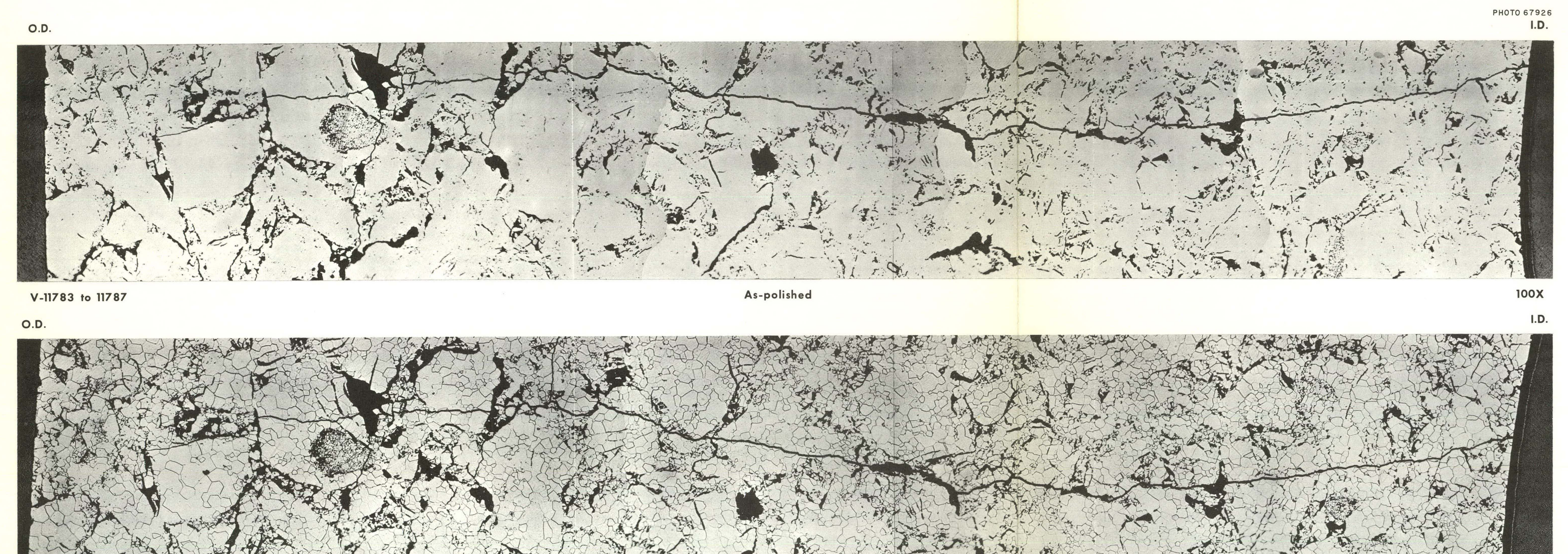

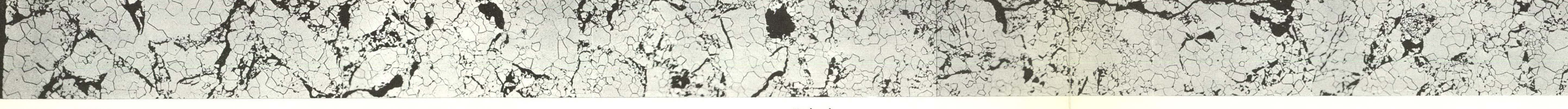
V-14018 to 14022 


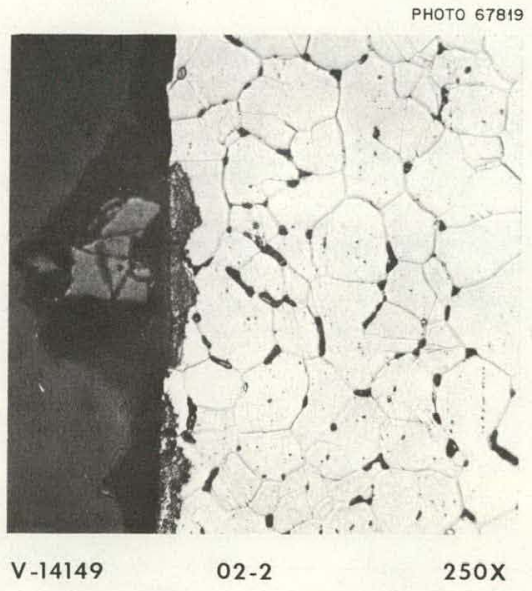

(Etched-Electrolytic, oxalic acid)

Voids left by removal of sigma phase.

Notice slight reaction at $\mathrm{UO}_{2}$ S.S. interface.

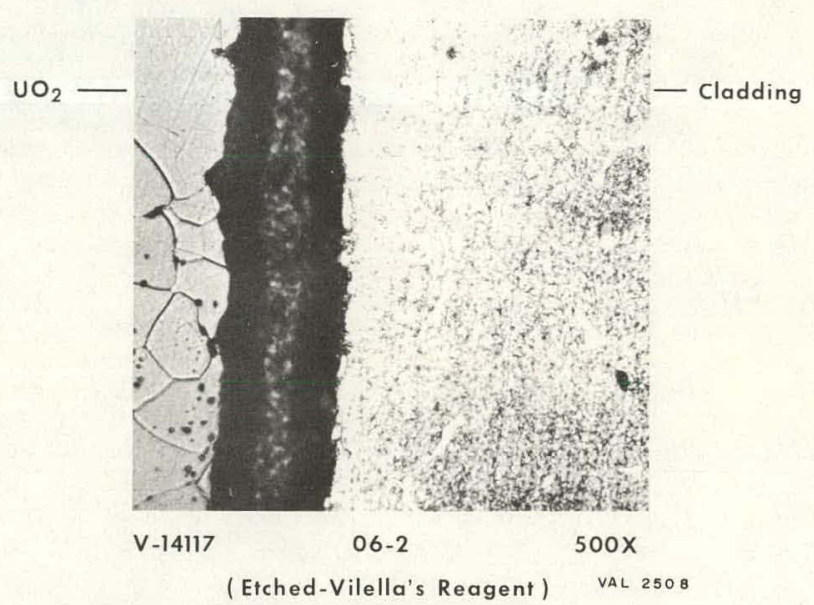

Austenite matrix has been heavily attacked

leaving the sigma phase in relief-white phase.

Fig. C.57. Sigma Phase in Cladding. Reduced $40 \%$. 


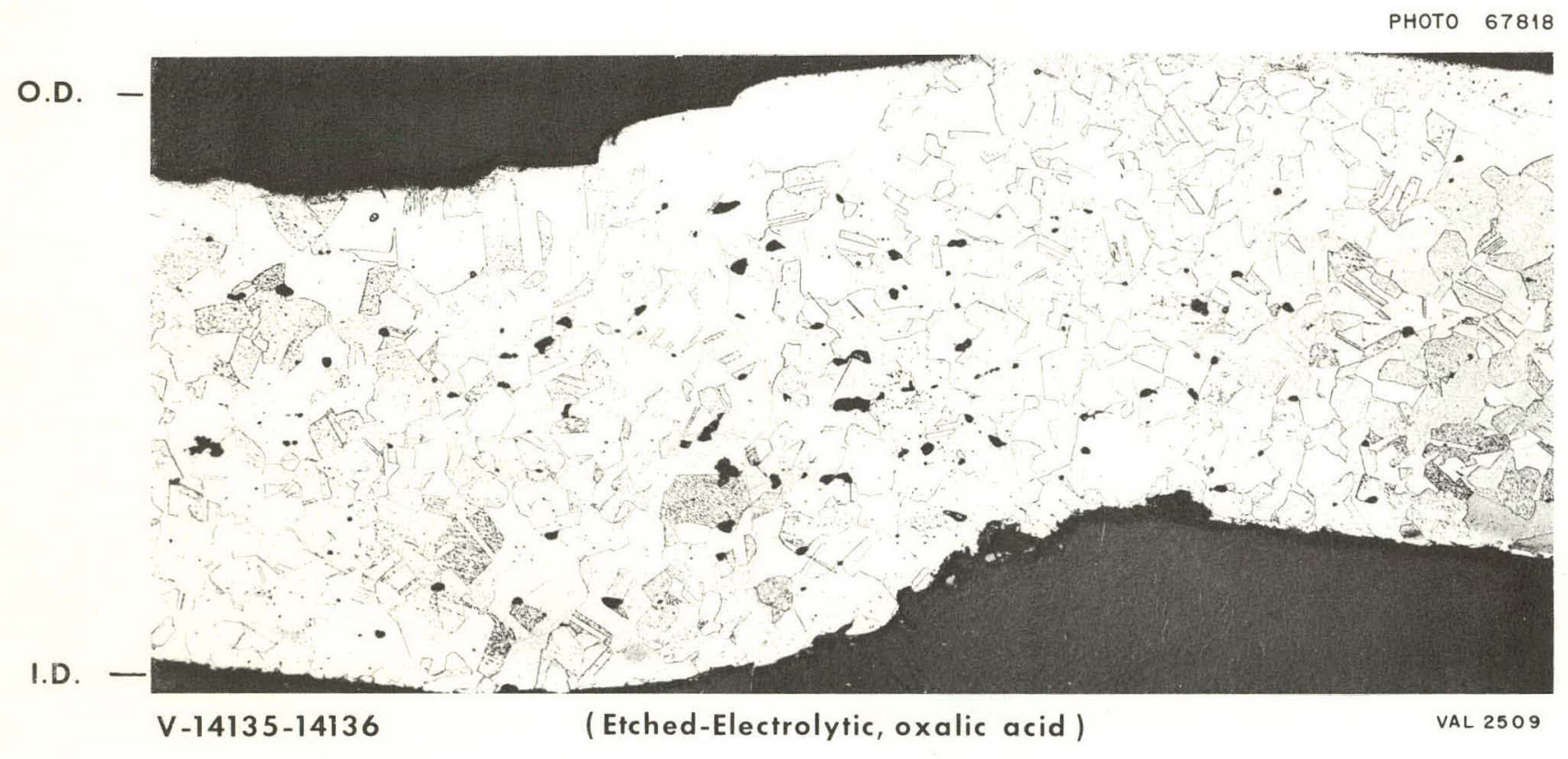

Notice large amount of porosity in cladding. Embedded $\mathrm{UO}_{2}$ was lost when sample was etched. The large grains at the clad O.D. may be result of strain cycling.

Fig. C.58. Longitudinal Section Through Cladding Wrinkle at No. 10 and No. 11 Pellet Interface (Capsule 05-2). $100 x$. Reduced $17 \%$. 

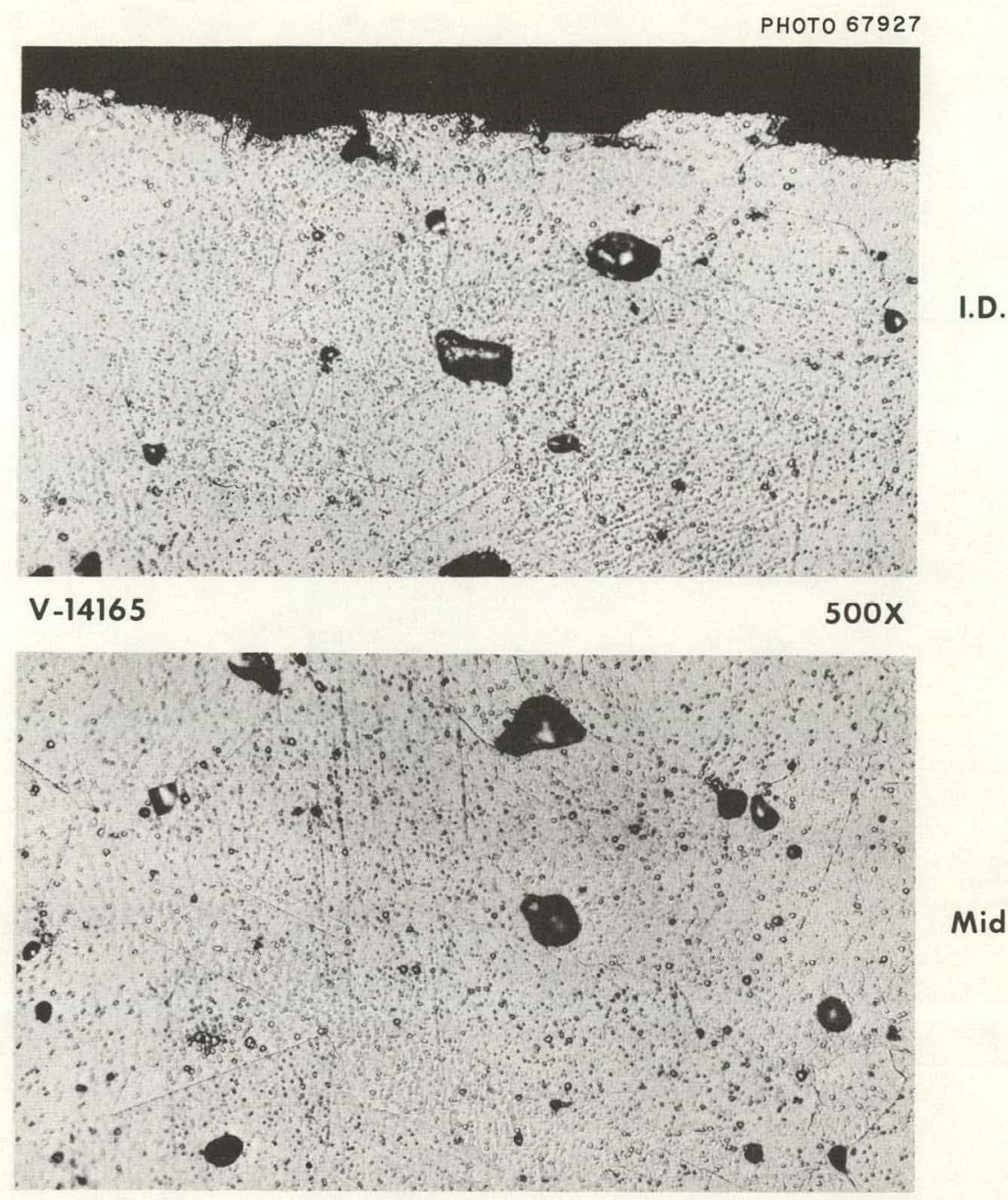

Mid

V-14166

$500 x$

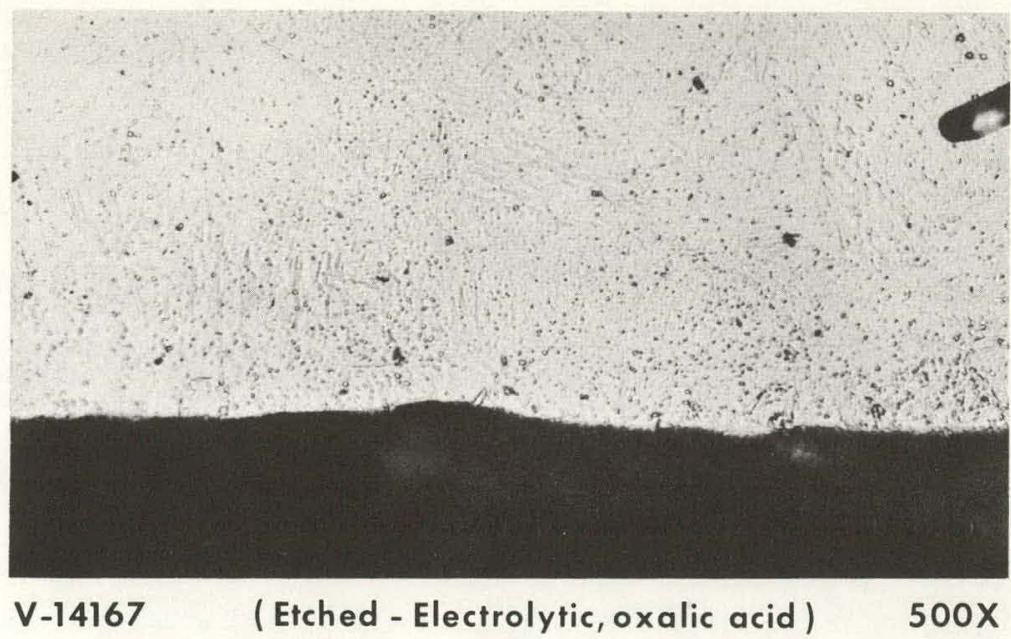

O.D.

Fig. C.59. Unidentified Precipitate Most Numerous at ID of Capsule 02-2; Voids Left by Removal of Sigma Phase. Reduced $12.5 \%$. 
VAL 251 I

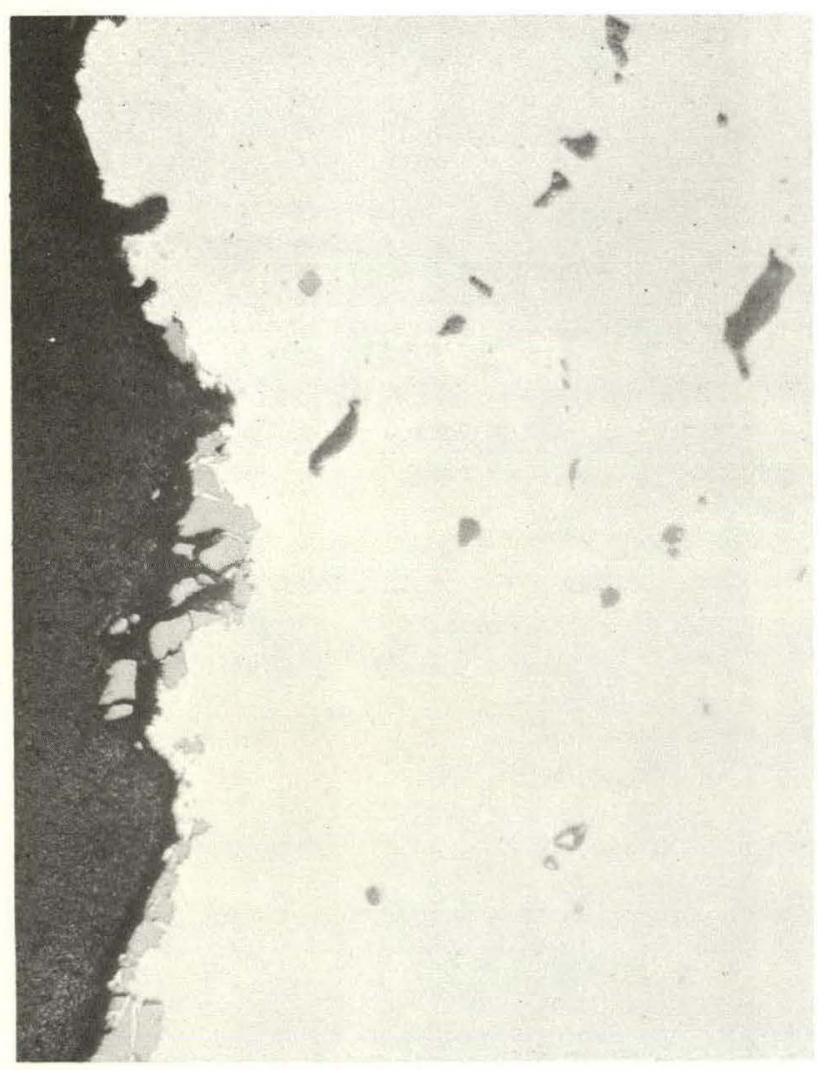

V-11623
05-2
$250 x$

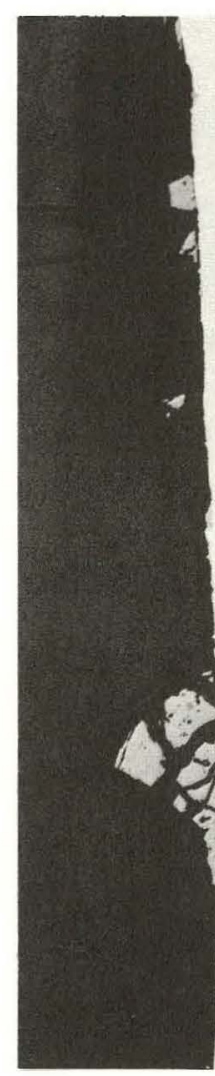

V-11584

PHOTO 67928

Notice porosity in cladding. As-polished Notice porosity in cladding.

Fig. C.60. UO $\mathrm{U}_{2}$ Embedded in Cladding at Fuel-Clad Interface. Reduced $9.5 \%$. 


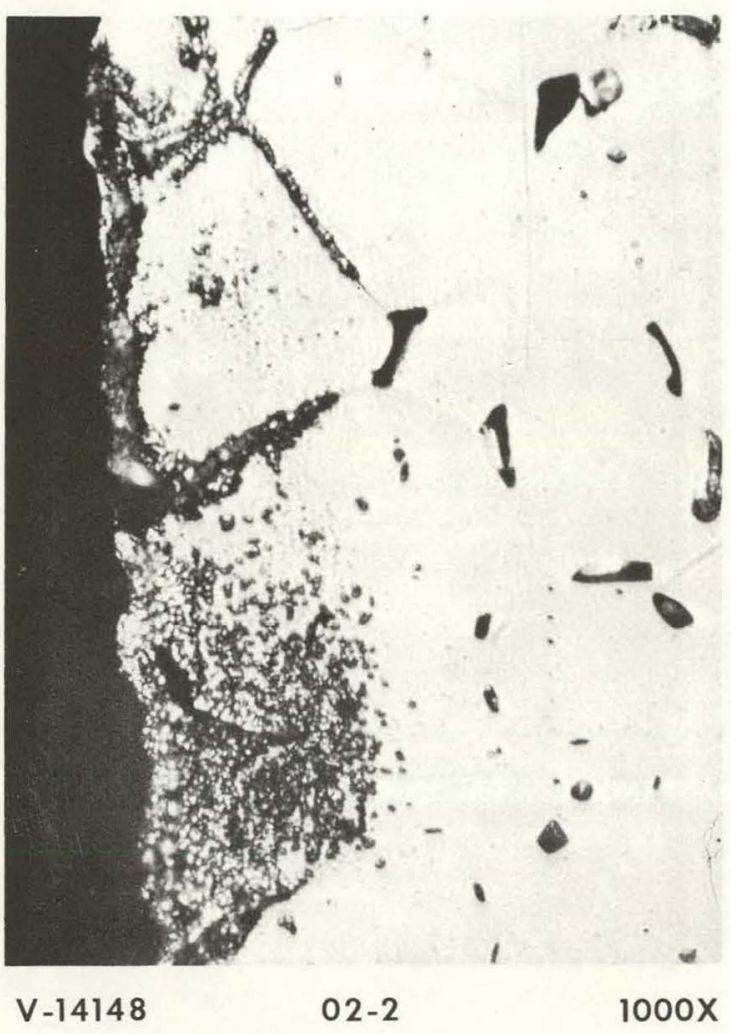

(Electrolytic oxalic acid etch)

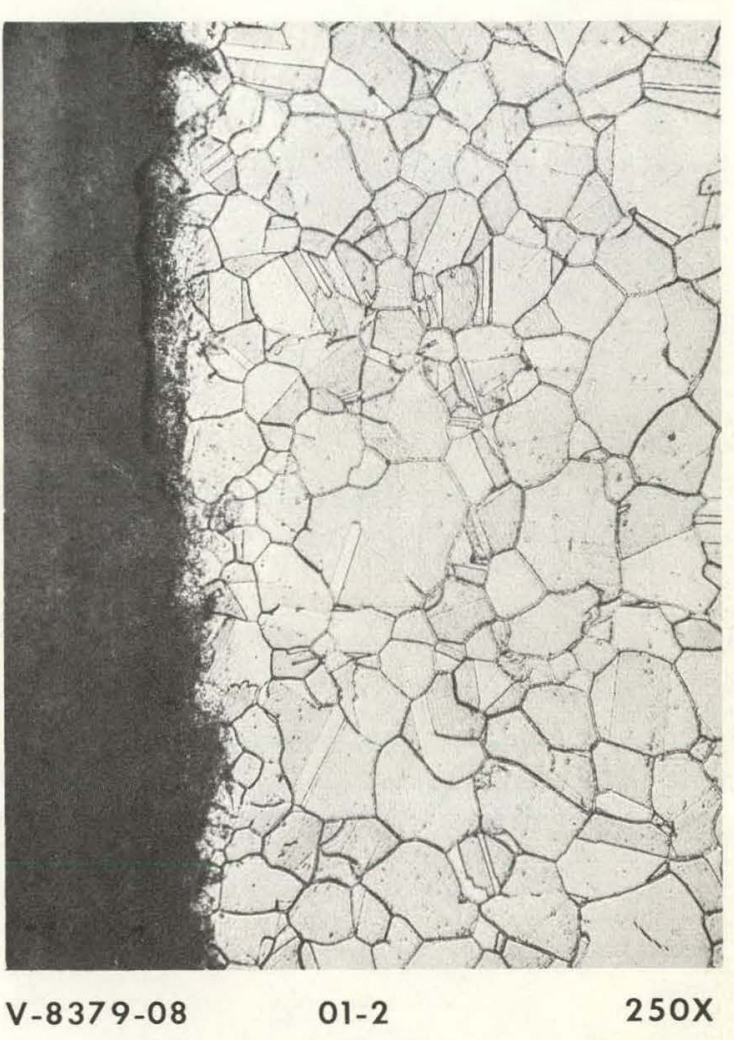

(Etched-modified Marble's reagent) Notice wide grain boundaries.

VAL 2512

Fig. C.61. Slight Reaction Between UO 2 and Stainless Cladding. Reduced $15 \%$. 


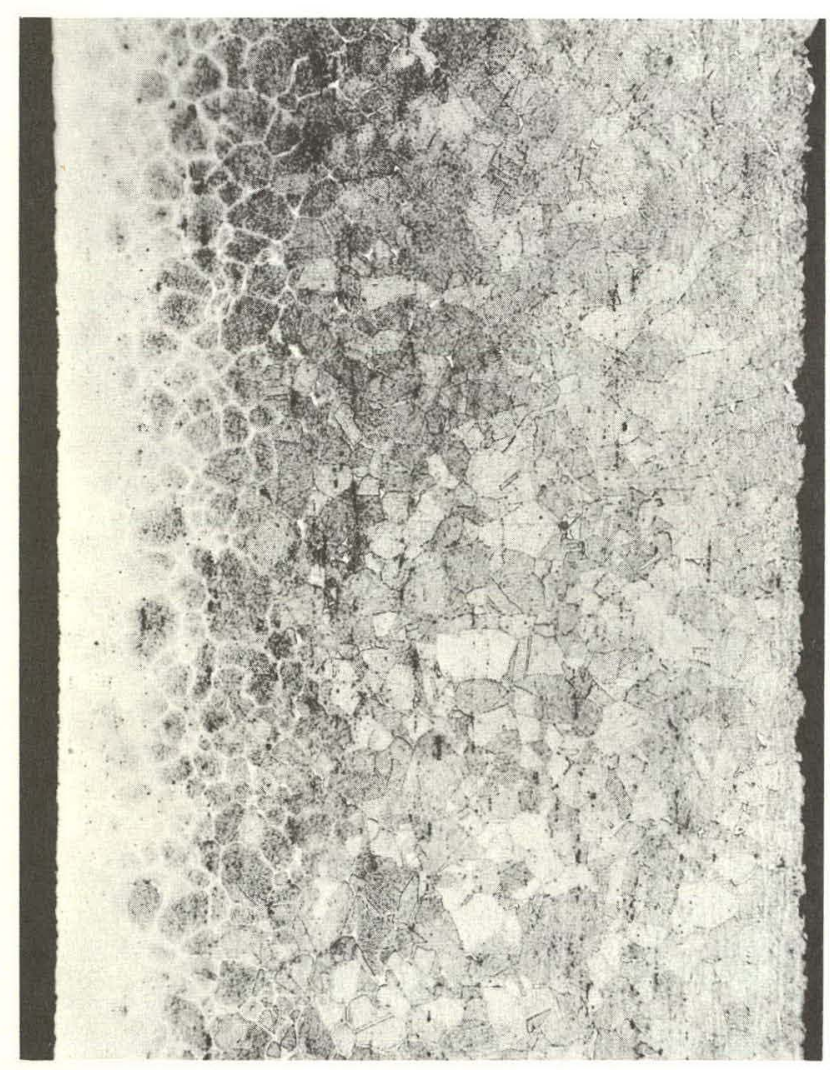

V-8381-14
04-2

(Etched-Vilella's reagent)

Reagent has attacked austenite showing decarburization of approximately $1 / 3$ of cladding.

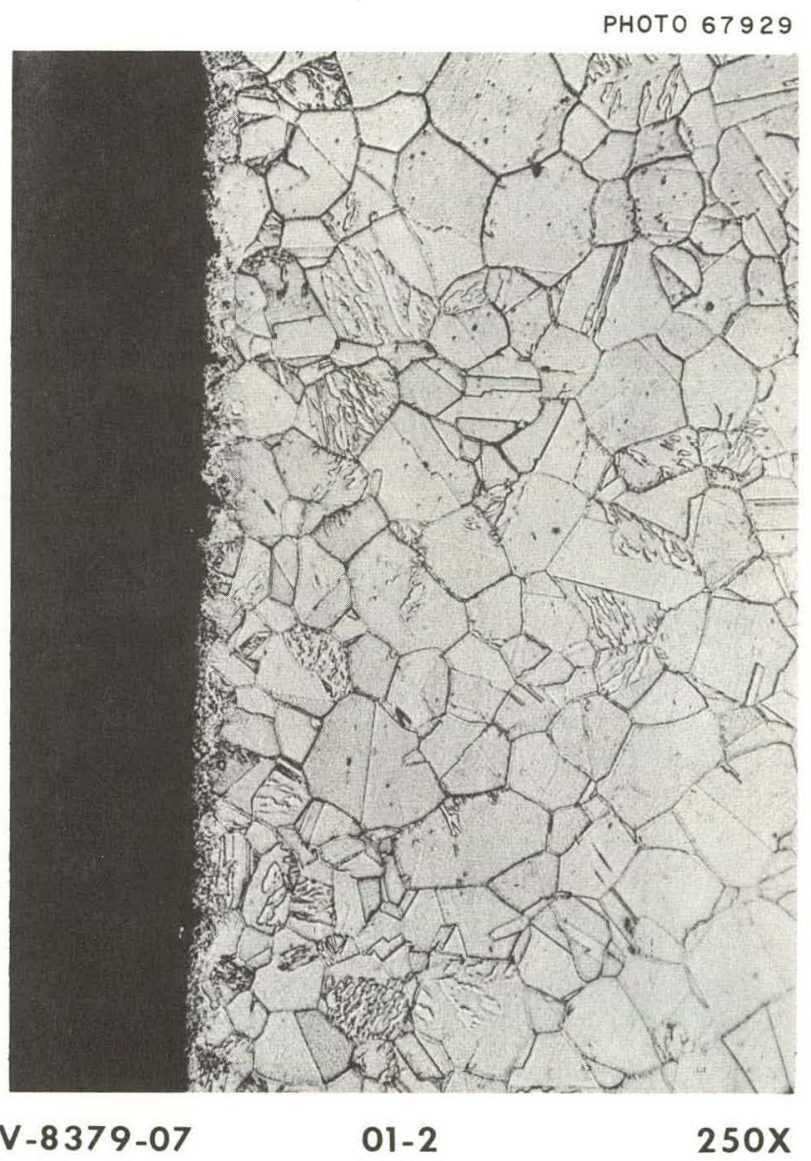

(Etched-modified Marble's reagent)

Feathery structure within grains has appearance of ferrite.

Fig. C.62. Decarburization of Stainless Cladding. Reduced 10\%. 


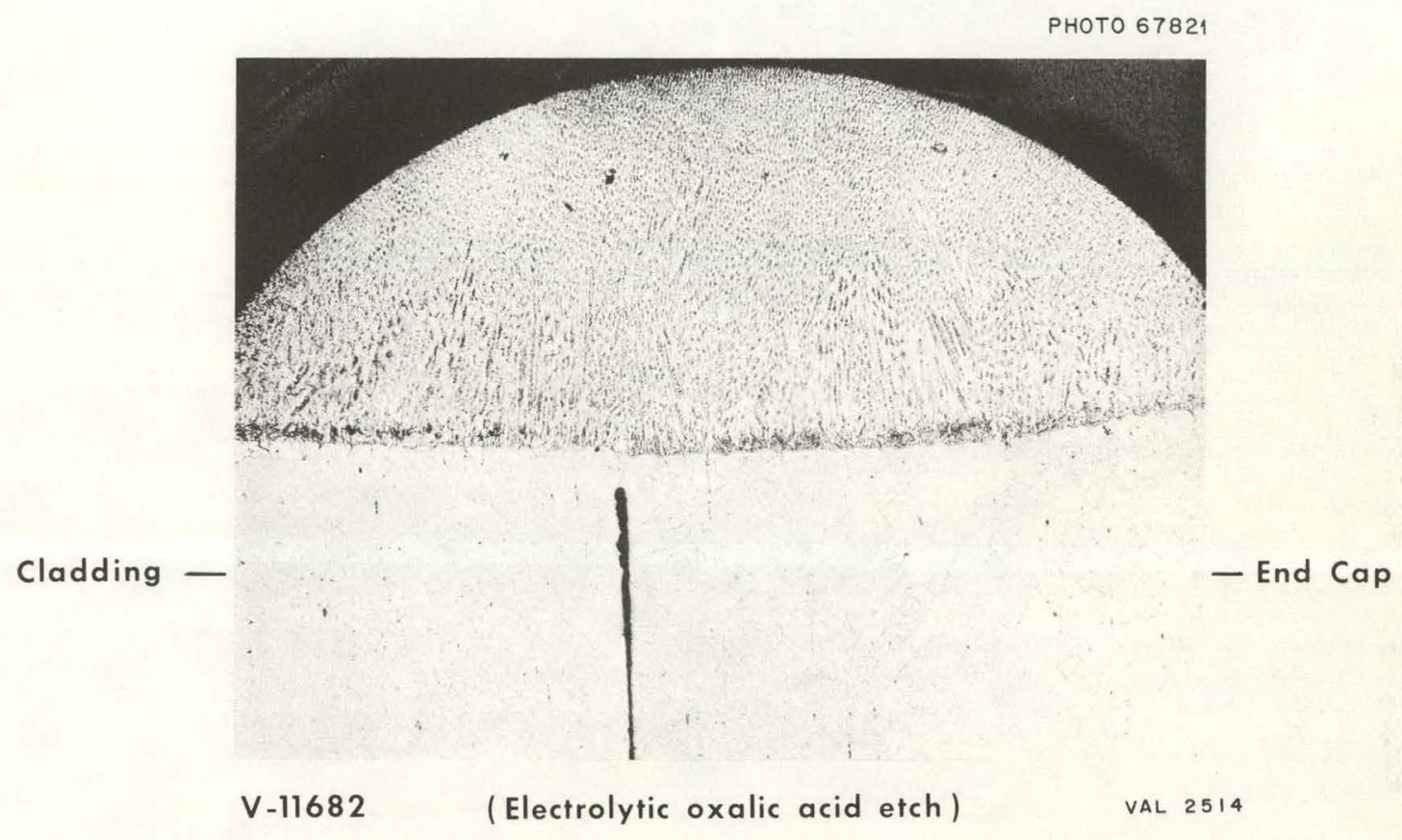

Fig. C.63. Top End Cap Weld from Capsule 02-2 (Heliarc Weld). 100x. Reduced 15\%. 


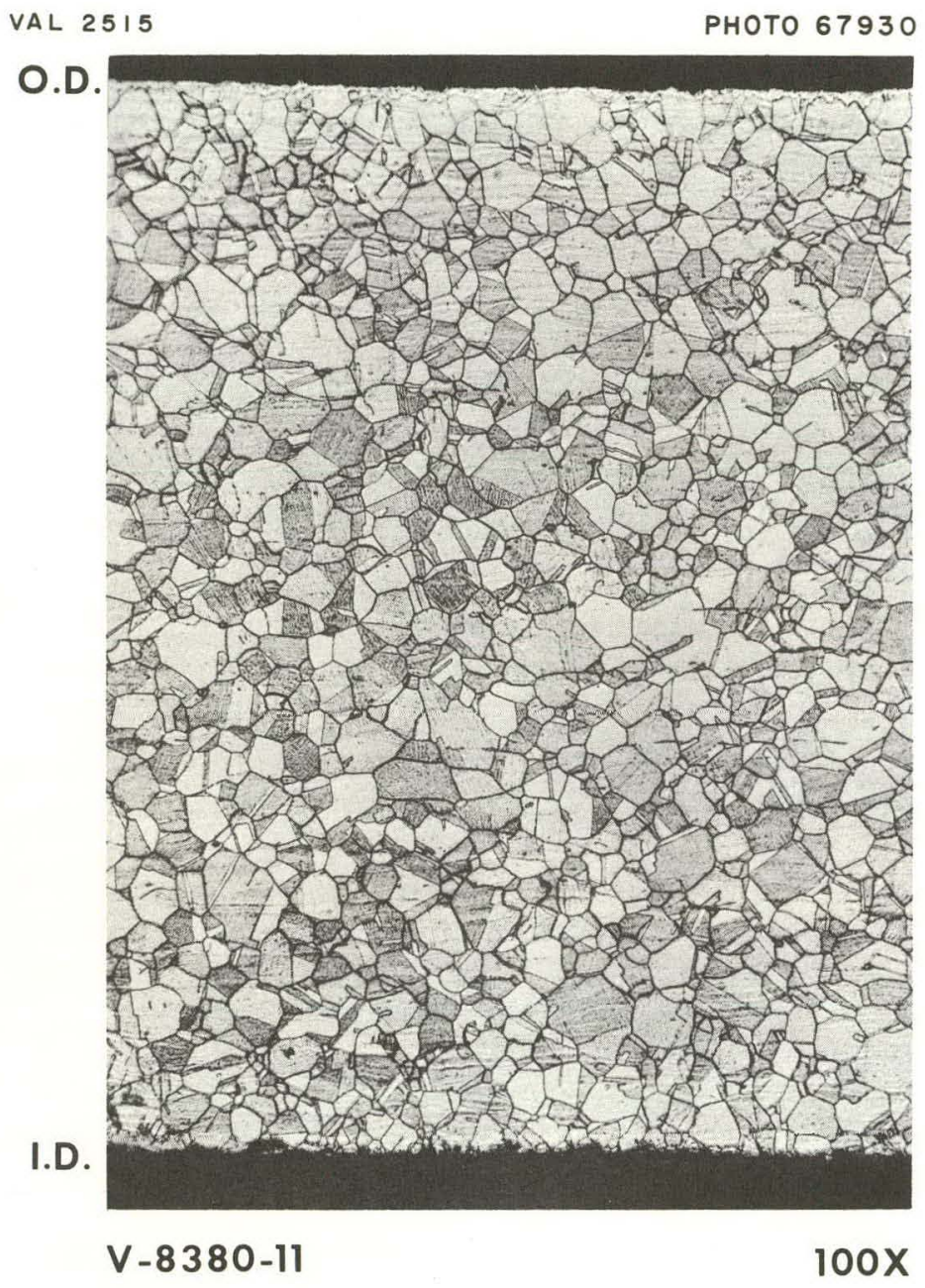

(Etched - modified Marble's reagent) General cladding structure.

Fig. C.64. General Structure (Capsule 03-2). 


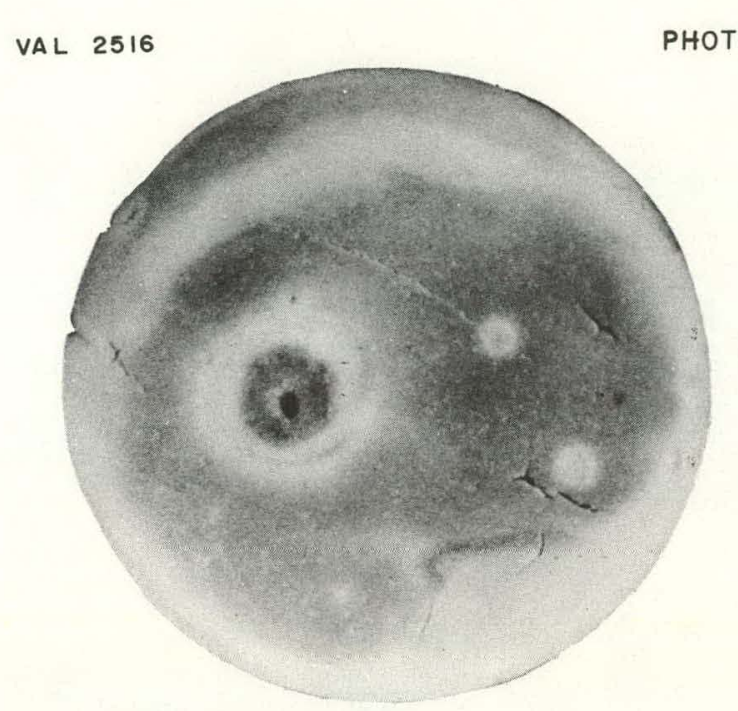

V-11706

As-polished

$8 x$

Light area at O.D. contains most of fission products.

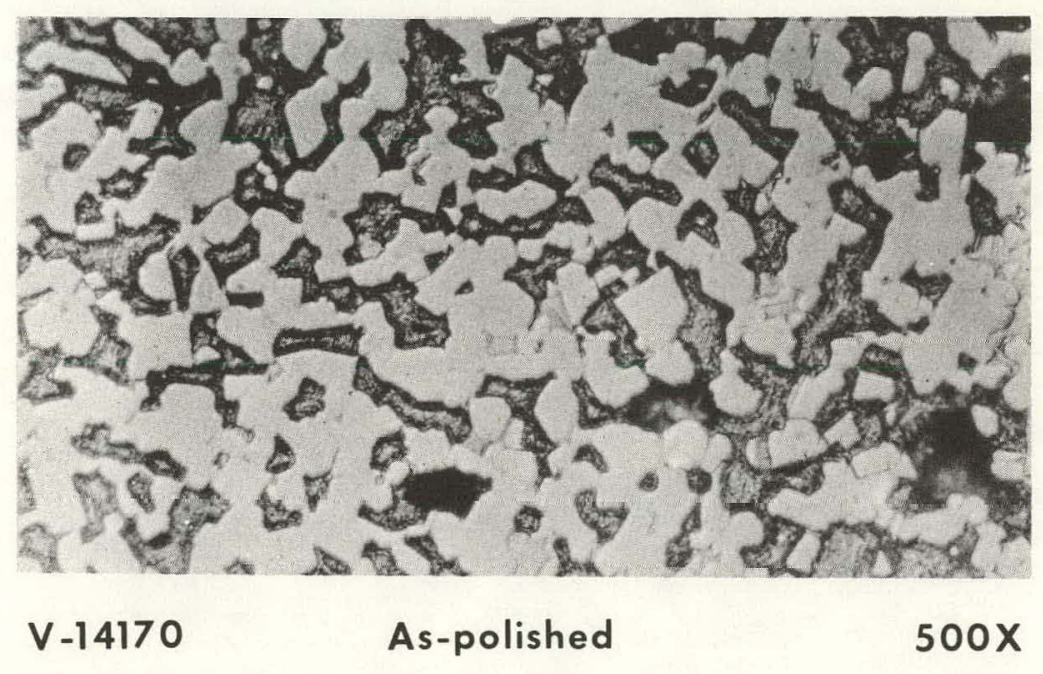

Notice second phase material within BeO grains.

Fig. C.65. Metallography of BeO Rod No. 3 (Capsule 04-2). 


\section{Fuel Side}

VAL 2517

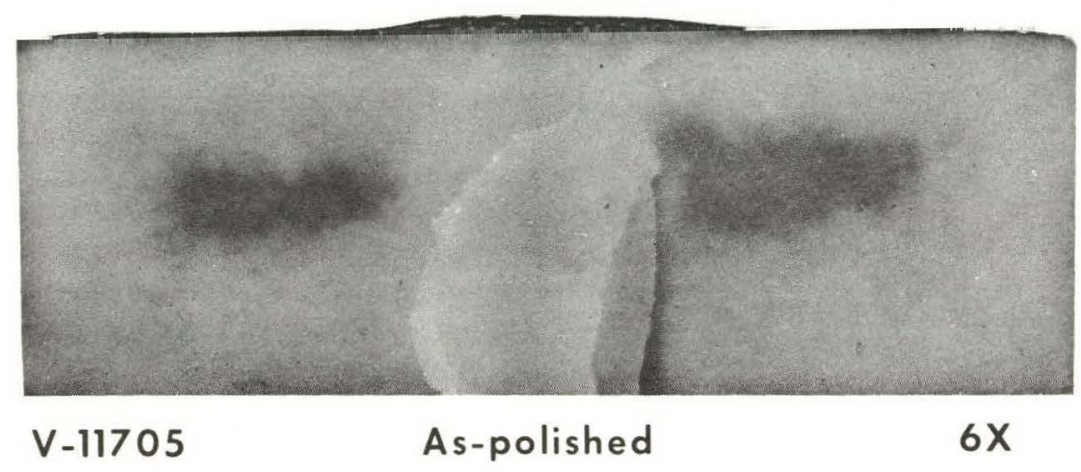

Notice two discolored regions.

MgO surface in confact with $\mathrm{UO}_{2}$.

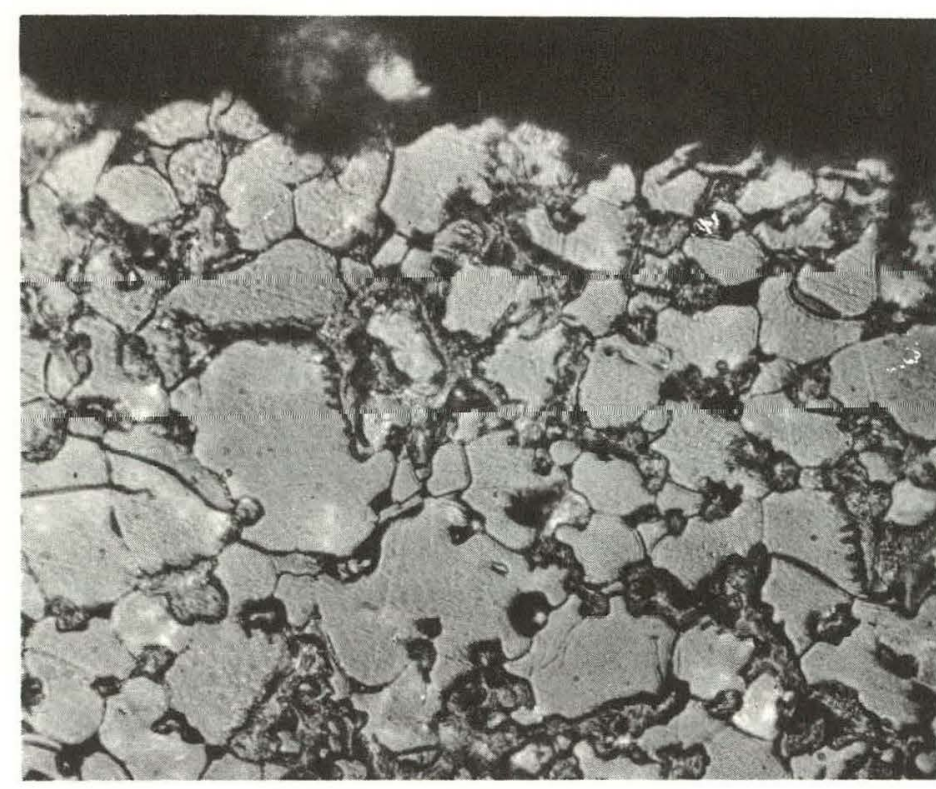

V-14130

Etched

$500 x$

No structure could be developed.

Fig. C.66. Metallography of Top MgO Spacer (Capsule 03-2). 
ORNL-3504

UC-80 - Reactor Technology

TID.4500 (4lst ed.)

INTERNAL DISTRIBUTION

1. Biology Library

2-4. Central Research Library

5. Reactor Division Library

6-7. ORNL - Y.12 Technical Library Document Reference Section

8-42. Laboratory Records Department

43. Laboratory Records, ORNL R.C.

44. R. E. Adams

45-50. C. D. Baumann

51. R. J. Beaver

52. G. E. Boyd

53. C. A. Brandon

54. J. H. Coobs

55. W. H. Cook

56. J. E. Cunningham

57. W. S. Ernst, Jr.

58. R. B. Fritts

59. D. A. Gordiner

60. A. E. Goldman

61. W. R. Grimes

62. R. S. Holcomb

63. M. E. Lackey

64. C. E. Lamb

65. C. E. Larson

66. E. L. Long, Jr.
67. A. W. Longest

68. H. G. MacPherson

69. W. R. Martin

70. F. R. McQuilkin

71-80. J. G. Morgan

81. A. R. Olson

82. M. F. Osborne

83-84. R. B. Parker

85. P. Patriarca

86. G. Samuels

87. H. W. Savage

88. J. L. Scott

89. O. Sisman

90. M. J. Skinner

91. G. M. Tolson

92. D. B. Trauger

93. G. M. Watson

94. A. M. Weinberg

95. R. C. Weir

96-116. G. D. Whitman

117. G. C. Williams

118. L. Brewer (consultant)

119. F. Daniels (consultant)

120. R. W. Dayton (consultant)

121. E. A. Mason (consultant)

122. Research and Development Division, AEC, ORO

123-697. Given distribution as shown in TID-4500 (41 st ed.) under Reactor Technology category (75 copies - CFSTI) 